\title{
BANCOS DE DADOS ORIENTADOS A OBJETOS E UMA PROPOSTA PARA UM MODELO CONCEITUAL
}

\author{
Eugênio Akihiro Nassu
}

\author{
DISSERTAÇÃO APRESENTADA \\ $\mathrm{AO}$ \\ INSTITUTO DE MATEMÁTICA E ESTATÍSTICA \\ DA \\ UNIVERSIDADE DE SÃO PAULO \\ PARA OBTENÇÃO DO GRAU DE MESTRE \\ EM \\ MATEMÁTICA APLICADA
}

Área de Concentração: Ciência da Computação

Orientador: Prof. Dr. Valdemar Waingort Setzer

Durante a elaboração deste trabalho, o autor recebeu o apoio financeiro do CNPq.

São Paulo, outubro de 1997 


\title{
BANCOS DE DADOS ORIENTADOS A OBJETOS E UMA PROPOSTA PARA UM MODELO CONCEITUAL
}

\author{
Este exemplar corresponde à redação final da dissertação apresentada \\ por Eugênio Akihiro Nassu, devidamente corrigida e aprovada pela \\ comissão julgadora
}

São Paulo, novembro de 1997.

Banca examinadora:

Prof. Dr. Valdemar Waingort Setzer (orientador)

IME-USP

Profa. Dra. Cláudia M. B. Medeiros

IC-UNICAMP

Prof. Dr. Marcelo Finger

IME-USP 


\title{
BANCOS DE DADOS ORIENTADOS A \\ OBJETOS E UMA PROPOSTA PARA UM \\ MODELO CONCEITUAL
}

\author{
por Eugênio Akihiro Nassu
}

\section{Resumo}

Os Bancos de Dados Orientados a Objetos surgiram na década de 80, visando possibilitar a representação de tipos de dados complexos, como dados multimídia e conjuntos, entre outros, não representáveis de uma forma direta no Modelo Relacional de Dados (Normalizado). Neste trabalho, apresentamos as principais características e alguns exemplos de Bancos de Dados Orientados a Objetos e apresentaremos uma proposta de um modelo de dados, derivado de um Modelo de Entidades e Relacionamentos estendido, contendo a linguagem de declaração e uma linguagem de consulta englobando atributos multivalorados. Como parte prática, apresentamos a conversão de nosso modelo para o Banco de Dados Orientado a Objetos Poet.

OBJECT-ORIENTED DATABASES AND A PROPOSAL FOR A CONCEPTUAL MODEL

\section{by Eugênio Akihiro Nassu}

\begin{abstract}
The Object-Oriented Databases emerged in the 80 's, partially aiming at the representation of complex data types such as multimedia, sets and others, not directly representable through the (Normalized) Relational Model. In this work, we present the main features and some examples of Object-Oriented Databases, and make a proposal for a new data model, based on an extended Entity-Relationship model containing the data definition language and a query language accessing also multivalued attributes. As a practical application, we present the conversion of our model to the Poet Object-Oriented Database model.
\end{abstract}


Ao final deste trabalho, chegou a hora de agradecer as pessoas que tomaram-no possível:

- Obviamente, ao Prof. Dr. Valdemar W. Sezter, meu orientador, pela paciência (e quanta), dedicação, trabalho (principalmente no final), por toda a ajuda e por ter aceito ser meu Orientador.

- Claro, minha noiva, Vívian Tamaki, pela paciência, apoio nas horas difíceis, pelo carinho e compreensão. Obrigado Vivi!

- À minha família, por todo o apoio.

- À família da Vívian também, por toda a ajuda.

- À Profa. Dra. Dilma, por toda a ajuda prestada quando precisei.

- Ao Prof. Dr. José Augusto, meu orientador de programa, que, apesar de não achar que eu sou um exemplo de aluno, me ajudou a chegar aqui, sempre concordando em assinar minha matrícula.

- Ao CNPq, pela bolsa concedida.

- À minha amiga Denise Iguma, por todos os livros emprestados.

- A todos os funcionários do IME, pelo apoio direto e indireto.

- Um abraço para as seguintes pessoas: Janaína, Tárcio, Ingrid, Denis, Mirian, Profa. Dra. Daisy, Huang, Marie e Jorge.

- Ao Orlando, pela ajuda na preparação da apresentação.

- À Borland e à Microsoft, pela venda de produtos a preços especiais para estudantes e professores. Todos os softwares utilizados neste trabalho são originais e licenciados.

- À Poet Software, Computer Associates (Jasmine), $\mathrm{O}_{2}$ Tech. e Object Design (ObjectStore), pelas versões de demostração de seus sistemas e informações gentilmente enviadas a mim.

- À Profa. Alice, diretora da faculdade onde leciono, Rosi, Geraldo e Enes, meus chefes.

- Ao IP'T, e à UniCastelo, pelo trabalho e apoio ao mestrado.

- A todos os meus professores, amigos e colegas de trabalho e aula, que não posso citar um a um para não ocupar tanto espaço, ou simplesmente por que não consegui me lembrar do nome de todos eles (e por que eu tenho que imprimir este trabalho agora).

Obrigado a todos! Finalmente acabei! 


\section{ÍNDICE}

1. INTRODUÇ̃̃O

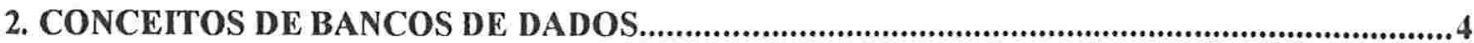

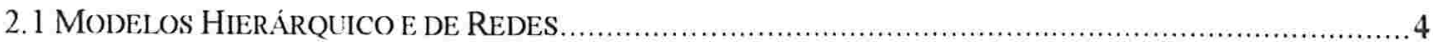

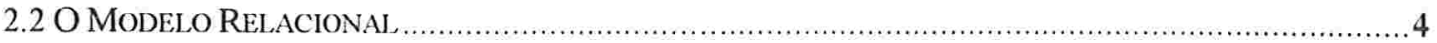

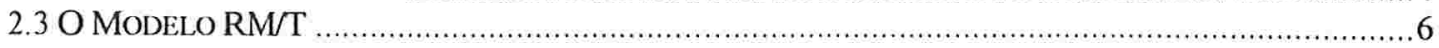

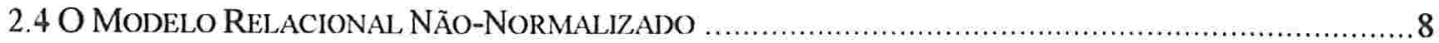

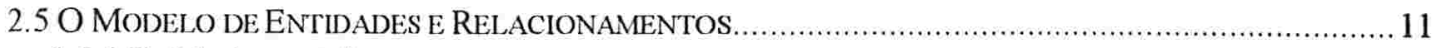

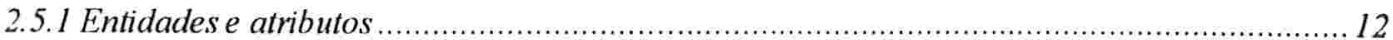

2.5.2 Relacionamentos e multiplicidade de relacionamentos...................................................... 13

2.5.3 Auto-relacionamentos, relacionamentos múltiplos......................................................... 16

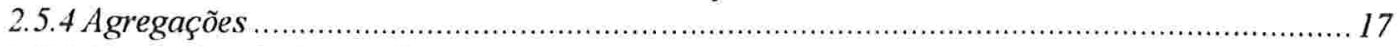

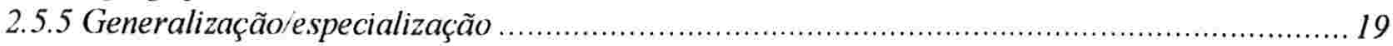

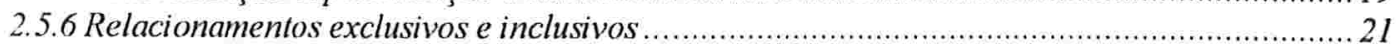

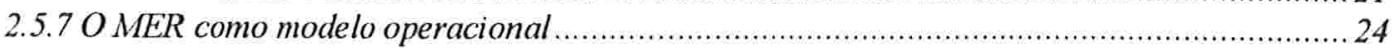

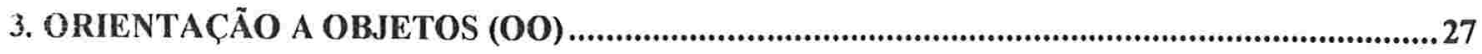

3.1.1 Conceitos principais da Orientação a Objetos...................................................................... 28

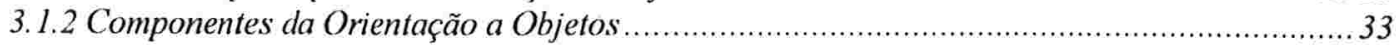

4. BANCOS DE DADOS ORIENTADOS A OBJETOS ....................................................................38

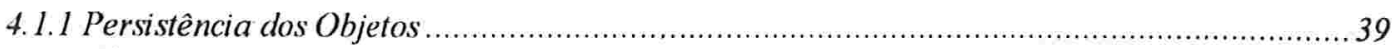

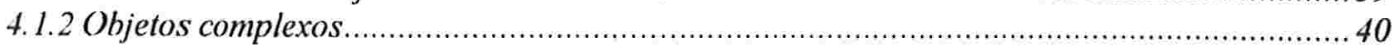

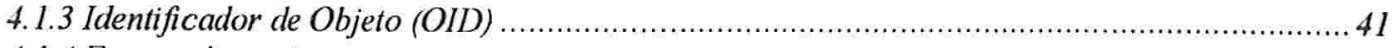

4.1.4 Encapsulamento ................................................................................................. 41

4.1.5 Acesso aos Dados: Linguagens de programação e de consulta..........................................42

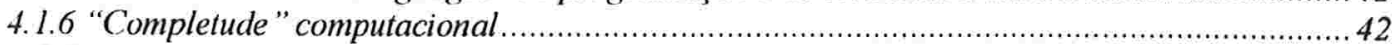

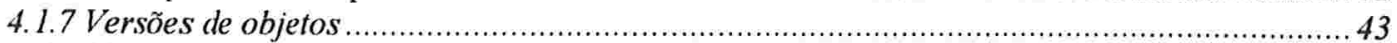

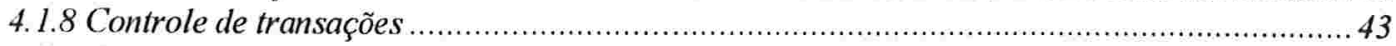

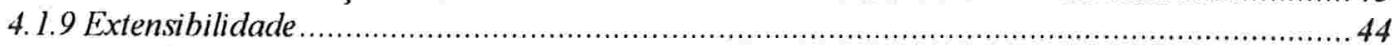

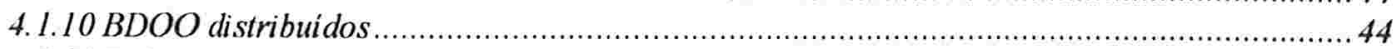

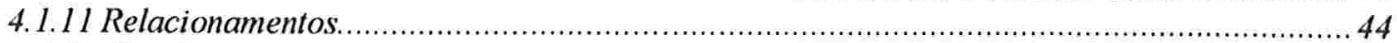

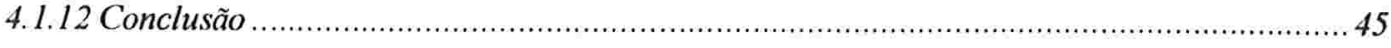

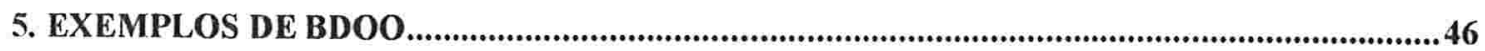

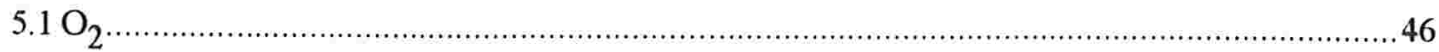

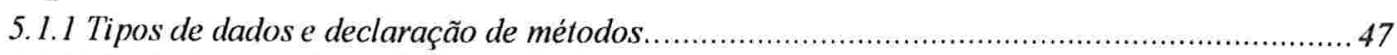

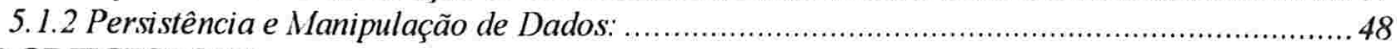

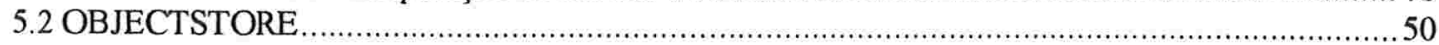

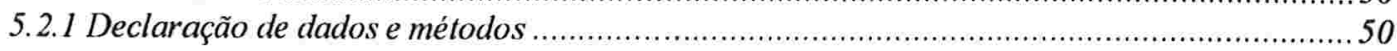

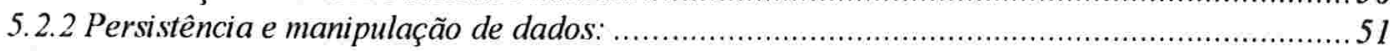

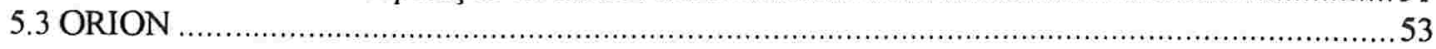

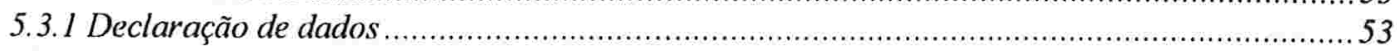

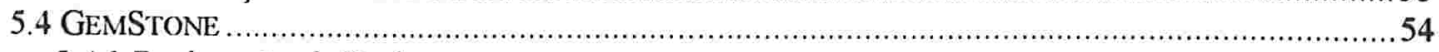

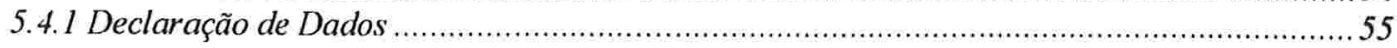

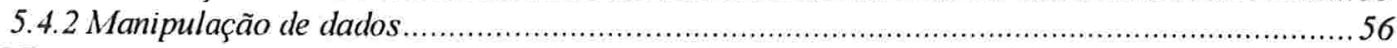

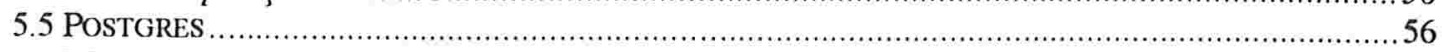

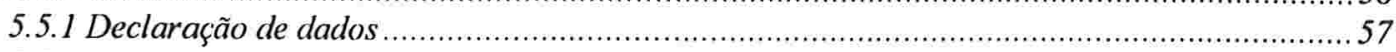

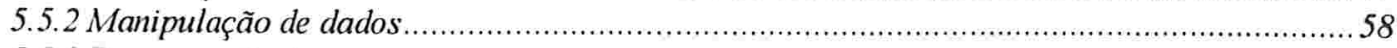

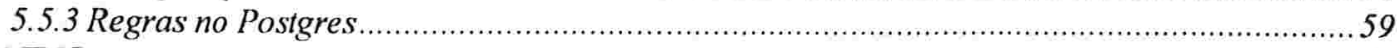

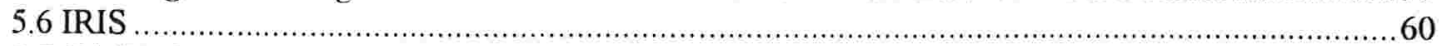

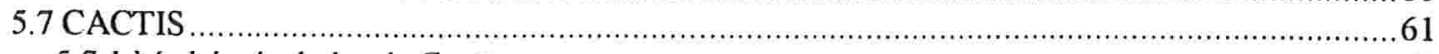

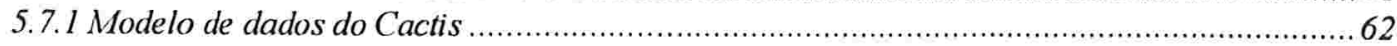


5.8 SIM

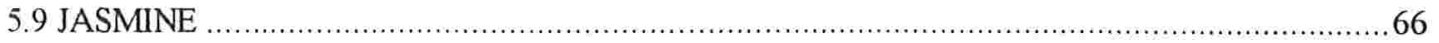

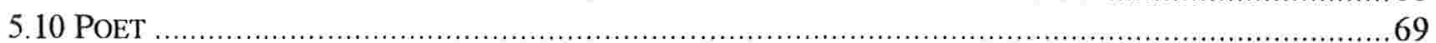

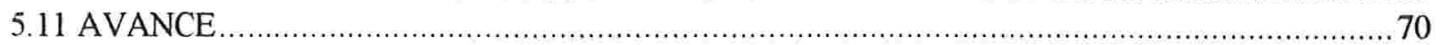

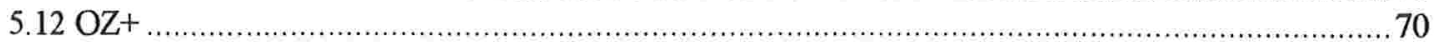

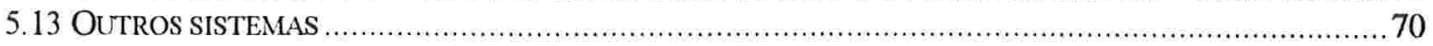

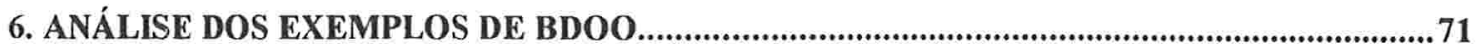

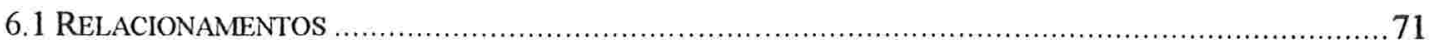

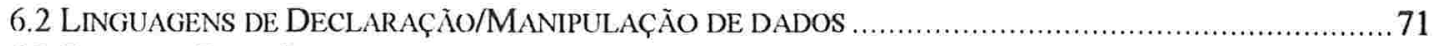

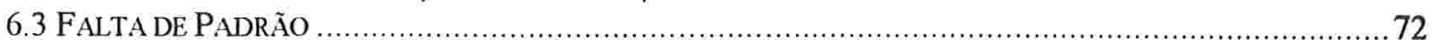

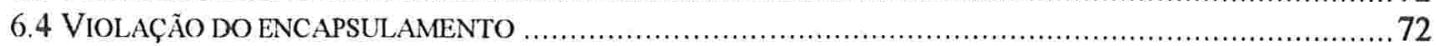

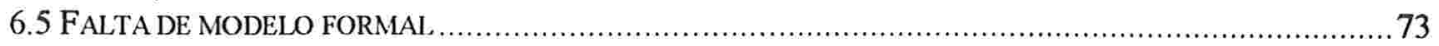

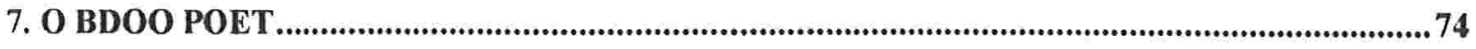

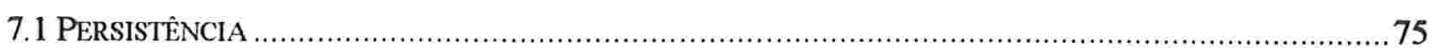

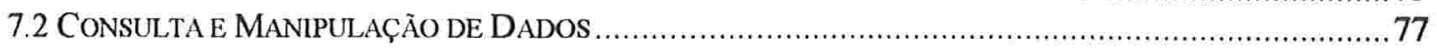

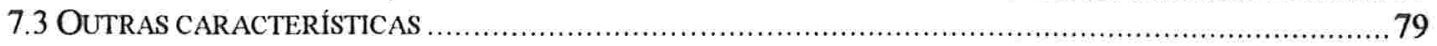

8. NOSSA PROPOSTA: O MODELO OER (OBJECT ENTITY-RELATIONSHIP).......................81

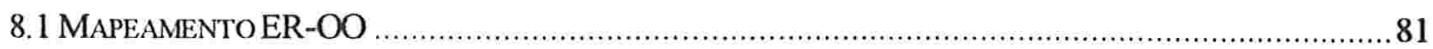

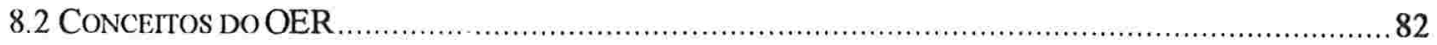

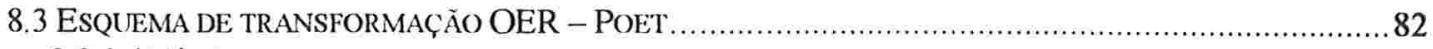

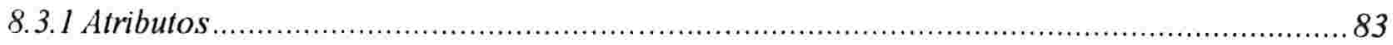

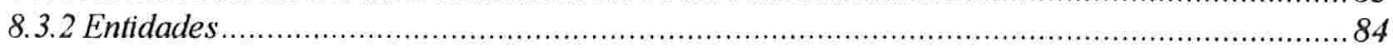

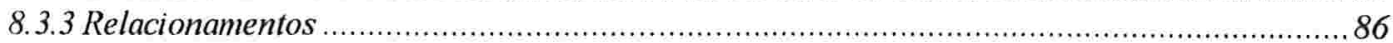

8.3.4 Relacionamentos múltiplos, inclusivos, exclusivos e auto-relacionamentos .......................... 90

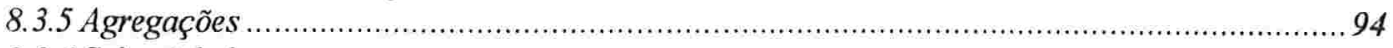

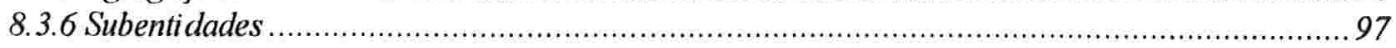

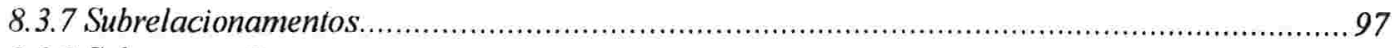

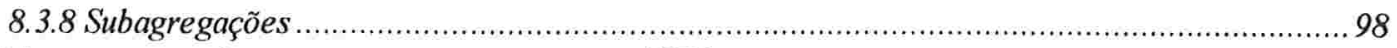

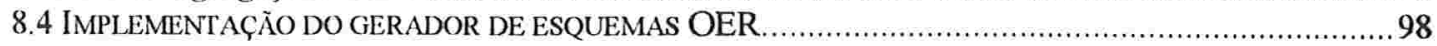

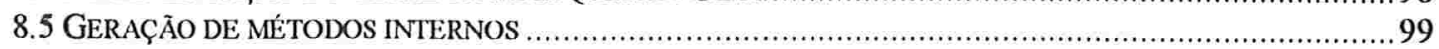

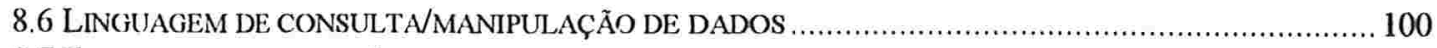

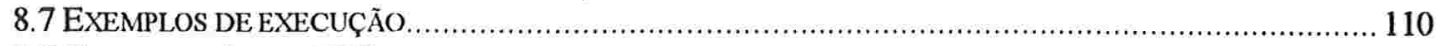

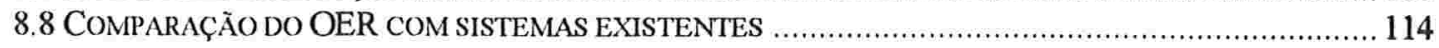

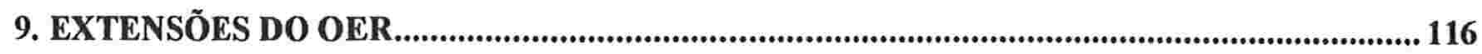

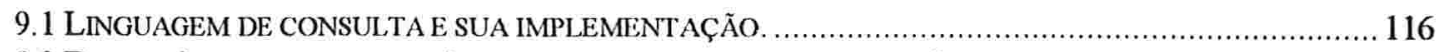

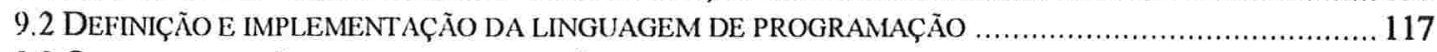

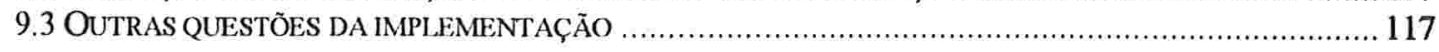

10. CONCLUSÃO

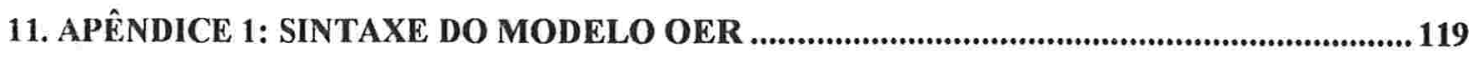

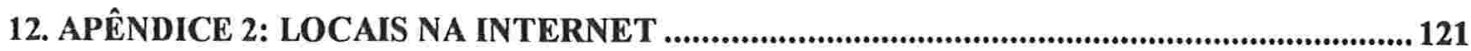

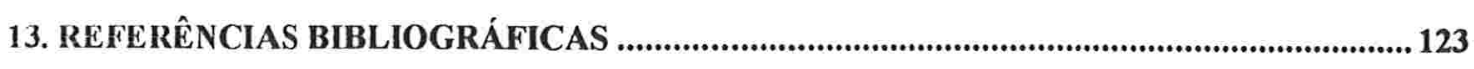

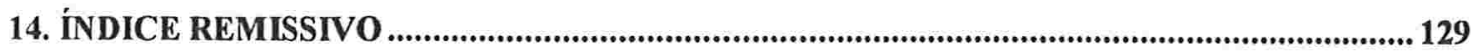




\section{ÍNDICE DE FIGURAS}

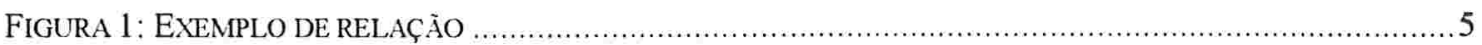

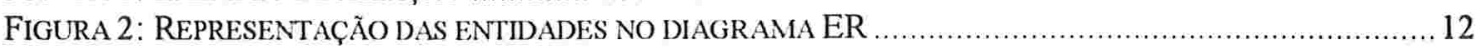

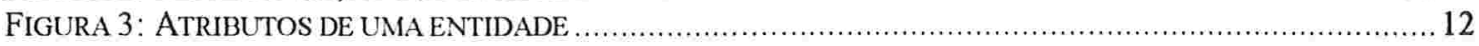

FIGURA 4: ATRIBUTOS COMPOSTOS, DETERMINANTES E MULTIVALORADOS ................................... 13

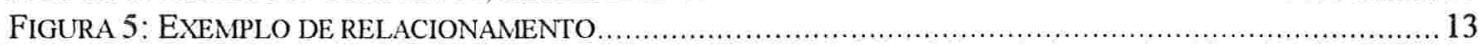

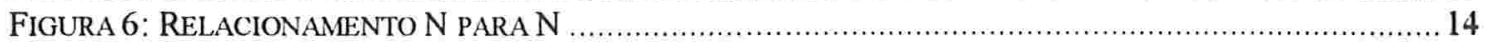

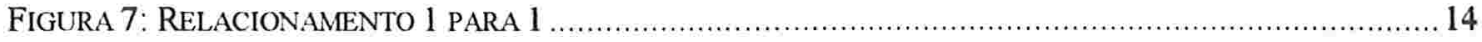

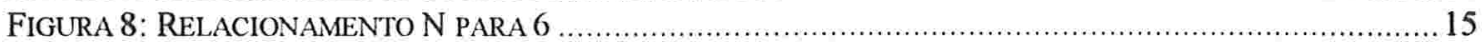

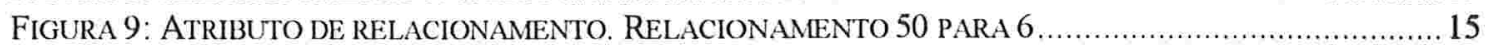

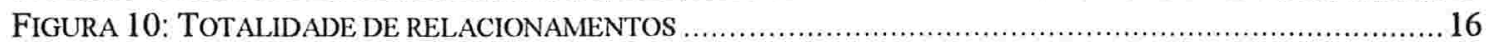

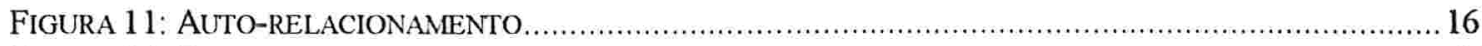

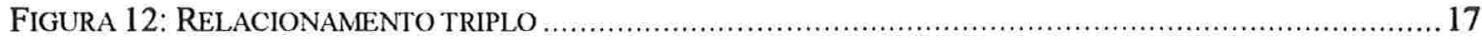

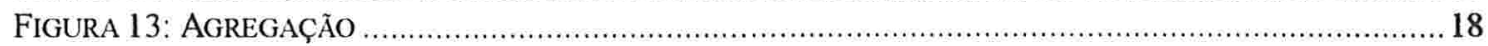

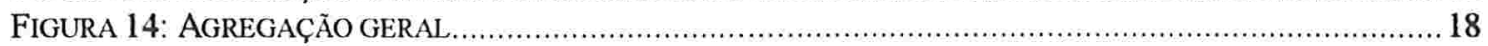

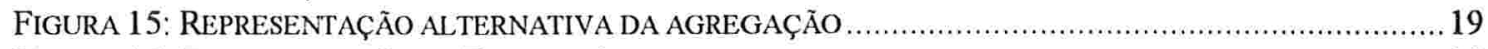

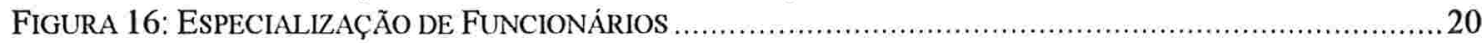

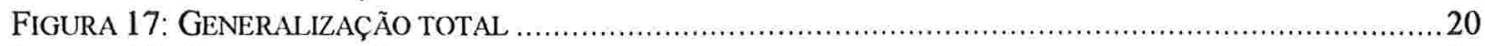

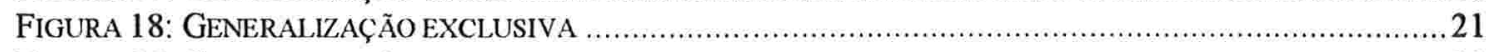

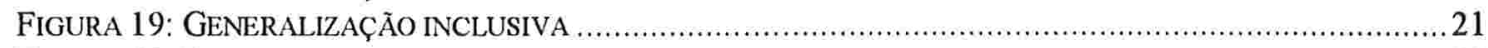

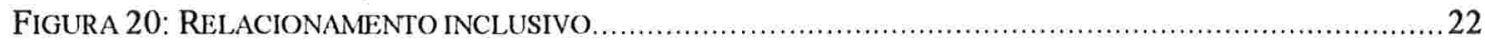

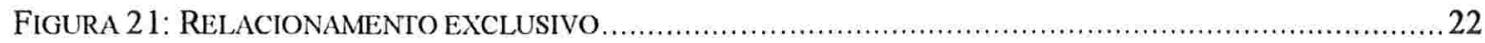

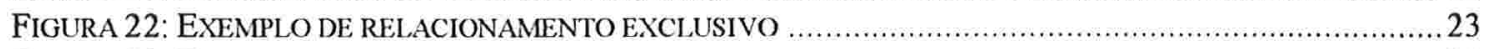

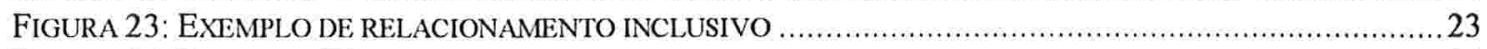

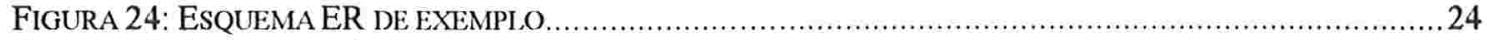

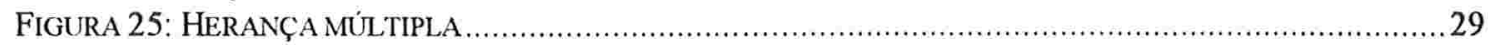

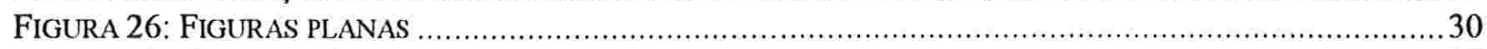

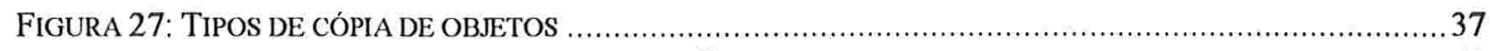

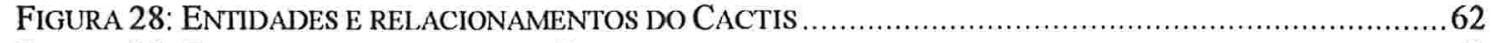

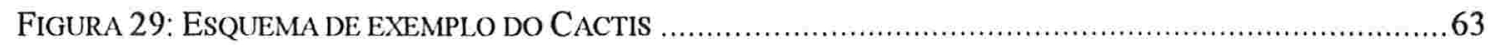

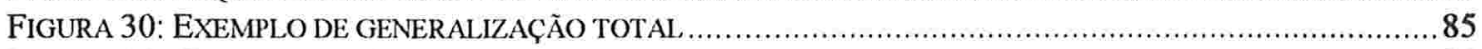

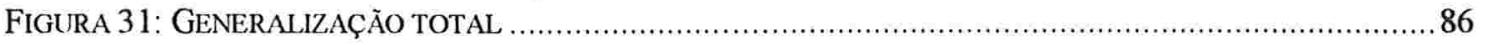




\section{Introdução}

Os Bancos de Dados surgiram aproximadamente em meados dos anos 60, decorrentes da possibilidade dos computadores armazenarem e gerenciarem grandes quantidades de dados em meios de armazenamento permanente de acesso direto e eficiente a cada dado (em geral discos magnéticos) e a necessidade de estruturar esses dados e prover rotinas padronizadas de acesso aos mesmos. Um Sistema Gerenciador de Banco de Dados (SGBD) é um programa, ou um conjunto de programas destinado a controlar todos os aspectos de um Banco de Dados, tais como a declaração de sua estrutura de dados, gravação e leitura dos dados, recuperação de falhas na comunicação ou no meio de gravação, controles de concorrência, de acesso e de segurança dos dados, entre outros.

Um Modelo de Dados é uma coleção de ferramentas conceituais utilizada para descrever a estrutura dos dados de um SGBD. Os primeiros modelos de dados utilizados foram os modelos bierárquico e o modelo de redes. Em 1970 Codd [COD 70] apresentou o modelo relacional (MR), que se impôs como padrão nos SGBD atuais. Todos esses modelos foram concebidos visando a sua utilização em ambientes comerciais onde, em geral, existe uma grande quantidade de registros de mesma estrutura (por exemplo, um cadastro de clientes de um grande banco).

O MR possui uma estrutura extremamente simples, uma das razões a que pode se atribuir o seu grande sucesso. Porém, suas limitações logo apareceram, e o próprio inventor do MR apresentou em 1979 [COD 79] uma extensão ao MR, denominado RM/T. Outras propostas de extensão ao MR foram feitas, de onde destacamos o Modelo Relacional Não Normalizado (MRNN), onde uma das principais restrições do modelo original (a primeira forma normal de Codd) é retirada, aumentando sua complexidade, mas permitindo uma melhor modelagem dos dados, como apresentado por Setzer [SET 86]. A grande maioria, senão quase todos os SGBD relacionais comerciais, seguiu o modelo normalizado de Codd. Outro destaque deste período é o surgimento de alguns modelos conceituais, que têm como objetivo facilitar a modelagem dos dados, em um nível mais elevado que no MR. Destacamos nessa categoria o modelo de entidades e relacionamentos (MER), apresentado por Chen em 1976 [CHE 76]. 
O grande avanço da computação, a difusão das redes e a utilização do computador em áreas cada vez mais diversas mostraram necessidades novas, para as quais os bancos de dados baseados no MR se mostraram inadequados. Dentre os novos usos do computador, podemos citar o $\mathrm{CAD} / \mathrm{CAM}$ (projeto/manufatura auxiliados por computador), o CASE (desenvolvimento de sistemas de computação auxiliado por computador), o GIS (sistemas de informação geográfica), o hipertexto, aplicações multimídia, aplicações em medicina, etc. Essas aplicações necessitam de representação de tipos complexos de dados, como listas ordenadas, conjuntos, dados multimídia, texto, som e imagens, entre outras, para os quais o MR não oferece uma base adequada. Essas aplicações, ao contrário do MR que em geral possui muitos objetos de estrutura simples, manipulam objetos muito complexos e normalmente em menor número.

Durante os anos 80 , visando aumentar a produtividade do desenvolvimento, facilitar a reutilização e a manutenção do software, a programação orientada a objelos se tomou popular ([PAG 95], [TAK 90], [SIL 90]), causando grande sensação na época, sendo considerada pelos mais entusiasmados como uma revolução na forma de se criar programas. Talvez para acompanhar a tendência da momento, mas certamente para tentar resolver os problemas de limitação do MR normalizado citados, foram propostos os Bancos de Dados Orientados a Objetos (BDOO) ([A'TK 89], [BER 91], [HUG 91], [KIM 90a], [KHO 93], [BAN 92a]). Desde então vários sistemas surgiram, entre sistemas comerciais, protótipos produzidos por grandes empresas e sistemas desenvolvidos em universidades.

O objetivo principal deste trabalho é de estudar os BDOO, e compará-los aos Bancos de Dados baseados em outros modelos, principalmente o MR. Procuraremos esclarecer as diferenças entre os BDOO e as linguagens de programação orientadas a objetos, além de definir quais conceitos de orientação a objetos aplicam-se ou não aos bancos de dados tradicionais.

No capítulo 2 apresentaremos os conceitos fundamentais de Bancos de Dados e seus modelos mais importantes, o Modelo Relacional, O RM/T, o Modelo Relacional Não-Normalizado e o Modelo de Entidades e Relacionamentos. No capítulo 3 mostraremos os conceitos principais da Programação Orientada a Objetos. No capítulo 4 apresentaremos os conceitos dos Bancos de Dados Orientados a Objetos. No capítulo 5 mostraremos alguns exemplos de sistemas de BDOO implementados, mostrando sua linguagem de definição e manipulação de dados. No capítulo 6 faremos uma análise dos 
sistemas apresentados. No capítulo 7 descrevemos o BDOO Poet, utilizado na nossa implementação. No capítulo 8 faremos uma proposta de um modelo de dados baseado no MER, como alternativa para a solução dos problemas de implementação dos modelos conceituais de dados. Como ele engloba atributos compostos e multivalorados, vemos que se trata da primeira proposta para um BDOO sobre um Modelo Relacional Não Normalizado. O uso do MER preserva as características semânticas dos relacionamentos, o que não é o caso nos $\mathrm{BDOO}$ existentes. No capítulo 9 citamos algumas extensões ao nosso trabalho, que tem sua conclusão no capitulo 10. Finalmente, no capítulo 12 (apêndice) apresentaremos também alguns locais na Internet onde podem ser encontradas mais informações sobre BDOO. Também conseguimos uma boa revisão bibliográfica sobre o assunto, com cerca de 100 artigos e livros encontrados. 


\section{Conceitos de Bancos de Dados}

\subsection{Modelos Hierárquico e de Redes}

Tanto nos Modelos Hierárquico e no de Redes os dados são representados por coleções de registros, que contêm os dados e ligações fisicas, como contigüidade e uso de ponteiros, que representam as ligações entre os dados. No Modelo Hierárquico os registros são organizados como coleções de árvores, e não como grafos arbitrários, como são basicamente organizados no Modelo de Redes, isto é, as ligações entre registros são basicamente hierárquicas: cada registro pode estar ligado a vários "Filhos", mas conecta-se a um único registro "pai". No Modelo de Redes, não há essa distinção. Como nem tudo é puramente hierárquico, todos os modelo hierárquicos permitem alguma representação de redes, como é o caso por exemplo, do IMS (IBM). Como exemplos de SGBD baseados no modelo de redes podemos citar o Integrated Data Store (IDS) e o Associate PL/1 (APL).

Uma característica importante desses dois modelos é que ambos são principalmente "navegacionais". A partir de um registro qualquer, o usuário pode "navegar" através da implementação das ligações entre os registros. As ligações são armazenadas explicitamente nos registros, o que faz com que o usuário do banco de dados tenha uma visão que reflete a forma com que os registros estão organizados, armazenados e são localizados no meio físico. Dizemos então que tais sistemas não oferecem independência fisica dos dados. Além de obrigar o usuário a conhecer detalhes físicos do banco de dados, esse fato limita a extensibilidade, a manutenção, e a portabilidade dos aplicativos desenvolvidos. Tornou-se necessário então, um modelo que oferecesse maior independência fisica, e em 1970 Codd apresentou o Modelo Relacional, descrito a seguir.

\subsection{O Modelo Relacional}

O Modelo Relacional ([ULL 88], [ELM 94], [DAT 90] e [KOR 86]), apresentado por Codd em 1970 [COD 70], teve grande aceitação e ainda hoje é utilizado na maioria dos principais SGBD atuais, seguindo suas idéias básicas. 
Vesse modelo, os dados são armazenados em tabelas bidimensionais, denominadas relações. Cada linha da tabela representa um elemento do conjunto de dados e cada coluna da tabela contém valores de um conjunto definido, denominado domínio. Uma linha da relação é chamada de tupla. Um exemplo de relação, representando uma lista de funcionários de uma empresa está na Figura 1.

Funcionários
\begin{tabular}{|l|l|l|l|}
\hline Nome & RG & Departamento & Salário \\
\hline José & 1234 & Finanças & 1000 \\
\hline João & 4321 & Diretoria & 2000 \\
\hline Maria & 1111 & Marketing & 1500 \\
\hline Paula & 2222 & Secretaria & 500 \\
\hline
\end{tabular}

Figura 1: Exemplo de relação

Vamos definir formalmente uma relação. Uma relação é um conjunto $\mathrm{R}$ de tuplas ordenadas (linhas), tal que:

$\mathrm{R} \subseteq \mathrm{D}_{1} \times \mathrm{D}_{2} \times \ldots \times \mathrm{D}_{\mathrm{m}}$

Onde $\mathrm{D}_{\mathrm{i}}$ são conjuntos chamados domínios, e m o grau da relação. Chamando de coluna $\mathrm{C}_{\mathrm{i}}$ o domínio $\mathrm{D}_{\mathrm{i}}$, o esquema da relação $\mathrm{R}$ é descrito da seguinte forma:

$\mathrm{R}\left(\mathrm{C}_{1}, \mathrm{C}_{2}, \ldots, \mathrm{C}_{\mathrm{m}}\right)$

Vamos chamar cada elemento de uma tupla de célula. Cada célula, portanto, contém um elemento do domínio correspondente à sua coluna.

Outro conceito importante do MR é o conceito de chaır. Uma chave é um conjunto de colunas da relação que determina univocamente cada tupla, sendo que nenhum subconjunto próprio de colunas possui essa propriedade. Tal conjunto sempre existe pois sendo a relação um conjunto, implica que não existem elementos repetidos, ou seja, no máximo a chave poderia ser o conjunto inteiro de colunas. Uma relação pode ter várias chaves. Nos SGBD, geralmente, uma das chaves é escolhida como uma chate primária, o que faz com que a relação seja armazenada no meio fisico seguindo a ordem dos valores da chave, facilitando a busca seqüencial ordenada pelos valores da mesma. No esquema, indicam-se as colunas da chave primária sublinhando-as. No esquema anterior podemos ter: Funcionários( Nome, $\underline{\mathrm{RG}}$, Departamento, Salário) 
Todo SGBD possui uma linguagem para a declaração e manipulação dos dados. Essa linguagem é conhecida como Linguagem de Consulta, apesar dela possuir em geral mais recursos do que apenas consultar os dados. Algumas das linguagens mais conhecidas incluem a QBE (Query By Example), QUEL e principalmente a SQL. Estas linguagens permitem especificar o acesso às tuplas do Banco de Dados de forma simples e declarativa, e é talvez uma das principais razões do sucesso do MR. Outro fato é que tais linguagens se basciam na Álgebra Relacional e no cálculo de predicados de primeira ordem, dando uma forte base teórica ao MR. A Álgebra Relacional se baseia em poucas operações: operações sobre conjuntos (união, interseção, diferença, Produto Cartesiano) e nas operações relacionais (seleção, projeção e junção).

Logo no primeiro artigo [COD 70], Codd definiu que os valores dos domínios deveriam ser "atômicos", ou seja, não podem ser subdivididos. Com isso, não se pode armazenar atributos compostos, conjuntos, vetores ou listas em uma célula da tabela. A esta restrição se dá o nome de Primeira Forma Normal (1FN). Isto toma o MR mais simples, porém limita a modelagem dos dados, forçando estruturas que nem sempre são convenientes. Por exemplo, uma relação contendo informações sobre livros não pode conter duas colunas essenciais, uma para os autores de cada livro e outra para os assuntos. Devido a $1 \mathrm{FN}$, é necessário usar uma relação à parte para cada um desses atributos, o que não modela fielmente a realidade: cada livro é uma entidade só, não é composta de muitas diferentes [SET 86].

\subsection{O Modelo RM/T}

O Modelo RM/T ${ }^{1}$ definido por Codd em 1979 [COD 79], procura superar algumas deficiências de modelagem que se tomaram claras logo que o MR começou a ser utilizado, principalmente em aplicações muito complexas. No RM/T, um banco de dados é dado como um conjunto de entidades que representam os "objetos", bem como seus relacionamentos. Ou seja, no RM/T os relacionamentos são modelados pelas entidades, ao contrário do Modelo de Entidades e Relacionamentos, onde os relacionamentos representam um conceito à parte. Cada entidade possui um conjunto de propriedades associadas, e as entidades podem ser manipuladas por um conjunto pré-definido de operações, para criação, eliminação e atualização de entidades.

${ }_{1}$ RM - Relational Model - T - Tasmânia 
Cada entidade do Banco de Dados é definida como uma instância de um tipo, e todas as entidades de um tipo compartilham as propriedades desse tipo. O modelo define uma bierarquia de tipos, onde um tipo herda todas as propriedades de seus supertipos. As entidades são classificadas como caracteristica, associativa, ou mícleo ("kemel"). A classificação tem o seguinte significado:

- Se a entidade tem o papel subordinado de descrever entidades de outro tipo, ela é característica.

- Se a entidade faz o papel de relacionar entidades de outros tipos, ela é chamada associativa.

- Uma entidade é do tipo núcleo se não cumpre nenhum dos papéis acima.

O modelo RM/T oferece dois modelos de relacionamento de supertipos/subtipos. Quando há generalização incondicional, cada instância de um subtipo deve ser um membro do supertipo. A generalizacão condicional é usada para formar subconjuntos de uma união de tipos. Por exemplo, se Funcionário é modelado como uma generalização condicional de Secretário, Engenheiro e Técnico, então cada funcionário pode ser um secretário, engenheiro ou técnico, porém o conjunto de empregados não contém todos os secretários, engenheiros e técnicos. O conceito de generalização/especialização foi introduzido no MR, por Smith \& Smith, em 1977 [SMI 77].

O modelo possui semântica adicional no nível conceitual, porém, o modelo pode ser implementado facilmente em um SGBD que seja baseado no MR, num nível de abstração mais baixo. Isso é uma vantagem, dada a extensa disponibilidade de sistemas Relacionais existentes.

Um conceito muito importante apresentado no RM/T é o do identificador substituto ("surrogate"). Cada entidade do banco de dados é identificada por um identificador único, gerado pelo sistema, o identificador substituto. Os usuários não podem fazer o acesso ou manipular os identificadores substitutos. Cada tipo de entidade possui uma relação de uma coluna denominada E-Relação (E-Relation), que guarda todos os identificadores substitutos de todas as instâncias desse tipo. Esse conceito reforça a necessidade da definição da chave primária. Um conceito semelhante (identificador de objeto) é um dos mais importantes nos BDOO, que descreveremos adiante. 


\subsection{O Modelo Relacional Não-Normalizado}

Uma das características do MR normalizado, como já citado, é o fato das células das relações poderem armazenar somente valores que não podem ser decompostos (Primeira Forma Normal). No MR Não-Normalizado (MRNN) essa restrição é retirada, permitindo a representação de atributos multivalorados ou compostos, ou de uma maneira geral, valores que são relações. O MRNN teve várias denominações na literatura, entre elas de "nested relations" (relações aninhadas), "relational model with relation-valued attributes", "non-first normal form", "NF2" entre outras. O MRNN foi apresentado inicialmente por Makinouchi em 1977 [MAK 77]. Em 1986 Dadam [DAD 86] apresenta um protótipo de um Banco de Dados que implementa o MRNN. Özsoyoglu em 1987 [OZS 87] mostra algumas extensões da álgebra relacional e cálculo relacional para o MRNN. Uma forma normal para o MRNN foi apresentado por Özsoyoglu também em 1987 [OZS 87a]. O uso do MRNN na modelagem de dados é apresentada por Setzer [SET 86].

A modelagem é facilitada em vários casos com a utilização do MRNN. Um excmplo típico de melhora em relação ao MR normalizado é o de uma biblioteca: um livro pode ter vários autores e vários assuntos. Para isso ser modelado com o MR pode ser necessária a utilização de três relações: Uma para os livros, uma para os assuntos e uma para os nomes dos autores. Vamos ilustrar com um exemplo:

Livros

\begin{tabular}{|l|l|}
\hline ISBN & Título \\
\hline 1234 & A Internet \\
\hline 4321 & Casa e Fogão \\
\hline 1111 & A arte no século XIX \\
\hline 2222 & Futebol \\
\hline
\end{tabular}

Assuntos

\begin{tabular}{|l|l|}
\hline ISBN_Livro & Assunto \\
\hline 1234 & Computadores \\
\hline 4321 & Cozinha \\
\hline 1111 & Artes \\
\hline 2222 & Esporte \\
\hline 1234 & Redes \\
\hline 4321 & Decoração \\
\hline 4321 & Arquitetura \\
\hline
\end{tabular}


Autores_Livros

\begin{tabular}{|l|l|}
\hline Nome Autor & CodLivro \\
\hline José & 1234 \\
\hline João & 1234 \\
\hline Maria & 1234 \\
\hline Ney & 4321 \\
\hline Marcelo & 1111 \\
\hline Geraldo & 1111 \\
\hline Pedro & 1234 \\
\hline Joaquim & 2222 \\
\hline
\end{tabular}

Se for utilizado o MRNN os dados acima podem ser representados em apenas uma relação:

Livros

\begin{tabular}{|l|l|l|l|}
\hline$\underline{\text { ISBN }}$ & Título & Assuntos* & NomeAutores* \\
\hline 1234 & A Internet & $\begin{array}{l}\text { Computadores } \\
\text { Redes }\end{array}$ & $\begin{array}{l}\text { José } \\
\text { João } \\
\text { Maria } \\
\end{array}$ \\
& & Pedro \\
\hline 4321 & Casa e Fogão & $\begin{array}{l}\text { Cozinha } \\
\text { Decoração } \\
\text { Arquitetura }\end{array}$ & Ney \\
\hline 1111 & A arte no século XIX & Artes & $\begin{array}{l}\text { Marcelo } \\
\text { Geraldo }\end{array}$ \\
\hline 2222 & Futebol & Esporte & Joaquim \\
\hline
\end{tabular}

Note no esquema que as colunas multivaloradas são marcadas com o asterisco $\left(^{*}\right)$, como no livro de Setzer [SET 86]. Notamos que o esquema fica muito mais simples e claro, e representa de uma maneira melhor a realidade: cada livro é apenas uma entidade, sendo representado por uma única linha e não por várias em diferentes relações. 
Outro exemplo de modelagem que se beneficia das características do MRNN é o do cadastro de funcionários ou clientes com atributos multivalorados: além de nome, endereço, data de nascimento, etc., queremos modelar o fato de um funcionário poder possuir vários telefones e dominar várias línguas. Para representar estes dados no MR, será necessário o uso de três relações: uma para armazenar os atributos monovalorados, uma para os telefones, e outra para as línguas. Será usado o seguinte esquema:

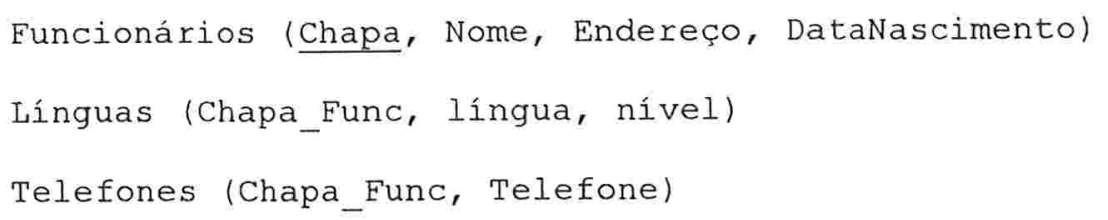

Funcionários

\begin{tabular}{|c|l|l|l|}
\hline \multicolumn{1}{|c|}{ RG } & Nome & Endereço & DataNascimento \\
\hline 1234 & José & Rua 1 & $01 / 01 / 70$ \\
\hline 1111 & Maria & Rua X & $01 / 05 / 60$ \\
\hline 4321 & João & Rua 2 & $31 / 12 / 69$ \\
\hline
\end{tabular}

Telefones

\begin{tabular}{|l|l|}
\hline Chapa_Func & Telefone \\
\hline 1234 & $555-5555$ \\
\hline 1111 & 707070 \\
\hline 4321 & $888-5555$ \\
\hline 1234 & $666-9999$ \\
\hline
\end{tabular}

Línguas

\begin{tabular}{|l|l|l|}
\hline Chapa_Func & Língua & Nivel \\
\hline 1234 & Inglês & 1 \\
\hline 1234 & Francês & 1 \\
\hline 1111 & Português & 4 \\
\hline 1111 & Alemão & 3 \\
\hline 4321 & Italiano & 2 \\
\hline
\end{tabular}

No MRNN utilizaremos apenas uma tabela para representar estes dados: 
Funcionários(Chapa, Nome, Endereço, DataNascimento, Línguas(Língua, Nível)*, Telefones*)

Os dados são armazenados apenas em uma relação:

Funcionários

\begin{tabular}{|l|l|l|l|l|l|}
\hline Chapa & Nome & Endereço & DataNascimento & $\begin{array}{l}\text { Línguas* }^{*} \\
\text { (Idioma,nível) }\end{array}$ & Telefones* \\
\hline 1234 & José & Rua 1 & $01 / 01 / 70$ & $\begin{array}{l}\text { (Inglês, 1) } \\
\text { (Francês, 1) }\end{array}$ & $\begin{array}{l}555-5555 \\
666-9999\end{array}$ \\
\hline 1111 & Maria & Rua X & $01 / 05 / 60$ & $\begin{array}{l}\text { (Português, 4) } \\
\text { (Alemão, 3) }\end{array}$ & 707070 \\
\hline 4321 & João & Rua 2 & $31 / 12 / 69$ & (Italiano, 2) & $888-5555$ \\
\hline
\end{tabular}

A solução com o MRNN além de diminuir a redundância das chaves das relações e o número destas (no exemplo, a existência de uma chave torna-se até supérflua), é mais simples e eficiente. Uma proposta de implementação física com um número qualquer de niveis de encadeamento pode ser encontrada no livro de Setzer [SET 86]. Com esse modelo ainda é possível a representação de listas, textos ou outras estruturas que são necessárias para algumas aplicações avançadas, tal como o CAD/CAM.

\subsection{O Modelo de Entidades e Relacionamentos}

O Modelo de Entidades e Relacionamentos (MER), apresentado por Chen [CHE 76], é um dos chamados "modelos semânticos". Este modelo serve para representação das estruturas de informações, sendo apresentado de forma gráfica, como um esquema. Vamos utilizar o modelo original, com as extensões apresentadas por Setzer [SET 86]. Apresentaremos ainda novas extensões ao MER.

O MER pode ser utilizado como um modelo puramente conceitual, como ferramenta de projeto e análise de dados [SE'T 86]. Porém o MER, acrescido de chaves e "chaves estrangeiras" pode ser utilizado como uma extensão do MR, como o próprio Chen apresenta em seu artigo original. Nossa proposta, apresentada adiante, será o de um modelo de dados baseado no MER, que pode ser efetivamente implementado em um sistema real. Como exemplo de sistema que implementa o MER operacionamente podemos citar o ZIM [ZIM 91]. 
Vamos mostrar os principais conceitos deste modelo, e os seus diagramas, que serão utilizados adiante.

\subsubsection{Entidades e atributos}

Uma entidade é uma representação abstrata de um "objeto" de interesse no mundo real. Como exemplo são entidades as representações abstratas de um funcionário, de um departamento, de um material usado em uma empresa, etc. Um grupo de entidades de mesma natureza no mundo real formam um conjunto de entidades, como por exemplo um conjunto de funcionários, um conjunto de alunos, etc. No esquema gráfico, representaremos uma entidade por um retângulo, com o nome do conjunto de entidades no seu interior, mostrado na Figura 2. Por conveniência, passaremos a chamar os conjuntos de entidades apenas de entidades.
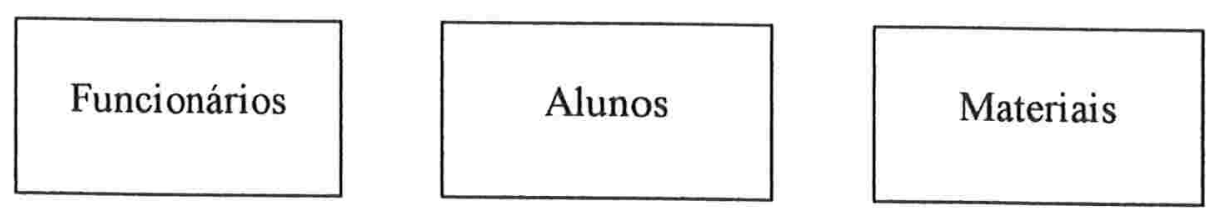

Figura 2: Representação das entidades no diagrama ER

As entidades possuem atributos, que são funções que levam um elemento do conjunto de entidades a um elemento de um conjunto de valores, como por exemplo os conjuntos de nomes, de datas de nascimento, de endereços, etc. Os atributos servem para representar as informações sobre os elementos dos conjuntos de entidades. Vamos representar os atributos como na Figura 3:

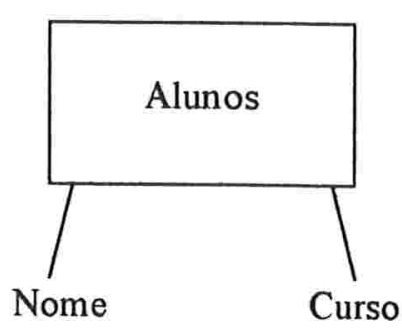

Figura 3: Atributos de uma entidade

Seguindo as extensões de Setzer [SET 86], atributos podem ser compostos, onde o atributo pode ser composto por vários sub-atributos; multivalorados, quando o atributo leva um elemento do conjunto de entidades a um conjunto de valores (uma função 
"multivalente"), ou ainda o atributo pode ser determinante, quando a função do atributo é bijetora, ou seja, o mesmo valor do atributo não ocorre em dois elementos do conjunto de entidades. Na Figura 4, Telefones é um exemplo de atributo multivalorado, Endereço um exemplo de atributo composto e RG de atributo determinante. Pode-se ter qualquer combinação de atributos multivalorados com compostos.

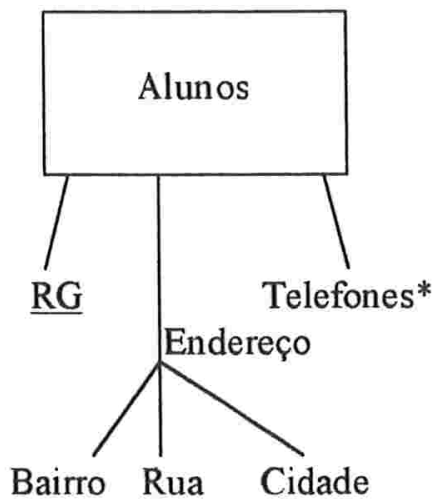

Figura 4: Atributos compostos, determinantes e multivalorados

\subsubsection{Relacionamentos e multiplicidade de relacionam entos}

Os Relacionamentos são estruturas conceituais que representam associações no mundo real, entre os objetos representados por diferentes conjuntos de entidades, como por exemplo o fato de um funcionário estar lotado em um determinado departamento, o fato de um cliente de um banco possuir várias contas bancárias, etc. Um relacionamento binário é um par ordenado $\left(\mathrm{e}_{1}, \mathrm{e}_{2}\right), \mathrm{e}_{1} \in \mathrm{E}_{1}$, e $\mathrm{e}_{2} \in \mathrm{E}_{2}$, onde $\mathrm{E}_{1}$ e $\mathrm{E}_{2}$ são conjuntos de entidades. No esquema gráfico, o relacionamento é representado por um losango, com vértices ligando as entidades que ele relaciona. Então, por exemplo, se $\mathrm{E}_{1}$ for o conjunto de funcionários $\mathrm{e}_{2}$ o conjunto de departamentos, o par (f,d) está no conjunto de relacionamentos Lotações se e somente se o funcionário $\mathrm{f}$ estiver lotado no departamento $\mathrm{d}$. $\mathrm{O}$ esquema deste relacionamento está na Figura 5.

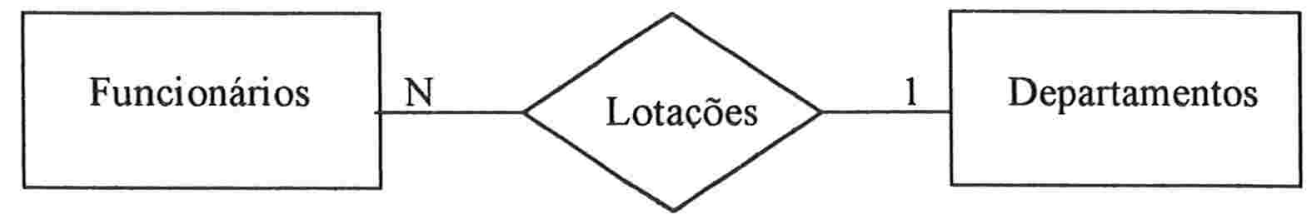

Figura 5: Exemplo de relacionamento 
No esquema nota-se o "N" e o "1", que determinam a multiplicidade (nome atualmente recomendado pelo prof. Setzer, no lugar de "classe" como colocou em seu livro [SET 86] antes da orientação a objetos se tomar popular) do relacionamento. Ele não recomenda a nomenclatura "cardinalidade" como encontrada na literatura, pois não se trata do número de elementos de um conjunto, mas sim uma representação do número máximo de associações a um outro elemento. O relacionamento acima é classificado como "N para 1" ou "muitos para um", que indica que vários funcionários (máximo ilimitado, representado por $\mathrm{N}$ ) podem estar lotados num mesmo departamento, porém, um funcionário pode estar lotado apenas em um departamento. O relacionamento ainda pode ser "N para N" ou "muitos para muitos", como por exemplo, o relacionamento Matrículas, entre alunos e disciplinas, representado na Figura 6. Cada aluno pode cursar várias disciplinas e cada curso pode ter vários alunos matriculados.

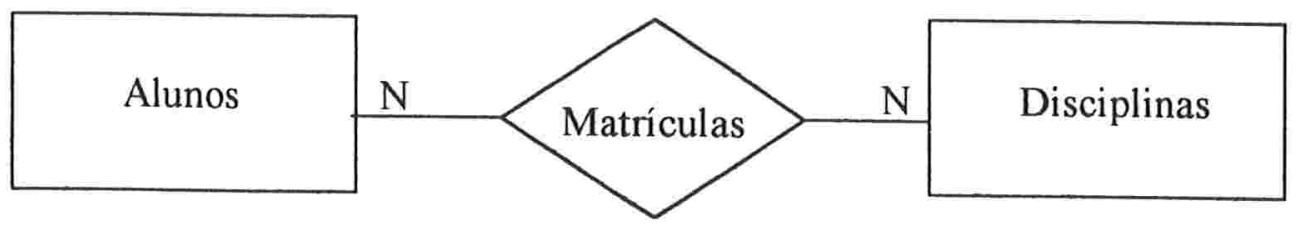

Figura 6: Relacionamento $\mathrm{N}$ para $\mathrm{N}$

Um relacionamento pode ser ainda "um para um", por exemplo no caso de uma chefia. Uma pessoa pode chefiar apenas uma equipe, e a equipe possui apenas um chefe (Figura 7).

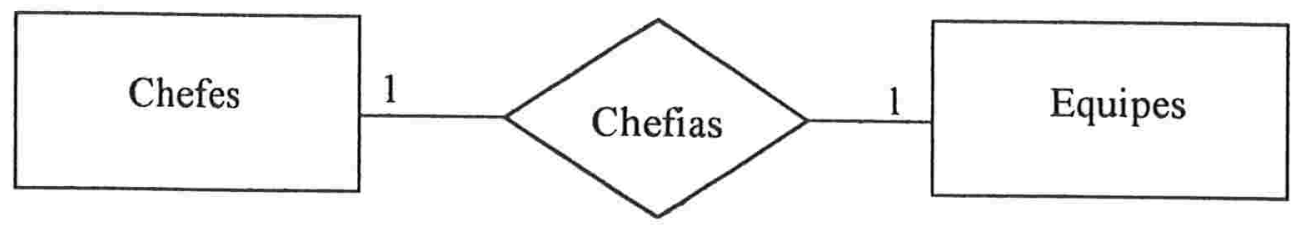

Figura 7: Relacionamento 1 para 1

Podemos generalizar este conceito, permitindo que se coloquem constantes como por exemplo, um relacionamento " $\mathrm{N}$ para 6", por exemplo, se cada aluno puder cursar no máximo 6 disciplinas (Figura 8). 


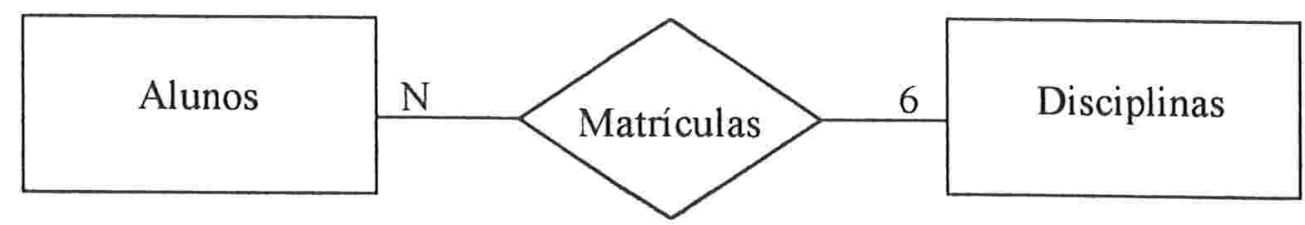

Figura 8: Relacionamento $N$ para 6

Esse conceito poderia ainda ser estendido, para o caso de por exemplo uma disciplina dispor de apenas 50 vagas, por exemplo. Aí teríamos um relacionamento "50 para 6". Com estas representações, podemos representar várias restrições de integridade quanto à multiplicidade nos esquemas; note que os relacionamentos "1 para N" e "1 para 1" são apenas casos particulares dessas restrições.

Os relacionamentos também podem possuir atributos, pois existem informações da associação que podem não pertencer a nenhuma das entidades do relacionamento correspondente. No exemplo anterior, as notas dos alunos de uma disciplina são um caso típico, pois a nota não é atributo do aluno, já que ele cursa várias disciplinas, ou seja, depende da disciplina. Também não é atributo da disciplina, pois evidentemente a nota pode ser diferente para cada aluno. Apresentamos um exemplo de representação abaixo, bem como o exemplo da última classe de relacionamentos ("50 para 6").

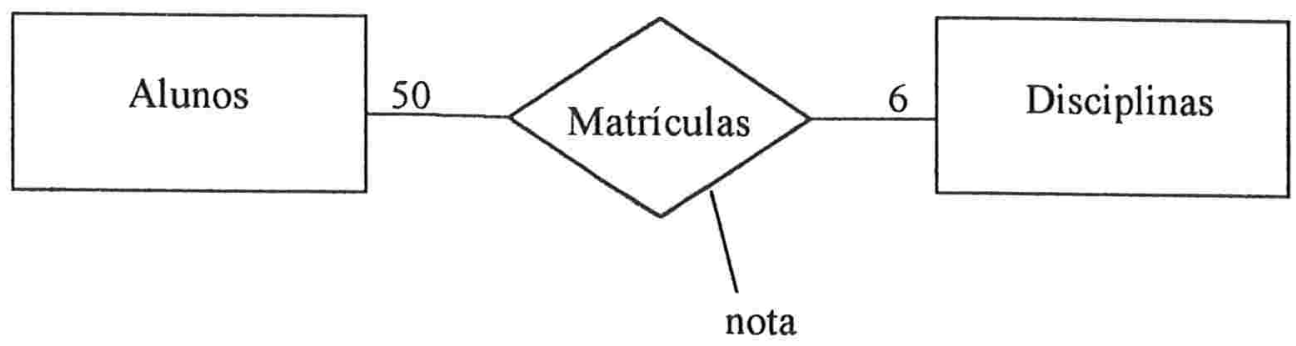

Figura 9: Atributo de relacionamento. Relacionamento 50 para 6

Vamos acrescentar mais uma informação no esquema, sob a forma de uma restrição de integridade. Suponha que cada aluno deva necessariamente estar matriculado em alguma disciplina. Representaremos tal fato com uma bolinha no lado de Alunos. Podemos também supor que não existe nenhuma disciplina sem no mínimo 5 alunos. Colocamos o número mínimo de alunos sobre a bolinha, como no esquema da Figura 10. Cada uma dessas restrições de integridade é denominada totalidade do relacionamento por Setzer [SET 86]. 


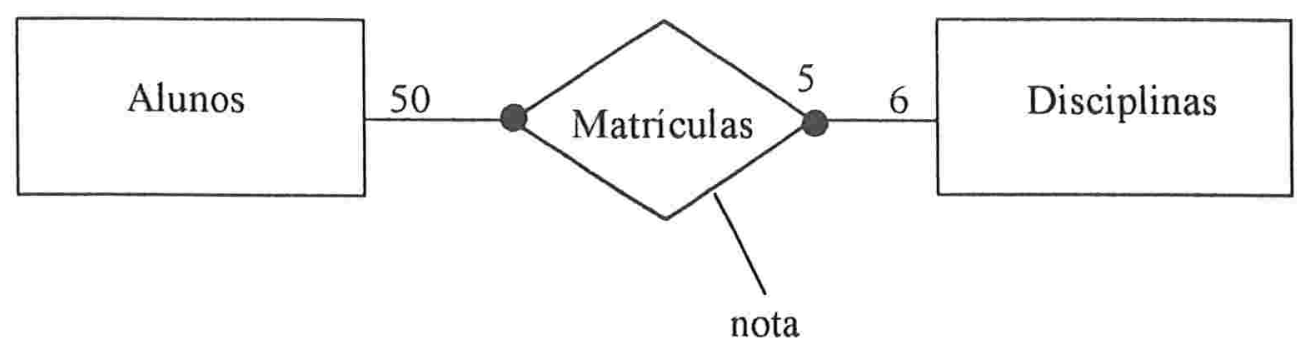

Figura 10: Totalidade de relacionamentos

Alguns autores representam o número mínimo e máximo de elementos que se relacionam como um par. No caso anterior, teríamos $[5,50]$ para o número de alunos e $[1,6]$ para o número de disciplinas.

\subsubsection{Auto-relacionamentos, relacionamentos múltiplos}

Um auto-relacionamento é um relacionamento onde os dois elementos do par ordenado são do mesmo conjunto de entidades. Um exemplo típico de auto-relacionamento é o de peças e composições. Uma peça compõe outras peças, e assim sucessivamente. Por exemplo, o motor é uma peça do carro, e o motor é composto pelo bloco, cilindros, etc.

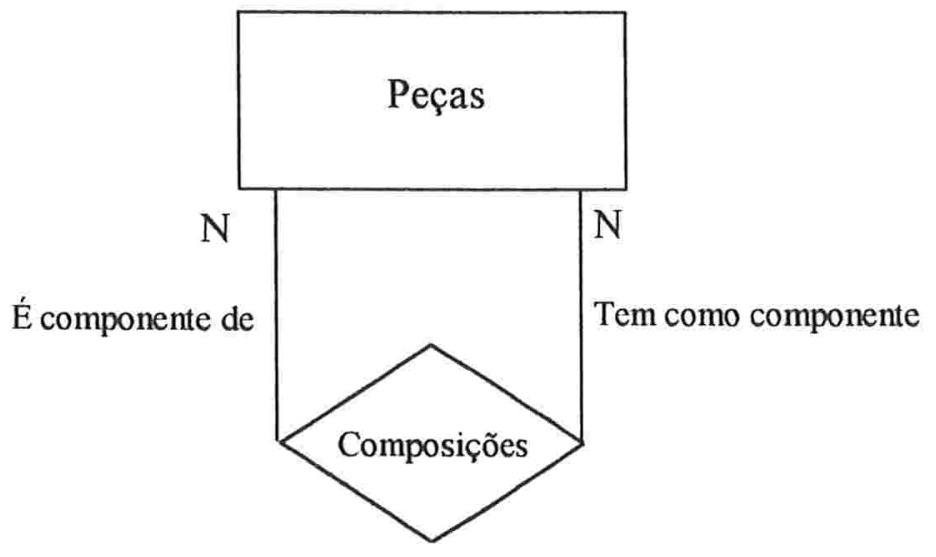

Figura 11: Auto-relacionamento

Nas arestas dos relacionamentos notamos os papéis, que são necessários para se distinguir qual peça é componente e qual é a peça composta. Por exemplo, o bloco é componente do motor, e motor tem como componente o bloco.

Um relacionamento múltiplo é uma generalização dos relacionamentos binários. Ao invés de um par ordenado, o conjunto de relacionamentos é composto por triplas ou 
n-uplas ordenadas. Um exemplo de relacionamento múltiplo é o do relacionamento entre professores, disciplinas e alunos. Segundo a interpretação da multiplicidade de Setzer [SET 86], o modelo da Figura 12 representa o fato de, dado um aluno matriculado em uma disciplina, haver apenas um professor associado a esse par, pois queremos representar o fato de que o aluno não cursa uma mesma disciplina com mais de um professor. Por outro lado, um professor pode ministrar uma certa disciplina para vários alunos, e um professor pode ser responsável por mais de uma disciplina para um certo aluno.

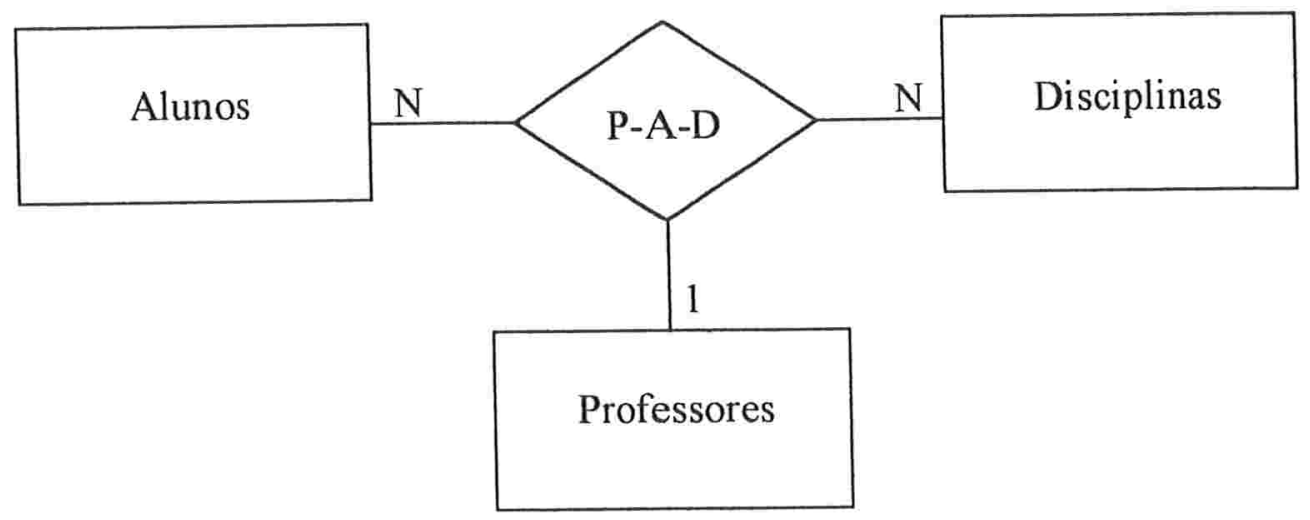

Figura 12: Relacionamento triplo

\subsubsection{Agregações}

Quando é necessário estabelecer relacionamentos entre relacionamentos, é interessante considerar um conjunto de relacionamentos e seus conjuntos de entidades como um conjunto de entidades, agregando todas as suas informações. Um exemplo de agregação [SET 86] ocorre num sistema de almoxarifado, que controla os materiais, requisições de materiais e a compra, quando necessário. Há um relacionamento $\mathrm{N}$ para $\mathrm{N}$ entre os materiais e as requisições. Por sua vez, alguns dos itens de requisição geram pedidos de compra. 


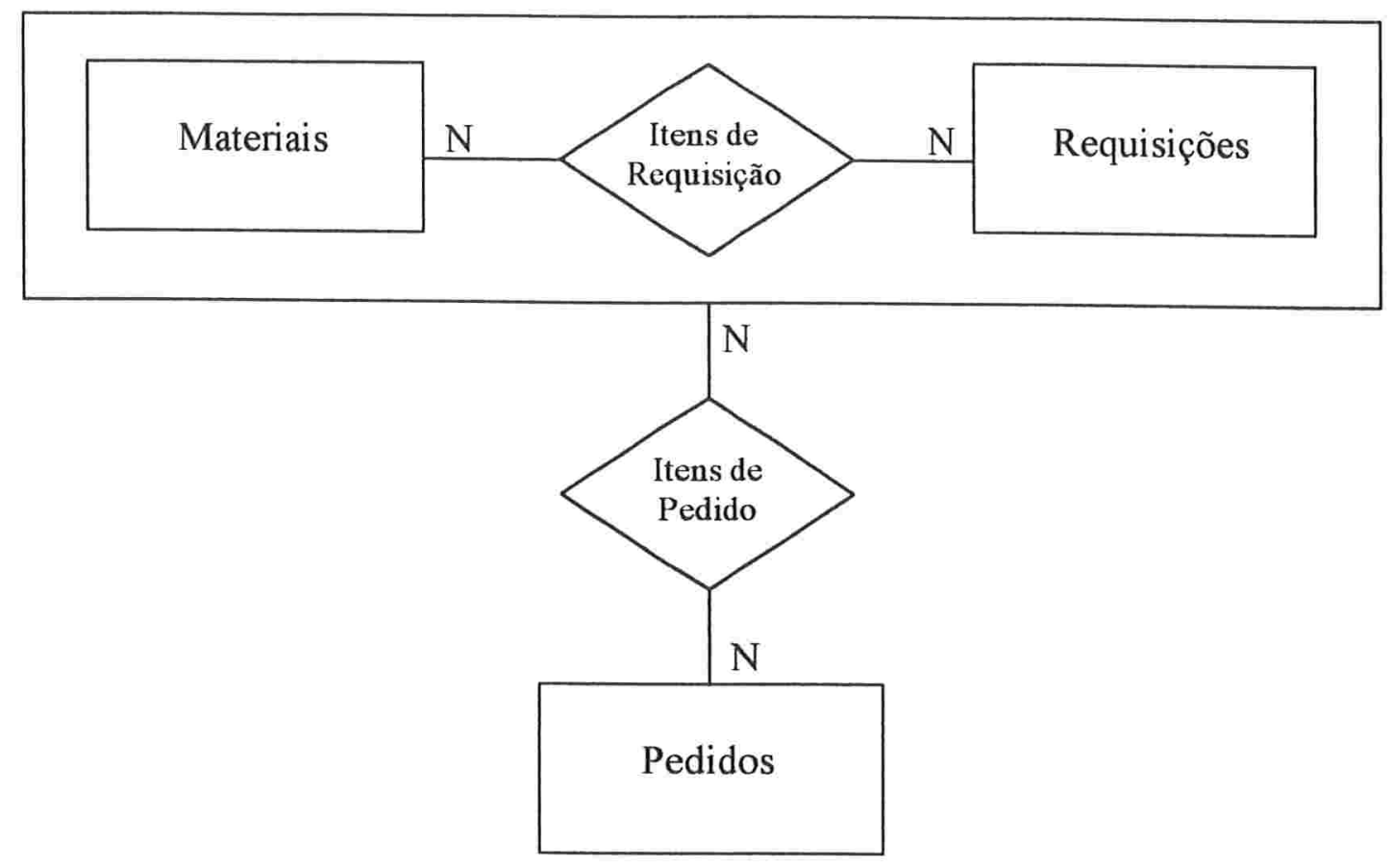

Figura 13: Agregaçẫo

Vamos mostrar um esquema genérico para definir melhor a agregação:

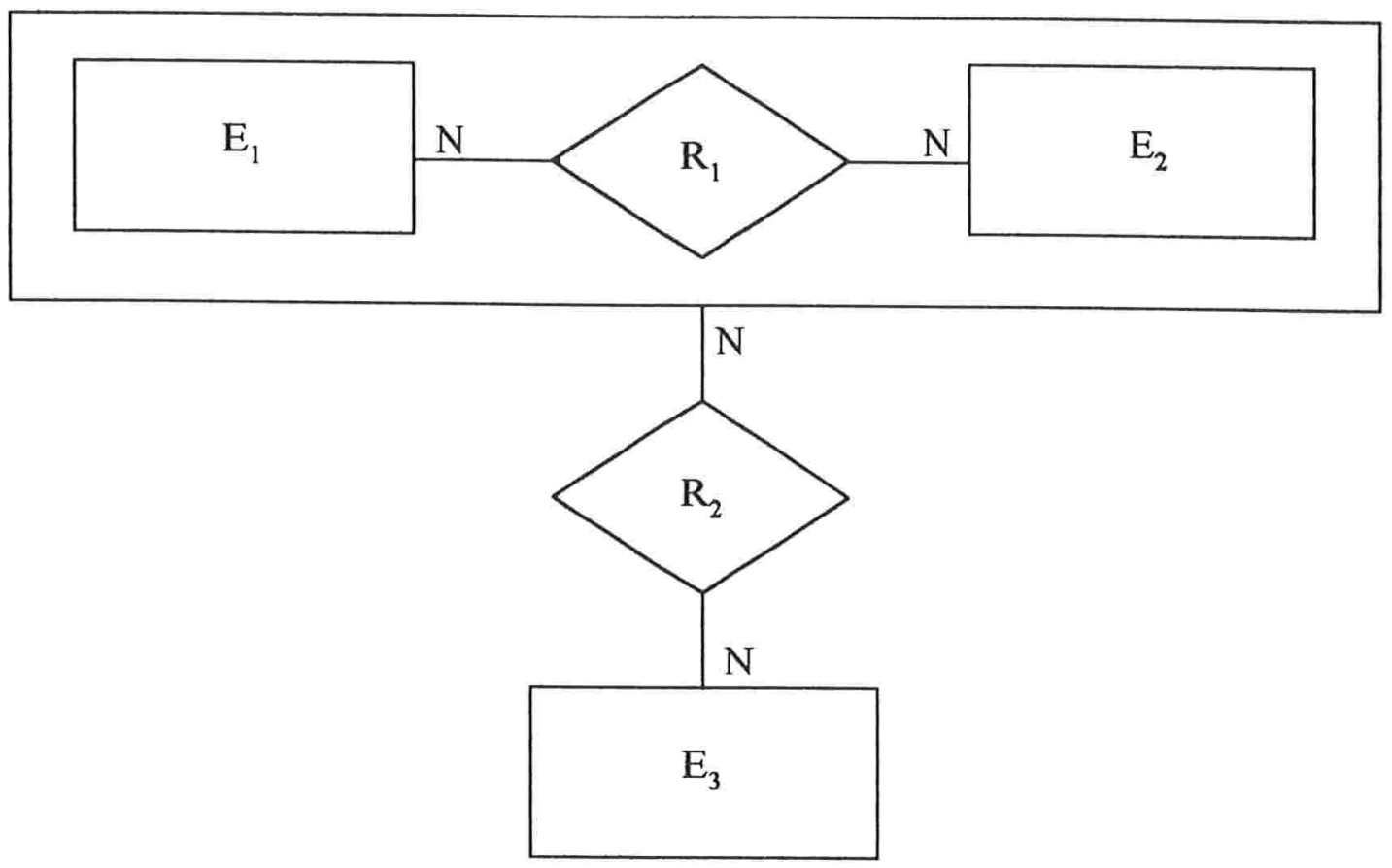

Figura 14: Agregaçào geral

Formalmente teremos o seguinte:

$$
\mathrm{R}_{2} \subseteq\left\{\left(\left(\mathrm{e}_{1}, \mathrm{e}_{2}\right), \mathrm{e}_{3}\right) \mid\left(\mathrm{e}_{1}, \mathrm{e}_{2}\right) \in \mathrm{R}_{1} \text { e } \mathrm{e}_{3} \in \mathrm{E}_{3}\right\}
$$


Em outras palavras, $\mathrm{E}_{3}$ se relaciona com o conjunto de relacionamentos $\mathrm{R}_{1}$, bem diferente do relacionamento triplo entre $E_{1}, E_{2}$ e $E_{3}$, que seria uma tripla com elementos dos três conjuntos. A agregação permite a existência de pares de $E_{1}$ e $E_{2}$ em $R_{1}$ sem que se relacionem com $\mathrm{E}_{3}$, o que seria impossível no relacionamento triplo.

A agregação também pode ser representada, como em algumas ferramentas CASE, por um retângulo em tomo do losango do relacionamento, como mostrado na Figura 15.

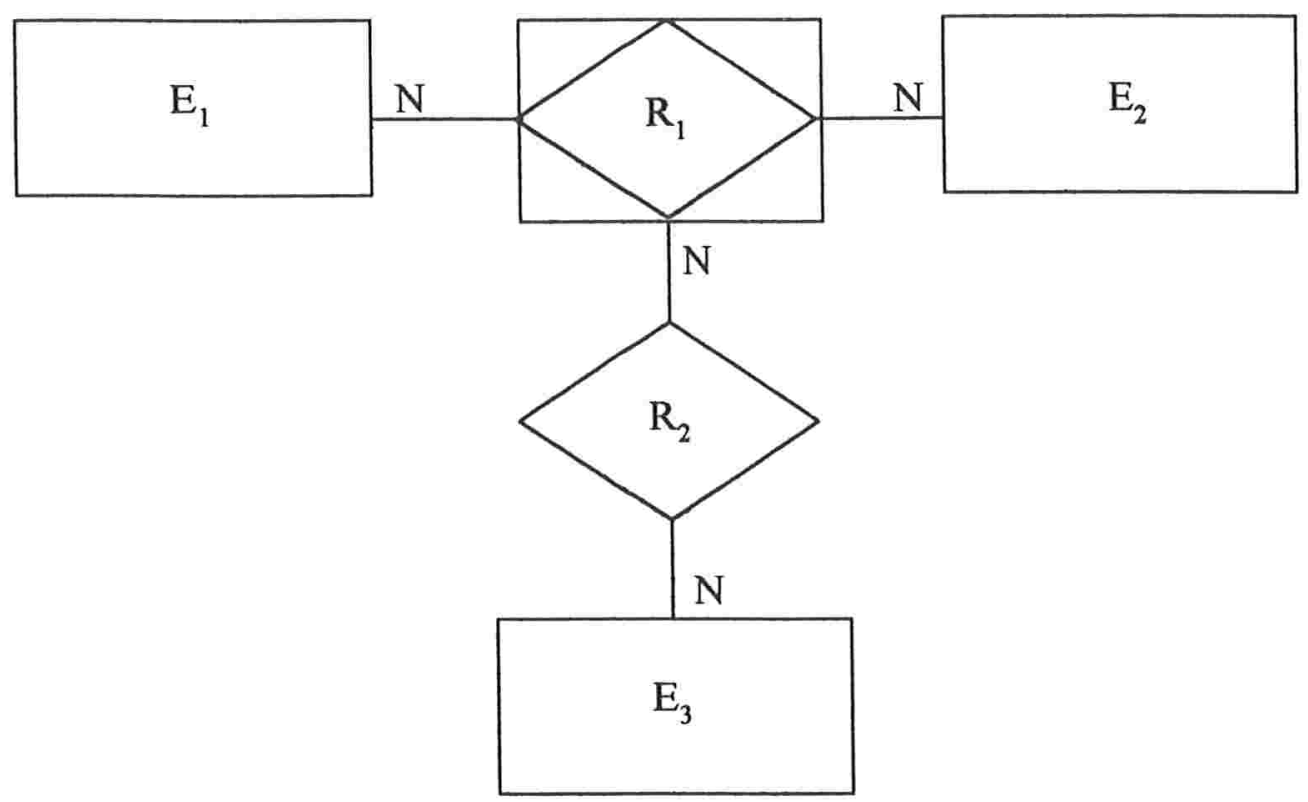

Figura 15: Representação alternativa da agregação

Essa notação é mais compacta, e mostra bem como o relacionamento das duas entidades $\mathrm{E}_{1}$ e $\mathrm{E}_{2}$ é considerado como se fosse uma só entidade. No entanto ela não pode ser usada no caso da agregação envolver dois relacionamentos distintos; nesse caso deve-se empregar a notação gráfica anterior.

\subsubsection{Generalização/especialização}

A generalização/especialização de um conjunto de entidades se assemelha ao do modelo RM/T. Um conjunto de entidades Funcionários pode ser especializado em Secretários, Engenheiros e Técnicos, e este fato será representado como no esquema da Figura 16: 


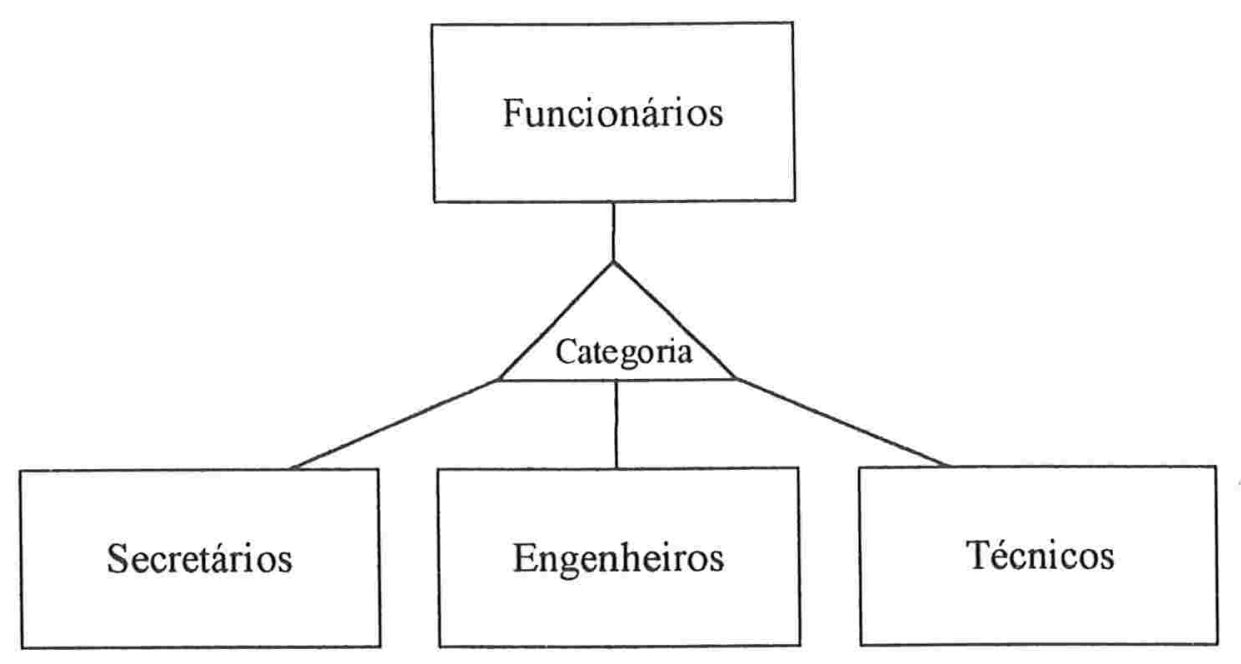

Figura 16: Especialização de Funcionários

Neste caso, considera-se que podem existir funcionários que não são engenheiros, técnicos ou secretários. Pode-se desejar que haja uma generalização total, ou seja, que as união de todos os subconjuntos seja o conjunto de entidades generalizado, por exemplo, se considerarmos que todos os funcionários de uma empresa ou são prestadores de serviço ou funcionários regulares, de carteira assinada, podemos representar este fato com uma bolinha na ponta do triângulo, representando uma generalização total:

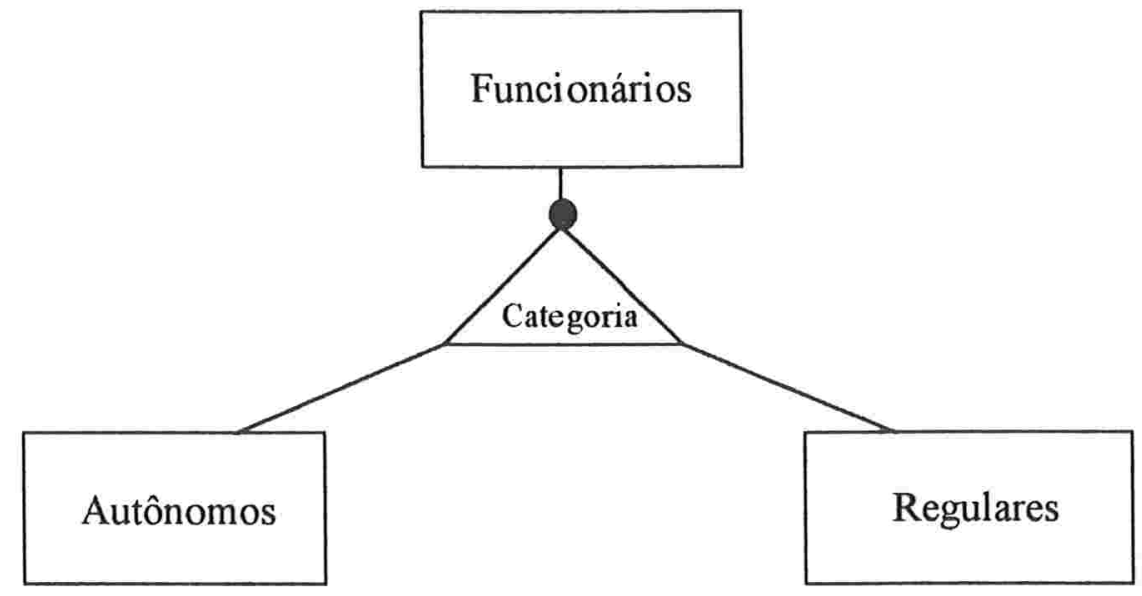

Figura 17: Generalização total

Nesse caso, todos os funcionários ou são regulares ou são autônomos, não existindo nenhum funcionário que não seja de uma dessas duas categorias.

Vamos introduzir um novo tipo de representação, sugerida como a totalidade, pelo prof. Setzer: uma generalização pode ser exclusiva ou inclusiva. Na generalização exclusiva os conjuntos de entidades que são especializações de um conjunto de entidades especificado 
são disjuntos, por exemplo, no exemplo anterior, os funcionários devem pertencer a apenas uma categoria. Representaremos este fato como na figura a seguir:

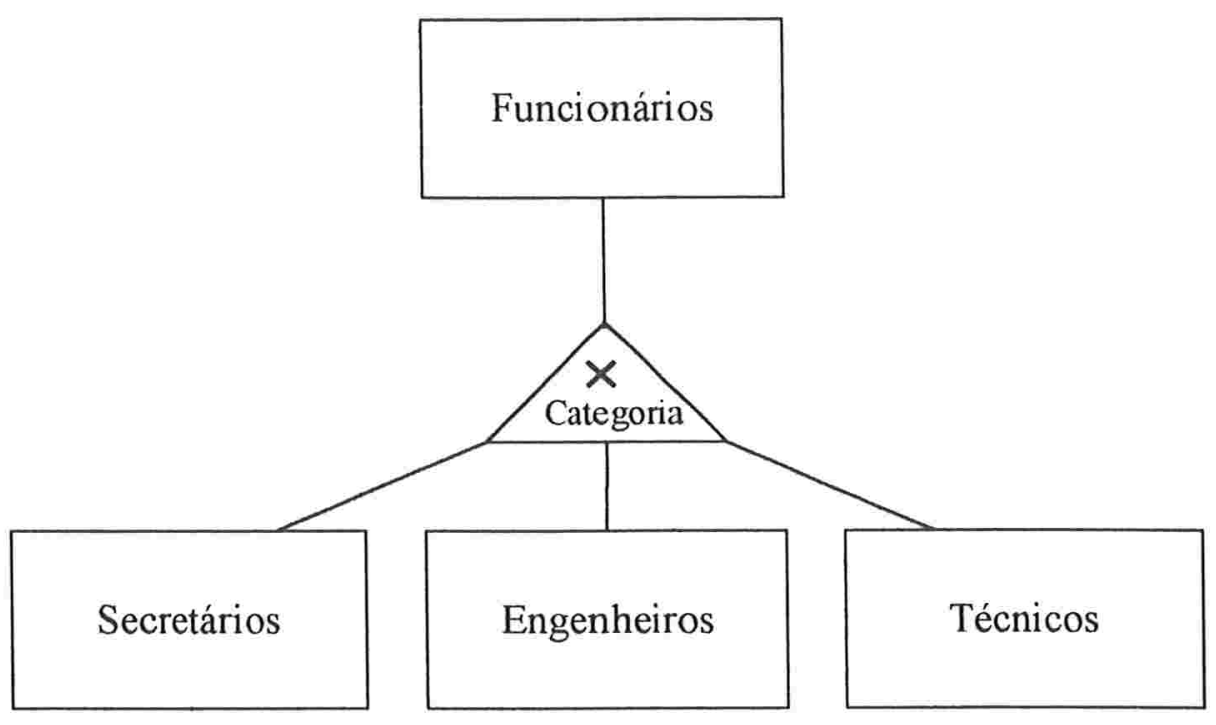

Figura 18: Generalizaçāo exclusiva

Uma generalização inclusiva pode acontecer, por exemplo, em um banco, onde uma pessoa física pode ser correntista do banco ou um funcionário, ou ambos.

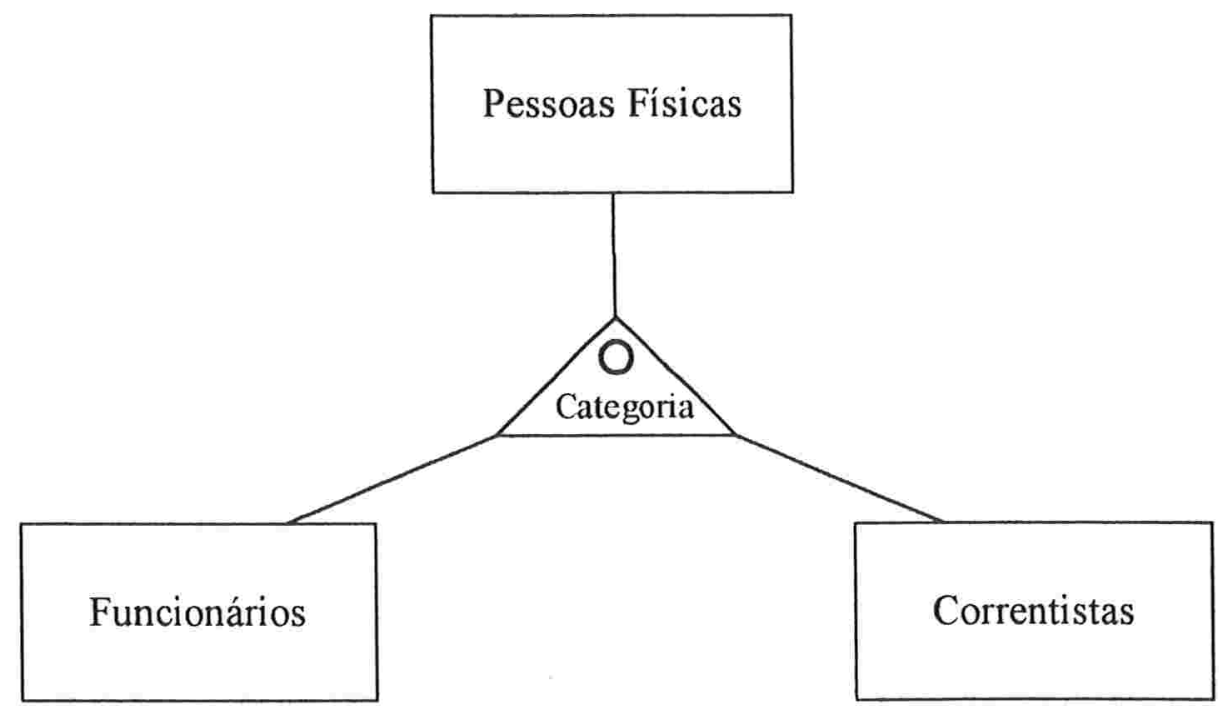

Figura 19: Generalizaçào inclusiva

\subsubsection{Relacionamentos exclusivos e inclusivos}

Aproveitando a notação da generalização/especialização inclusiva e exclusiva, vamos apresentar outra extensão ao modelo original de Chen sugerida pelo prof. Setzer. Quando 
um conjunto de entidades A relaciona-se por meio de vários relacionamentos de mesma natureza semântica com várias entidades B, C, etc., pode-se agrupar esses vários relacionamentos em um só. Note-se que a multiplicidade do lado A deve ser a mesma. Temos dois casos: cada elemento de A pode relacionar-se com elementos de vários conjuntos de entidades diferentes - é o relacionamento inclusivo, representado na Figura 20. Se o elemento de A puder se relacionar apenas com elementos de B ou (exclusivo) apenas com elementos de C, etc., temos um relacionamento exclusivo, representado na Figura 21.

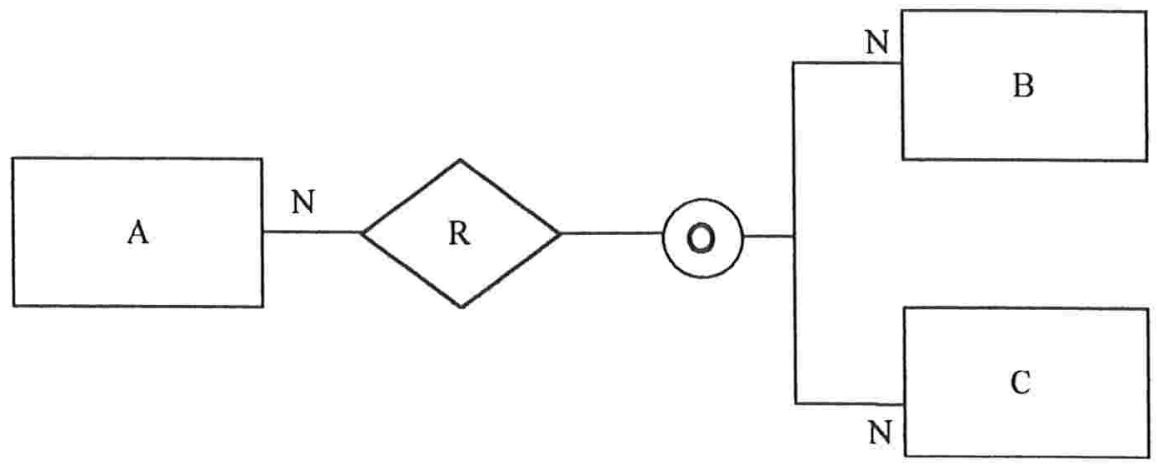

Figura 20: Relacionamento inclusivo

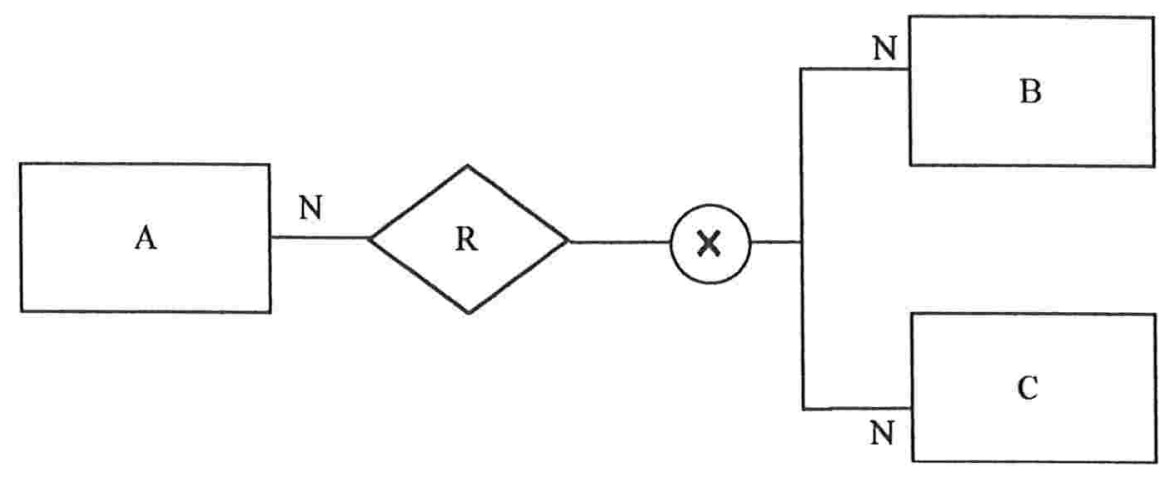

Figura 21: Relacionamento exclusivo

Vamos mostrar alguns exemplos de relacionamentos inclusivos e exclusivos. Um relacionamento exclusivo pode acontecer, por exemplo, em um sistema de controle de uma "software house". Um atendimento telefônico pode ser feito pelo setor de vendas, por um vendedor, ou pelo setor de suporte técnico, por um analista, mas não dos dois ao mesmo tempo. 


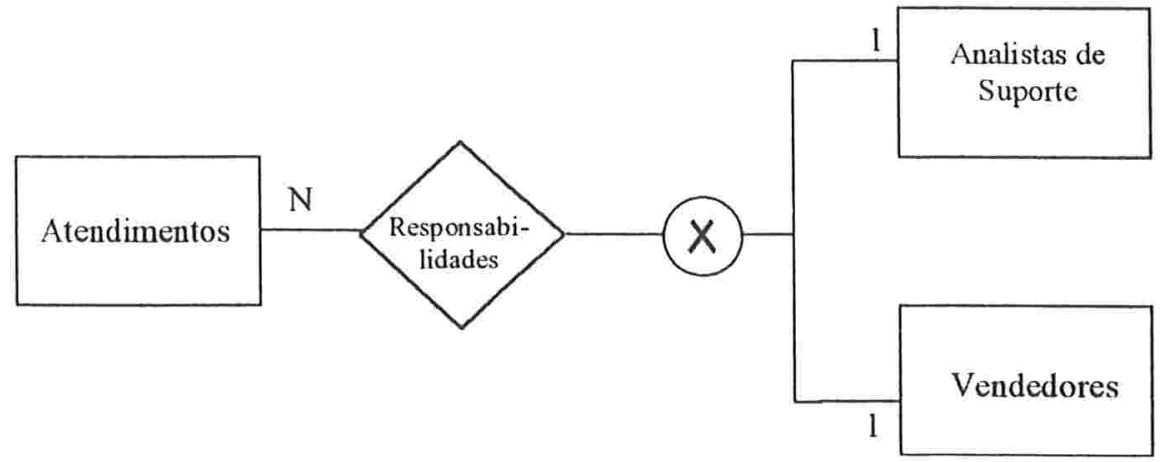

Figura 22: Exemplo de relacionamento exclusivo

Um exemplo de relacionamento inclusivo poderia ser o de controle de posses de veículos. Uma pessoa poderia possuir vários tipos de veículos, que podem estar representados em diferentes entidades.

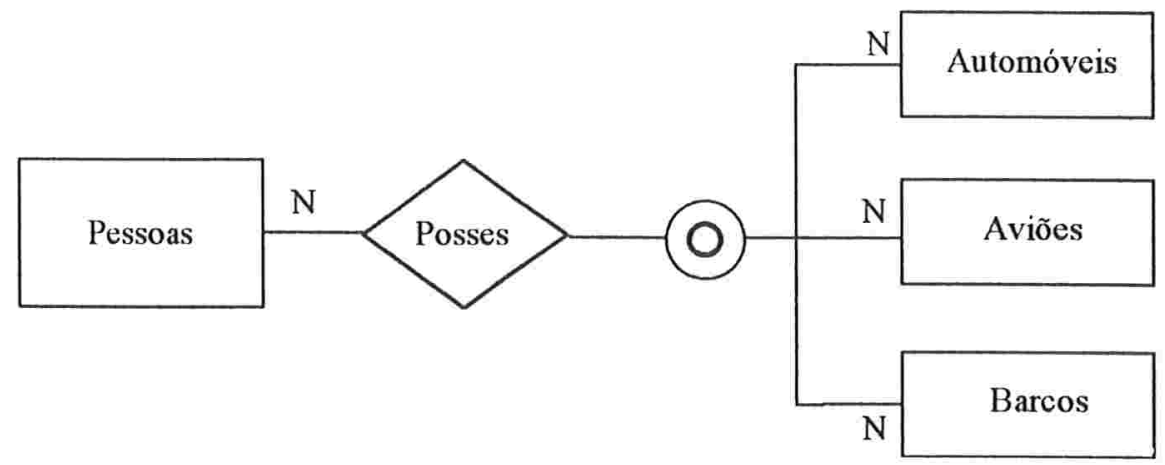

Figura 23: Exemplo de relacionamento inclusivo

Uma pessoa pode possuir vários barcos, aviões ou automóveis, e a associação de posse é a mesma para os vários tipos de veículos e seus donos.

Nesses dois exemplos, poder-se-ia imaginar uma generalização das entidades, substituindo-se o relacionamento inclusivo/exclusivo por um relacionamento binário comum com a entidade generalizada. Por exemplo, poder-se-ia imaginar para a Figura 23 a generalização Veículos, e na Figura 22, Funcionários.

No entanto, perder-se-ia informação se os relacionamentos exclusivos ou inclusivos se dessem apenas com algumas das entidades especializadas. No caso exclusivo, com relacionamento $\mathrm{N}$ para $\mathrm{N}$, ainda há a informação de exclusividade que seria perdida no relacionamento com a generalização. 
Pode ainda haver vários casos em que o relacionamento não se dá com entidades de mesma natureza, e portanto passíveis de generalização.

\subsubsection{O MER como modelo operacional}

O MER pode ser representado não apenas por forma de gráficos, mas também por uma linguagem de definição de dados, que permite uma representação dos esquemas de uma outra forma. Essa representação pode ser usada como uma linguagem de definição de dados para uma extensão do MR. Vamos mostrar com um exemplo como poderia ser uma definição de dados através dessa linguagem, representado o esquema da Figura 24:

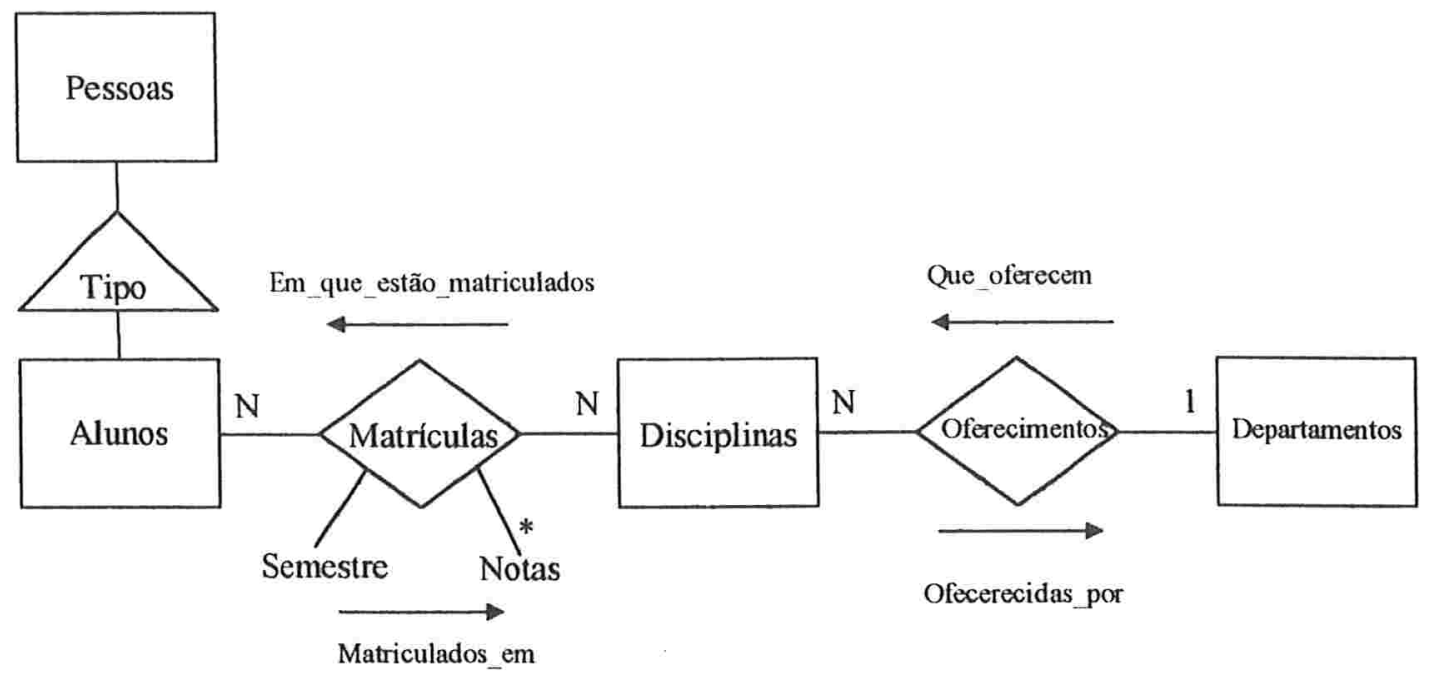

Figura 24: Esquema ER de exemplo

$\mathrm{Na}$ Figura 24, introduzimos uma nova notação. Seguindo o modelo do SGBD ZIM [ZIM 91], em cada relacionamento colocamos sinônimos, associados a cada entidade participante do relacionamento. Na figura, por exemplo, teremos Alunos Matriculados_em Disciplinas, e Disciplinas Em_que_estão_matriculados Alunos. Essa definição facilita a linguagem de consulta, que mostraremos a seguir.

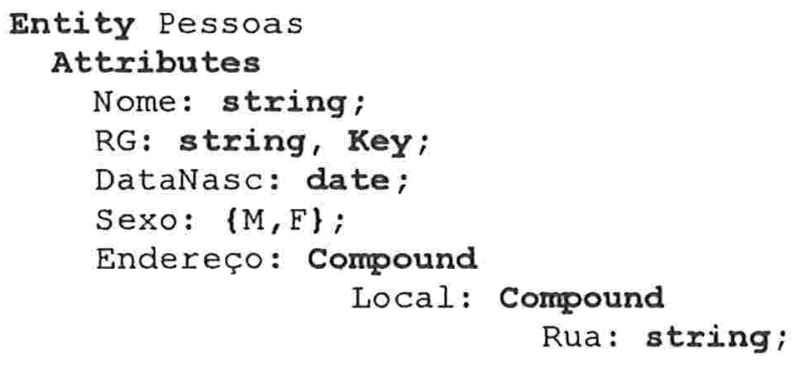




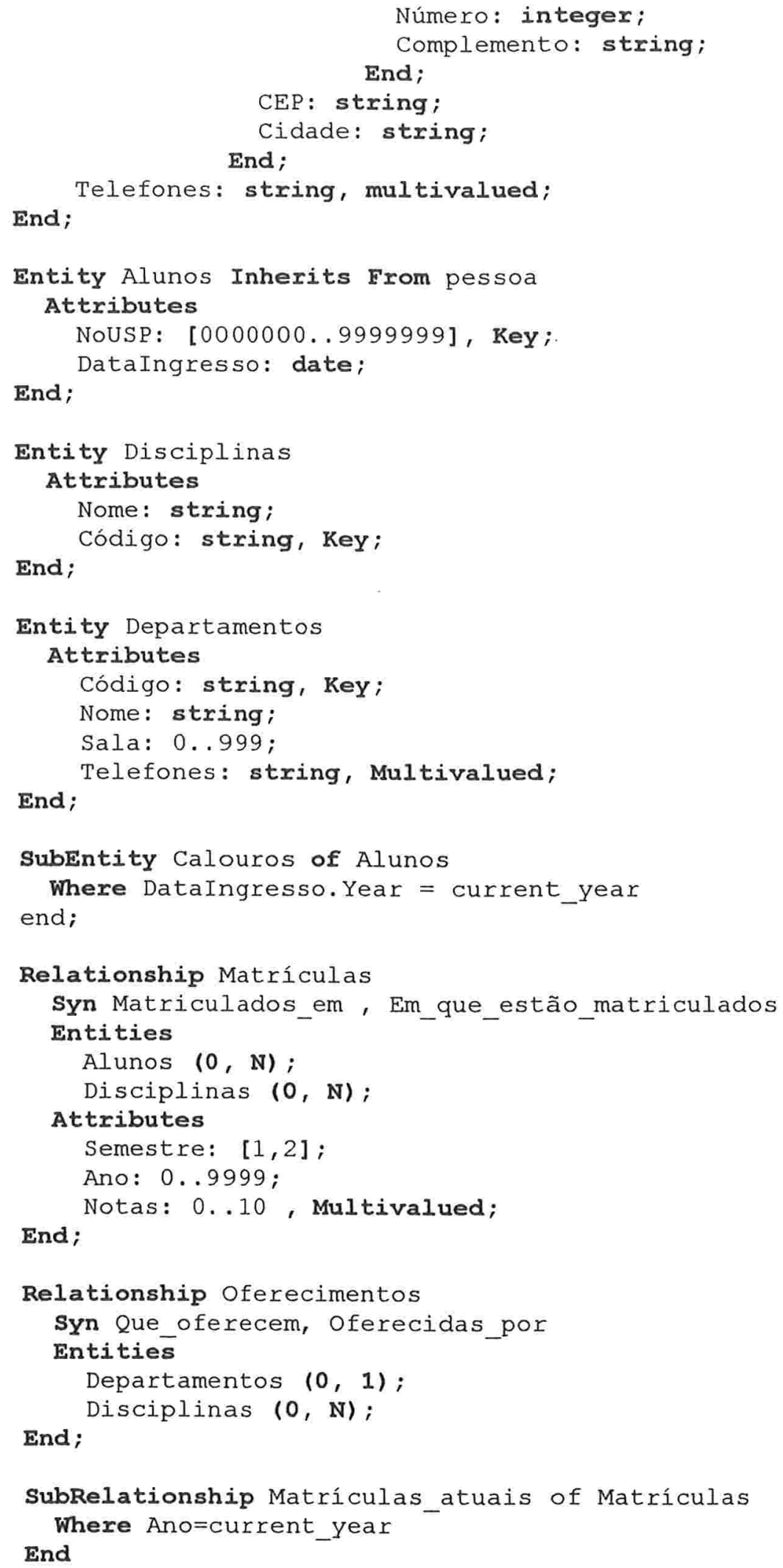

A palavra-chave compound define o atributo composto, de forma semelhante ao comando "record" da linguagem Pascal, ou o "struct" da $\mathrm{C} / \mathrm{C}++$. A palavra key define um atributo como determinante, e multivalued define o atributo como multivalorado. Em 
nosso modelo, podemos representar relações dentro de relações (relações aninhadas). Um atributo do tipo compound multivalorado seria uma relação dentro da outra. Um exemplo dessa relação poderia ocorrer se uma pessoa pudesse possuir vários endereços.

Um exemplo de consulta mostra o uso dos sinônimos:

select Alunos. Nome

from Alunos matruculados_em Disciplinas

where Disciplina.Código = "MAC-110"

Essa consulta lista o nome de todos os alunos que estão matriculados na disciplina de código "MAC-110". As consultas serão descritas com mais detalhes adiante (Item 8.6).

Essas declarações, além de serem uma tradução praticamente direta do esquema MER, podem gerar um esquema MR normalizado, através de um tradutor. O esquema correspondente poderia ser o seguinte:

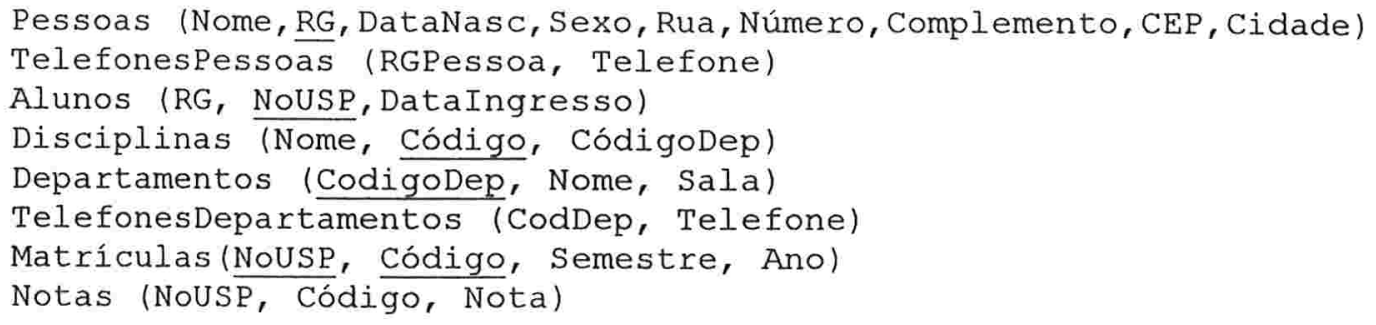

Note-se o uso das chaves para gerar as chaves estrangeiras. Em geral, cada entidade é representada por uma relação. Para representarmos o relacionamento "N para N", foi necessário criar uma relação auxiliar, assim como para representar os atributos multivalorados. Outra observação a ser feita é que o atributo composto é decomposto nos seus componentes-folha. Se fosse utilizado o MRNN, pode-se simplificar o esquema, seguindo Setzer [SET 86]:

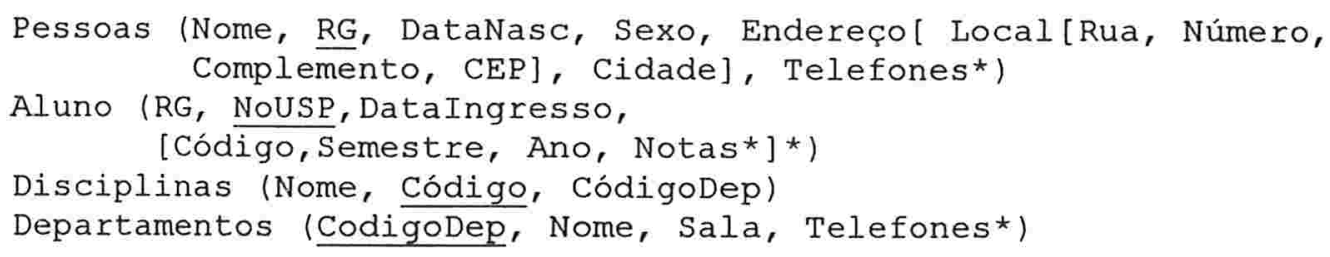

Notamos que nesse caso não foi necessário criar nenhuma relação auxiliar, o que melhora a eficiência do esquema, tanto no espaço ocupado como nas consultas, por diminuir a necessidade de junções (“joins"). A decisão de representar as matrículas dentro de Alunos e não de Disciplinas é devido ao fato de que os dados correspondentes são mais relativos aos alunos e não às disciplinas. 


\section{Orientação a Objetos (OO)}

Orientação a Objetos ([PAG 95], [SIL 90], [TAK 90]) é um paradigma de linguagens e de programação que se popularizou na década de 80 . A primeira linguagem orientada a objetos foi a linguagem SIMULA [POO 87] apresentada inicialmente por Dahl [DAH 66]. Hoje em dia, as linguagens orientadas a objetos mais conhecidas são a C++ [STR 86] e Smalltalk [GOL 83]. Na Programação Orientada a Objetos (POO), os programas são compostos por várias classes, uma extensão dos tipos de dados da programação tradicional, para conter também procedimentos (chamados de métodos) além dos tipos propriamente ditos. Os dados dos programas são armazenados em objetos, que correspondem às variáveis da programação tradicional (não orientada a objetos). Os objetos ao invés de criados na declaração das classes, são criados durante a execução do programa, ao contrário das variáveis das linguagens tradicionais onde seu espaço na memória é reservado antes da execução do programa. Os objetos executam ações e se comunicam entre si através de mensagens, uma extensão da "chamada" de procedimentos. Um objeto é basicamente composto por variáueis de instância e por métodos. As variáveis de instância armazenam as informações (dados, valores) dos objetos, definindo sua estrutura, enquanto que os métodos definem o comportamento do objeto. Como principais objetivos da programação orientada a objetos podemos destacar as seguintes:

- Modularização: divisão dos programas em módulos independentes, o que facilita o desenvolvimento, depuração e a manutenção do software, especialmente quando os programas são muito grandes e o trabalho é dividido por equipes. A modularização pode ser praticada nas linguagens de programação não orientadas a objetos, porém a modularização em $\mathrm{OO}$ é mais geral e potente que nessas linguagens.

- Projeto de módulos independente da aplicação: os módulos não devem possuir características particulares da aplicação para a qual está sendo desenvolvida, para facilitar a reutilização destes módulos em futuros programas, além de facilitar os testes de um módulo.

- Generalidade e flexibilidade: projeto de módulos independente do tipo de dados a serem armazenadas em suas estruturas de dados. Por exemplo, em uma linguagem 
de programação tradicional, para se implementar uma árvore de busca, ou uma pilha, ou mesmo para se implementar um simples algoritmo de ordenação são necessárias várias versões, uma para cada tipo de dado armazenado (inteiro, real, "string", registro). Com o uso de classes genéricas (a serem descritas adiante), pode-se implementar apenas uma versão, definida como uma classe genérica (por exemplo, a classe dos nós de uma árvore), que funcionará com qualquer tipo de dados que a classe assuma.

- Reutilização: Conseqüência dos objetivos anteriores, visa aproveitar ao máximo o trabalho de desenvolvimento já realizado para produzir novos programas.

Esses objetivos poderiam ser alcançados com o uso de linguagens de programação tradicionais, a menos da flexibilidade, que decorre de características próprias da orientação a objetos. Entretanto, a estrutura das linguagens orientadas a objeto força práticas de programação que ajudam o alcance destes objetivos.

\subsubsection{Conceitos principais da Orientação a Objetos}

Os principais conceitos da programação orientada a objetos são as seguintes:

- Herança

- Polimorfismo

- Encapsulamento

- Mensagens

Vamos explicar cada conceito separadamente:

\subsubsection{Herança}

Dispositivo no qual uma classe B é definida a partir de uma outra classe A, com todas as suas variáveis de instância e métodos, além de outras variáveis e métodos que diferenciam a classe B da classe A. Dizemos nesse caso que a classe B é uma subclasse da classe A, e que a classe B berda as variáveis e os métodos da classe A. A herança pode ser ínica, onde a classe herda características de apenas uma classe, ou múltipla, onde uma classe pode herdar características de duas ou mais classes. Portanto, as diversas classes formam várias bierarquias 
de classes. A linguagem Smalltalk oferece herança única, enquanto a linguagem $\mathrm{C}++$ possui herança múltipla.

Um exemplo de herança múltipla é o de uma hierarquia de veículos de transporte. Um veículo pode ser terrestre, aéreo ou naval. Por sua vez, também pode ser de transporte de cargas ou de passageiros (Figura 25).

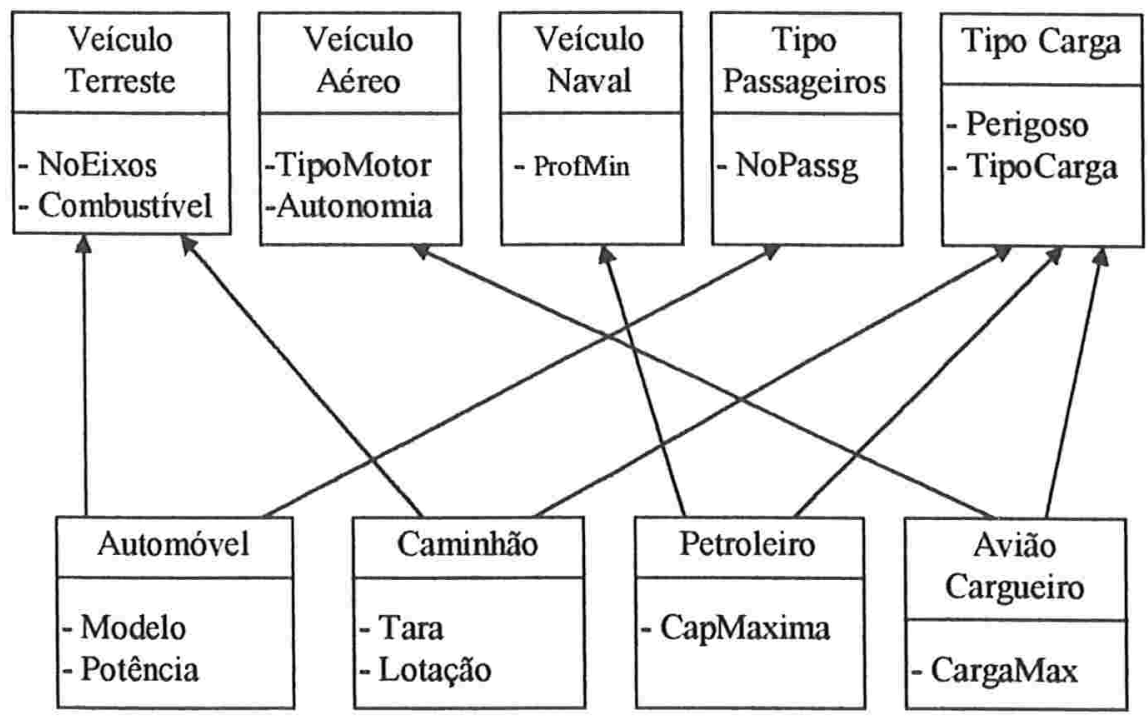

Figura 25: Herança múltipla

$\mathrm{Na}$ figura acima, uma classe está representada por um retângulo, sendo que o nome da classe se encontra na parte superior, enquanto que na parte inferior são colocadas as variáveis de instância (poderíamos ter ainda colocado em separado os métodos). A seta indica que a classe de onde a seta está "saindo" é uma subclasse da classe onde a seta "chega." No exemplo, um petroleiro é um veículo naval e também um veículo de carga, o automóvel é um veículo terrestre e também de passageiros, e assim por diante.

\subsubsection{Polimorfismo e Sobrecarga de operadores}

$\mathrm{Na}$ literatura encontramos duas definições para o polimorfismo. Apresentaremos as duas definições e mostraremos um exemplo que engloba ambas.

Polimorfismo é um dispositivo que permite que um nome de um mesmo método possa ser definido em várias classes, tendo implementações diferentes em cada classe. 
Na outra definição, polimorfismo é a propriedade pela qual uma variável pode conter um apontador para diferentes classes, em diferentes instantes, ou seja, assume várias formas distintas.

As definições ficarão mais claras através de um exemplo: Vamos considerar a classe Figura2d, que representa qualquer figura bidimensional. Alguns exemplos podem ser vistos na Figura 26:
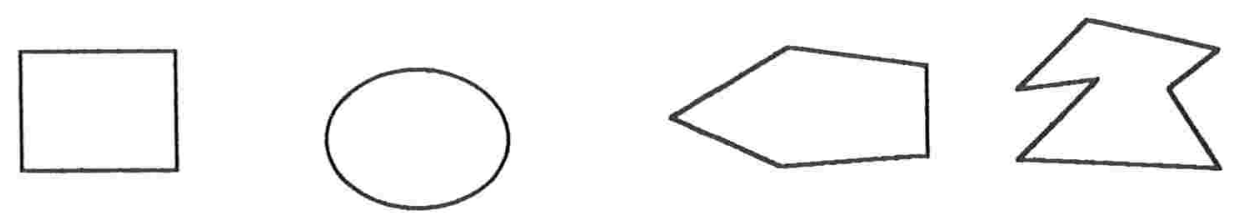

Figura 26: Figuras planas

Na classe Figura2d podemos definir um método, chamado Área, que retorna a área da figura. Este método, por ser muito genérico, deve cuidar de muitos casos de cálculo, eventualmente complicados e ineficientes. Podemos então criar novas classes, por exemplo Triângulo, Retângulo e Círculo que terão cálculos de área com fórmulas mais simples e conhecidas. Todos podem ser subclasses de Figura2d, por serem figuras bidimensionais. Em cada classe, porém, pode-se redefinir o método Área para termos um cálculo mais eficiente, conhecendo as particularidades de cada classe. Por exemplo, na classe Círculo, o método precisa calcular apenas a fórmula $\pi \mathrm{r}^{2}$, sendo muito mais simples e rápido que o método totalmente genérico. Este é um exemplo da primeira forma de polimorfismo. $\mathrm{Na}$ literatura diz-se que o método Área que havia sido definido para a classe mais geral foi redefinido na subclasse (“overriding").

Para exemplificar a segunda definição de polimorfismo, vamos supor, numa linguagem de programação fictícia, que temos uma variável, da classe Figura2d:

var f: Figura2d;

Esta variável pode apontar para qualquer objeto da classe Figura2d, além das subclasses desta classe. Ou seja, pode apontar para objetos das classes Triângulo, Retângulo, ou Círculo. Suponhamos que temos as seguintes variáveis no programa:

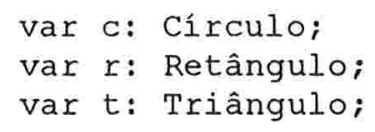


Neste caso, a variável f pode armazenar qualquer uma destas variáveis, ou seja, assume várias formas ( $2^{a}$ definição).

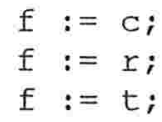

Se tentarmos atribuir um valor de uma classe que não é subclasse da classe Figura2d o programa deve acusar um erro:

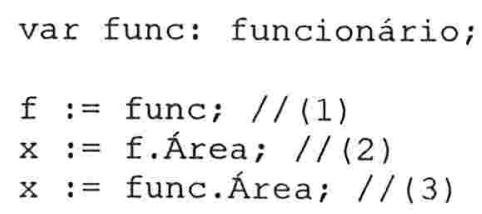

$\mathrm{Na}$ linha (1), será detectado um erro de execução do programa. $\mathrm{Na}$ linha (2), o programa deve chamar o método área que for o da classe a qual este pertence no momento, e não o da classe mais geral. Na linha (3), o método Área não está contido na classe funcionário, de modo que se deve gerar uma mensagem de erro. Nesses exemplos nota-se outra característica importante dos programas orientados a objetos: o compilador não possui em tempo de compilação informação sobre qual método ele deve chamar na linha (2); isso só pode ser conhecido em tempo de execução. Nesse caso dizemos que o compilador realiza o acoplamento tardio entre mensagens e métodos ("Late Binding").

Outro conceito associado ao polimorfismo é o da sobrecarga de operadores ("overloading"). Por exemplo, seja a soma abaixo:

$z=x+y ;$

O operador soma pode estar somando variáveis polimórficas, o que exige que haja várias versões para o mesmo operador de soma. Se os operandos fossem números inteiros, a operação de soma seria uma operação comum. Porém, devido ao polimorfismo, os operandos podem ser de vários tipos (classes). Por exemplo, $\mathrm{x}$ e y poderiam ser figuras geométricas, e um operador de soma especial pode ser definido, como por exemplo, a soma das áreas. Como o operador pode realizar operações distintas, que dependem do tipos dos operandos, dizemos que o operador está sobrecarregado. 


\subsubsection{Encapsulamento}

O encapsulamento é a proteção da estrutura interna do objeto por trás dos métodos, ou seja, o único modo de se obter informação sobre um objeto é através dos métodos. Essa característica é muito importante, pois possibilita uma maior independência de dados, uma vez que a implementação da estruturas de dados dos objetos não precisam ser conhecidas por quem utiliza os objetos.

$\mathrm{Na}$ definição estrita do encapsulamento, utilizada por exemplo na linguagem Smalltalk notamos as seguintes restrições:

1. Apenas métodos podem estar na parte pública do objeto, ou seja, visível ao exterior.

2. Os métodos são definidos em linguagem procedural.

3. Um método pode manipular somente dados dentro do objeto em que está definido.

$\mathrm{Na}$ linguagem $\mathrm{C}++$, a restrição (1) é relaxada, uma vez que podemos ter variáveis na parte visível do objeto.

Cada declaração de método em uma classe é chamada assinatura. $\mathrm{O}$ conjunto de todas as assinaturas é denominada interface do objeto.

Um exemplo clássico de encapsulamento é o de um objeto que implementa uma pilha. Um programador que esteja utilizando o objeto pilha precisa conhecer apenas a interface do objeto, que contém os métodos Empilha, Desempilha, Consulta_topo, etc.. Para ele, pouco ou nada importa a forma que a pilha está implementada e armazenada. Ela pode estar armazenada como um vetor, lista ligada, ou da forma que o implementador da pilha julgar conveniente. Isso fornece uma grande independência de dados, uma vez que se pode mudar a estrutura interna da pilha, sem afetar os programas que estejam a utilizando.

\subsubsection{Mensagens}

Os diversos objetos de um programa comunicam-se através de mensagens. Quando um objeto deseja uma informação sobre um outro objeto, ou quer modificar o estado de outro objeto, ele envia uma mensagem ao objeto desejado que, por sua vez, executa um método apropriado de acordo com a mensagem recebida. Vamos mostrar um exemplo de mensagem em $\mathrm{C}++$ : 


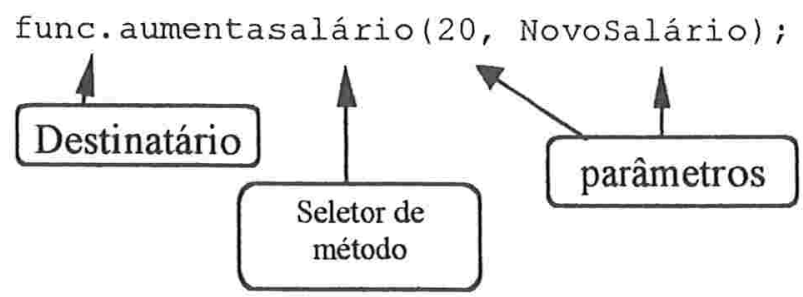

O destinatário é o objeto que vai receber a mensagem. Em geral, é uma variável que contém uma referência ao objeto que vai receber a mensagem. O seletor é assim chamado pois seleciona o método a ser executado pelo destinatário. Os argumentos fornecem informações adicionais ou armazenam valores de retomo. Nessa mensagem, é solicitado ao objeto func que suba seu salário em $20 \%$, retomando o valor do novo salário no objeto (variável) NovoSalário.

Em uma linguagem de programação não orientada a objetos, como Pascal ou C, é necessário fomecer nos parâmetros de chamada qual o funcionário deve ter o salário aumentado.

aumentasalário(Funcionário, 20, NovoSalário);

Nas linguagens orientadas a objetos, os procedimentos são acoplados aos dados, portanto quando é necessário aumentar o salário do funcionário, é enviada uma mensagem ao objeto Funcionário, como mostrado acima, que atua sobre seus dados. Nas linguagens tradicionais, o procedimento modifica a variável que contém os dados sobre o funcionário. Portanto, na Orientação a Objetos, os objetos agregam os dados e os métodos e agem sobre seus próprios dados, enquanto que na programação tradicional os dados são passivos, ou seja, os procedimentos atuam sobre os dados.

\subsubsection{Componentes da Orientação a Objetos}

Todos estes conceitos são implementados pelas classes e pelos objetos, que são os principais componentes da orientação a objetos.

\subsubsection{Classes}

Uma classe é um modelo de onde os objetos são criados (instanciados). Os objetos de uma mesma classe possuem a mesma estrutura e comportamento. As classes são uma 
extensão dos tipos de dados nas linguagens de programação tradicionais, para que os procedimentos sejam acoplados aos dados.

Para se criar um objeto em geral envia-se uma mensagem à classe instruindo para que um objeto seja criado. Devido a esse fato pode-se considerar as classes como objetos, que têm como função "fabricar" os objetos. De outro ponto de vista, pode-se considerar as classes como um "molde" de onde os objetos são criados.

A declaração de uma classe é dividida em geral em duas partes: as variáveis de instância, e a sua interface, que são os métodos disponíveis para a classe.

Os objetos quando criados pertencem a uma única classe. Isso pode ser questionado, se considerarmos duas situações na vida real:

- Um objeto poderia ter várias facetas (ex.: a pessoa de nome José é Estudante, Funcionário e Pai), o que significa que José deveria pertencer a três classes simultaneamente.

- Lm objeto pode evoluir com o decorrer do tempo, adquirindo e perdendo facetas (ex.: José forma-se e deixa de ser Estudante, passando a ser Desempregado, um dia toma-se Pai), o que significa que o objeto deveria poder assumir ou perder características de diversas classes durante a sua existência.

Algumas linguagens possuem essas características, porém não fazem parte do modelo básico, e nas linguagens mais comuns elas não são implementadas. Isso é coerente com o fato que as variáveis de um programa não podem mudar de tipo durante a sua existência.

\subsubsection{Classes genéricas}

Um tipo especial de classe que permite a generalidade são as classes genéricas. Um bom exemplo do uso de classes genéricas é o da implementação de estruturas de dados, digamos, uma árvore de busca binária. Em uma linguagem de programação sem a possibilidade do uso de classes genéricas, será necessário criar uma versão do programa ou função para cada tipo dos dados a serem armazenados na árvore. Isto cria dificuldades, pois na nova versão podem ocorrer erros de tradução, além do que se forem encontrados erros ("bugs") em uma versão, provavelmente todas as versões terão que ser corrigidas. Com a utilização das classes genéricas, será necessária apenas uma versão da árvore, sendo o tipo, ou melhor, a 
classe a ser armazenada definida somente durante a execução do programa, passada como parâmetro para a classe quando o objeto é criado. Por esse motivo, as classes genéricas são conhecidas também como classes paramétricas.

\subsubsection{Objetos}

Os objetos, como já citado, são instâncias das classes. Pode-se fazer um paralelo entre os objetos e as variáveis, assim como podemos fazer entre as classes e os tipos de dados. Uma das diferenças é que os objetos são criados durante a execução do programa, e podem deixar de existir, podem ser destruídos. Uma variável global não deixa de existir depois de ser declarada em uma linguagem comum.

Um objeto é composto por:

- estado interno, que é composto por variáveis que podem armazenar dados; pode ser modificado ao longo da vida do objeto

- comportamento, que é um conjunto de ações pré-definidas (métodos), com as quais os objetos respondem às mensagens enviadas por outros objetos.

Dois tipos de métodos especiais são definidos na POO: os métodos construtores ("constructors") e os destruidores ("destructors") ${ }^{2}$. O método construtor é chamado no momento em que o objeto é criado, permitindo que o seu estado interno seja iniciado com valores adequados. O método destruidor é chamado no momento em que o objeto deixa de existir, permitindo liberar alguma porção de memória que esteja sendo reservada pelo objeto que vai deixar de existir, ou executar outra ação que seja necessária antes que o objeto seja apagado da memória.

\subsubsection{Identificador de Objeto (OID)}

Quando se cria um objeto, ele recebe um identificador que o diferencia de todos os demais objetos durante a sua existência. Em geral, o endereço de memória do objeto é utilizado como OID, apesar de isso ser indesejável, uma vez que a posição de memória do objeto pode ser alterada, por exemplo em uma paginação de memória, ou mesmo pelo próprio código do programa.

\footnotetext{
2 Encontra-se em algumas traduções a palavra "destrutor". A parentemente, essa palavra não existe na língua Portuguesa.
} 
O OID introduz novos conceitos de comparação e de cópia de objetos. Considerando duas variáveis que armazenam OIDs de objetos, podemos classificar a igualdade de duas formas, como discutido por Khoshafian [KHO 86]:

- Se dois objetos são iguais, ou seja, se todas as variáveis de instância dos objetos possuem o mesmo valor, mas as variáveis que armazenam os OIDs contêm valores distintos.

- Se dois objetos são, na realidade, o mesmo objeto, ou seja, se duas variáveis armazenam o mesmo OID.

Se o modelo de dados não possuir OIDs, como por exemplo o MR, no primeiro caso se os valores armazenados em duas linhas forem iguais, trata-se obrigatoriamente da mesma linha o que é chamado de semântica por valor. Se o sistema possuir OIDs, dizemos que possui semântica por identificador.

Para ilustrar as operações de cópia vamos considerar o comando:

$\mathrm{b} \leftarrow \mathrm{c}$

Vamos supor ainda que $b$ tem como variável de instância um outro objeto qualquer $d$. Esse comando pode ter até três operações distintas:

- Compartilhamento: b passa a apontar para o objeto apontado por c, ou seja, b recebe o OID que c armazena.

- Cópia rasa ("shallow copy"): b passa a apontar para um novo objeto, com identidade própria, porém os objetos que compõem b são compartilhados com c.

- Cópia profunda (“deep copy"): b passa a apontar para um novo objeto; todos os objetos que compõem c são copiados em b.

Sem os OIDs, não há possibilidade de compartilhamento, somente cópia.

A Figura 27 ilustra o exemplo. 


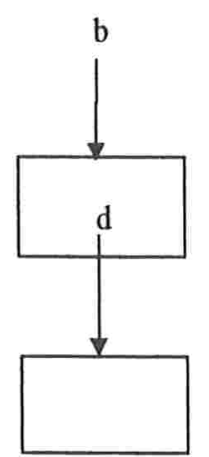

O objeto b

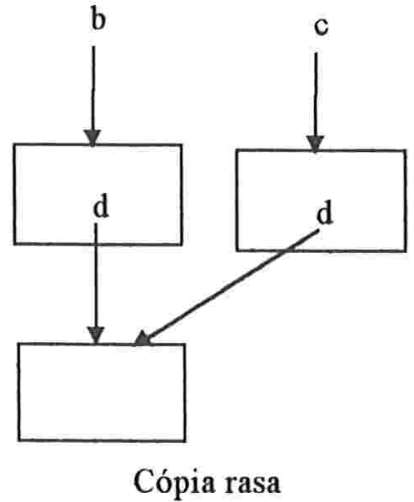

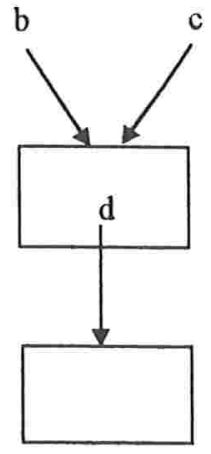

Compartilhamento

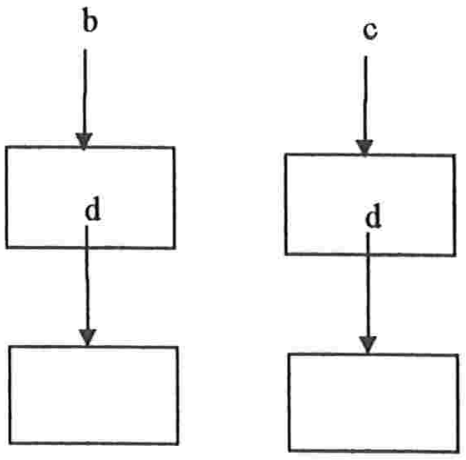

Cópia profunda

Figura 27: Tipos de cópia de objetos 


\section{Bancos de Dados Orientados a Objetos}

Um Banco de Dados Orientado a Objeto é basicamente um sistema em que a unidade de armazenamento é o objeto, com o mesmo conceito das linguagens de programação orientadas a objetos. A diferença fundamental é a persistência dos objetos, ou seja, os objetos continuam a existir mesmo após o encerramento do programa. Segundo Cattell [CAT 91] podemos classificar sistemas que oferecem persistência a objetos em quatro categorias, de acordo com sua arquitetura:

- Sistemas de Bancos de Dados Estendidos. Nessa arquitetura enquadram-se os sistemas baseados em algum SGBD com extensões para acrescer algumas características da Orientação a Objetos, tais como OIDs, métodos, classes, etc. O Postgres, UniSQL e o Starbust ([HAA 90], [LOH 91]) são exemplos de extensões do MR. O modelo de dados do Iris é uma extensão do modelo funcional de linguagem de programação. Por sua vez, o CACTIS possui um modelo de dados parcialmente baseado no MER.

- Linguagens de Programação de Bancos de Dados. A segunda arquitetura é representada por sistemas que estendem linguagens de programação como $\mathrm{C}++$ ou Smalltalk com persistência de objetos, controle de transações, concorrência e outras características próprias de SGBD. O sistema pode também possuir uma linguagem própria de declaração e manipulação de dados. A maioria dos sistemas conhecidos possui esta arquitetura, como por exemplo o $\mathrm{O}_{2}$, ObjectStore, ONTOS, Vbase, GemStone, Orion, Poet, Versant, JASMINE, entre outros.

- Gerenciadores de Objetos. Neste caso temos pacotes que fornecem extensões a sistemas de arquivos ou de memória virtual para fomecer persistência dos objetos. Esses sistemas não possuem todas as características das linguagens de programação de banco de dados, e são úteis quando se precisa da persistência dos objetos, sem a necessidade de recursos mais complexos. Como exemplo desta arquitetura citamos o POMS e o ObServer.

- Geradores de Sistemas de Bancos de Dados. Estes sistemas permitem que o modelo de dados seja definido pelo usuário, para uma aplicação particular. Como 
exemplos desses sistemas, destacamos o GENESIS [BAT 86] e o EXODUS [CAR 89].

Neste trabalho vamos tratar apenas das duas primeiras arquiteturas, que na maioria dos casos são consideradas como sendo BDOOs, pois os Geradores de Sistemas de Bancos de Dados a princípio podem gerar qualquer tipo de banco de dados, e os Gerenciadores de Objetos apenas cuidam do armazenamento dos objetos, e não dos outros aspectos dos Bancos de Dados, como a linguagem de programação, de consulta, controle de concorrência, transações, etc.

Em 1989 Atkinson apresentou o que é considerado a primeira definição dos BDOO [ATK 89]. Nesse artigo algumas características são consideradas obrigatórias:

1. Persistência

2. Objetos complexos

3. Identidade forte dos objetos

4. Encapsulamento

5. Tipos ou classes

6. Herança

7. Sobrecarga de operadores, redefinição de métodos e acoplamento tardio

8. "Completude" computacional

9. Extensibilidade

10. Gerenciamento do armazenamento secundário

11. Controle de concorrência

12. Recuperação de falhas

13. Consultas ad boc

Nas linguagens de programação orientada a objetos, já temos a presença dos itens 2 , 4, 5, 6, 7 e 8. As características 1, 10, 11, 12 e 13 são típicas de sistemas de bancos de dados. Vamos analisar algumas características principais, que diferenciam os BDOO das linguagens de programação.

\subsubsection{Persistência dos Objetos}

Sem dúvida, a característica que diferencia os BDOO em relação às linguagens de programação orientadas a objetos é a persistência dos objetos. Nas linguagens de programação, os objetos existem apenas durante a execução do programa. Nos BDOO, os 
objetos podem continuar existindo mesmo após o encerramento do programa, tendo seu estado armazenado em um meio físico persistente (normalmente, o disco rígido). A forma pela qual o objeto se toma persistente depende de cada sistema. No $\mathrm{O}_{2}$, o comando name toma um objeto persistente. Em outros sistemas, como no Poet, todos os objetos de uma classe são persistentes, se esta for declarada como uma classe persistente. No ObjectStore objetos de qualquer classe podem tomar-se persistentes, o que é definido no momento da construção do objeto. Especificamente, podemos considerar as seguintes formas de tomar um objeto persistente:

1. Por tipo (classe): Como no caso do Poet, os objetos pertencentes às classes assim declaradas serão persistentes.

2. Por chamada explícita: No $\mathrm{O}_{2}$ o objeto pode tomar-se persistente após sua criação, através do comando name. No ObjectStore, na criação do objeto um comando especial o toma persistente.

3. Por referência: Alguns sistemas adotam este sistema, em que objetos referenciados por objetos persistentes (objetos raizes) também tomam-se persistentes, como no caso do $\mathrm{O}_{2}$.

Normalmente são preferidas as alternativas dos itens 2 e 3 , pois permitem a ortogonalidade entre os tipos e a persistência do objeto, ou seja, é desejável que qualquer tipo de objeto possa ou não ser persistente, dependendo da necessidade da aplicação.

\subsubsection{Objetos complexos}

Para a representação direta de objetos complexos, com muitas partes e várias associações, como listas de composição de peças, e outras características complexas, que não possuem representação direta no MR (exigindo uma relação auxiliar), é proposta a utilização do modelo de dados das linguagens orientadas a objetos. Notamos que a $1 F N$ não é respeitada nos $\mathrm{BDOO}$, pois podemos representar em um objeto valores não atômicos, come conjuntos, listas, vetores ou mesmo outros objetos. Como ocorre tradicionalmente em linguagens orientadas a objetos, a representação é facilitada justamente por este fato (não normalização). No MRNN os objetos complexos teriam representação mais ortogonal, pois tudo é relação. Lamentavelmente, não houve nenhuma extensão de um MRNN para conter algumas características da orientação a objetos. Procuraremos sanar essa lacuna na proposta do capítulo 8 . 


\subsubsection{Identificador de Objeto (OID)}

Nos $\mathrm{BDOO}$, os objetos possuem uma identidade mais forte que nas linguagens de progtamação, pois continuam existindo mesmo após a execução do programa e podem voltar a serem utilizados, na próxima execução, ou mesmo ser utilizados por outro programa simultancamente. O identificador de objeto deve ser único e imutável, durante toda a existência do objeto. Nas linguagens de programação, os objetos podem existir somente durante a execução atual do programa. O sistema deve fornecer de alguma forma os OIDs únicos quando os objetos são criados.

Como os OIDs são identificadores únicos, válidos para todo o banco de dados, eles são utilizados nos BDOO também para estabelecer relacionamentos entre objetos, além de servirem como uma forma de se recuperar os objetos do banco de dados. O usuário não deve ter acesso ao valor do OID, nem mudar o seu valor. Nesse sentido, aproximam-se do conceito do "surrogate" do RM/T.

\subsubsection{Encapsulamento}

O conceito de encapsulamento continua sendo utilizado, porém, quando se faz uma consulta ao banco de dados, não é possível prever todas as consultas e atualizações que o usuário possa desejar. Assim, não se pode agregar todos os métodos nas classes de antemão. No próprio artigo original de Atkinson [ATK 89], é admitido que o conceito de encapsulamento não é adequado aos $\mathrm{BDOO}$ em algumas situações. $\mathrm{O}$ encapsulamento é uma das características principais da orientação a objetos, e a sua não utilização nos BDOO pode descaracterizar parcialmente a orientação a objetos.

Na maioria dos BDOO, como no caso da linguagem $\mathrm{C}++$, a restrição (1) citada no item Encapsulamento (Item 3.1.1.3) é relaxada, especialmente nos sistemas em que há uma linguagem de consulta. Em geral nesses sistemas é permitido que o usuário tenha acesso direto às variáveis de instância do objeto, pois elas eventualmente contêm os atributos das relações. 


\subsubsection{Acesso aos Dados: Linguagens de programação e de consulta}

O acesso aos dados armazenados é feito basicamente de duas formas: por uma linguagem de programação, através dos OIDs dos objetos, ou através de uma linguagem de consulta, em geral derivada da SQL.

O acesso aos dados através de linguagem de programação vem tentar resolver uma das principais críticas aos SGBD relacionais, o chamado não-casamento de impedâncias ("impedance mismatch"). Quando é utilizada uma linguagem de programação qualquer para se desenvolver uma aplicação que utilize dados armazenados em um banco de dados baseadc no MR, é necessário compatibilizar os dados obtidos nos acessos efetuados na linguagem de consulta para as estruturas de dados da linguagem, já que a única estrutura do MR é a relação. Por exemplo, para se gravar no banco de dados uma estrutura tipo "record" do Pascal, com vários níveis, será necessário subdividir todos os seus campos para os atributos de nome correspondentes em uma linha da relação, e o contrário ocorre quando este faz a leitura a partir do banco de dados. Ou seja, é necessário desestruturar os dados para que possam ser representada em uma única linha, e reestruturá-los, quando a linha é lida no banco de dados, Se a estrutura contiver conjuntos, vetores ou outro tipo de atributo multivalorado, será necessário até mesmo gravar os dados de uma única estrutura em várias relações separadas. Quando se usa uma linguagem e um banco de dados que possuem dados com a mesma estrutura, este trabalho é poupado, implicando em diminuição de código e de tempo de execução, além de possibilitar o compartilhamento de estruturas entre aplicações.

As linguagens de consulta atendem à característica 13, permitindo consultas ad boc. porém, como destacado como no item anterior, em geral violam o encapsulamento da orientação a objetos.

\subsection{6 "Completude" computacional}

A "completude" computacional pode ser atingida com as linguagens de programação persistentes. Uma das críticas ao modelo relacional, além da dificuldade de representação e modelagem dos dados, é a de que as linguagens de consulta não são computacionalmente completas, ou seja, nem todas as consultas podem ser formuladas. De fato, SQL, QUEL e QBE não são linguagens de programação, e sim de acesso aos arquivos do Banco de Dados. 
Por exemplo, no esquema da Figura 11 (auto-relacionamento) não é possível formular uma consulta que liste todas as peças que compõem uma dada peça em todos os níveis de composição, através do SQL padrão. Esse problema foi elegantemente resolvido na linguagem QBE. Porém, em alguns sistemas como por exemplo no SYBASE (13) ${ }^{3}$, ORACLE (14) ou SQL Server, o SQL possui extensões que incluem controle de fluxo ("while"), condicionais ("if..then..else"), desvio ("goto") além dos cursores já existente na proposta original do SQL ("SEQULL"), que permitem o processamento linha a linha da relação, o que diminui consideravelmente este problema, introduzindo, no entanto, uma desvantagem enorme: o tratamento passa a ser procedural e não declarativo (isto é, um comando é a definição de um conjunto como em SQL).

\subsubsection{Versões de objetos}

Uma característica presente $\mathrm{em}$ alguns sistemas é o controle de versões de objetos. Nos sistemas de CAD ou CASE, pode ser necessário o armazenamento de versões anteriores dos objetos, para que se possa retomar a um estado anterior do banco de dados, para o caso do novo objeto possuir algum erro, por exemplo.

Outra situação pode ocorrer quando houver modificação nos métodos ou na estrutura dos objetos, quando é desejável manter uma versão já estável e testada do objeto enquanto a nova versão do objeto ainda é testada.

No sistema Postgres, o sistema mantém dados históricos, de forma que se pode consultar o estado do banco de dados no pàssado. Por exemplo, pode-se consultar o salário que um funcionário possuía em uma data determinada. Este é um dos únicos sistemas que tem essa característica.

\subsubsection{Controle de transações}

Nos BDOO, o controle de transações difere das aplicações tradicionais. Podem ser necessárias transações de longa duração, como por excmplo em sistemas de CAD, onde um projetista pode trabalhar no desenho de uma determinada peça durante um longo tempo, podendo chegar a alguns dias ou até alguns meses.

\footnotetext{
${ }^{3}$ A partir deste ponto o número entre parênteses representa uma referência da Intemet, apresentado no Apêndice 2.
} 
A recuperação de falhas também possui características particulares, como no caso do projetista citado anteriormente. No caso da falha do sistema, pode ser desejável que o sistema recupere o estado mais avançado possivel, para evitar uma grande perda de trabalho. Isto contraria a atomicidade das transações em geral presente nos SGBD relacionais, o que neste caso poderia fazer com que todo o trabalho do projetista se perdesse, ao recuperar o estado antes da transação ser iniciada ("rollback"). É necessária a introdução do conceito de transação lógica, isto é, o usuário define a seqüência de transações que deve ser considerada como atômica para o efeito de recuperação em caso de falhas (nesse caso, o estado volta ao que era no início da transação lógica). Tradicionalmente, um par de comandos "start transaction" e "end transaction" (ou "commit") é usado para resolver esse problema.

\subsubsection{Extensibilidade}

Todos os Bancos de Dados possuem tipos básicos de dados: inteiros, reais, strings, caractere, que são predefinidos. Nos BDOO, os novos tipos de dados criados pelo usuário não podem ter diferença de tratamento em relação aos tipos predefinidos, pelo menos na visão do usuário, o que geralmente não ocorre no MR. Nele, os tipos de dados que podem ser armazenados nas células são em geral pré-definidos e não se pode criar novos tipos para serem armazenados nas relações.

\subsubsection{BDOO distribuídos}

Todos os conceitos dos BDOO são ortogonais à distribuição, portanto os sistemas de BDOO podem ser distribuídos. Um exemplo de sistema que implementa um BDOO distribuído é o ORION-2 cujas características de implementação são apresentados por Kim [KIM 91].

\subsubsection{Relacionamentos}

Normalmente, os $\mathrm{BDOO}$, a exemplo do $\mathrm{MR}$, não possuem um elemento específico no sistema para a representação dos relacionamentos entre os objetos. Isso é feito através de variáveis de instância que armazenam o OID do objeto relacionado. Por exemplo, em um objeto Automóvel, deve ser inserido entre suas variáveis de instância a variável Proprietário, 
que contém o OID do dono do automóvel. Isto pode causar confusão em alguns sistemas, já que outras variáveis de instância que guardam informações sobre peças ou características do automóvel serão todas misturadas com os objetos relacionados com o automóvel. Além disso, a inserção de um atributo Proprietário dentro de Automóvel dá a impressão de que o primeiro pertence ao segundo; em outras palavras, não se está especificando claramente que se trata de um relacionamento, como faremos em nossa proposta no capitulo 8. Finalmente, os atributos do relacionamento precisam ser duplicados quando os relacionamentos são "N para N" (no exemplo, a classe Proprietário conterá uma variável Automóvel, e a Data de Aquisição deverá estar em ambos, por isometria).

Alguns sistemas implementados mantêm a integridade referencial, isto é, por exemplo, se um objeto Automóvel for excluído do banco de dados, no objeto que contém uma referência a esse objeto, por exemplo, o Proprietário, essa referência será automaticamente seu valor mudado para vazio ("null”).

Uma cstrutura especial para representação de relacionamentos como existe no MER ajuda na organização do sistema, auxiliando na manutenção e tomando o esquema mais claro. Isso será obrigatório em nossa proposta (Capítulo 8).

\subsubsection{Conclusão}

Para um sistema de banco de dados seja considerado orientado a objetos são consideradas as seguintes características: presença de OIDs, mecanismo de herança (única ou múltipla), métodos, objetos complexos e persistência de objetos. A seguir, vamos mostrar vários sistemas que implementam essas características. 


\section{Exemplos de BDOO}

Nos últimos anos foram produzidas muitas implementações de sistemas de BDOO, entre protótipos de empresas comerciais, universidades, e produtos comerciais. Como exemplos, podemos citar o $\mathrm{O}_{2}$, ObjectStore (3), Poet (2), Versant (5), Orion (12), Iris, Postgres, UniSQL (10), entre muitos outros.

A seguir vamos apresentar as principais características de alguns sistemas existentes, dando destaque às linguagens de definição e de manipulação de dados.

Para o exemplo de definição de dados, usaremos o diagrama de Entidades e Relacionamentos da Figura 24, que seria uma parte do diagrama de uma seção de alunos de uma faculdade. Para mostrar a manipulação de dados, vamos tentar obter um histórico escolar de um aluno e a listagem com as suas notas de uma certa disciplina, em um determinado semestre.

A sintaxe das linguagens de definição e manipulação de dados não pôde ser testada em todos os sistemas, portanto pode não estar $100 \%$ correta. Procuramos apenas mostrar os conceitos básicos do modelo de dados de cada sistema.

\section{$5.1 \mathrm{O}_{2}$}

O sistema $\mathrm{O}_{2}$ ([DEU 90], [DEU 91], [BAN 92], [SOL 92]) é um projeto iniciado na França em 1988. O projeto inicial previa um protótipo, que foi apresentado por Bancilhon et al. [BAN 88]. Até 1991 o projeto era experimental, e com o fim do convênio que o financiava, tomou-se um produto comercial. Foi criada uma empresa, a $\mathrm{O}_{2}$ technology, que passou a comercializar e desenvolver $\mathrm{O}_{2} . \mathrm{O}_{2}$ pode ser executado em estações Sun Sparc, HP9000, IBM RISC System 6000, Bull DPX/20, Silicon Graphics, SNI RM, Dec Alpha e INTEL. O sistema fornece um ambiente gráfico para criação de telas, o $\mathrm{O}_{2}$ Look, e um "browser" para percorrer os objetos no banco de dados. É fornecido também um ambiente integrado para a programação, com um compilador e depurador integrados. Para facilitar a migração a partir de SGBD relacionais, há ferramentas de conversão e migração $\left(\mathrm{O}_{2}\right.$ DBAccess). Nas versões mais recentes foi incorporado uma ferramenta de ligação do 
banco de dados à WWW (World Wide Web), que permite que objetos armazenados no banco de dados sejam exibidos em páginas H'TML $\left(\mathrm{O}_{2}\right.$ WEB $)$. O sistema permite integração com as linguagens $\mathrm{C}$ e $\mathrm{C}++$, e mais recentemente Java.

\subsubsection{Tipos de dados e declaração de métodos}

A declaração dos dados é feita através de uma linguagem que é uma extensão da linguagem $\mathrm{C}, \mathrm{O} \mathrm{O}_{2} \mathrm{C}$.

A linguagem possui herança múltipla. Os tipos primitivos do $\mathrm{O}_{2}$ são boolean, character, integer, real, string, e bit. São disponíveis também os construtores de tipos complexos de dados, que podem ser aplicados recursivamente: 'Tuple, List e Set. Não há difercnça na declaração de objetos persistentes e não persistentes, o que mantém a ortogonalidade dos tipos e a persistência.

Abaixo, mostramos o exemplo do departamento declarado com o $\mathrm{O}_{2} \mathrm{C}$ :

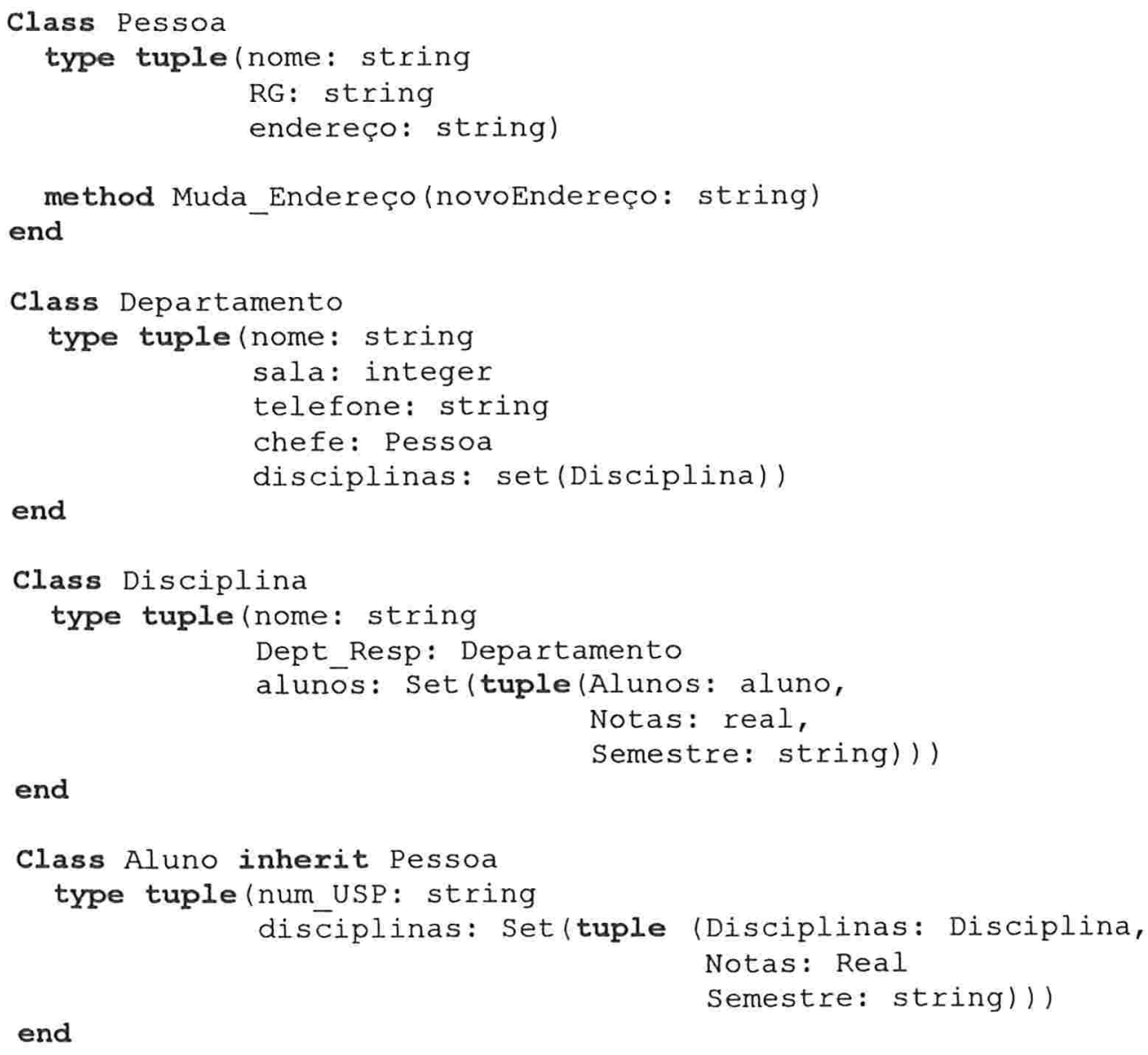


Note-se que, contrariamente ao MER e ao MR, usamos os nomes das classes no singular. De fato, a classe é uma extensão de um tipo, e não se refere a um conjunto como por exemplo um conjunto de entidades e uma relação.

$\mathrm{O}$ relacionamento $\mathrm{N}$ para $\mathrm{N}$ pode ser representado de duas formas: através de uma ligação dupla, com dois conjuntos de objetos interligados, como no exemplo acima, ou decompondo o relacionamento, como na implementação a seguir:

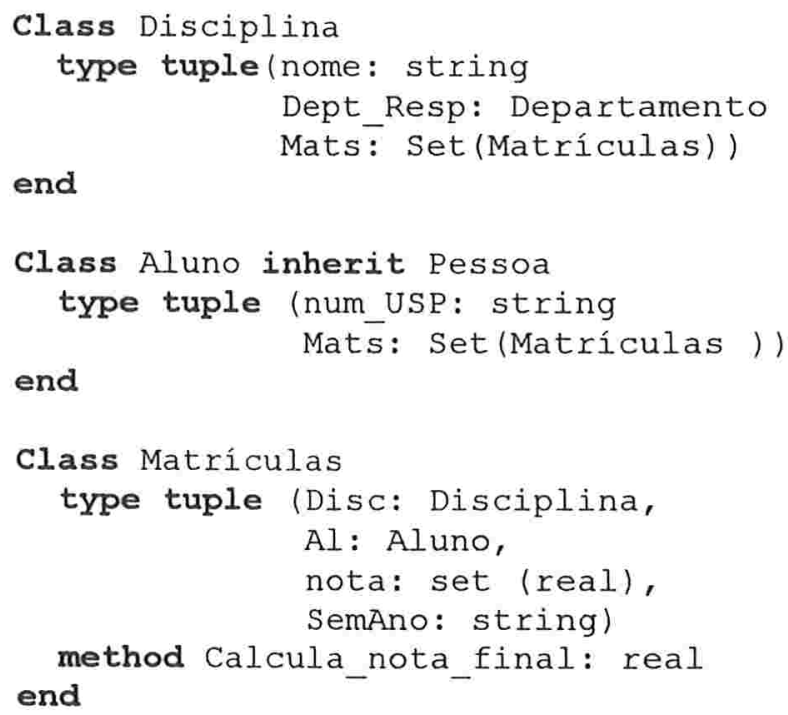

$\mathrm{O} \mathrm{O}_{2}$ garante a integridade referencial nos relacionamentos automaticamente. Quando um objeto referencia outro objeto que também o referencia, o sistema detecta este fato, mantendo a integridade das variáveis, ou seja, se um dos objetos for excluído do banco de dados, o sistema automaticamente toma as referências a este objeto nulas.

\subsubsection{Persistência e Manipulação de Dados:}

Para fazer um objeto tornar-se persistente, usa-se o comando add name, que faz com que o OID de um objeto seja associado a um nome de uma variável, para ser recuperado posteriormente. O comando delete name faz com que seja retirada essa associação entre OID do objeto e a variável. Outra forma de um objeto se tomar persistente é ser referenciado por outro um objeto que já é persistente, chamado raiz. ("persistent root").

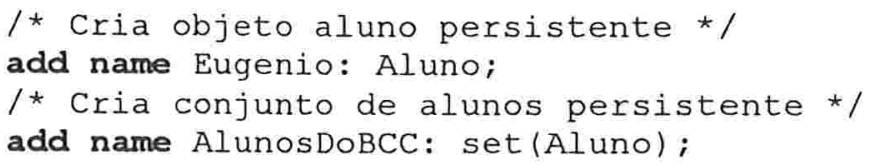




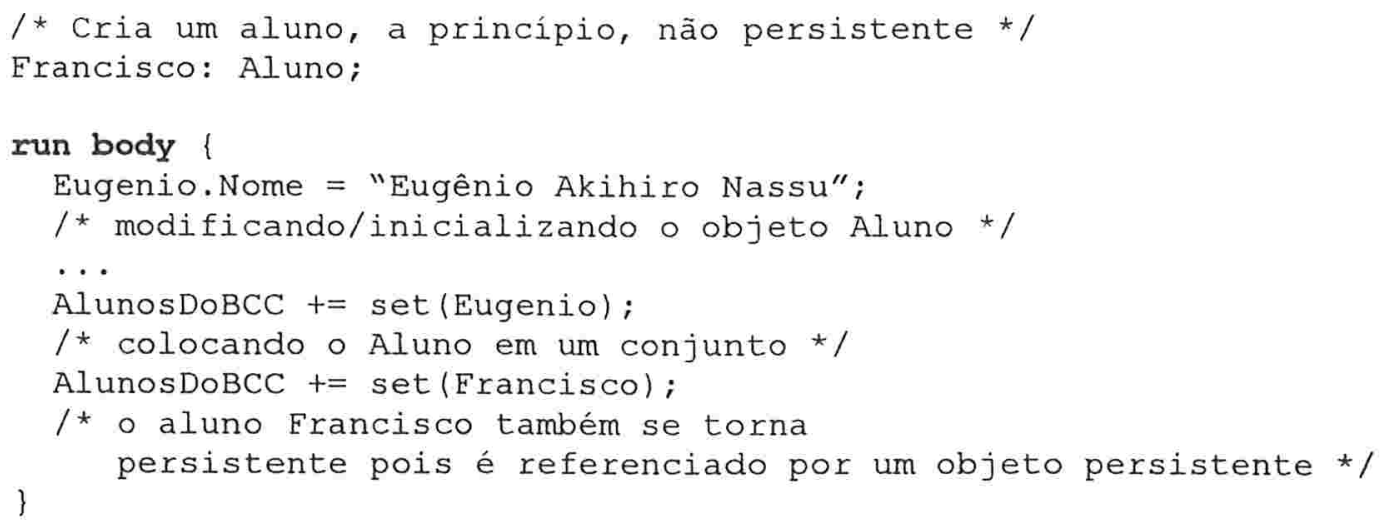

A Manipulação dos dados no $\mathrm{O}_{2}$ pode ser feita de duas maneiras: através da sua linguagem de programação, $\mathrm{O}_{2} \mathrm{C}$, ou pode-se fazer consultas com o OQL, que pode ser utilizada como um comando do $\mathrm{O}_{2} \mathrm{C}$ ou como uma linguagem de consulta interativa, do tipo SQL. A modificação e a exclusão dos dados é feita com a linguagem $\mathrm{O}_{2} \mathrm{C}$.

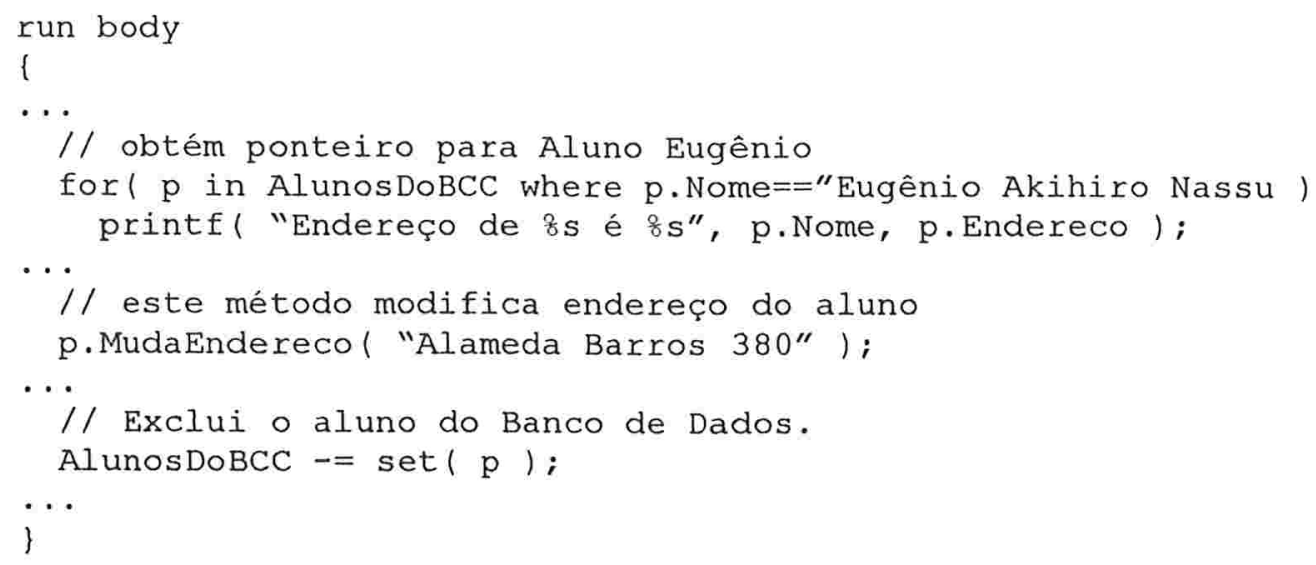

Para exemplificar o uso da linguagem de consulta no $\mathrm{O}_{2}$ vamos fazer as seguintes tarefas, utilizando os esquemas anteriores, com a linguagem OQL: Fazer uma lista de notas de uma disciplina, e o boletim de notas de um aluno em um semestre:

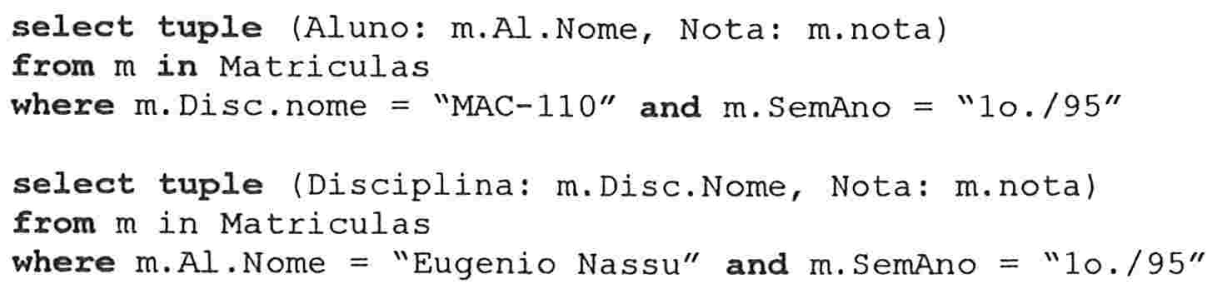

Notamos a semelhança das consultas com a linguagem SQL. Um dos pontos distintos é a forma com que os dados de outra classe são consultados, através de uma 
expressão com um caminho, por exemplo, m.disc.nome. ( "join", não precisa ser declarado explicitamente, pois os objetos relacionados são encontrados através dos OIDs.

Uma descrição de uma versão antiga da OQL foi feita por Bancilhon [BAN 89].

\subsection{OBJECTSTORE}

O ObjectStore [LAM 91] é um banco de dados produzido pela Object Design Inc. O principal objetivo deste sistema é tomar a linguagem $\mathrm{C}++$ uma linguagem para banco de dados. Uma das principais características do sistema é a uniformidade de tratamento de objetos comuns e persistentes, sem grande perda de desempenho, graças a um esquema de uso de memória virtual: os objetos persistentes fazem parte da memória virtual, portanto ficam gravadas no disco. Quando se faz um acesso ao objeto, é gerada uma falha de página de memória no sistema, que faz com que o objeto seja carregado na memória principal.

O sistema é disponível para estações SUN sob SunOS, IBM RS/6000 sob AIX, DEC DS3100 sob Ultrix, HP 300/400/700 sob P/UX, DEC sob VMS e MS-Windows.

\subsubsection{Declaração de dados e métodos}

O ObjectStore usa os tipos e a linguagem $\mathrm{C}++\operatorname{como}$ base. As declarações são quase idênticas ao $\mathrm{C}++$, o que permite que programas escritos em $\mathrm{C}++$ sejam convertidos para o uso do ObjectStore apenas com pequenas modificações. Há algumas classes pré-definidas que implementam conjuntos e listas, com métodos para inserção e remoção, entre outras.

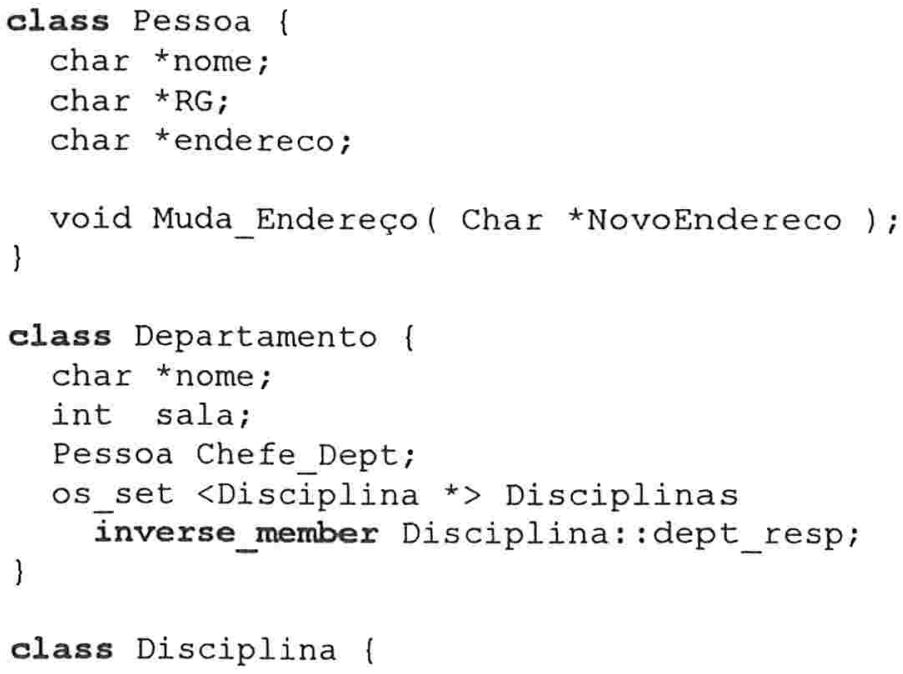




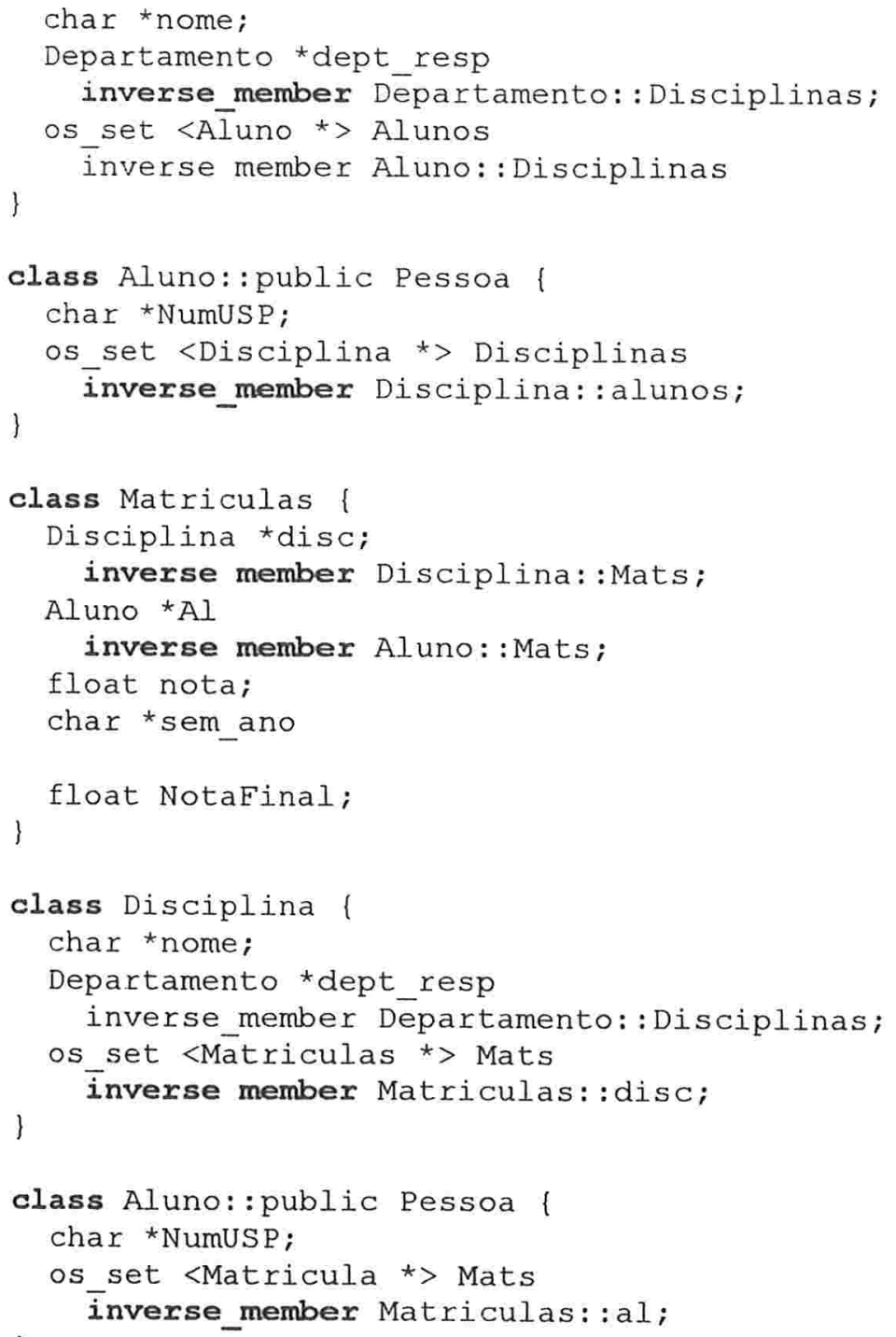

O comando inverse member faz com que seja mantida a integridade referencial, mantendo os ponteiros para objetos com valores válidos. O os_set é uma classe paramétrica, que implementa conjuntos de objetos.

\subsubsection{Persistência e manipulação de dados:}

Para guardar um objeto no banco de dados no ObjectStore, devemos declarar uma variável do tipo database, abrir o arquivo, incluir e excluir, usando para isso os métodos new e delete. Vamos mostrar um exemplo a seguir.

\#include <objectstore/objectstore.H>

\#include <records.H>

$\operatorname{main}()($ 


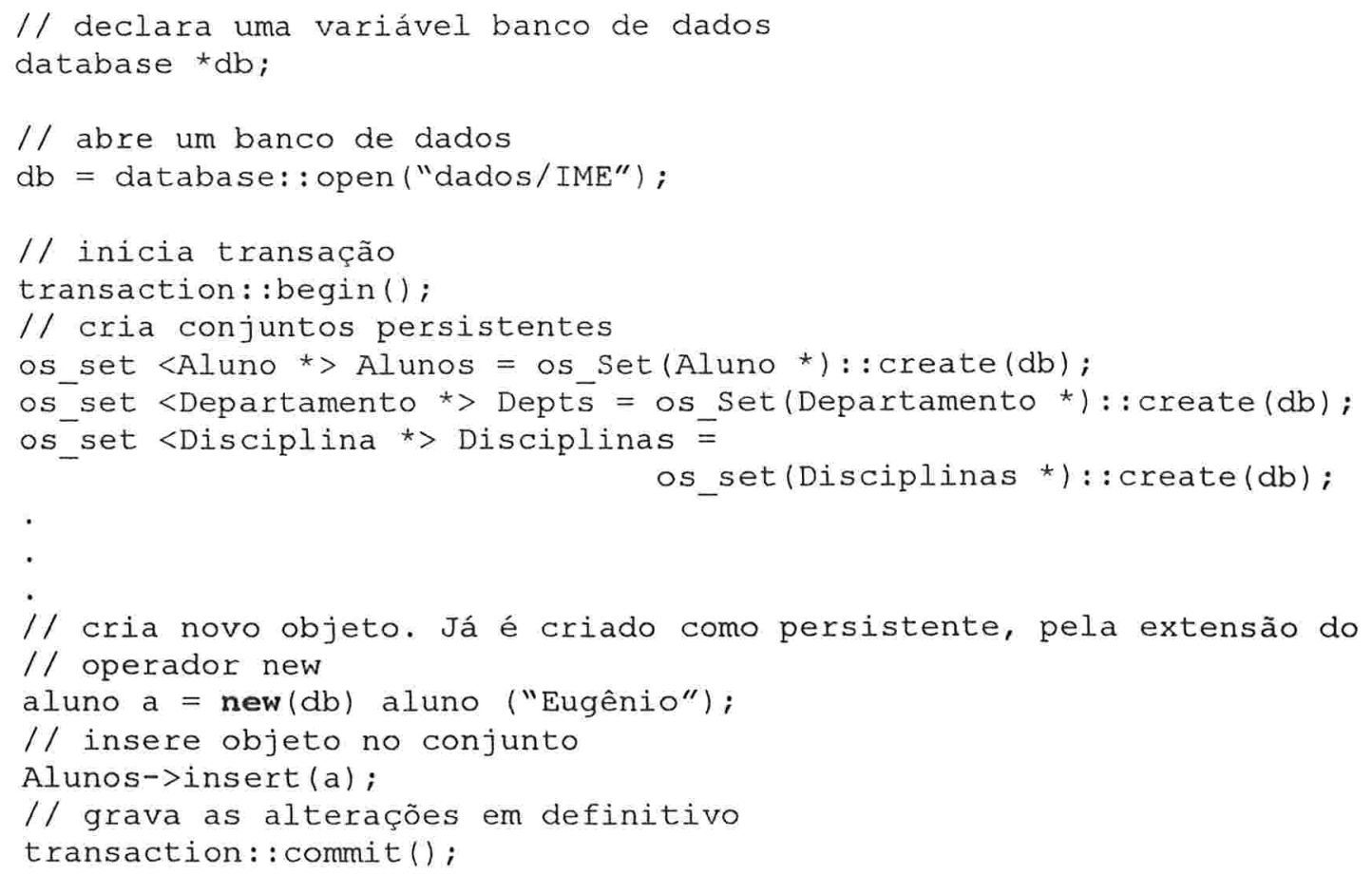

Para recuperar um elemento no conjunto do banco de dados, scriam usados os seguintes comandos:

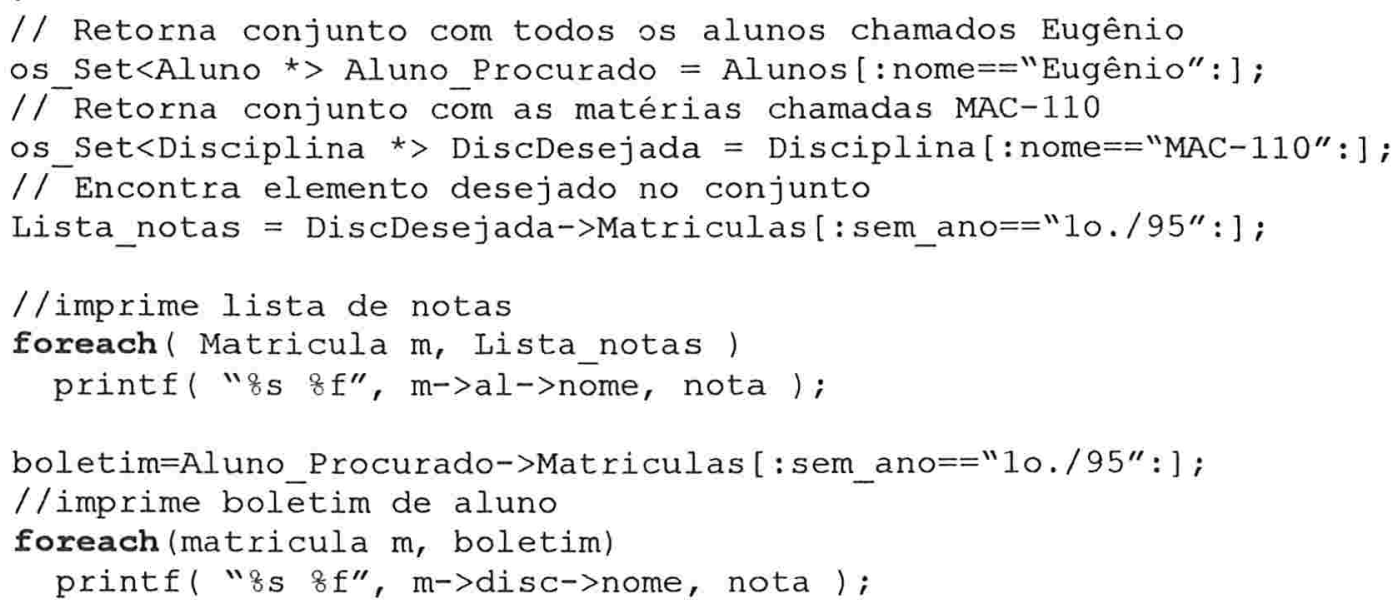

A única difcrença para a linguagem $\mathrm{C}++$ normal é a presença de extensões para manipulação dos conjuntos, foreach e a extensão utilizada no exemplo para a busca de elementos no conjunto que satisfaçam a condição indicada. Até o momento de nossa pesquisa, o sistema não possuía linguagem de consulta ad boc como a OQL do $\mathrm{O}_{2}$. 


\subsection{ORION}

O Orion ([KIM 89a], |KIM 90|) consiste de uma série de protótipos de BDOO, que possui três versões: Orion-1, Orion-1SX e Orion-2. () Orion-1 é um sistema mono-usuário e multitarefa. O Orion-1SX é um sistema cliente/servidor, em uma arquitetura em que as estações de trabalho são "diskless", e não tem banco de dados para gerenciar, que é controlado pelo servidor. O Orion-2 é um sistema distribuído, onde todas as estações participam no controle do banco de dados compartilhado. Esse era originalmente um projeto de pesquisa, e agora é um produto comercial, denominado I'TASCA, que é comercializado por uma empresa denominada IBEX.

Todas estas versões foram implementadas em Common LISP, em uma máquina 3600 LISP, sendo também disponivel para estações SUN, sob sistema UNIX.

Os sistemas Orion possuem características próprias, como o suporte a versão de objetos bastante desenvolvido, assim como uma semântica para objetos compostos. O Orion-2 possui caraterísticas adequadas para sistemas distribuídos, tais como melhor controle de acesso a objetos, controle de versões também para o esquema do banco de dados, e uma semântica mais geral para os objetos compostos.

\subsubsection{Declaração de dados}

A linguagem utilizada pelos sistemas Orion são extensão do IISP, no qual eles foram implementados. O Orion fornece herança múltipla. Vamos mostrar a seguir o exemplo:

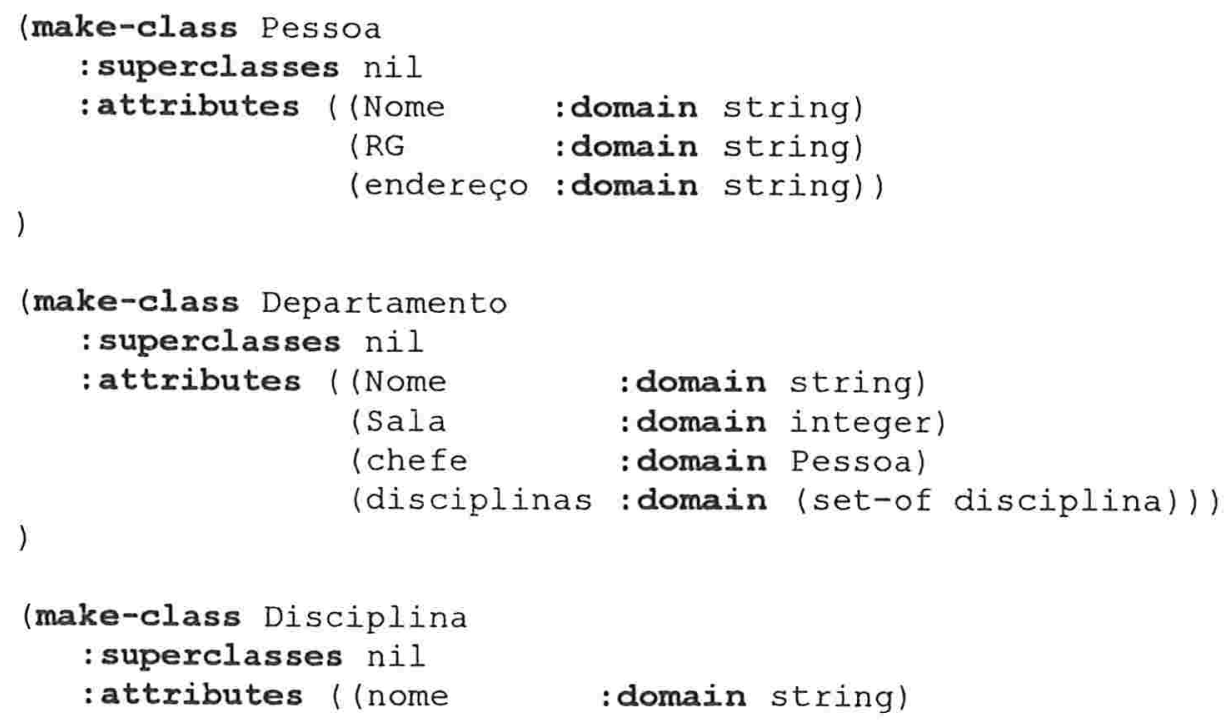




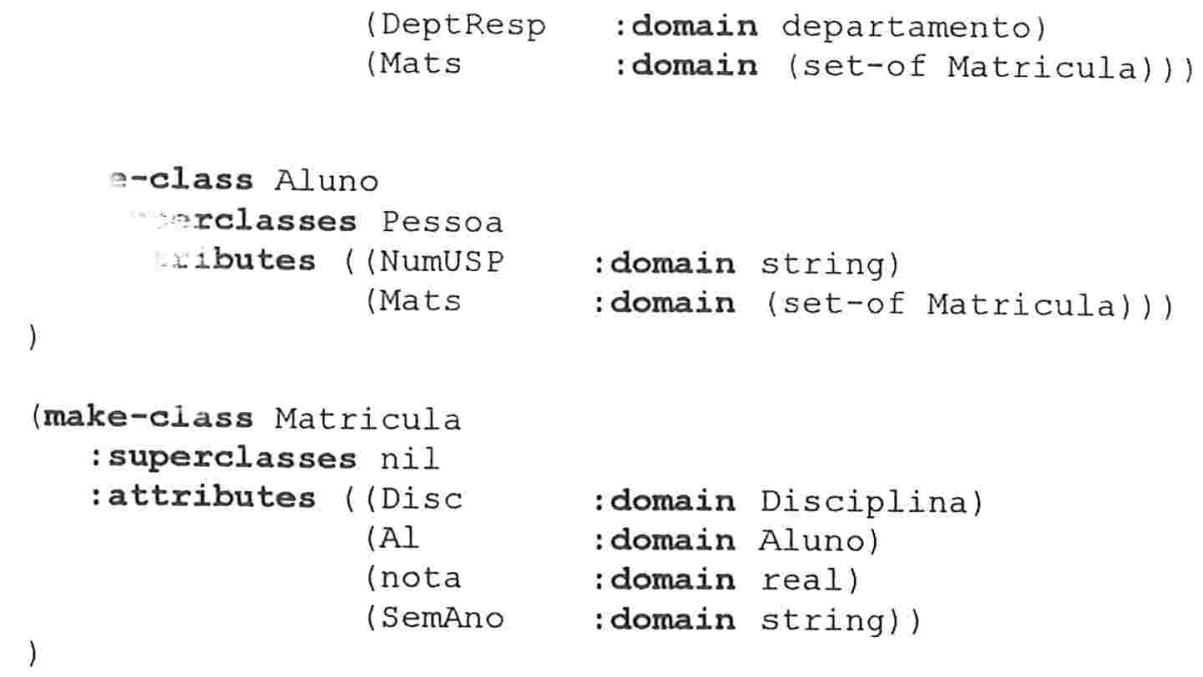

A Manipulação de dados é feita com a linguagem LISP, com extensões semelhantes à SQL. Vamos mostrar alguns exemplos de consultas:

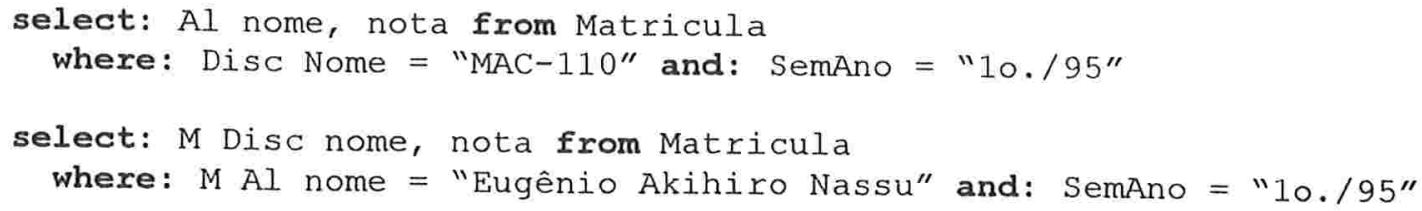

Notamos grande semelhança dessas consultas com as formuladas para a OQL, do $\mathrm{O}_{2}$.

\subsection{GemStone}

O GemStone ([BRE 89], [BUT 91]) foi desenvolvido pela Servio Logic. A idéia inicial do sistema é a de transformar a linguagem Smalltalk em uma linguagem para banco de dados, de onde surgiu a linguagem de declaração e manipulação de dados, a linguagem OPAL. O sistema é composto basicamente por dois processos principais, o Gem e o Stone. O servidor Gem executa os métodos, além da avaliação das consultas. O monitor Stone é responsável pela alocação de OIDs, gerenciamento os objetos persistentes, controle de concorrência, autorização, transações, e serviço de recuperação. O Stone em geral reside na máquina servidora, enquanto o Gem pode ser executado no servidor ou em uma estação cliente. As servidoras podem ser máquinas VAX, SUN 3 e SUN 4, enquanto as máquinas clientes podem ser IBM PC, Macs, SUN3 e 4, ou Tektronix. 


\subsubsection{Declaração de Dados}

A linguagem do GemStone, OPAL, como já mencionado, é baseada na linguagem Smalltalk. O GemStone oferece herança única, como a Smalltalk.

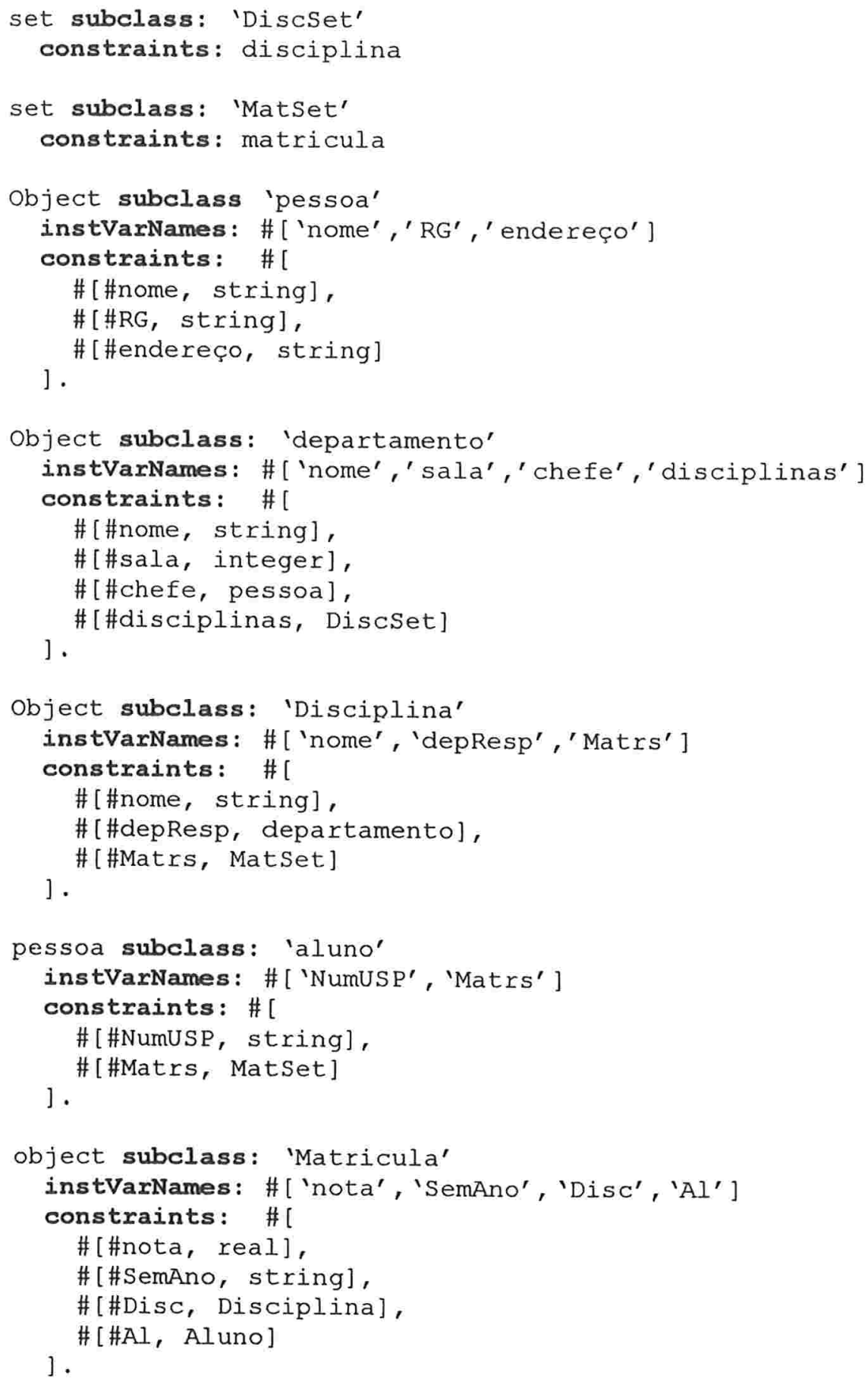




\subsubsection{Manipulação de dados}

No GemStone, os conjuntos possuem um comando especial select, que seleciona os objetos que possuam uma condição, especificado dentro do comando. Estes comandos são semelhantes ao já mostrados no OBJECTSTORE.

Matriculas select: $[\mathrm{m} / \mathrm{m}$.Al. nome= 'Eugênio' and m.SemAno= '1o./95']

Matriculas select: $\left[\mathrm{m} / \mathrm{m}\right.$. Disc. nome= 'MAC-110' and $\mathrm{m}$. SemAno=' $\left.10 . / 95^{\prime}\right]$

Nestes dois casos, foram selecionados os objetos com as condições correspondentes, sendo obtido um subconjunto do conjunto Matrículas.

\subsection{Postgres}

O POSTGRES ([STO 90], [STO 91], [POS 94]) é um protótipo desenvolvido na Universidade da Califómia, Berkeley, como sucessor do INGRES [STO 76], banco de dados relacional, da mesma universidade. Atualmente existe uma versão comercial, denominada Miro. A última versão não comercial do sistema (Postgres 95) pode ser obtida gratuitamente na Universidade, através de FTP (6).

O sistema foi escrito em C e possui cerca de 180000 linhas de código. Ele pode ser executado em estações SUN3, SUN4, DECstation e máquinas Sequent Symmetry.

O POSTGRES é baseado num modelo relacional estendido, oferecendo objetos, OIDs, objetos compostos, herança múltipla, versões, dados históricos, e uma linguagem de consulta, POSTQUEL, extensão da linguagem do INGRES, QUEL. Uma descrição do modelo de dados no início do projeto foi feita por Rowe \& Stonebraker [ROW 87].

Uma das características mais importantes do Postgres é a de armazenar dados históricos. Pode-se fazer uma consulta sobre o estado do banco de dados em um determinado momento do passado. Isto é possível devido à utilização de discos ópticos que armazenam o estado do banco de dados, depois de cada alteração. Um exemplo de utilização dessa característica é uma consulta sobre o salário de um funcionário há um ano atrás. 


\subsubsection{Declaração de dados}

O POSTGRES tem um modelo de dados baseado no modelo relacional. O sistema oferece um tipo abstrato de dados (ADT) para que se possa definir um novo tipo base de dados, que tem o mesmo status que um tipo primitivo do sistema.

O Postgres fomece um OID para cada elemento da relação. Vamos mostrar com o exemplo a definição do esquema:

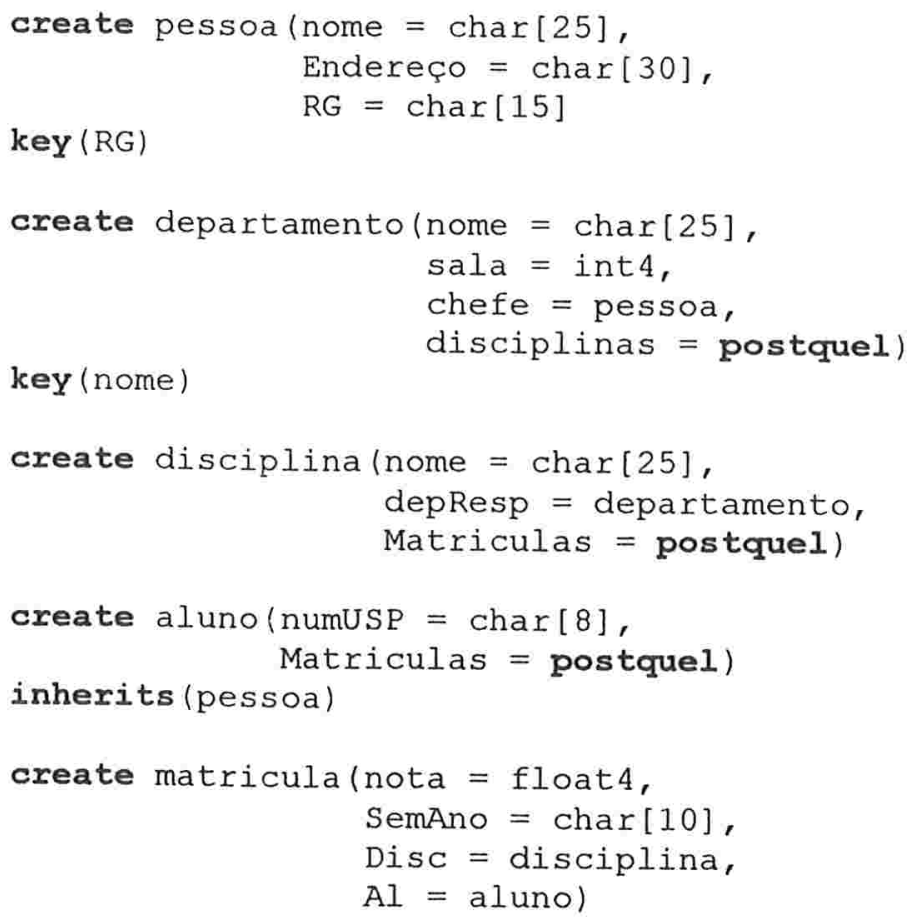

O Postgres permite herança múltipla, portanto no comando inherits mostrado no exemplo, pode ser utilizado mais de uma relação.

As definições do tipo postquel são dadas posteriormente como uma especificação em linguagem POSTQUEL ("stored procedure"). Mostraremos exemplos de consultas POSTQUEL adiante.

A definição da chave primária da relação pode ser feita pela palavra chave key que pode definir um ou mais atributos como chave primária. Se um atributo for definido como parte da chave primária, o seu valor não poderá ser nulo em todas as tuplas da relação. Opcionalmente, pode-se definir o operador de igualdade a ser considerado. Por exemplo, suponha que a chave foi definida como um atributo seja derivado de um ADT defínido pelo usuário. Se um atributo Retângulo foi definido como parte da chave primária, neste caso, o 
operador de comparação deve ser definido, uma vez que vários operadores podem ser utilizados para a comparação de dois retângulos (ex. Igualdade de área ou igualdade de coordenadas ). Temos um exemplo abaixo em que o operador de igualdade de área (AE), define a igualdade de retângulos:

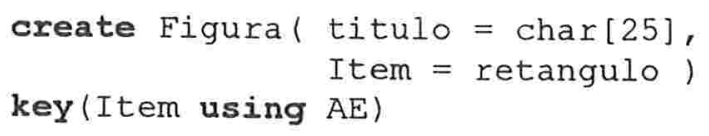

Para a definição dos atributos do tipo postquel primeiramente devemos definir uma função.

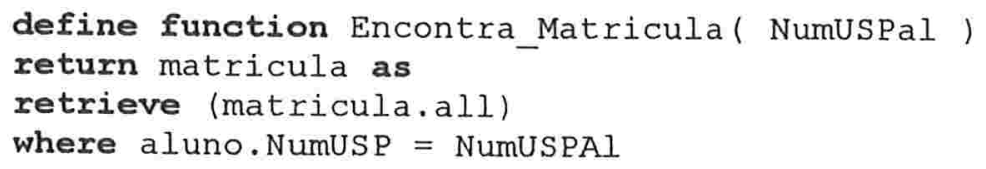

Definida a função, podemos atribuir um valor para um objeto Aluno.

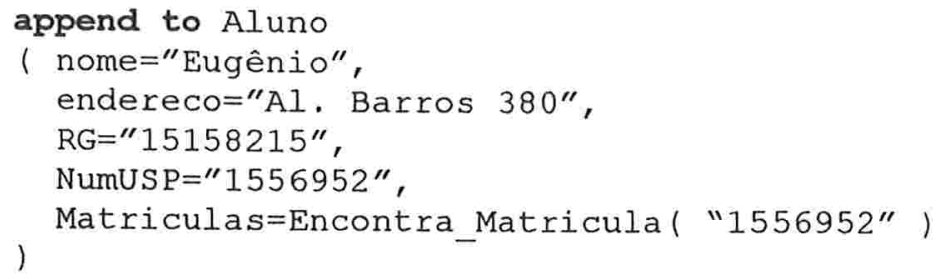

\subsubsection{Manipulação de dados}

Como já mencionado, o Postgres possui uma linguagem de consulta derivada do QUEL. Vamos mostrar alguns comandos da linguagem, supondo feitas as definições anteriores:

Adiciona uma pessoa ao banco de dados:

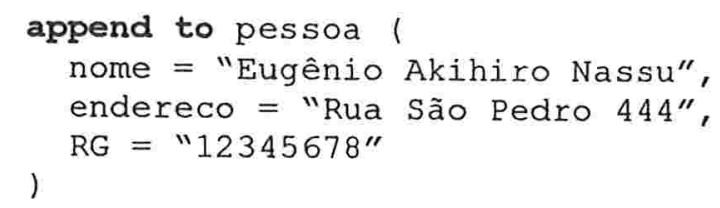

Para obtermos as notas do aluno Eugênio:

retrieve( A.nome, M.nota)

where A.nome = "Eugênio Akihiro Nassu"

Vamos mostrar um exemplo do uso de dados históricos: 
retrieve (Eunc.Salário)

from Func $[\mathrm{T}]$

where Func.nome = "Eugênio"

Nesta consulta, obtemos o salário do funcionário Eugênio no instante $T$.

Outra característica importante da linguagem de consulta é a de percorrer o fecho transitivo de um esquema. Por exemplo, num esquema de parentesco, é possível obter todos os ancestrais de uma pessoa. Consideremos a classe:

Pail velho, novo )

Os ancestrais de Eugênio pode ser obtido pela seguinte consulta:

retrieve* into resposta

(Pai.velho) from a in resposta

where Pai.novo = "Eugênio"

or parent.novo $=a$. velho

O asterisco $\left({ }^{*}\right)$ após o comando retrieve indica que a consulta deve ser executada até que o conjunto resposta não possa crescer mais.

Outra funcionalidade é a de percorrer as hierarquias de classes.

retrieve (E.nome) from $E$ in pessoa*

where E.nome = "Eugênio"

Desta vez, o asterisco após a classe pessoa indica que a consulta deve procurar não só em todos os objetos da classe pessoa, mas também em todas os objetos de todas as classes descendentes da classe pessoa.

Além dos comandos append e retrieve apresentados acima, a linguagem possui os comandos delete e replace, respectivamente para a exclusão de um objeto e troca de um objeto por outro.

\subsubsection{Regras no Postgres}

Uma característica importante do Postgres é o seu sistema de regras. Uma regra é uma ação executada no banco de dados, gerada por um determinado evento. Uma regra comum a todos os bancos de dados é a integridade referencial. Porém, em sua implementação o objetivo do sistema de regras é o de oferecer as seguintes funcionalidades: gerenciamento de visões, gatilhos ("triggers"), restrições de integridade, integridade referencial, proteção e controle de versões. Uma regra do Postgres tem a sintaxe apresentada a seguir. 
ON evento (TO) objeto WHERE

qualificador-POSTQUEL

THEN DO [instead]

comando (s) - POSTQUEL

Onde evento pode ser um comando retrieve, replace, delete, append, new (replace ou append) ou old (delete ou replace). O comando POSTQUEL é executado após o evento. O objeto se refere ao nome de uma classe ou de um atributo da classe. O qualificadorPOSTQUEL é um qualificador comum utilizado na linguagem POSTQUEL. O comando instead indica que a ação na regra deve ser executada no lugar da que gerou o acionamento da regra. Se o instead não estiver presente, o comando é executado em adição ao evento que o acionou. Os comandos POSTQUEL podem referenciar a new e current em lugar do nome da classe (valores durante a transição, antes do comando ser efetivado). Outro comando disponível para as regras é o comando refuse.

No exemplo a seguir, a regra implementa o fato que o salário do funcionário João deve ser o mesmo que o de José.

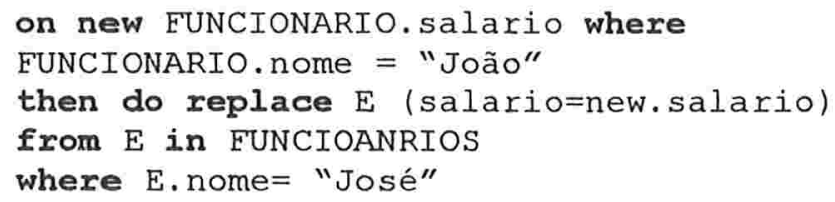

\subsection{IRIS}

O gerenciador de banco de dados Iris é um protótipo de pesquisa desenvolvido nos laboratórios da Hewlett-Packard ([FIS 87], [FIS 89]). O Iris foi implementado em linguagem C, em Estações Unix HP-9000/350. O Iris funciona como uma "casca", pois o armazenamento é feito em um Banco de Dados Relacional. Um tradutor se encarrega do acesso de dados e da tradução da linguagem de consulta.

O modelo de dados do Iris é baseado no modelo funcional, com extensões que o aproxima dos BDOO, como OIDs, herança múltipla, entre outras. A seguir, apresentamos um exemplo da linguagem de declaração de dados.

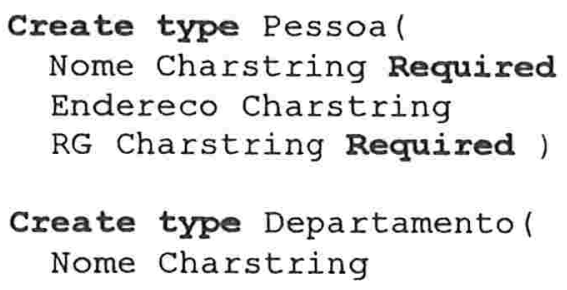




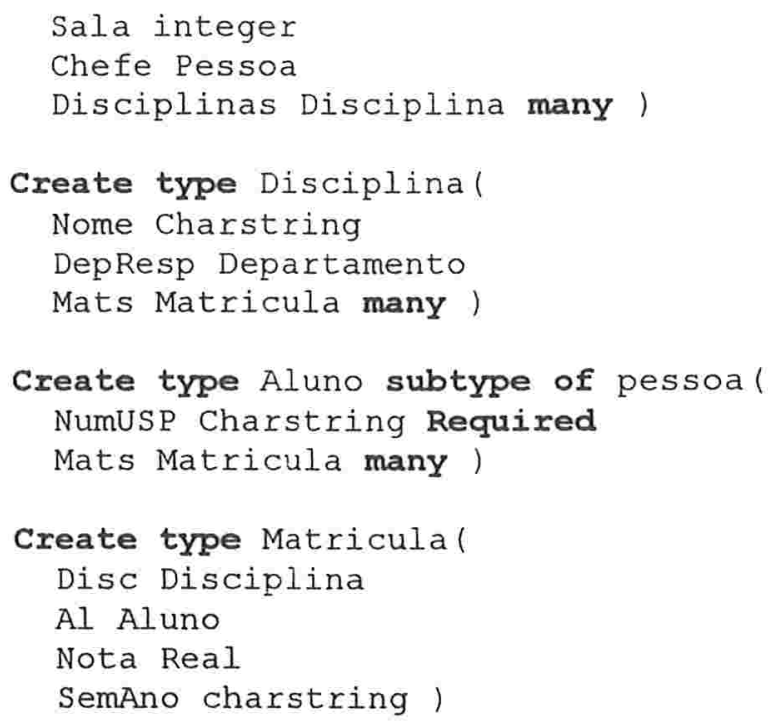

A consulta de dados no Iris é feita através de uma extensão do SQL, e é análoga à maioria dos sistemas apresentados.

\subsection{CACTIS}

O Cactis [HUD 89] é um BDOO, multiusuário desenvolvido na Universidade de Colorado para auxiliar a implementação de ferramentas CASE, de projeto de circuitos VLSI, entre outras aplicações que demandem uma boa capacidade para modelagem de dados, além de um bom desempenho. O sistema pode ser executado em estações SUN, e foi desenvolvido em linguagem $C$ por estudantes da Universidade. Uma das características importantes da implementação deste sistema é o fato dele ser auto-adaptativo, isto é, a organização física e os algoritmos de atualização são mudados dinamicamente para reduzir o acesso a disco. 


\subsubsection{Modelo de dados do Cactis}

O modelo de dados do CACTIS é um modelo incomum se comparado à grande maioria dos BDOO. Como na maioria dos BDOO os "objetos" do mundo real são modelados como classes de objetos, com atributos e métodos, porém, a interface do objeto com o mundo exterior é um conjunto de valores que podem entrar e sair do objeto, através de relacionamentos. Os relacionamentos por sua vez, se ligam aos objetos através de conectores. Nas linguagens OO, a interface do objeto com o exterior é um conjunto de mensagens reconhecidas pelo objeto. Um atributo do objeto pode ser intrinseco, quando o seu valor é simplesmente armazenado, ou derivado, quando seu valor é calculado a partir de uma regra de avaliação, associada ao atributo. Essa regra pode envolver cálculos a partir dos atributos intrínsecos e a partir de valores transmitidos a partir de relacionamentos. $O$ tipo dos atributos pode ser qualquer tipo padrão da linguagem $\mathrm{C}$.

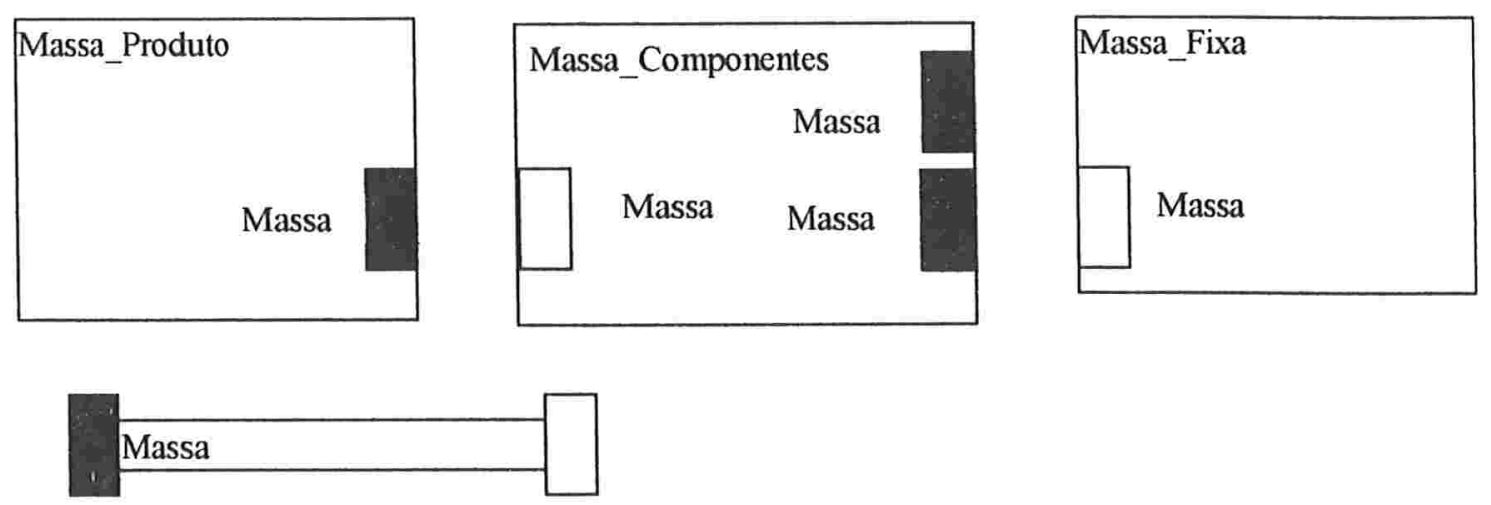

Figura 28: Entidades e relacionamentos do Cactis

Os relacionamentos no Cactis têm uma diferença grande em relação ao MER. Os membros de um relacionamento podem mudar dinamicamente durante a execução de um aplicativo, o que não ocorre no MER. Um relacionamento do Cactis é um tipo de "objeto" que serve para conectar objetos uns aos outros. Cada relacionamento no Cactis é dirigido, sendo que cada relacionamento possui dois conectores, um "preto" e um "branco". Outra informação na declaração dos relacionamentos são as variáveis que transitam pelo relacionamento. Isto é necessário, uma vez que não se sabe de antemão as classes que serão relacionadas. A interface dos objetos consiste de vários conectores, que se casam com conectores de relacionamentos. Vamos mostrar um esquema gráfico para exemplificar este modelo. Consideremos três classes de objetos: Massa_Produto, Massa_Componentes, e 
Massa_Fixa, e um relacionamento Massa. Os objetos da Classe Massa_Produto, que possuem um conector preto, podem estar relacionados com quaisquer objetos que possuam conectores brancos, no caso Massa_Componentes ou Massa_Fixa, e esse relacionamento pode ser modificado durante a execução de uma aplicação, desde que os conectores estejam casados. Os métodos da classe Massa_Produto não têm conhecimento das classes que estão relacionadas ao objeto; somente os valores que trafegam pelo relacionamento Massa são conhecidos.

Suponha-se então que a partir de informações em suas variáveis de instância e mais os valores que trafegam a partir do relacionamento Massa, um objeto da classe Massa_Produto estime a Massa total de um produto. Os valores que trafegam no relacionamento são fornecidos por em objeto Massa_Componentes, que calcula os valores a transmitir a partir de outro objeto Massa_Componente e um objeto Massa_Fixa. Um esquema desse exemplo está na Figura 29.

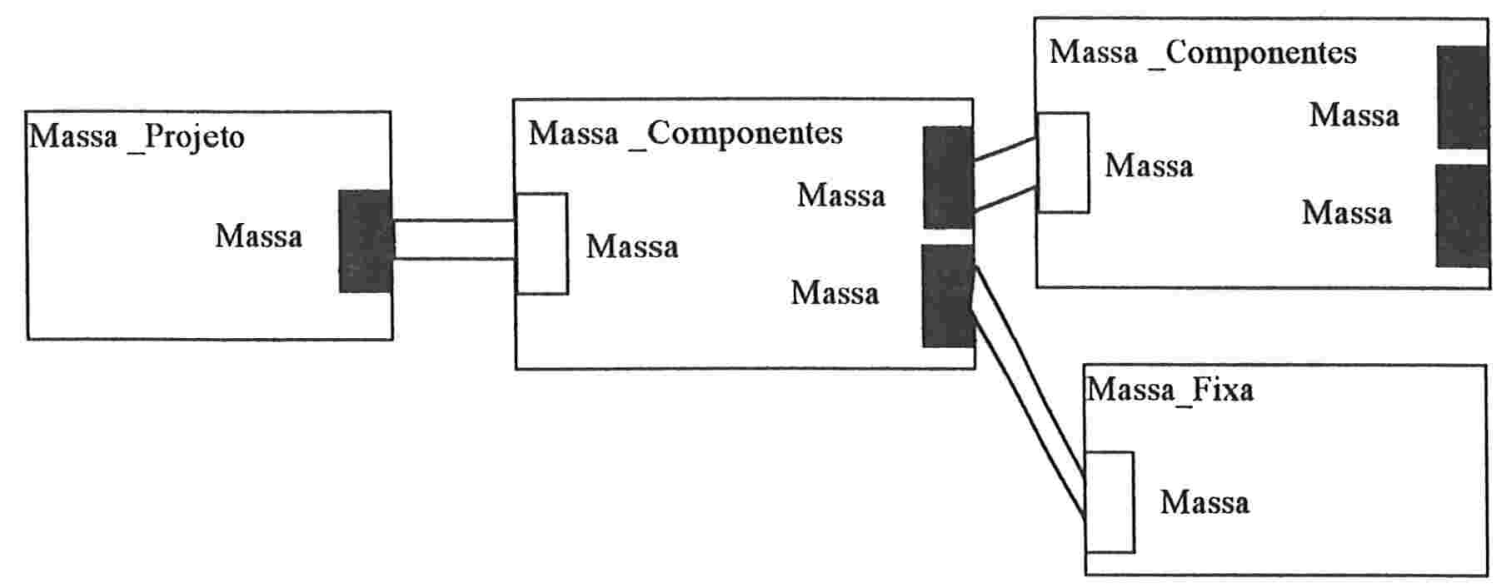

Figura 29: Esquema de exemplo do Cactis

Uma alteração no objeto Massa_Fixa ou Massa_Componente pode se propagar no cálculo da massa final. Os algoritmos de atualização, bem como a análise de sua eficiência são descritos no artigo de Hudson \& King [HUD 89].

Vamos agora mostrar um exemplo de declaração de dados com a linguagem de definição de dados do Cactis.

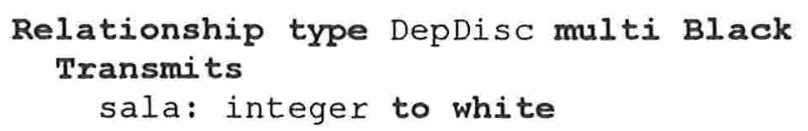


end;

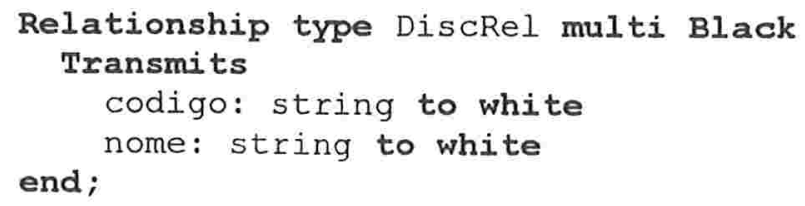

Relationship type AlunoRel multi White Transmits

num_usp: string to black

Nome: string to black

RG: string to black

endereço: string to black

end;

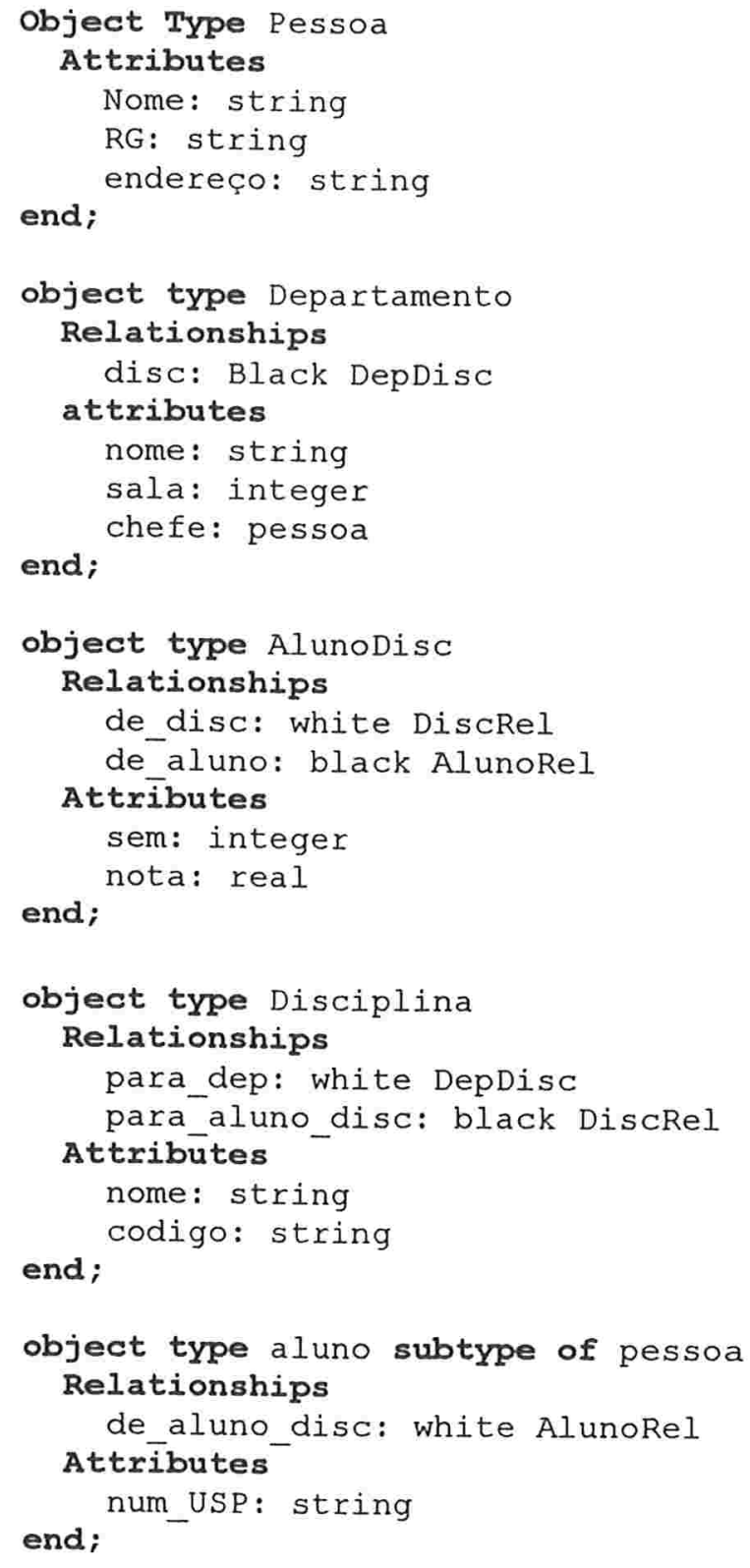


Em cada relacionamento é necessário declarar os dados que transitam pelo relacionamento, bem como o seu sentido. Um dos conectores do relacionamento pode ser declarado como múltiplo (multi), para representar relacionamentos "1 para N".

O Cactis transforma estas declarações em estruturas de dados declaradas em linguagem C, que podem ser utilizadas em um compilador padrão. Até a versão pesquisada, não havia uma linguagem de consulta de alto nível implementada. Portanto, o acesso aos dados é feito com o uso da linguagem $\mathrm{C}$.

\subsection{SIM}

O SIM é um sistema comercial, desenvolvido pela Unisys. Ele é baseado em um modelo semântico similar ao SDM. No SIM, há dois tipos de atributos, $D V A$ ("data-valued attribute") e EVA ("entity valued attribute"). Os atributos DVA são os de tipos comuns, como inteiro, caractere ou "string", enquanto que os EVA são atributos que associam a classe a outra(s), representando relacionamentos entre as classes. O SIM é um dos únicos sistemas a fazer esse tipo de distinção. Outra característica do sistema é a presença de atributos multivalorados. Mostramos a seguir um exemplo de declaração de dados do SIM.

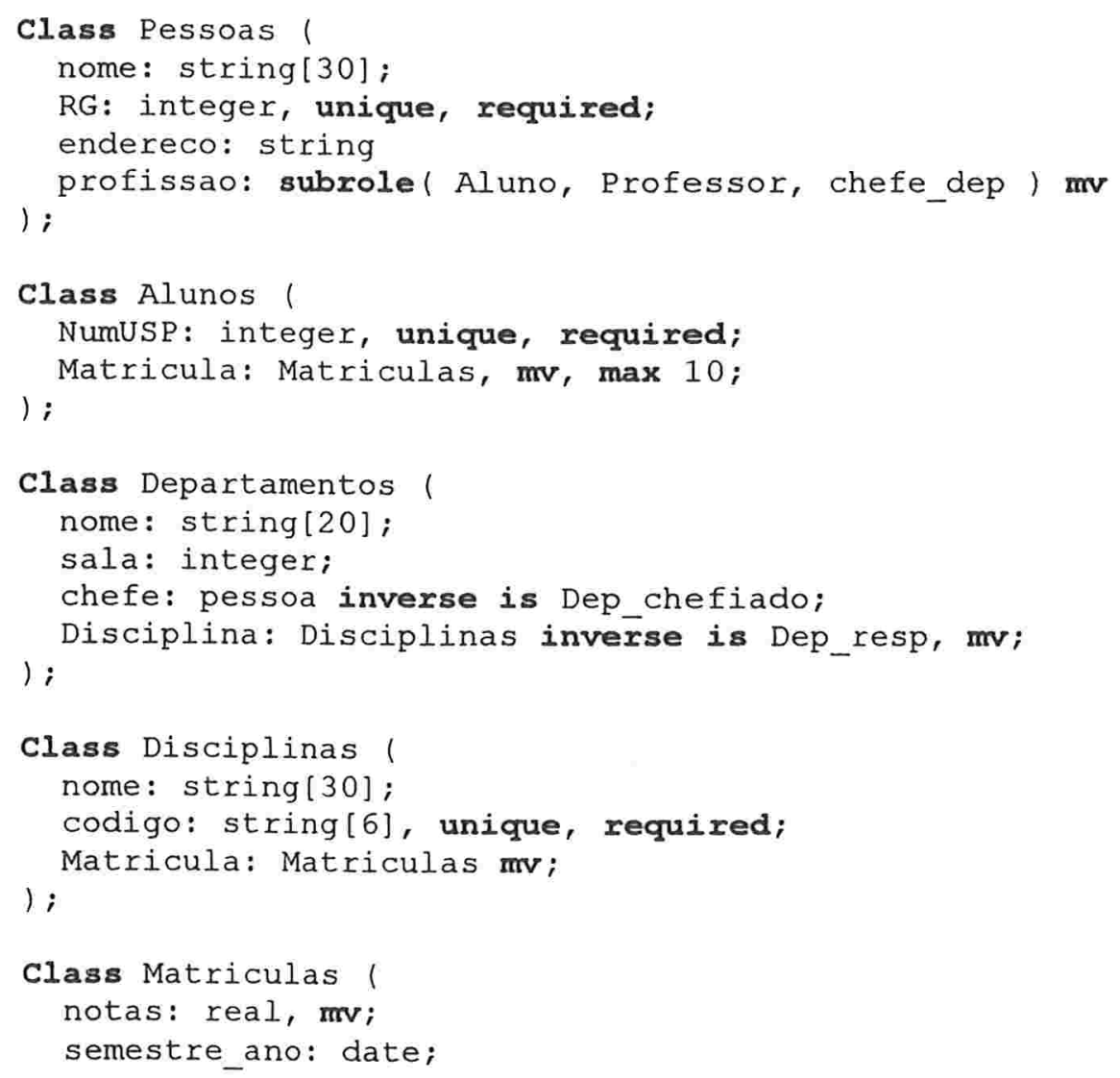




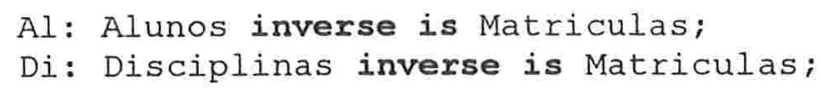

Quando presente, o comando required indica que o atributo junto a ele não pode ter o valor nulo. $\mathrm{O}$ unique indica que o valor do atributo não se repete em duas entidades da classe. O SIM possui atributos multivalorados, que são denotados pela palavra-chave mv. Quando o atributo multivalorado estiver acompanhado do comando distinct, indica que os valores do atributo multivalorado não podem ser repetidos, fazendo com que ele se assemelhe a um conjunto. O max indica o número máximo de elementos do atributo multivalorado.

Finalmente, o comando inverse indica o relacionamento entre as classes, para manter a integridade referencial. A herança no SIM é indicada na classe que possui subclasses, que devem ser enumeradas na declaração subrole.

A manipulação de dados se dá por uma linguagem de alto nível, semelhante ao DAPLEX. Essa linguagem basicamente consiste de uma cláusula RETRIEVE, alguns comandos de atualização, tais como INSERT, MODIFY e DELETE, além de funções de agregação como AVG (média), COUNT, etc. No esquema anterior, para obter os nomes dos departamentos e seus chefes, podemos executar o comando a seguir.

FROM Departamento

RETRIEVE Nome, Nome of chefe

A sintaxe geral do comando retrieve e a seguinte:

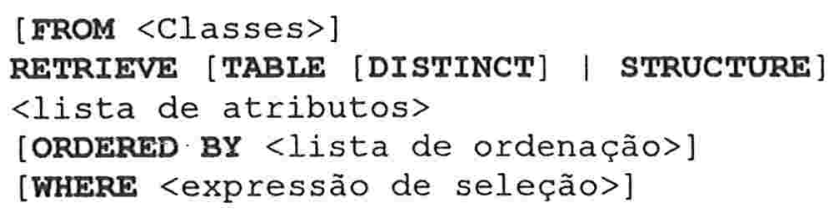

\subsection{JASMINE}

Este sistema foi desenvolvido pela Fujitsu, do Japão. Inicialmente o gerenciador de objetos foi implementado como uma "casca" de um Banco de Dados Relacional não-normalizado, também da Fujitsu. Atualmente o JASMINE (15) é comercializado pela Computer Associates, sendo talvez o primeiro BDOO comercializado por uma grande empresa de Software. O sistema pode ser executado na plataforma Intel, sob Windows NT 4.0. O pacote ainda inclui um ambiente gráfico para desenvolvimento de aplicativos 
multimídia e manutenção do Banco de Dados, o JADE (Jasmine Application Development Environment).

Para a definição e manipulação de dados no JASMINE é usada a linguagem ODQL (Object Database Query Language). A ODQL pode ser usada tanto como linguagem de consulta ad boc, como pode ser embebida em aplicativos escritos em C e C++. Segue um exemplo de definição de classes:

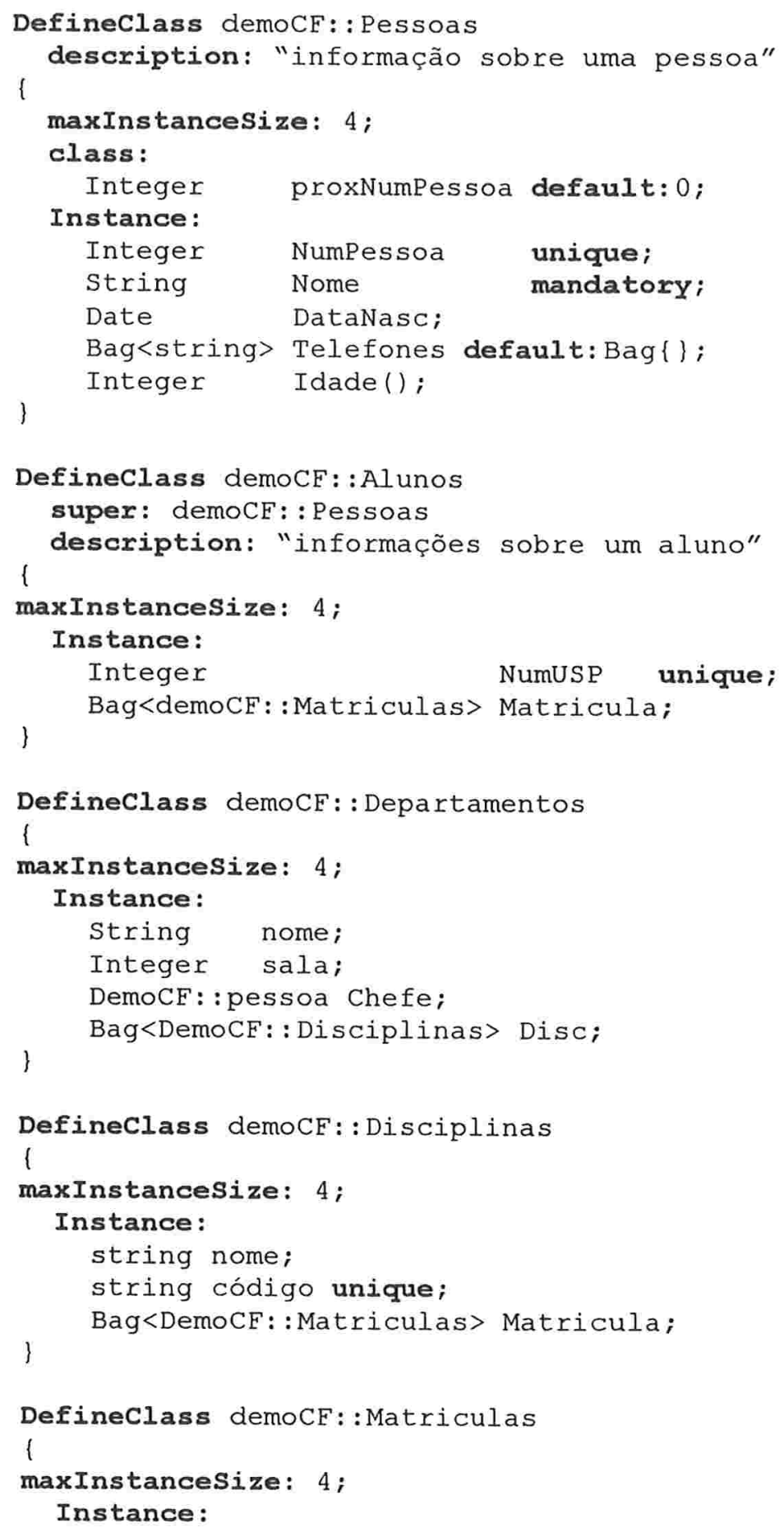




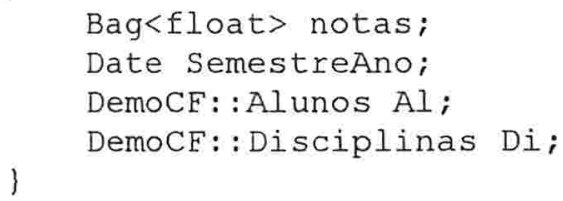

Podem ser criadas várias famílias de classes. A unicidade do nome da classe é exigido somente dentro de cada família. Nas declarações, quando se faz referência a uma classe, é sempre necessário informar ao sistema de que família de classes ela pertence (no exemplo, a família de classes usada foi demoCF). Após o comando description, pode ser colocado um comentário descritivo da classe. O JASMINE possui herança múltipla. O comando super define as superclasses da classe sendo definida. $\mathrm{Na}$ declaração das variáveis de instância e métodos, podem ser definidas variáveis de instância para as classes e para as instâncias, ou seja, quando o atributo é da classe obtemos um comportamento semelhante aos atributos globais (Item 2.5.1). Notamos também a presença dos comandos mandatory, que indica que o atributo não pode assumir o valor NIL (vazio), o unique, que indica que o valor do atributo não se repete na classe (uma chave) e o comando default, que permite definir um valor padrão para o atributo, caso durante a criação do objeto o valor não tenha sido fornecido. O maxInstanceSize é o tamanho máximo que os objetos ocupam na memória (em múltiplos de $2 \mathrm{~KB}$ ). O sistema possui diversas classes pré-definidas para implementação de listas e conjuntos. O bag, que aparece no exemplo é um conjunto onde é admitida a repetição de elementos. $\mathrm{O}$ sistema possui ainda as classes set $\mathrm{e}$ list.

As consultas retornam valores que normalmente são atribuídos a uma variável, lembrando o "cursor" da SQL. Por exemplo:

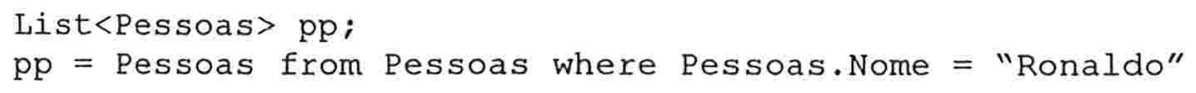

A variável pp é um apontador para uma lista contendo apontadores para os objetos selecionados. Para varrer a lista, podem ser utilizadas classes do tipo Iterator, que tem pré-definidas as funções advance e get, funcionado como um cursor associado à lista.

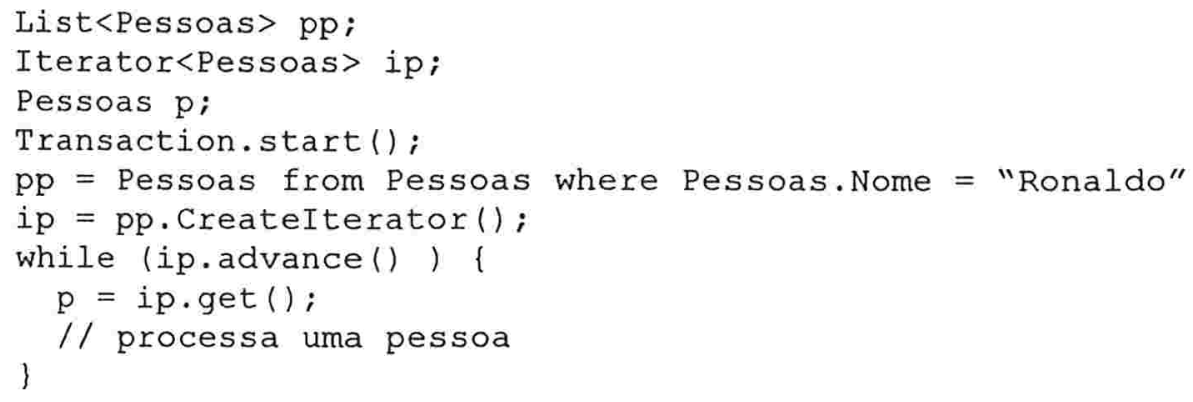


Os objetos do tipo lista ou conjunto, são definidos ainda métodos para excluir e encontrar um elemento (delete e find), funções de agragação para elementos numéricos (average, sum, etc.), funções de operação de conjuntos, como união, intersecção, e para exibir os elementos em uma ordem desejada (sort.).

A consulta pode retornar vários atributos, bastando listar os atributos desejados, como em uma cláusula select da SQL:

Bag< $<$ string Nome, Bag<string > Telefones $>$ NomeTel;

NomeTel $=$ [Pessoas.Nome, Pessoas.Telefones $]$ from Pessoas

Para criar novos objetos, a exemplo da $\mathrm{C}++$, usa-se o comando new. Por exemplo:

Pessas p;

$\mathrm{P}=$ Pessoas.new( Nome := "Romário" );

Para modificar dados, basta fazer as atribuições desejadas a um apontador para o objeto desejado.

Pessoas pp;

$\mathrm{pp}=$ Pessoas from Pessoas where Pessoas. NumPessoa $=111$

pp. Nome = "Novo Nome!"

Pode-se adicionar valores aos atributos compostos, com um comando como o seguinte:

Pessoas pp;

$\mathrm{pp}=$ Pessoas from Pessoas where Pessoas. NumPessoa $=111$

pp.Telefones = pp.Telefones.add ( "555-2222" )

Toda classe possui um método delete, para excluir objetos. Na consulta a seguir, removemos a pessoa de número 222 supondo número uma chave primária.

Pessoas pp;

$p p=$ Pessoas from Pessoas where Pessoas. NumPessoa $=222$

pp.delete () ;

\subsection{Poet}

O Poet é um sistema desenvolvido pela Poet Software. O principal objetivo do Poet é formecer persistência à linguagem $\mathrm{C}++$. O Poet é descrito de forma detalhada neste trabalho, no capítulo 7, pois o sistema que desenvolvemos gera especificações para o Poet. 


\subsection{AVANCE}

AVANCE [BJÖ 88] é um sistema desenvolvido na Universidade de Estocolmo e no SISU (Swedish Institute for Systems Development), e seu principal objetivo é o de dar suporte a aplicações que necessitam que as versões de um objeto sejam armazenadas. A linguagem de manipulação de dados é a linguagem PAL, que é semelhante à SMALLTALK. Outra característica interessante do AVANCE são as transações encadeadas, um dos únicos sistemas a possuir tal característica.

\section{$5.12 \mathrm{OZ}+$}

O OZ+ [WEI 90] é um BDOO desenvolvido na Universidade de Toronto, projetado para ser o sistema de armazenamento de um sistema também da mesma universidade, o OTM (Office Task Manager). Este sistema também funciona como uma "casca" de outro SGBD relacional, o EMPRESS. O sistema foi escrito em C e Turing Plus, em máquinas UNIX.

\subsection{Outros sistemas}

Podemos ainda citar como exemplos de BDOO o ONTOS [AND 91a], sucessor do Vbase [AND 91], [DAM 91], [DAM 91a], O ODE [AGR 89], O DAMOKLES [DIT 86], [SAN 91], o ZEITGEIST [FOR 88], VODAK (11), o OBST+ (9). Uma descrição de vários sistemas existentes também foi feita por Horowitz [HOR 91]e Zand [ZAN 95]. 


\section{Análise dos Exemplos de BDOO}

Vamos discutir as nossas principais críticas aos modelos de dados apresentados anteriormente.

\subsection{Relacionamentos}

Em todos os sistemas apresentados, com exceção do Cactis, notamos que os relacionamentos não são declarados explicitamente, mas de forma implícita, através de variáveis de instância. Os relacionamentos 1 para $\mathrm{N}$ e $\mathrm{N}$ para $\mathrm{N}$ são representados através de conjuntos e referências cruzadas a objetos, e os atributos dos relacionamentos tem que ser armazenados em objetos auxiliares, que representam os relacionamentos, ou em ambos os lados do relacionamentos. Em qualquer desses casos perde-se em parte ou totalmente a noção de relacionamento.

As linguagens de consulta como nas tradicionais para SGBD relacionais (com a honrosa exceção do ZIM) não reconhecem os relacionamentos. Segundo o prof. Setzer, é um absurdo em uma linguagem com a SQL, ter-se que declarar a condição de join em cada consulta, já que a ligação relacional é uma característica em geral estrutural, proveniente de um relacionamento que existe permanentemente.

O MR possui uma deficiência na modelagem dos relacionamentos, que vem do fato de somente existir uma estrutura de armazenamento, a relação. Nos BDOO observamos uma limitação semelhante, sendo que a única estrutura é a classe. Não existe uma estrutura conceitual para os relacionamentos tanto no MR como nos BDOO. A grande diferença entre o MR e os $\mathrm{BDOO}$ é que nos $\mathrm{BDOO}$ não possuem a $1 \mathrm{FN}$, o que facilita a representação de objetos complexos. No MRNN a representação pode ser feita de modo semelhante, sem truques de representação como relações auxiliares para atributos multivalorados.

\subsection{Linguagens de Declaração/Manipulação de dados}

Um dos argumentos mais usados pelos defensores dos BDOO é a que com as linguagens de programação com objetos persistentes não seria necessário aprender uma 
nova linguagem para manipular os bancos de dados. Porém, o aprendizado das novas linguagens, principalmente as de última geração está se tomando cada vez mais fácil e rápida, não justificando mais este argumento. Como os $\mathrm{BDOO}$, na sua maioria, são extensões de linguagens de programação orientadas a objetos, especialmente a linguagem $\mathrm{C}++$, um novo desenvolvedor de Bancos de Dados seria obrigado a aprender essas linguagens, muito mais complexas e de dificil aprendizado, o que invalida este argumento. Segundo o prof. Setzer, os BDOO, por usarem linguagens algoritmicas, apresentam um retrocesso em relação às linguagens de $4^{a}$ geração. Seria desejável que se fizesse extensões às linguagens de $4^{2}$ geração para que estas tivessem características das linguagens orientadas a objetos. $\mathrm{O}$ que a maioria dos $\mathrm{BDOO}$ propõem, que é fornecer persistência às linguagens orientadas a objetos não nos parece adequado.

\subsection{Falta de Padrão}

Uma das maiores críticas aos BDOO é a falta de padrão, tanto no modelo de dados, como no armazenamento. Não é uma tarefa fácil migrar de um BDOO para outro, ou compartilhar dados entre BDOOs diferentes. $\mathrm{Na}$ tentativa de padronizar os BDOO, os produtores do GemStone, Orion, $\mathrm{O}_{2}$, ObjectStore, Objectivity, Poet, UniSQL e Versant formaram um grupo, a ODMG (Object Database Management Group) [LOO 93], a fim de criar padrões para os BDOOs. Porém, mesmo assim há grande diferença entre os sistemas, e um dos motivos é que cada BDOO é projetado para aplicações específicas, o que diferencia um modelo de outro. No Cactis, por exemplo, o modelo de dados é concebido especificamente para aplicações CASE. Não é desejável que para cada aplicação seja necessário um BDOO diferente. Um modelo de dados mais geral, apropriado para a maioria das aplicações é o ideal.

\subsection{Violação do encapsulamento}

Outra crítica aos BDOO é o fato do encapsulamento ser relaxado principalmente nas linguagens de consulta derivadas da SQL. O fato de um dos principais conceitos da orientação a objetos ter que ser relaxado indica que a orientação a objetos utilizada pelas linguagens de programação não se aplica integralmente aos bancos de dados. Nesse sentido, poder-se-ia dizer que os BDOO não são de fato, orientados a objetos, na definição estrita deste paradigma 


\subsection{Falta de modelo formal}

O MR possui, como já citado, uma forte base teórica, baseada principalmente na álgebra relacional e na teoria dos conjuntos. Isso não ocorre nos $\mathrm{BDOO}$, que ainda não tem uma base teórica consagrada, apesar de já haver propostas de um modelo formal para o modelo de dados desses sistemas [WAN 89]. 


\section{O BDOO Poet}

Em nosso trabalho, foi utilizado o BDOO Poet para a implementação de um pré-processador para o modelo de dados proposto. Essa escolha foi feita pelos seguintes motivos:

- Uma versão de teste está disponível gratuitamente através da Internet.

- A empresa que produz o Poet participa da ODMG, e o sistema oferece muitas das características propostas pela entidade.

- O Poet integra-se com o compilador utilizado, o Borland $\mathrm{C}++4.52$.

$\mathrm{Na}$ versão gratuita, que foi utilizada, pode-se definir um esquema de no máximo seis classes. A versão testada é a 3.0. A versão 4.0 já está disponível desde o segundo semestre de 1996.

O Poet é um sistema comercial, produzido pela Poet Software, cuja principal característica é a de fornecer persistência dos objetos à linguagem $\mathrm{C}++$. Ele funciona em conjunto com compiladores bastante populares para a plataforma Microsoft Windows, o Borland C++ e o Microsoft Visual C++.

O Poet possui um ambiente integrado para desenvolvimento, que possui as seguintes funcionalidades:

- Possibilidade de edição da linguagem de definição do esquema do banco de dados.

- Gerador de código fonte na linguagem $\mathrm{C}++$, através de um pré-processador, denominado P'XX. Após a geração, o código gerado pode ser utilizado em uma aplicação, que passa a possuir classes persistentes.

- Um visualizador gráfico dos objetos armazenados num banco de dados.

- Outro visualizador gráfico, este para inspeção das classes pertencentes a um banco de dados.

- Também podem ser executadas consultas ad boc, através da linguagem OQL, em uma janela separada. 
- É possível ainda criar um novo banco de dados ou um objeto de uma classe, além de outras operações em objetos, tais como exclusão, inclusão e travamento de um objeto selecionado, em ambientes multi-usuário.

Há outro ambiente destinado à administração de bancos de dados (Poet Administrator). Com ele é possível executar várias tarefas administrativas dos bancos de dados:

- Cópias de reserva ("backup").

- Recuperação de um banco de dados danificado.

- Reorganização de um banco de dados (reindexação e desfragmentação).

- Controle de versões dos objetos.

- Conversão de bancos de dados de versões anteriores do POET.

- Controle de segurança.

\subsection{Persistência}

A linguagem aceita pelo pré-processador PTXX para definição do esquema de dados é uma extensão da linguagem $\mathrm{C}++$. Para um objeto ser persistente ele deve pertencer a uma classe declarada como persistente. O Poet mantém a integridade referencial entre os objetos, através de um contador de referências acoplado a cada apontador para objeto persistente. Além dos tipos da própria linguagem $\mathrm{C}++$, o Poet adiciona extensões para construção de conjuntos. Outra característica importante é a possibilidade de criação de índices, que são associados a uma variável de instância, a fim de otimizar o armazenamento dos objetos e acelerar as consultas.

Vamos mostrar o exemplo com a linguagem aceita pelo pré-processador do Poet:

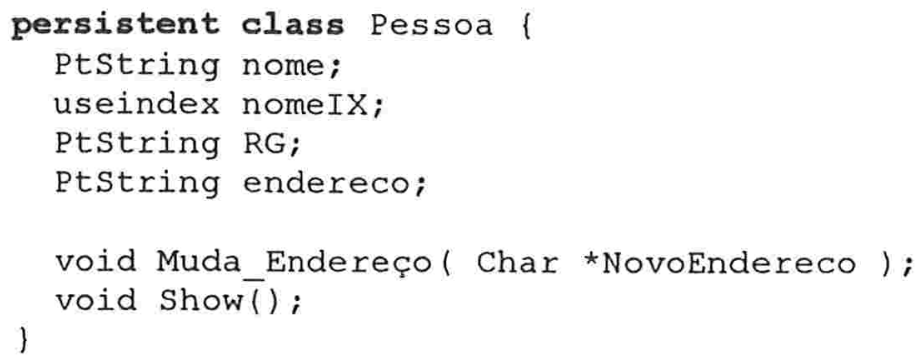




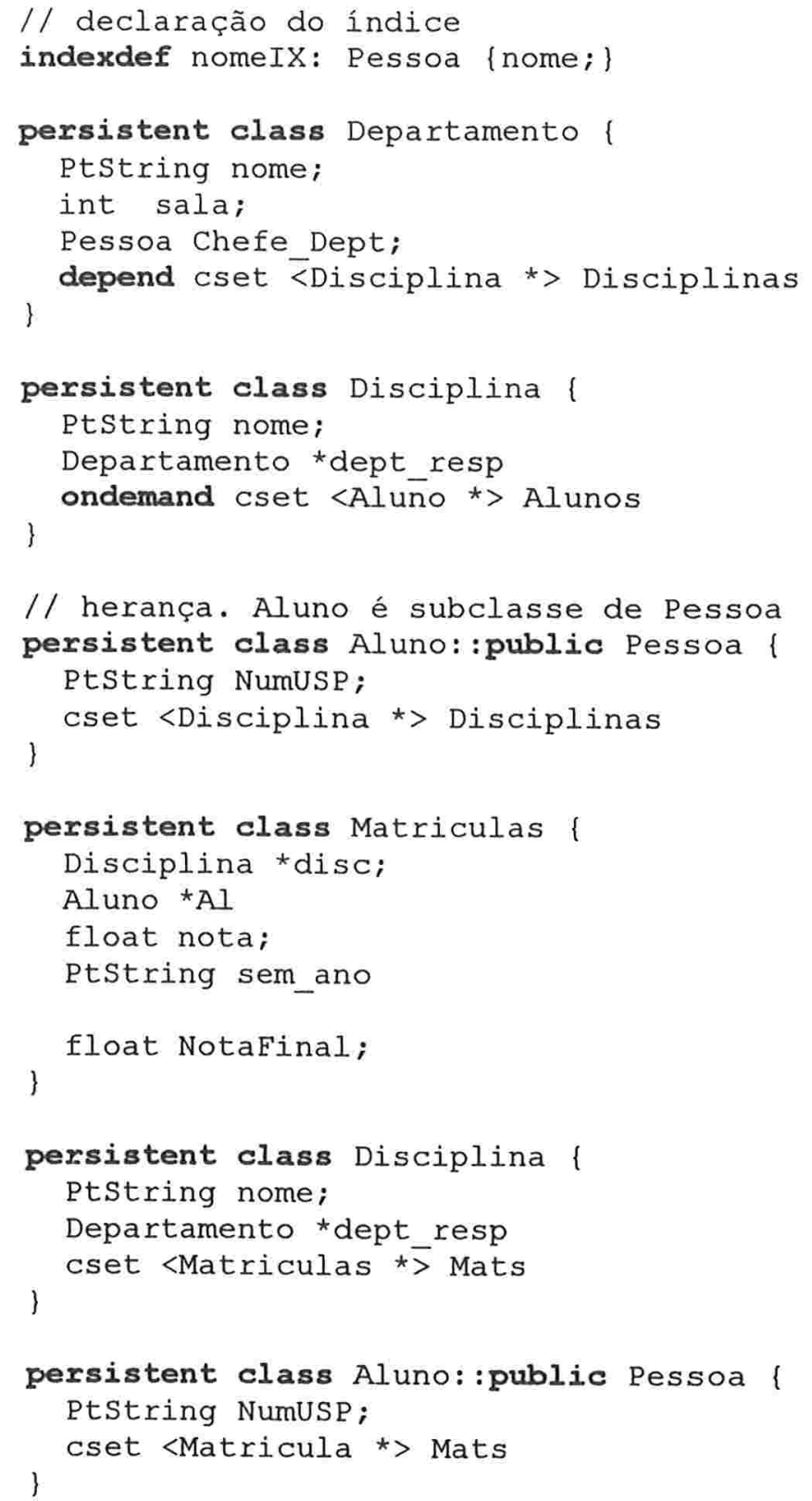

Vamos comentar algumas particularidades do Poet: $\mathrm{Na}$ classe Pessoa, o comando useindex indica que a variável nome é usada como índice para a classe Pessoa, e a definição do índice nome IX vem logo depois da declaração da classe, na declaração indexdef.

O comando depend faz com que os objetos que são referenciados sejam apagados, caso o objeto seja excluído do banco de dados, analogamente ao comando de exclusão em cascata do SQL. No exemplo, se um departamento fosse excluído, todas as disciplinas ministradas pelo departamento também seriam excluídas. 
Outra característica interessante é o comando ondemand, que faz com que os objetos referenciados sejam carregados para a memória somente quando utilizados. Se esse comando não fosse utilizado, quando um objeto da classe Disciplina fosse carregado, todos os alunos do conjunto seriam carregados, o que aumentaria o tempo da carga do objeto. Com o uso desse comando, somente são carregados alunos que forem consultados ou modificados, no momento da consulta ou modificação.

O Poet possui classes paramétricas ("templates") pré-definidas para o uso de conjuntos, cset, lset e hset. Os tipos de conjuntos diferem na capacidade de armazenamento, sendo o de menor capacidade (cset - compact set), de manipulação mais rápida.

Na versão analisada do sistema (3.0), não é permitida a herança múltipla de classes persistentes, ou seja, uma classe persistente não pode ter mais de um antecessor direto.

\subsection{Consulta e Manipulação de Dados}

$\mathrm{Na}$ definição da ODMG, são propostas duas formas de consulta e manipulação de dados:

- Através da navegação por ponteiros e referências ao OID do objeto.

- A partir de uma linguagem de consulta, que é preferivelmente uma linguagem semelhante ao SQL.

O Poet oferece as duas formas de recuperação de dados. Toda classe persistente declarada possui um conjunto associado, que contém todos os elementos da referida classe. O conjunto possui os métodos Seek, Get e Unget, que permitem percorrer o conjunto da forma desejada. O método Get devolve um ponteiro para o objeto desejado, e podemos assim navegar através dos objetos associados ao objeto apontado, através das referências (ponteiros) contidas na sua estrutura.

Utilizando o esquema mostrado acima, vamos mostrar um trecho de código em $\mathrm{C}++$ que mostra os dados sobre um conjunto de pessoas que está armazenado em um banco de dados:

// cria uma nova instância de conjunto e carrega dados armazenados psetofAllPessoas = new PessoasAllset (GetDb() ) ; 


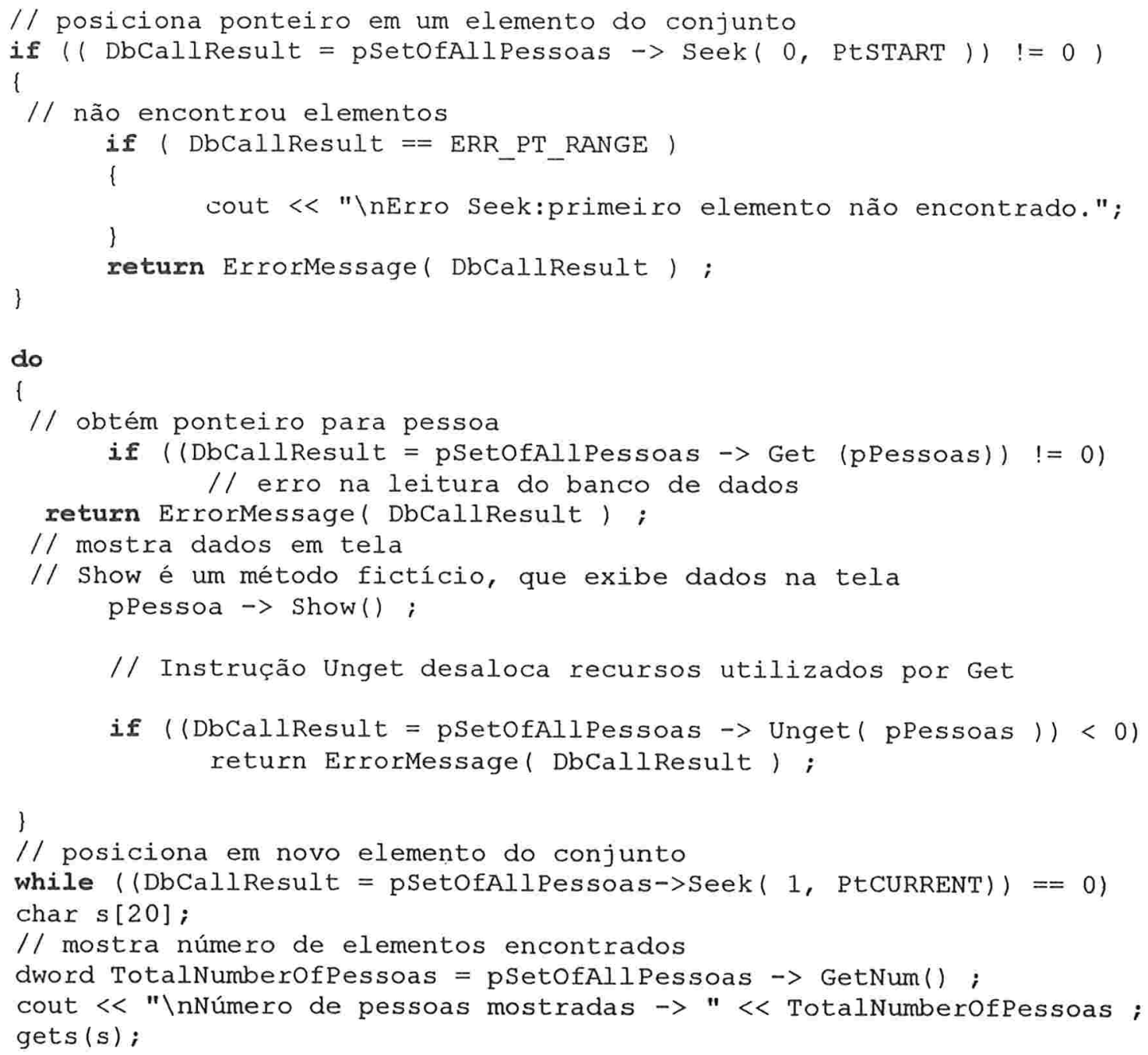

Outra forma de consulta e manipulação de dados é através da linguagem OQL. Esta linguagem pode ser utilizada para efetuar consultas ad boc, ou pode ser utilizada dentro de um programa escrito em $\mathrm{C}++$. Vamos exibir uma pequena consulta na linguagem OQL:

define extent Pessoas for Pessoa; //1

select $x$ from $x$ in Pessoas

where $x$. name = "Eugênio"

$\mathrm{Na}$ linha 1, é definido o conjunto ("extent" na nomenclatura do sistema) de todas as pessoas, que são agrupadas num conjunto automaticamente. No restante, podemos observar a semelhança com a linguagem SQL. Uma das limitações presentes na versão 3.0 do Poet é que somente é possível recuperar um objeto pré-definido, como no caso anterior, ou um tipo primitivo de dados. Não é possivel recuperar uma tupla de uma classe não definida, ou outro objeto composto que não esteja previamente declarado. Outra limitação 
presente na versão analisada do POET é que não se pode chamar métodos das classes consultadas numa consulta OQL.

Para utilizar consultas baseadas na linguagem OQL em um programa escrito em $\mathrm{C}++$, o sistema define uma classe Consulta, (OQL_Query). Para se executar uma consulta, constrói-se uma instância da classe OQL_Query, que tem como uma de suas variáveis de instância o texto do comando. Para executar a consulta, basta executar o método execute, que devolve o resultado da consulta em um conjunto ou em um ponteiro. No exemplo abaixo, um trecho utilizando consultas OQL da forma descrita

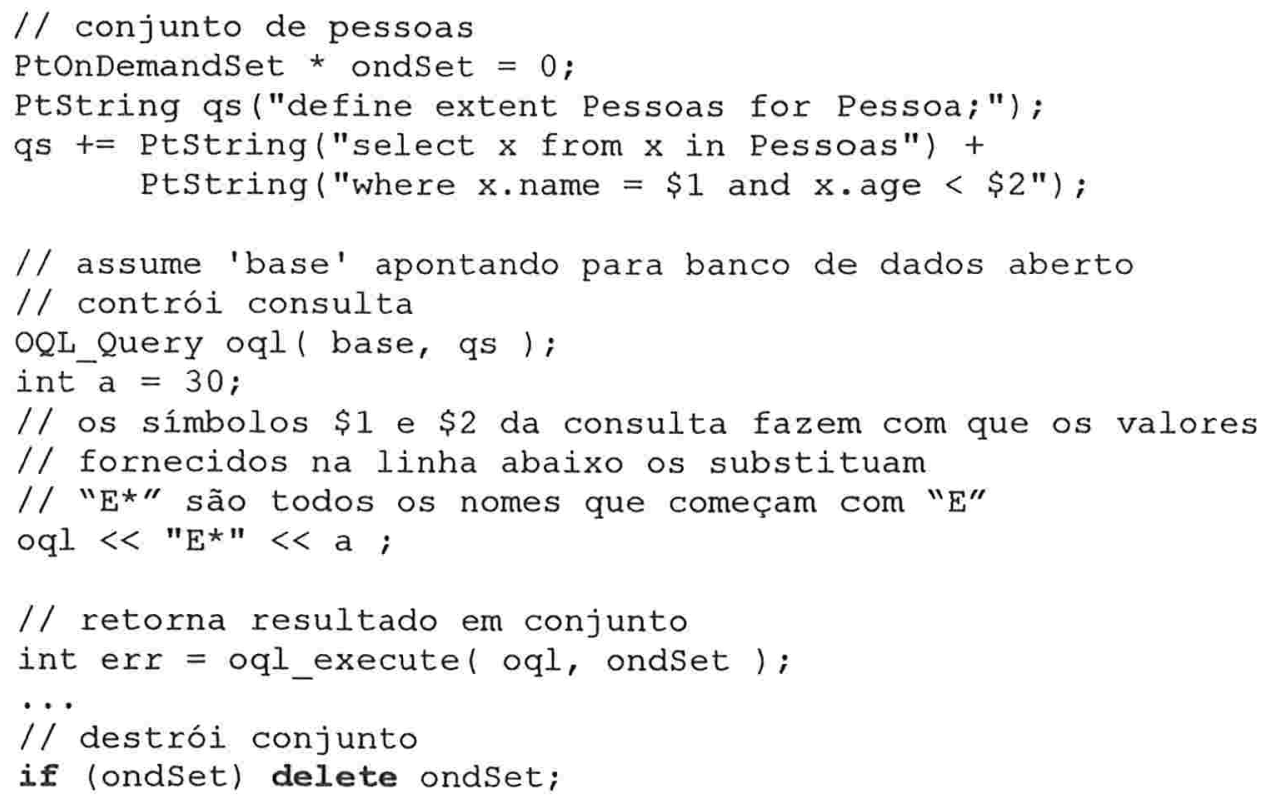

Uma vez recuperado, podem ser utilizados os métodos definidos para os conjuntos (get, unget) para obter os elementos desejados do conjunto.

\subsection{Outras características}

O POET oferece também o controle de transações, que é semelhante ao do ObjectStore. Qualquer alteração nos objetos entre as instruções BeginTransaction e CommitTransaction não são efetivamente gravadas em disco, mantendo os dados em um estado válido. Essa alteração só é efetivada ao se executar a segunda instrução.

Outra característica presente no POET é o controle de versões de objetos. Quando há uma alteração no esquema de um banco de dados já existente, os objetos já armazenados 
tem sua estrutura atualizada após uma operação de atualização presente no ambiente de administração do banco de dados.

No ambiente de administração é possível a criação de novos usuários, e é possível atribuir permissões de leitura, atualização e exclusão para cada variável de instância de uma classe. Quando se abre um banco de dados em que há o controle de usuários, é mostrada uma tela de login, onde é solicitada a entrada da senha do usuário. Este controle de acesso ao banco de dados é bastante complexo, e é considerado um dos melhores entre os BDOO existentes. 


\section{Nossa Proposta: o modelo OER (Object Entity-Relationship)}

Nossa proposta consiste de um sistema cujo modelo de dados é uma extensão do Modelo de Entidades e Relacionamentos. Além de algumas das extensões já apresentadas anteriormente (Item 2.5), nosso modelo permite a declaração de métodos nas entidades, atributos, relacionamentos e agregações. Nosso modelo também permite o uso de atributos multivalorados e compostos, mantendo-se assim a estrutura relacional (não normalizada) na representação de muitos tipos de objetos complexos, como vimos no Item 2.4.

Foi implementado um pré-processador que aceita uma linguagem de definição de dados de nosso modelo, traduzindo-o para um esquema do BDOO Poet. O pré-processador foi desenvolvido para o Ambiente MS-Windows, sendo utilizado o compilador Borland C++4.52. Como já citado anteriormente, a versão do Poet utilizada foi a versão 3.0.

\subsection{Mapeamento ER-OO}

Uma proposta para este problema é apresentado por Narasimhan et al [NAR 93], por Elmasri \& Navathe [ELM 94] e ainda por Fong [FON 97]. Nessas propostas, são definidas as seguintes correspondências:

- Entidade $\Leftrightarrow$ Objeto

- Conjunto de Entidades $\Leftrightarrow$ Classe

- Atributo $\Leftrightarrow$ Variável de instância

- Relacionamento $\Leftrightarrow$ Conjunto de apontadores para objetos

No MER, não há nenhum elemento que corresponda aos métodos. Duas das principais vantagens do uso de métodos é o de implementação de restrições de integridade sobre os atributos e a representação de atributos calculados (chamados de "virtuais" em alguns sistemas), como por exemplo a idade: o método pode calcular a idade de uma pessoa a partir de sua data de nascimento e da data do sistema. Outro papel dos métodos e a de 
manter a multiplicidade e a totalidade dos relacionamentos do MER, além de encapsular as aplicações junto com as estruturas de dados.

Nosso sistema utiliza basicamente o mesmo mapeamento proposto nesses artigos.

Os gerenciadores de BDOO permitem estruturas complexas, como conjuntos, listas, etc. A diferença para nosso modelo é que ele conceitua essas estruturas como atributos multivalorados. Assim, podemos manter a conceituação e a linguagem relacional no armazenamento e busca desses atributos.

\subsection{Conceitos do OER}

Em nosso modelo, dividimos as classes em várias categorias. As classes basicamente podem ser Atributos, Entidades, Relacionamentos e Agregações. As classes Entidade, Relacionamento e Agregação possuem o mesmo papel que no modelo ER. A classe Atributo serve como tipo para os atributos das entidades. Nosso modelo possui atributos multivalorados que são variáveis de comportamento semelhante aos conjuntos. A diferença é que os atributos multivalorados admitem repetição de valores. Como a classe atributo pode ser composta, temos também a presença de atributos compostos. Esse tipo de conjunto é denominado " $b a g$ " na literatura. Em todas as classes podem ser definidos métodos. A herança pode ser usada apenas na definição das classes entidade. Uma classe agregação, porém, pode fazer o papel de uma superclasse de uma classe entidade.

Outros tipos de classes presentes em nosso modelo são as classes Subentidade, Subrelacionamento e Subagregação, que são, repectivamente, subconjuntos de alguma classe Entidade, Relacionamento ou Agregação já definidas anteriormente.

\subsection{Esquema de transformação OER - Poet}

Descreveremos a seguir os elementos de nosso modelo e suas declarações e mostraremos a transformação correspondente para o sistema Poet. Em nosso modelo, as classes de objetos foram divididas em várias categorias: 


\subsubsection{Atributos}

Cada atributo de uma entidade ou de um relacionamento deve pertencer a uma classe específica, a classe Atributo. Todas as classes e tipos básicos da linguagem $\mathrm{C}++$ (int, float, char, double, etc.) podem ser utilizadas como classe atributo. Somente as classes e tipos básicos, as classes definidas pelo usuário e as classes atributo podem ser utilizadas como classes de atributos de entidades e de relacionamentos. Segue um exemplo de declaração de classe atributo:

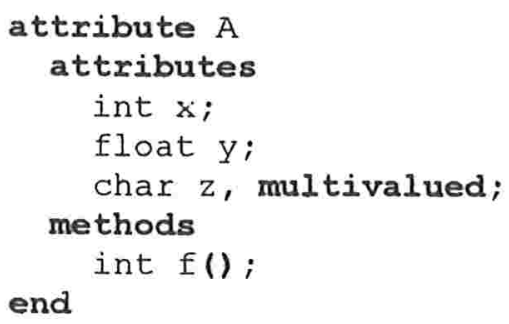

Nesse caso, a tradução para o esquema OO é praticamente direta, observando-se apenas a declaração de atributo multivalorado, que deve gerar uma declaração de um conjunto:

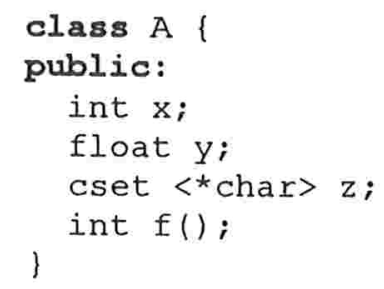

Em nosso modelo, não foi implementada a herança na classe atributo. A declaração não é de uma classe persistente, pois a intenção desta declaração é justamente a de fazer parte de uma entidade, como elemento que a compõe. Sendo parte de uma classe persistente, suas instâncias tomar-se-ão persistentes. Se for necessário armazenar apenas uma instância da classe atributo no Banco de Dados, isso pode ser uma indicação de que a classe atributo deveria ser modelada como uma Entidade. Por exemplo, se desejássemos armazenar o atributo acima, poderíamos criar o esquema:

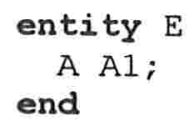

Se A não for utilizada em outra lugar como atributo, poder-se-ia simplesmente declarar uma classe entidade com a mesma estrutura, como descrito a seguir. 


\subsubsection{Entidades}

As instâncias das classes entidade são o componente principal do Banco de Dados. Praticamente toda informação será armazenada nas estruturas geradas pela classe entidade. Mostraremos a seguir um exemplo genérico de declaração, em que A é uma especialização de B.

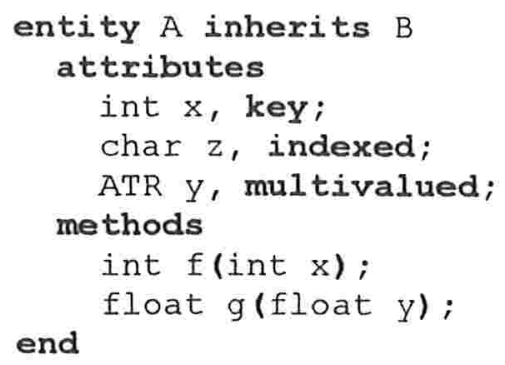

Esse esquema geraria a seguinte declaração no Poet:

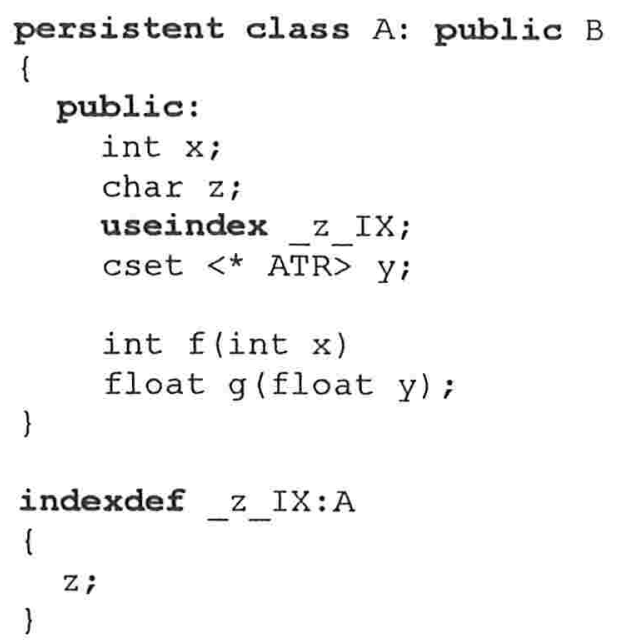

A declaração e o esquema correspondente são semelhantes, se desconsideradas as diferenças de sintaxe. Desta vez, a classe correspondente é declarada como classe persistente, pois suas instâncias devem ser armazenadas no meio de armazenamento permanente. A variável de instância x é declarada como chave, mas isto não se reflete na declaração do Poet, pois não há um índice único, nem uma declaração que indique a unicidade do atributo, portanto a repetição da chave deve ser detectada quando se cria um novo objeto, em um método adequado. No Poet, pode-se indexar uma das variáveis de instância, e isto foi transportado para nosso modelo. A variável $z$ é indexada, e este fato gera as declarações useindex e indexdef. $\mathrm{O}$ atributo y é multivalorado, o que é representado no Poet como um conjunto (cset). 
Na versão testada do Poet, não é permitida a herança múltipla em classes persistentes, e por isso no nosso modelo também não há tal mecanismo. Se a herança múltipla for incluída em novas versões do Poet, pode-se modificar o gerador com facilidade. Outra característica presente é a herança total (Descrito no Item 2.5.5). Se a entidade vier acompanhada da palavra chave partitioned, todos as classes descendentes formam uma herança total. Vamos mostrar o esquema e a declaração correspondente.

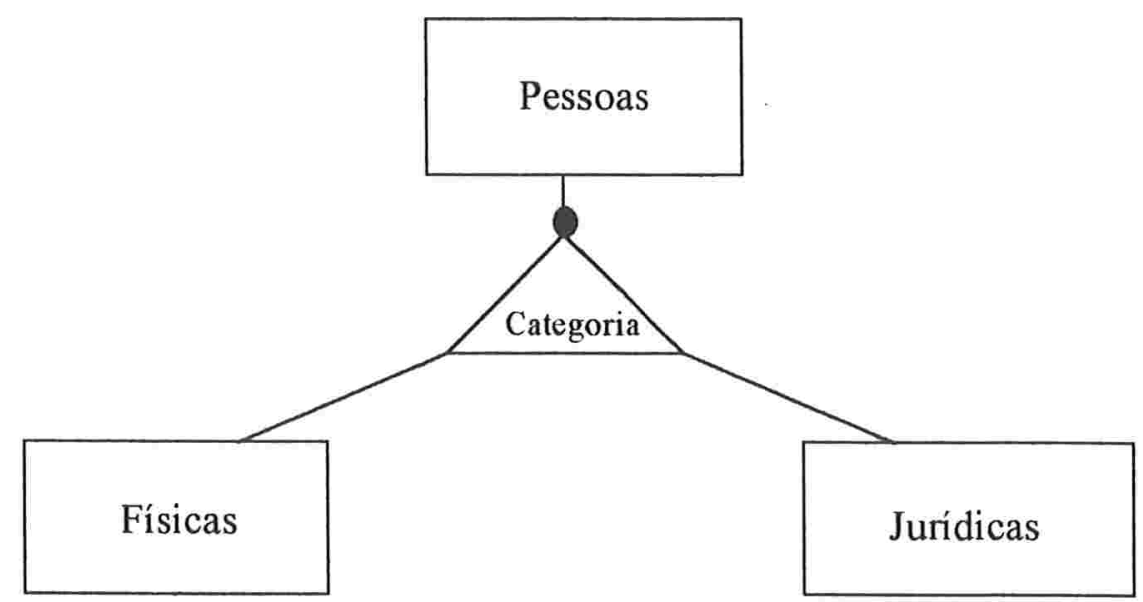

Figura 30: Exemplo de generalização total

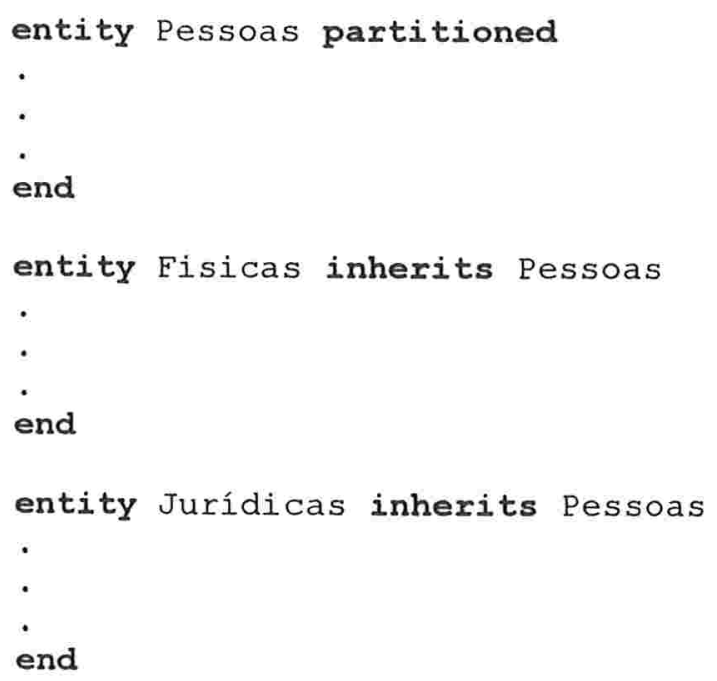

No esquema acima, todos os clientes são pessoas fisicas ou jurídicas. No cadastro de um banco, essa informação pode ser obrigatória. Não seria permitido o cadastro de um cliente que não se enquadre em uma das duas categorias. Segue um exemplo de generalização que não é total. 


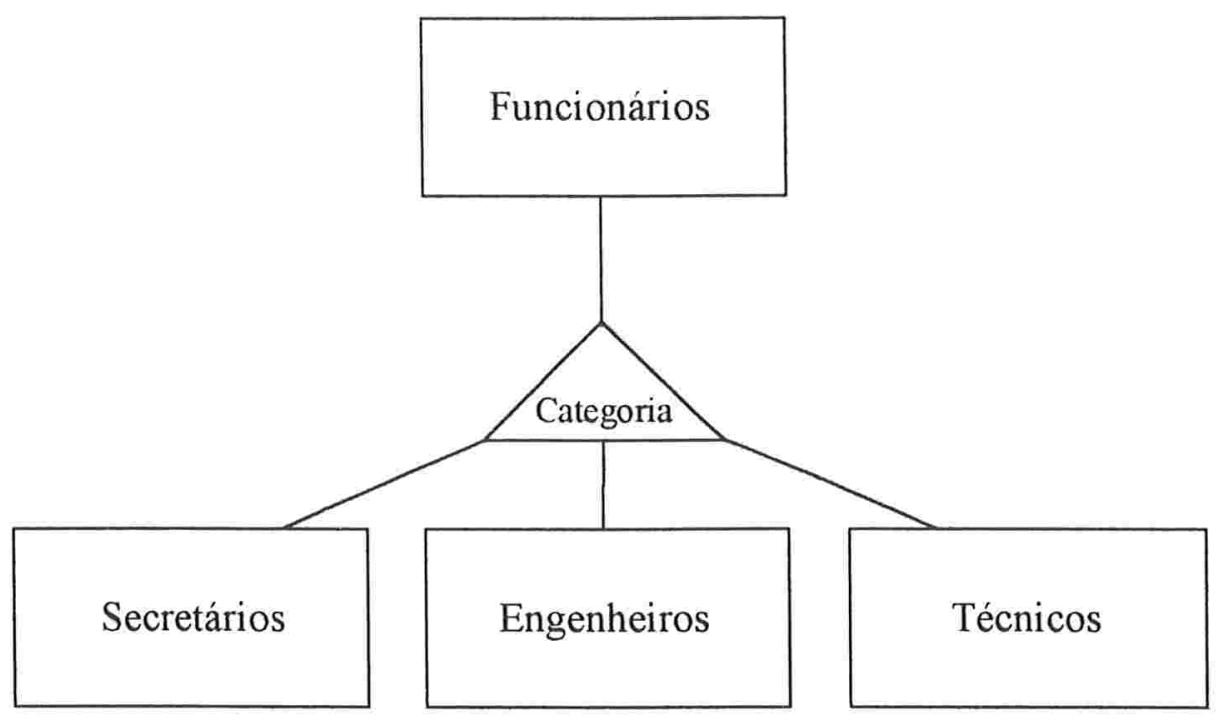

Figura 31: Generalização total

Nesse caso, os funcionários da empresa são secretários, engenheiros ou técnicos, podendo haver funcionários que não se enquadre em uma das subentidades. A seguir, A declaração do OER correspondente.

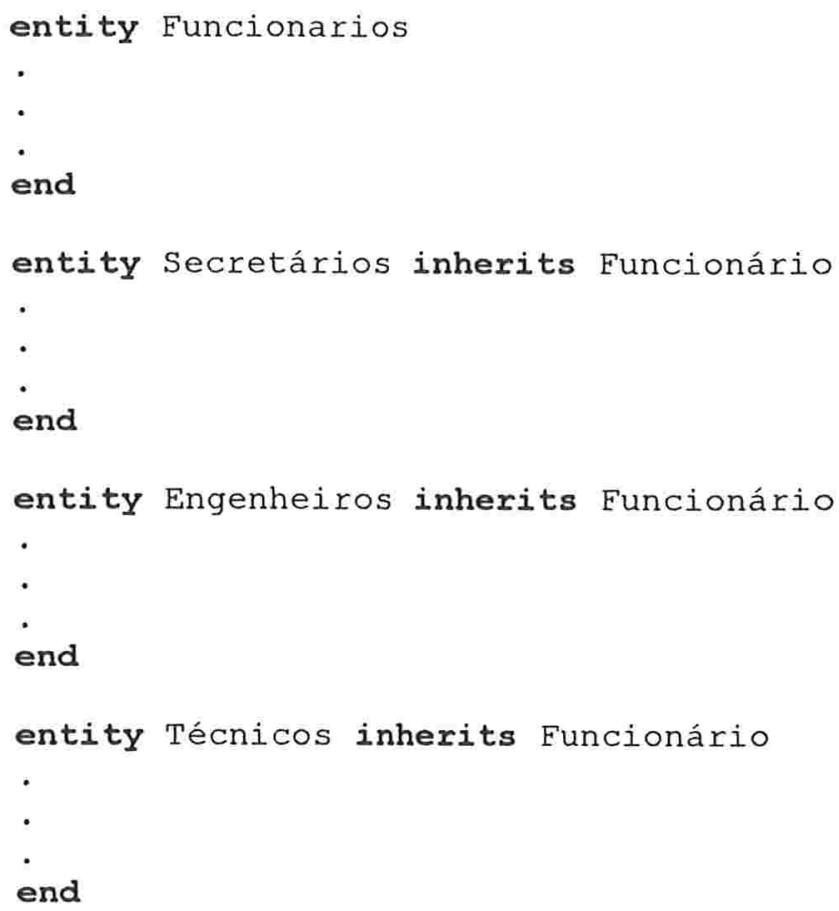

\subsubsection{Relacionamentos}

No Poet, assim como na maioria dos $\mathrm{BDOO}$, os relacionamentos não possuem uma declaração explícita. Na conversão, os relacionamentos são representados de forma implícita 
nas entidades ou em classes auxiliares, no caso de relacionamentos N para N. No exemplo a seguir, mostramos uma declaração de relacionamento entre duas entidades.

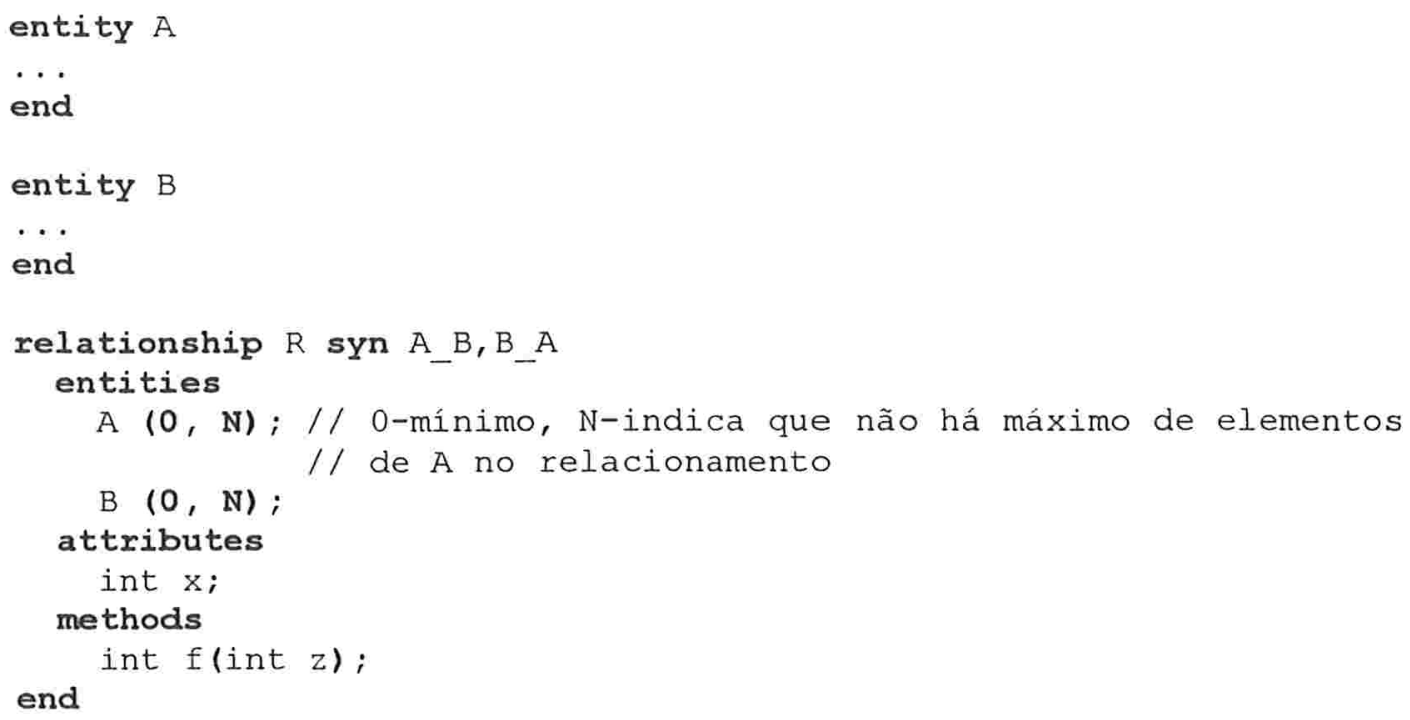

O fato do relacionamento ser $\mathrm{N}$ para $\mathrm{N}$ está indicado nos parênteses após os nomes das entidades que fazem parte do relacionamento. Dentro dos parênteses, o primeiro valor indica o número mínimo de entidades e o valor seguinte mostra o valor máximo, de acordo com a multiplicidade do relacionamento. No exemplo anterior, temos um relacionamento $\mathrm{N}$ para N, não total.

Como vimos no Capítulo 5, nos gerenciadores de BDOO declara-se um relacionamento como esse inserindo-se por exemplo a declaração dentro de $\mathrm{A}$ e de $\mathrm{B}$, de conjuntos de ponteiros para a outra entidade. Nossa representação é mais conceitual.

O gerador permite que se declare os sinônimos para o relacionamento como no exemplo acima, ou de forma independente da definição do relacionamento, através de uma declaração como no exemplo a seguir.

relationship R syn Novo_Sinonimo;

Nesse caso, um novo sinônimo é definido para o relacionamento R. Um novo sinônimo não acarreta nenhum aumento no modelo do Poet, apenas acrescenta um novo elemento no conjunto de sinônimos do relacionamento, armazenados em um dicionário de dados, utilizado pela linguagem de consulta do modelo.

As declarações geradas para o exemplo anterior seriam as seguintes: 


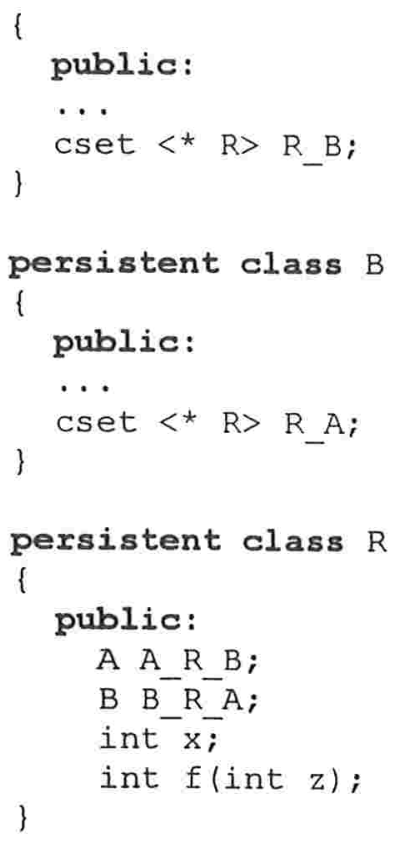

Para cada par $(\mathrm{a}, \mathrm{b}) \in \mathrm{A} \times \mathrm{B}$, que estiver no relacionamento $\mathrm{R}$, será criado um objeto da classe $\mathrm{R}$ (vamos denominá-lo objeto relacionamento). Portanto, o conjunto dos objetos da classe $\mathrm{R}$ corresponde ao conjunto de relacionamentos $\mathrm{R}$ entre $\mathrm{A}$ e $\mathrm{B}$. A verificação da multiplicidade do relacionamento deve ser feita nos métodos que tratam da inclusão de novos objetos, uma vez que não existe representação correspondente no modelo de dados do Poet.

Outra solução possível para a tradução não utilizaria uma classe auxiliar para representar o relacionamento $\mathrm{N}$ para $\mathrm{N}$. O esquema gerado seria como a seguir.

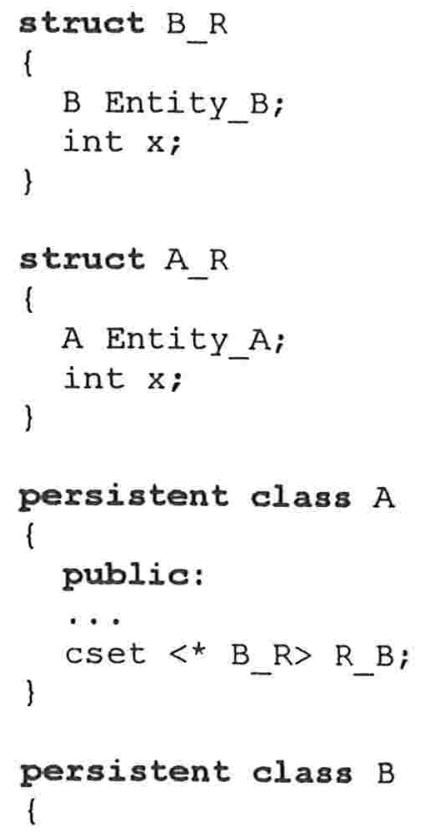




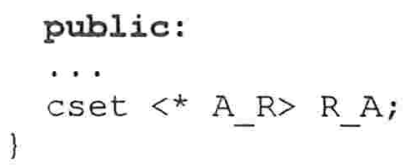

Nesse caso, é necessário criar uma estrutura auxiliar para armazenar o atributo do relacionamento. O relacionamento se faz através da referência cruzada entre os conjuntos declarados nas classes A e B. Além das variáveis de instância, a representação dos métodos do relacionamento ficam redundantes, uma vez que o método deve mudar os atributos em ambos os lados do relacionamento. Poder-se-ia representar o atributo apenas de um lado do relacionamento, porém o acesso aos dados do outro lado ficaria prejudicado, demandando várias varreduras nos conjuntos que representam os relacionamentos. Por esses motivos, preferimos a solução de se criar uma classe auxiliar para os relacionamentos $\mathrm{N}$ para $\mathrm{N}$., como é tradicionalmente feito nos Modelos Relacional e de Redes.

Os relacionamentos 1 para $\mathrm{N}$ e 1 para 1 são tratados da mesma forma que os relacionamentos $\mathrm{N}$ para $\mathrm{N}$, uma vez que são apenas casos particulares. No esquema de um BDOO, porém, podemos representar esses relacionamentos de uma forma alternativa. Por exemplo, no esquema a seguir:

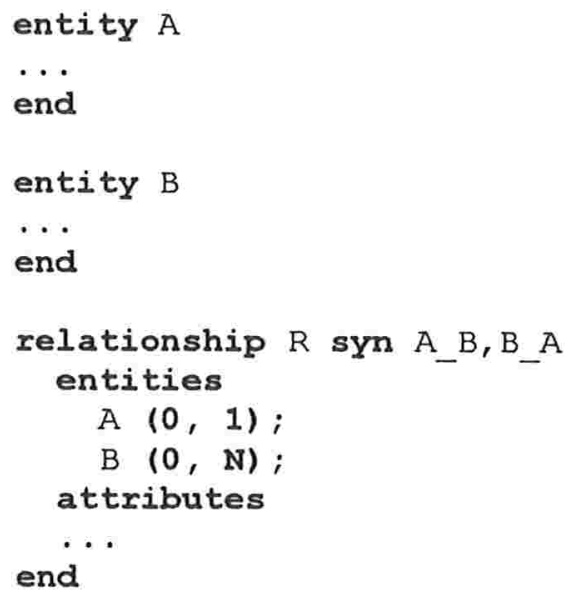

Poderia ser gerado o seguinte esquema:

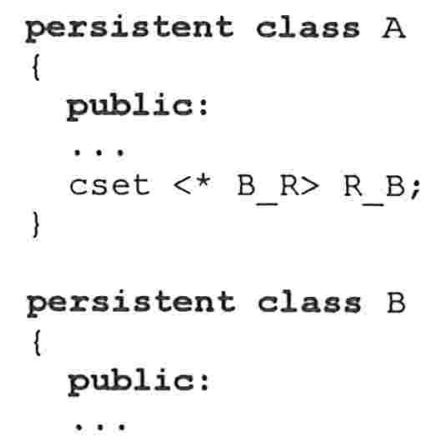


$\mathrm{Na}$ classe B, é colocado um ponteiro para a entidade de A que é relacionada com a entidade de B. No caso de um relacionamento 1 para 1, é colocado um ponteiro de cada lado, como no esquema a seguir.

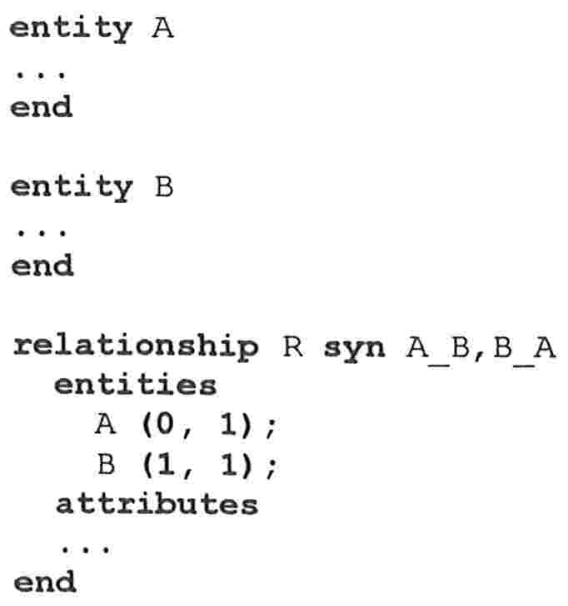

Que geraria o seguinte esquema do Poet.

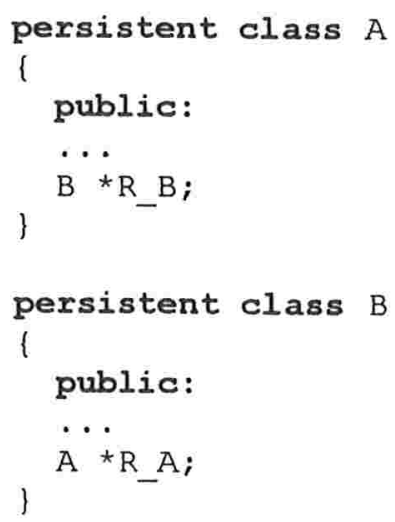

Para simplificar nosso sistema, decidiu-se por tratar todos os relacionamentos da mesma forma, sem diferenciar os casos particulares de multiplicidade 1 para 1 e 1 para $\mathrm{N}$. Como opção, o gerador poderia gerar os esquemas específicos, que são mais simples e compactos.

\subsubsection{Relacionamentos múltiplos, inclusivos, exclusivos e auto-relacionamentos}

Pode ser declarado um número qualquer de entidades na declaração de um relacionamento, sendo possivel a modelagem de relacionamentos múltiplos (Item 2.5.3). No exemplo, vamos declarar um relacionamento triplo, entre as entidades $\mathrm{A}, \mathrm{B}, \mathrm{e} \mathrm{C}$ 


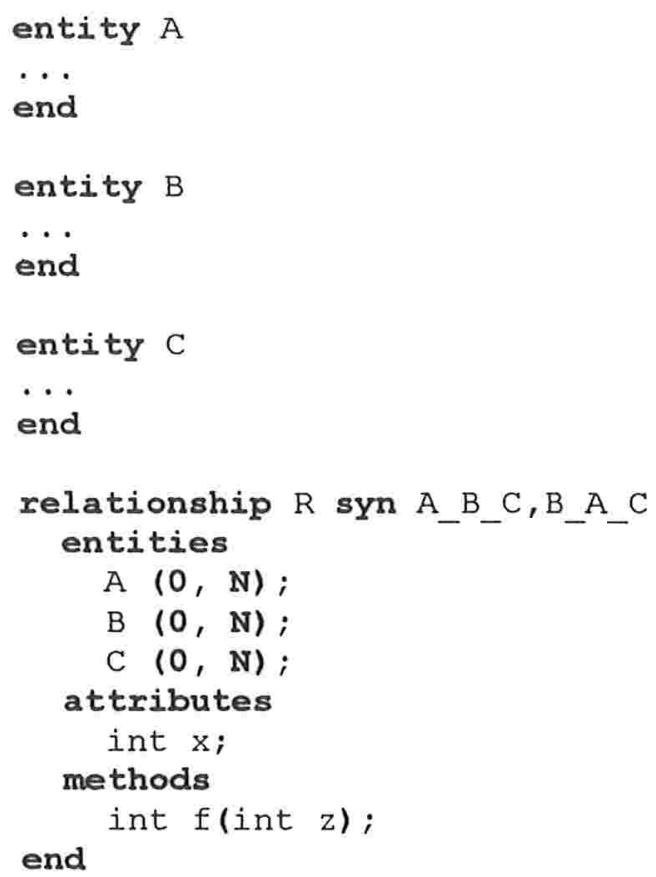

Podemos ainda definir sinônimos parciais para relacionamentos múltiplos. Para o esquema da Figura 12, podemos definir o esquema a seguir, definindo sinônimos parciais.

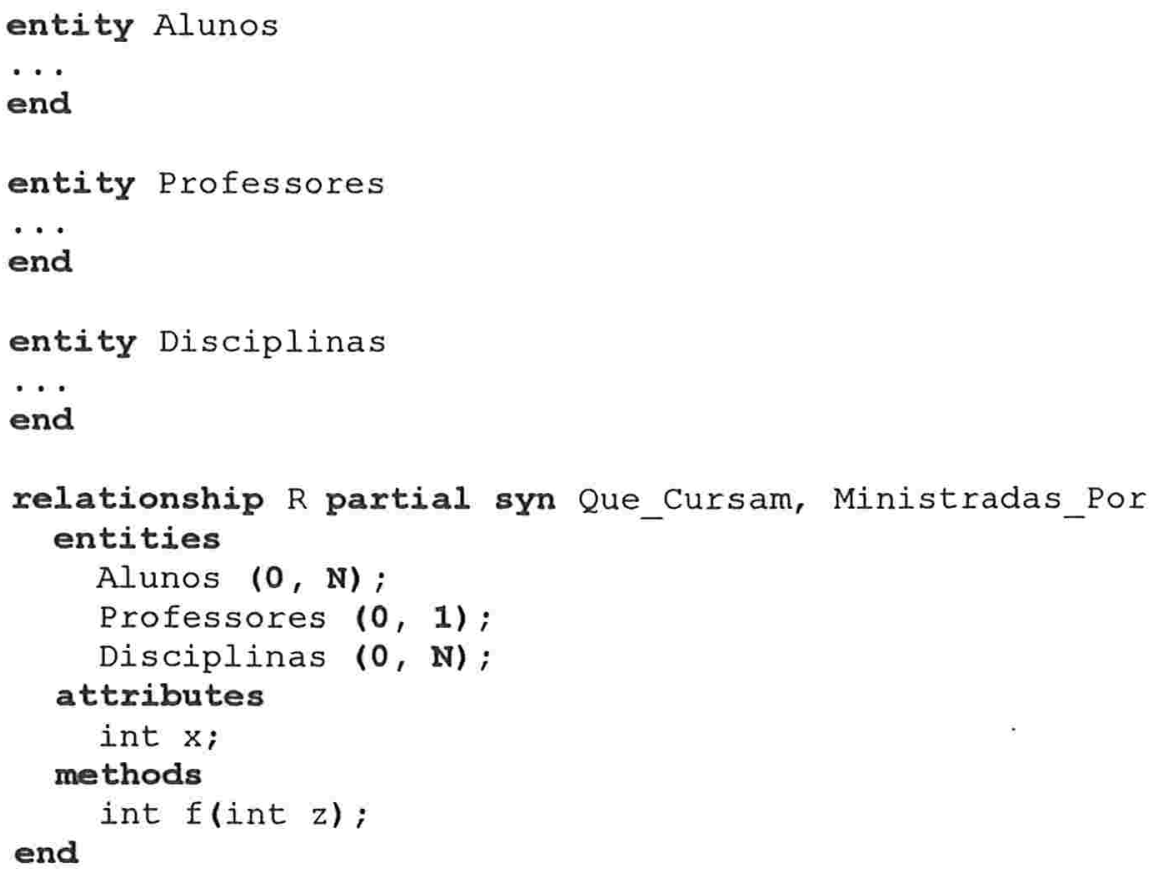

Pode ser definido um sinônimo parcial para cada par de entidades. Definiremos o uso dos sinônimos parciais mais tarde, na definição da linguagem de consulta.

O modelo gerado é análogo ao do relacionamento binário, também sendo gerada uma classe auxiliar, que contém um apontador para cada entidade, que representa o relacionamento triplo. 


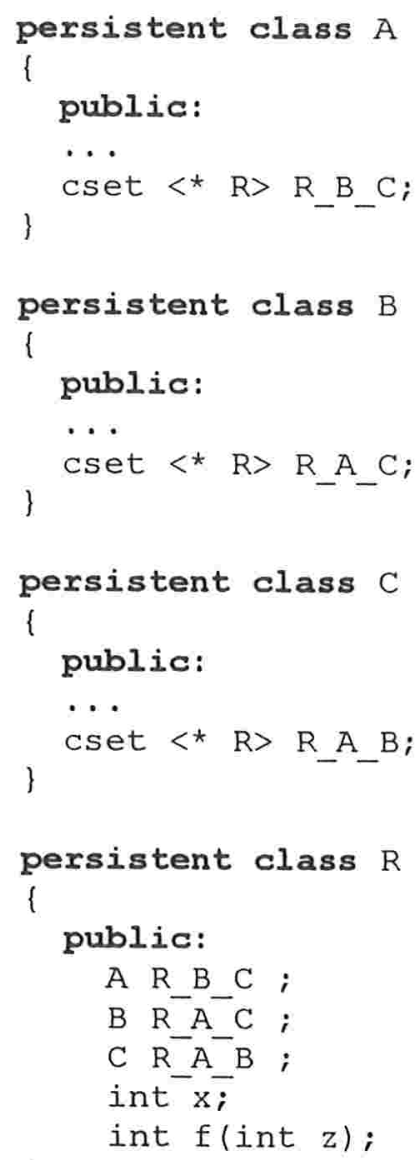

Nosso modelo incorpora as extensões do MER apresentadas anteriormente na apresentação do MER (Item 2.5.6): Os relacionamentos inclusivos e exclusivos. Em uma declaração de um relacionamento, podemos relacionar uma certa entidade corn várias entidades, indicando se os relacionamentos são inclusivos ou exclusivos.

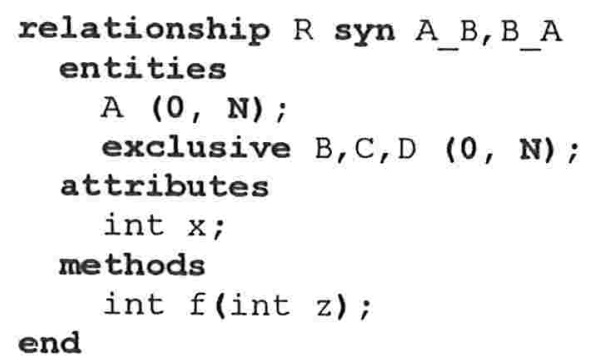

No exemplo, a entidade A se relaciona com as entidades B, C e D, através de um relacionamento exclusivo. $\mathrm{Na}$ geração do esquema Poet, esta declaração cria um objeto relacionamento com vários apontadores.

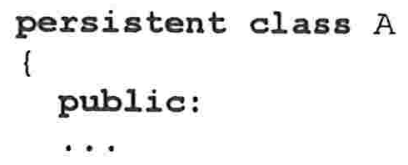




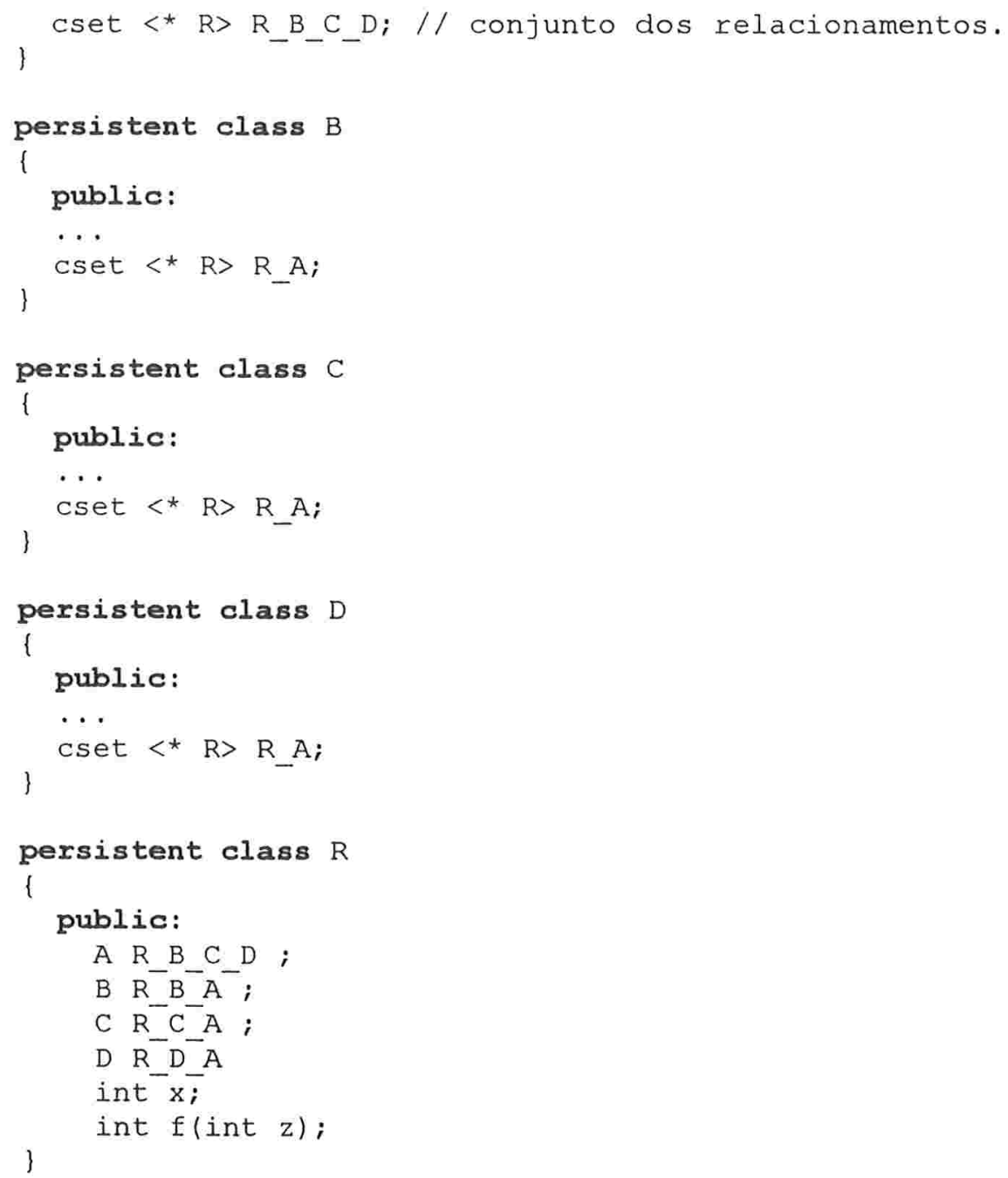

A verificação da exclusividade do relacionamento, fica mais uma vez a cargo dos métodos que manipulam os relacionamentos. Nesses métodos, quando houver inclusão ou modificação de um relacionamento, é feita uma verificação para garantir que um elemento de A relaciona-se somente com um elemento de $\mathrm{B}, \mathrm{C}$ e $\mathrm{D}$, isto é, os outros dois relacionamentos são vazios. Bastaria verificar todos os objetos relacionamento, procurando pelo elemento de A em questão. Se não for encontrado, o relacionamento pode ser criado. No exemplo a seguir, declaramos um relacionamento inclusivo.

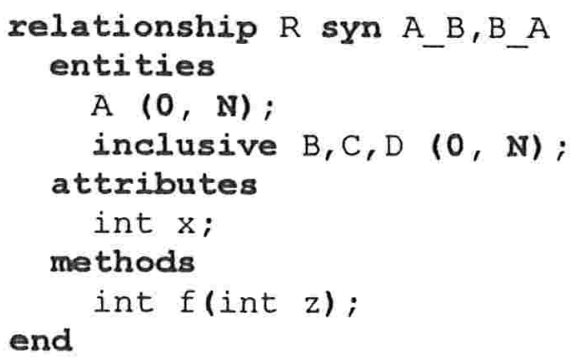


Nesse caso, o esquema para o Poet que é gerado é o mesmo que no relacionamento exclusivo, diferindo apenas nos métodos que manipulam os relacionamentos, que são mais flexiveis, permitindo que um mesmo elemento da entidade $A$ se relacione com elementos das entidades B, C, ou D.

Da mesma forma que nos relacionamentos convencionais, poder-se-ia representar esses relacionamentos sem o auxílio de uma classe específica, mas além dos problemas já citados, a verificação das restrições de integridade ficam ainda mais complicadas, uma vez que é necessário percorrer todos os elementos dos conjuntos de ligações para sua verificação em cada inclusão.

No caso de auto-relacionamentos, informamos no esquema que se trata de um auto-relacionamento, e definimos sinônimos para cada sentido do relacionamento. Isso fará com que seja criadam duas variáveis de ligação, com nomes diferentes, cada uma associada a um sinônimo em um sentido.

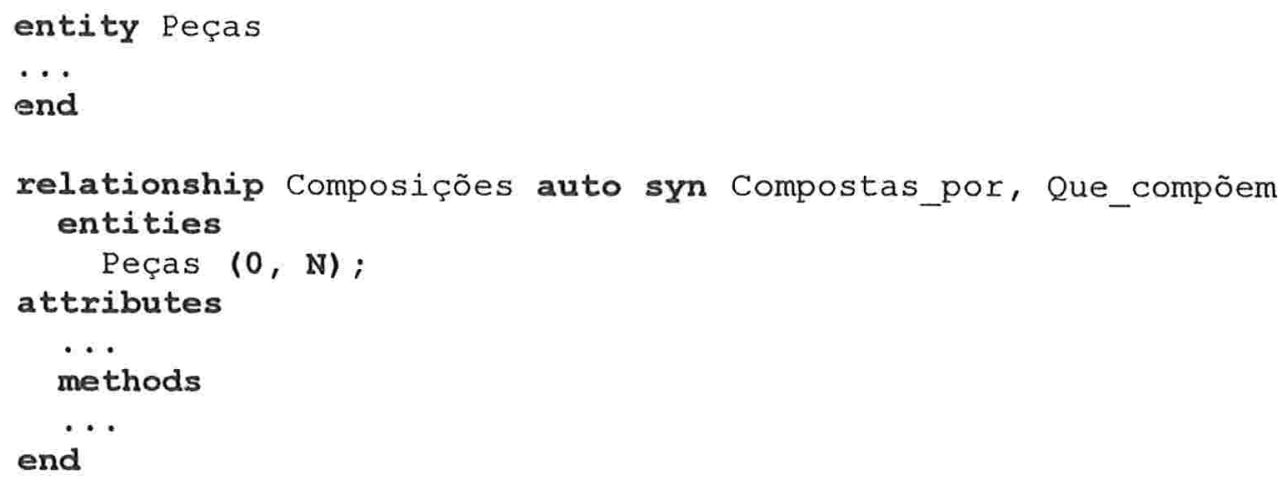

\subsubsection{Agregações}

As agregações em nosso modelo podem ser declaradas englobando um ou mais relacionamentos. No gerador, foi implementado somente o caso em que a agregação é declarada a partir de um único relacionamento. Nesse caso, o objeto relacionamento passa a ser tratado de forma semelhante a uma entidade. Pode-se declarar atributos e métodos também para as agregações.

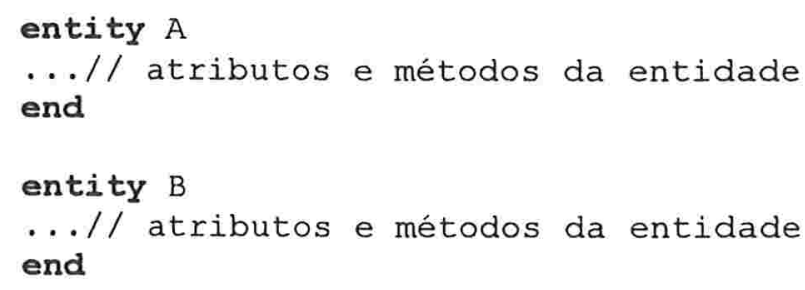




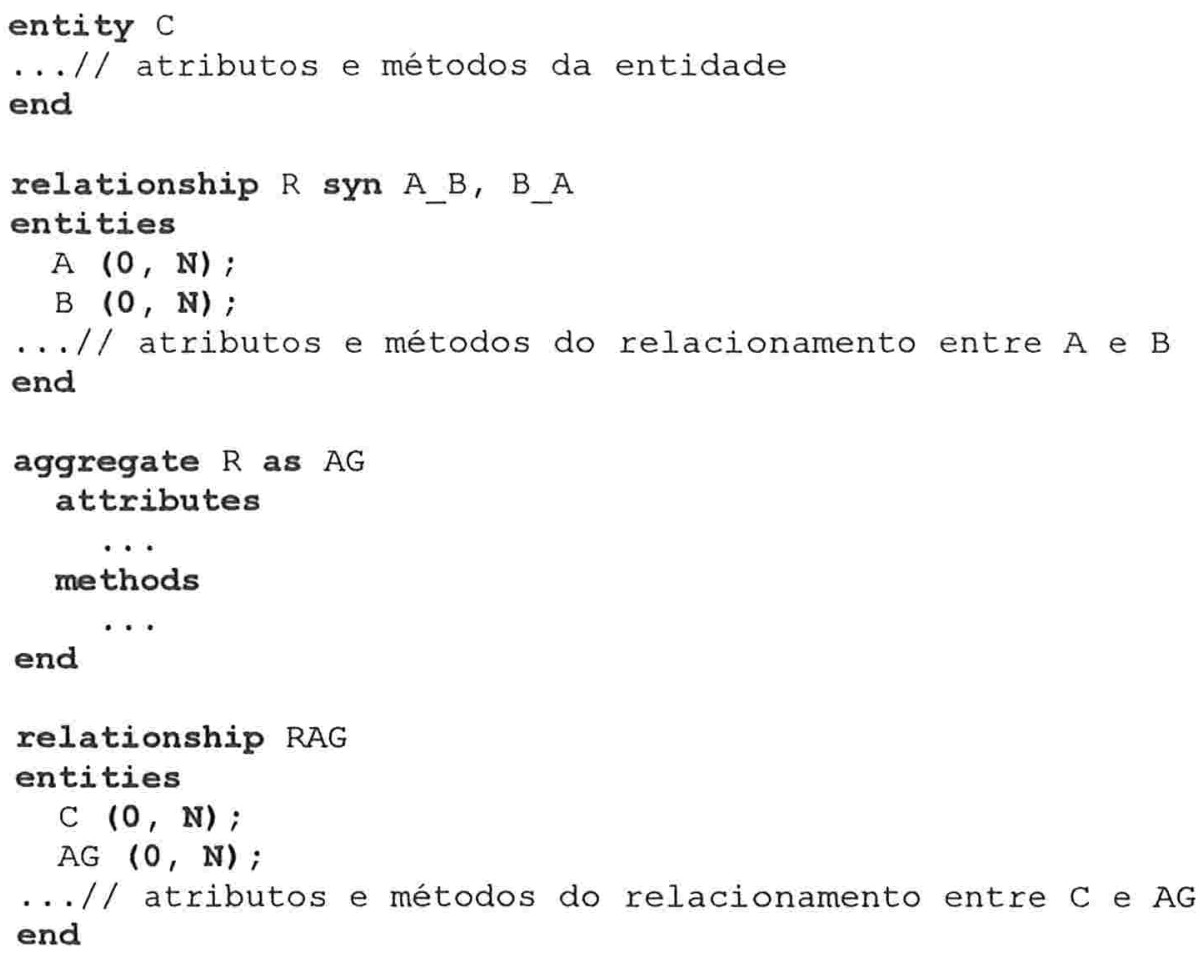

O esquema gerado neste caso faz com que a classe relacionamento funcione como uma classe entidade. Os métodos e atributos da classe agregação são incluídos na classe relacionamento que está sendo agregada.

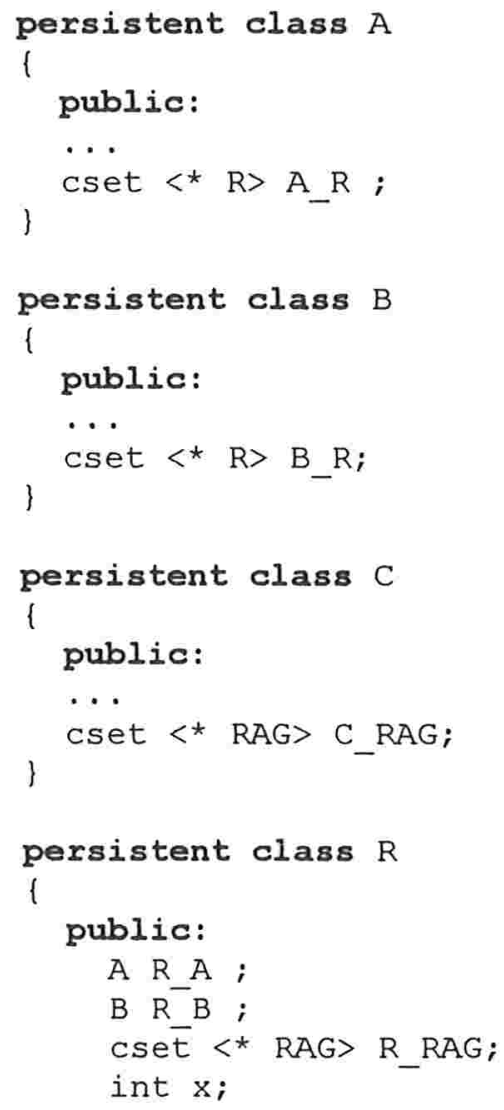




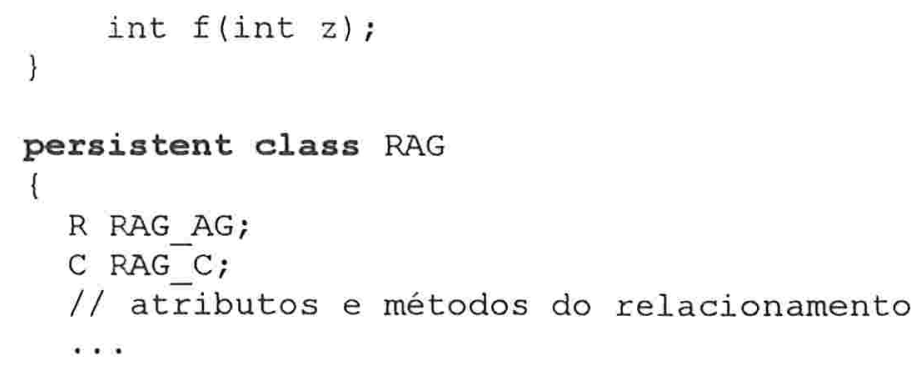

Uma representação altemativa para a agregação com apenas um relacionamento seria idêntica a um relacionamento triplo entre as entidades $A, B$, e $C$. A diferença estaria nos métodos de manipulação dos dados, que manteriam as restrições de integridade adequadas a cada caso. No relacionamento com a agregação, elementos desta podem existir sem se relacionarem com elementos de $\mathrm{C}$, o que não é possível no relacionamento triplo. Para nosso exemplo, o código altemativo seria como o mostrado a seguir.

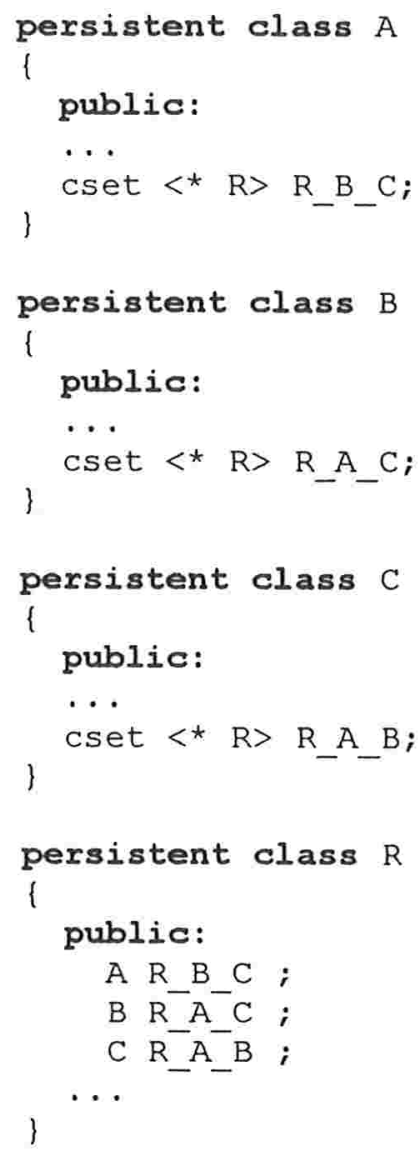

A primeira geração foi a escolhida por oferecer maior independência de dados, e por separar os relacionamentos que compõem a agregação. $\mathrm{Na}$ segunda proposta os dois relacionamentos seriam representados em uma mesma classe, o que poderia dificultar a construção de consultas. 


\subsubsection{Subentidades}

Uma Subentidade é um subconjunto de um conjunto de entidades., definidos por uma restrição sobre os elementos do conjunto. Nosso modelo, além de permitir herança, permite também a definição destes subconjuntos que correspondem a uma "user view" de uma única relação. Para definir a Subentidade, é necessário fomecer a condição que todos os elementos devem obedecer.

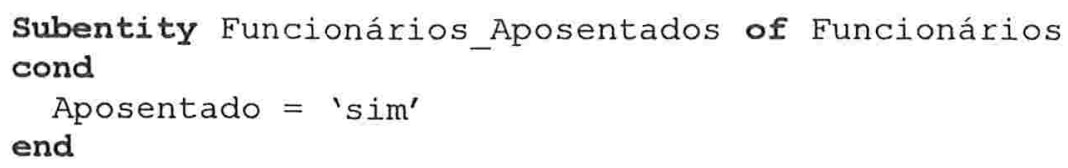

Os atributos utilizados na condição podem ser atributos da entidade original, ou de qualquer entidade relacionada ou relacionamento em que a entidade participe. Os subrelacionamentos são definidos utilizando-se conjuntos. É gerada uma instrução OQL que recupera os elementos do conjunto de todas as entidades que satisfaçam a condição da declaração. No exemplo, o conteúdo do conjunto é virtualmente o resultado da consulta a seguir

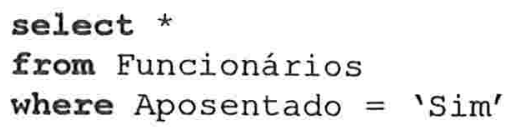

Como nas definições de "user-views" em SQL, a parte da cláusula where dessa consulta é concatenada às consultas a Funcionários_Aposentados.

A subentidade pode ser utilizada normalmente como uma entidade na manipulação de dados em nosso modelo.

\subsubsection{Subrelacionamentos}

Subrelacionamentos também estão presentes em nosso modelo. Analogamente às subentidades, são subconjuntos de um conjunto de relacionamentos. A condição fornecida é dependente dos atributos dos relacionamentos, podendo então representar pares de conjuntos relacionados sob certas condições que se deseja. Por exemplo, podemos definir um subrelacionamento do relacionamento entre alunos e disciplinas, definindo como condição os pares aluno-disciplina em que os alunos formam reprovados.

Subrelationship Reprovados of Matriculas 
cond

average (notas) $<5$ \&\& disciplina = "MAC-110"

end

O Subrelacionamento pode então ser utilizado para relacionar as entidades, como um sinônimo do relacionamento que contém a condição especificada.

select Alunos

from Alunos Reprovados

Quando processada, a condição do subrelacionamento é acrescentada às presentes na cláusula where.

\subsubsection{Subagregações}

De forma análoga, em nosso modelo estão presentes as subagregą̧ões. Também são definidos como subconjuntos de um conjunto agregação, que possuem determinada propriedade desejada. As subagregações podem ser utilizadas normalmente como se fossem entidades ou agregações.

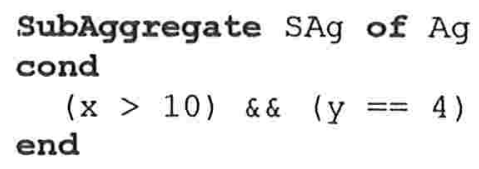

\subsection{Implementação do gerador de esquemas OER}

O gerador de esquemas foi implementado na linguagem $\mathrm{C}++$. A técnica de análise sintática foi o método recursivo descendente, com recuperação automática de erros simplificada. A sintaxe completa da linguagem encontra-se no apêndice. Durante a análise sintática, são preenchidas estruturas de dados que armazenam as informações necessárias para a criação do esquema na linguagem aceita pelo Poet. A geração não se dá em um só passo, pois a estrutura de cada classe entidade só é definida no final da geração, uma vez que cada relacionamento declarado que envolve a classe entidade adiciona variáveis de instância à sua estrutura, porém o arquivo contendo a definição do esquema é lido apenas uma vez. As informações sobre as classes são armazenadas em um objeto, que depois será inserido em um vetor, que será utilizado para a geração do esquema

A análise é feita por um objeto da classe Anasint. Ele possui como variáveis de instância várias estruturas, descritas no esquema a seguir: 
- TabClasses: armazena informações sobre todas as classes.

- ElemTabClasses: Elemento da classe que está sendo construída.

Quando ocorre erro de sintaxe, a análise do elemento atual (entidade, atributo, relacionamento ou agregação) é interrompida, recomeçando a partir do próximo elemento.

Após a análise sintática do texto de entrada, é gerado o esquema para o pré-processador PTXX do Poet em um arquivo de texto. O PTXX, por sua vez gera código em C++ para ser utilizado em conjunto com as aplicações que utilizam os objetos declarados.

Para modificar o gerador para outro sistema, bastaria modificar a rotina que trata $\mathrm{da}$ geração de esquema a partir das estruturas obtidas após a análise sintática, para esta gerar um esquema com a sintaxe do sistema desejado. Em nosso caso, modificações para o ObjectStore, $\mathrm{O}_{2}$ e outros que usam a linguagem $\mathrm{C}++$ podem ser feitas com facilidade, bastando ajustes de sintaxe no modelo gerado.

Foi criado um ambiente de desenvolvimento simples, com editor de texto para a edição dos esquemas ER, sendo possível a geração do esquema Poet através de um comando de menu ou por um botão. Uma extensão interessante ao ambiente seria o de edição de esquemas ER gráficos, que podem ser traduzidos para a linguagem proposta sem grande dificuldade. Isso tomaria a implementação do Banco de Dados mais fácil e direta.

\subsection{Geração de métodos internos}

Seguindo a geração do esquema, é necessária a geração de alguns métodos intemos pré-definidos para manipulação dos objetos do banco de dados, principalmente para a inserção, remoção e modificação de objetos. Esses métodos se encarregam da manutenção das restrições de integridade do sistema.

Por exemplo, para inserir um novo objeto entidade no banco de dados devem ser executadas as seguintes ações:

- Verificar se existe um atributo chave. Caso exista, consultar todos os objetos da classe para verificar se o valor do atributo já existe. 
- Verificar também se a classe participa de um relacionamento. Se pertencer, deve consultar os valores máximo e mínimo da multiplicidade, contar o número de objetos já inseridos, verificando a restrição. Se não for respeitada, deve dar opção para que o objeto seja incluído, excluído e modificado mesmo desrespeitando a regra.

- Se a entidade for partitioned, não permite a criação do objeto.

$\mathrm{Na}$ alteração, seria necessário somente verificar a modificação de um eventual atributo chave e outras restrições de integridade. No caso de exclusão, somente a verificação de totalidade de relacionamento precisa ser feita.

Quando um relacionamento é criado, algumas ações precisam ser tomadas:

- Verificar também o número de entidades já existentes para verificar as restrições de máximo e mínimo dos relacionamentos.

- Colocar a referência inversa na variável da entidade.

No caso das agregações, o tratamento é semelhante ao das entidades, tratando o relacionamento associado como uma entidade.

\subsection{Linguagem de consulta/manipulação de dados}

Vamos fazer uma proposta para uma linguagem de consulta para nosso modelo, baseada na linguagem na SQL.. Vamos apresentar alguns comandos para criação modificação, e exclusão de dados. A seguir, mostramos um exemplo de consulta simples:

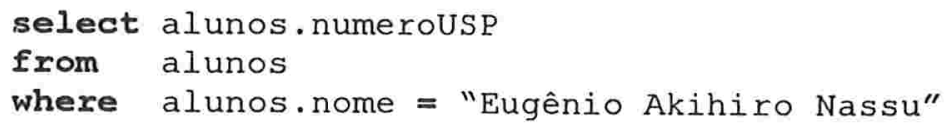

Como na linguagem SQL, uma consulta é composta por três partes básicas:

- a cláusula select, que define as entidades que servem de base para a consulta (no exemplo, a entidade alunos) e os atributos que devem ser obtidos dessas entidades (no exemplo, o atributo nome).

- a cláusula from, que indica quais conjuntos de entidades e relacionamentos participam da consulta. A cláusula from pode ser omitida, se redundante. No caso 
anterior, como todos os atributos consultados são da entidade alunos, o from poderia ser omitido.

- a cláusula where, que especifica um predicado que deve ser utilizado para selecionar os elementos do conjunto definido na cláusula select a partir dos quais deve ser construído o resultado da consulta. A exemplo da cláusula from, também é opcional. Se ausente, todos os elementos do conjunto são selecionados.

Pode-se especificar várias entidades na cláusula select. Se existir um relacionamento entre as entidades somente são selecionados $n$-uplas de entidades que estejam no relacionamento. Se não houver relacionamento entre as entidades, é feito um produto cartesiano.

Para fazer consultas através de entidades relacionadas utiliza-se o nome do relacionamento ou um de seus sinônimos para relacionar entidades na cláusula from. A seguir, mostramos um exemplo de consulta de entidades relacionadas:

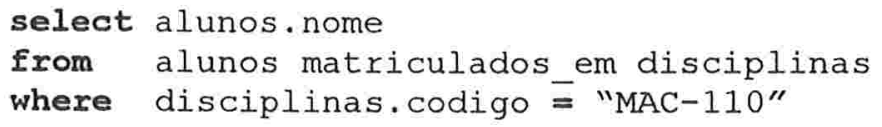

Esta consulta lista os alunos matriculados na disciplina de código MAC-110, em nosso esquema de exemplo. Essa extensão à SQL permite que os relacionamentos sejam consultados sem a necessidade de incluir a expressão de relacionamento sob a forma de uma equação de função na cláusula where, como na linguagem SQL. Esse tipo de expressão se baseia nas consultas do ZIM [ZIM 91], que no entanto não usa a sintaxe da SQL.

Quando um atributo multivalorado fizer parte da cláusula select, o valor obtido para esse atributo é um conjunto. Por exemplo, na consulta a seguir, supondo como exemplo os dados sobre livros no Item 2.4 , que mostramos novamente. 


\begin{tabular}{|l|l|l|l|}
\hline$\underline{\text { ISBN }}$ & Título & Assuntos & NomeAutores \\
\hline 1234 & A Internet & $\begin{array}{l}\text { Computadores } \\
\text { Redes }\end{array}$ & $\begin{array}{l}\text { José } \\
\text { João } \\
\text { Maria } \\
\end{array}$ \\
& & Pedro \\
\hline 4321 & Casa e Fogão & $\begin{array}{l}\text { Cozinha } \\
\text { Decoração } \\
\text { Arquitetura }\end{array}$ & Ney \\
\hline 1111 & A arte no século XIX & Artes & $\begin{array}{l}\text { Marcelo } \\
\text { Geraldo }\end{array}$ \\
\hline 2222 & Futebol & Esporte & Joaquim \\
\hline
\end{tabular}

Na consulta a seguir, é selecionado um conjunto de assuntos.

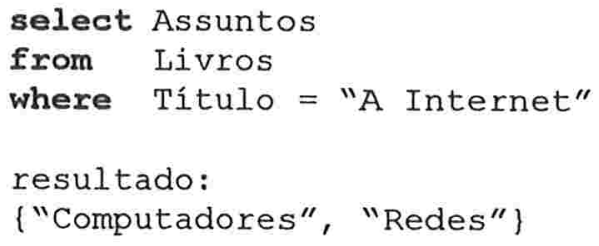

Nesta outra consulta, desta vez são selecionados vários conjuntos.

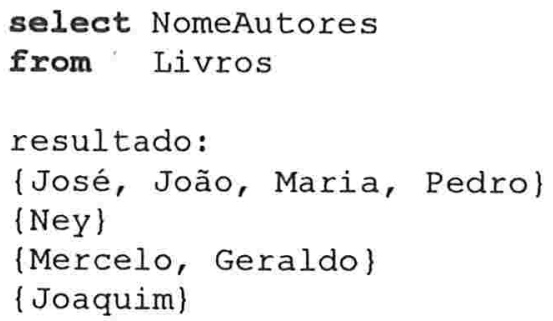

Esse resultado é uma conseqüência lógica da seguinte interpretação desse comando select: deseja-se o valor do atributo NomeAutores para cada tupla de livros. Isso é compatível com a visão monovalorada, considerando-se o resultado de um select como um conjunto de mono-valores (ou tuplas de mono-valores)

Pode ser desejado que ao invés de vários conjuntos, os valores sejam retomados em apenas um conjunto. Isso poderia ser feito através do comando union. No exemplo a 
seguir, a consulta anterior é modificada para retomar apenas um conjunto, contendo todos os autores.

select union NomeAutores

from Livros

resultado:

\{José, João, Maria, Pedro, Ney, Mercelo, Geraldo, Joaquim\}

Para uso na cláusula where, podem ser usados além da igualdade, o operador contains e o operador in, que verificam se um conjunto é subconjunto de outro. Em um esquema de livros, poderíamos consultar livros que contenham dois ou mais assuntos em sua lista de assuntos:

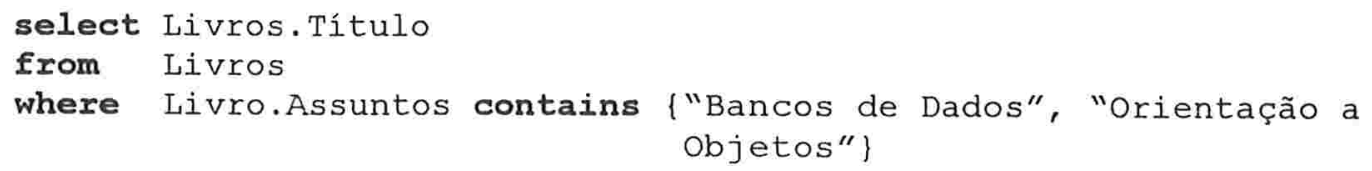

Ou utilizando o operador in temos uma consulta equivalente:

select Livros.Título

from Livros

where ("Bancos de Dados", "Orientação a Objetos") in Livro.Assuntos

Note-se que essa é uma sintaxe válida de SQL, mas que tradicionalmente não se aplica a atributos multivalorados.

Quando o atributo multivalorado é composto, o valor de retorno é um conjunto de tuplas, que pode ser tratado como uma relação. Vamos mostrar um esquema mais complexo, correspondente a uma faculdade, onde as informações sobre alunos são armazenadas em um atributo multivalorado.

Departamentos (NomeDep, Alunos (NomeAluno, Disciplinas(CodDisc, Notas*)*)*1

Vamos usar os dados na relação seguinte como exemplo. 
Departamentos

\begin{tabular}{|c|c|}
\hline Computação & $\begin{array}{l}\{\text { José, }\{(\text { MAC110, }\{5,4,5\}),(\operatorname{MAC} 122,\{6,6,6\})\}), \\
\text { (João, }\{(\operatorname{MAC} 110,\{10,9,10\}),(\operatorname{MAC} 123,\{10,5,0\})\}), \\
\text { (Maria, }\{(\operatorname{MAC} 444,\{10,10,9\},(\operatorname{MAC} 555,\{5,4,6\}),(\operatorname{MAC} 111,\{3,4,5\})\}), \\
\text { (Pedro, }\{(\operatorname{MAC} 122),\{1,1,1\})\})\}\end{array}$ \\
\hline Matemática & $\ldots$ \\
\hline Estatística & $\ldots$ \\
\hline
\end{tabular}

A consulta a seguir retoma um conjunto de tuplas, correspondentes aos alunos do departamento "Computação".

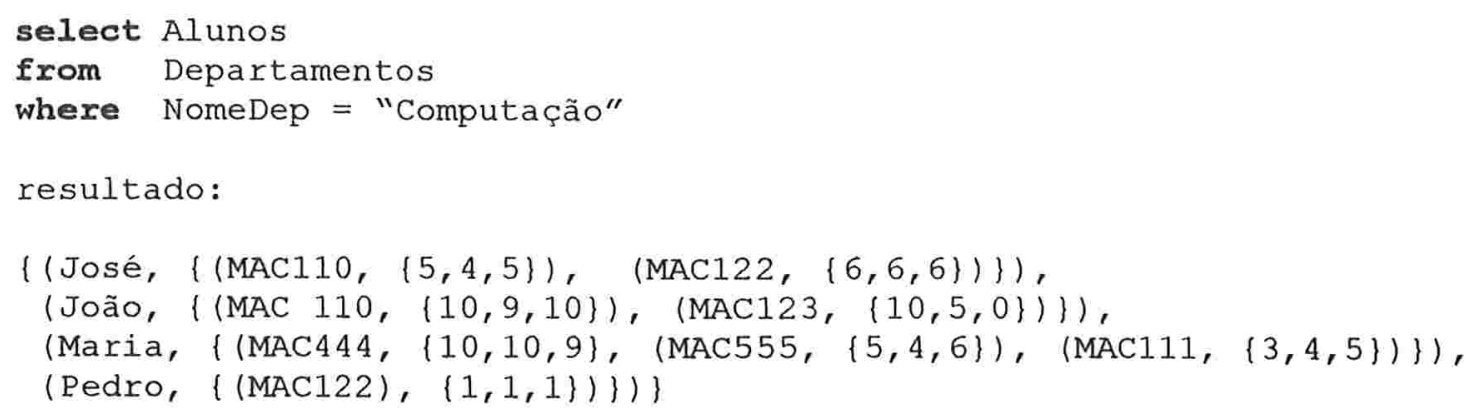

Poder-se-ia aplicar alguma restrição no atributo multivalorado, o que pode ser feito com uma consulta encadeada com uma cláusula where adequada. Na relação acima, vamos selecionar os nomes de alunos do departamento computação matriculados em "MAC-110" e suas notas nessa disciplina.

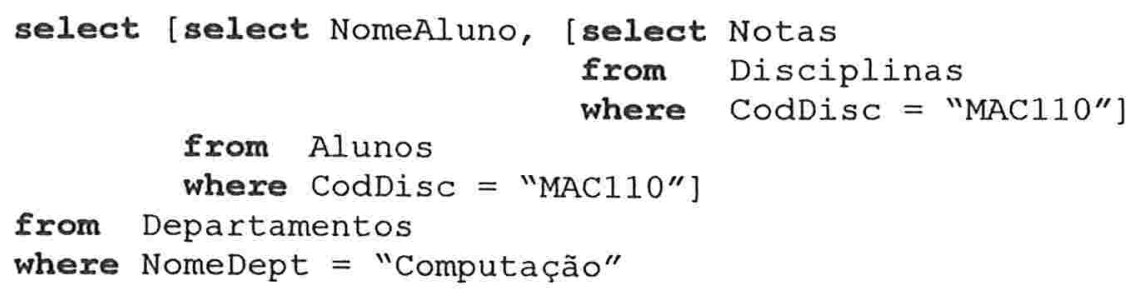

$\mathrm{Na}$ consulta mais externa, são selecionados todas as linhas da relação Alunos, cujo nome do departamento é "Computação". O primeiro atributo desejado nesse nível mais externo é NomeAluno; no entanto, deseja-se qualificá-lo apenas para aqueles que tenham matrícula em MAC110. O segundo atributo é Notas com sua qualificação novamente de MAC110. Se esta restição não fosse feita, todas as notas do aluno seriam selecionadas, não somente as da disciplina MAC110. No nível seguinte, são selecionados alunos que são matriculados em "MAC110". O comando tem como resposta o conjunto a seguir. 
$\{($ José, $\{5,4,5\})$, (João, $\{10,9,10\})\}$

Vamos definir um novo comportamento para a cláusula where: quando usamos os operadores in e contains, para um atributo multivalorado composto, como no caso de disciplinas, o símbolo especial '*' (asterisco) faz com que os valores deste atributo sejam sempre aceitos. No exemplo, todos os alunos que estiverem matriculados em "MAC110", independentemente das notas são selecionados.

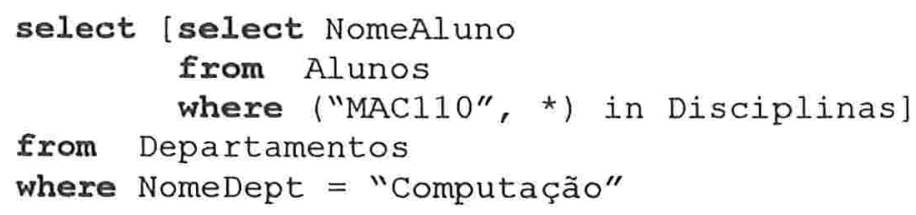

As cláusulas where da consulta podem ser colocadas no nível mais extemo. Isso se justifica pois em uma possível implementação física de nosso modelo, em uma busca seqüencial varre-se as linhas mais externas, e para cada uma dessas varre-se cada um de seus atributos, e assim por diante. No caso da existência de um índice, os ponteiros da B-Árvore de um índice apontam para as linhas da relação mais externa, sendo então feita a varredura pelos atributos da linha apontada. O novo formato da consulta é:

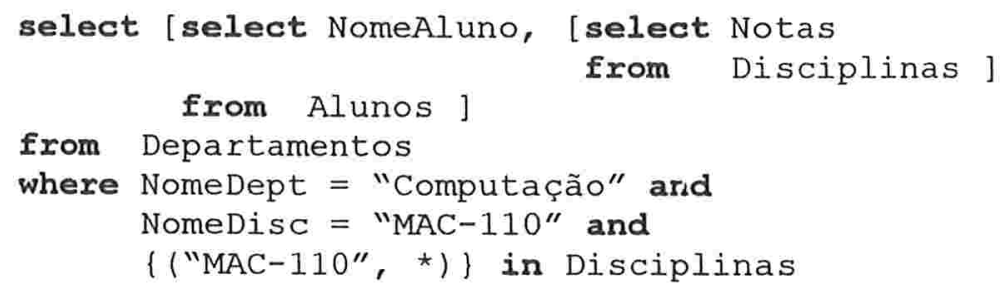

Nesse tipo de consulta a interpretação deve ser a seguinte: cada atributo que ocorre na cláusula where deve ser entendido como sendo aplicado ao select das tuplas (em qualquer nível) que contêm esse atributo.

Vamos definir as funções de agregação para atributos multivalorados. No esquema da faculdade, vamos usar a função de agregação average para obter diversas médias. As funções de agregação desse tipo (average, sum, max, min), podem apenas ser aplicadas a atributos multivalorados simples e numéricos, ou senão para um atributo monovalorado (exatamente como na SQL). Por exemplo, para obter a média de um aluno em uma disciplina, faríamos a consulta a seguir

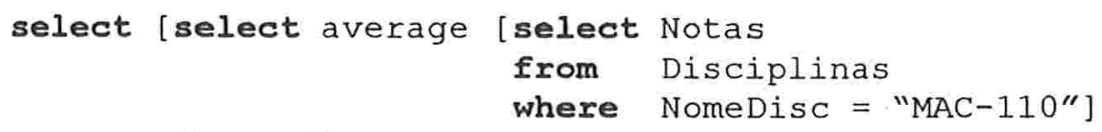




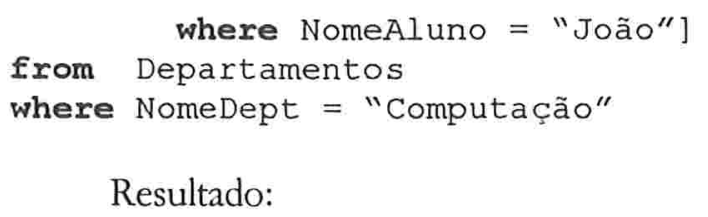

9.666

$\mathrm{Na}$ consulta a seguir, pedimos os nomes e as médias de todos os alunos em uma determinada disciplina, no caso, "MAC110", para o departamento de computação:

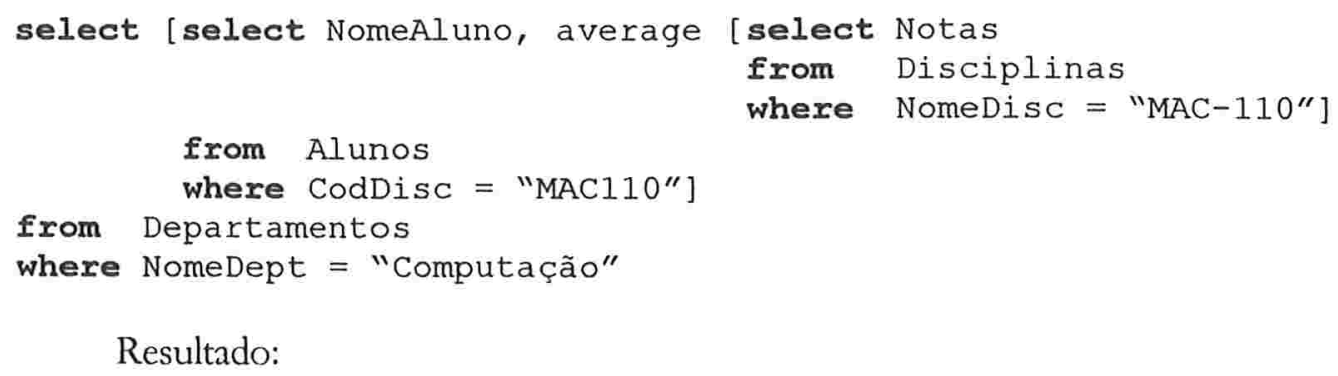

Resultado:

José 4.666

João 9.666

Se o valor do atributo forem vários conjuntos, pode-se usar o operador union em conjunto com o de agregação para o cálculo. Por exemplo, se quisermos calcular a média das notas de todos os alunos em todas as disciplinas, podemos fazer a consulta:

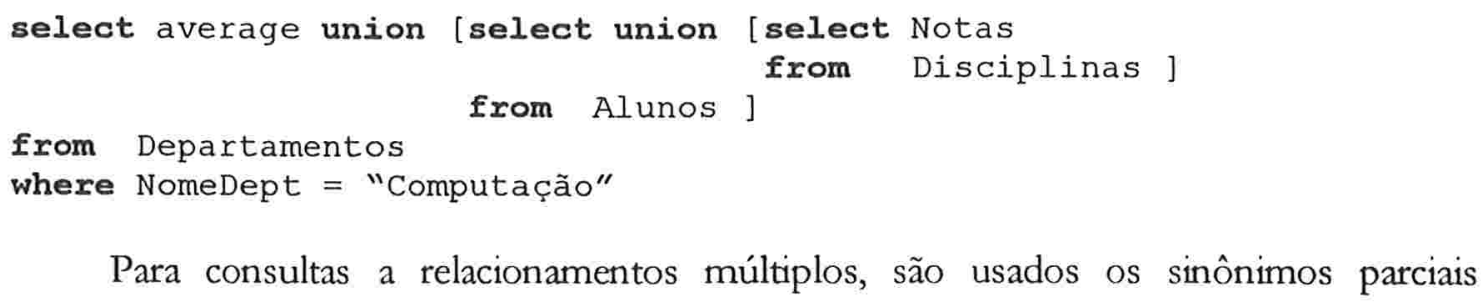

Para consultas a relacionamentos múltiplos, são usados os sinônimos parciais definidos no Item 8.3.4. Um exemplo de consulta usando os sinônimos parciais é mostrado a seguir.

select Nome aluno

from Alunos Que_cursam Disciplinas Ministradas_por Professores

Entre cada par de entidades deve haver um sinônimo parcial do relacionamento múltiplo.

Consultas a auto-relacionamentos podem ser usados os sinônimos definidos também no Item 8.3.4.

select Nome_peça

from Peças Que compõem P Peças 
where P.Nome_peça = "Motor"

Essa consulta todas as peças que compõem o motor.

Para efetuar processamento entidade a entidade, definimos o comando find (inspirado do SGBD ZIM) com funcionamento muito similar ao select, com uma diferença: a resposta, ao invés de ser devolvida como um conjunto de tuplas, é devolvida tupla a tupla. Isso possibilita a inserção de comandos da linguagem de programação de nosso sistema para cada tupla da reposta da consulta. Se houverem atributos multivalorados nas tuplas, estas podem ser processadas elemento a elemento através de outro comando find encadeado. Para exemplificar o comando find, vamos calcular a média em MAC110 dos alunos do departamento de computação sem utilizar a função de agregação:

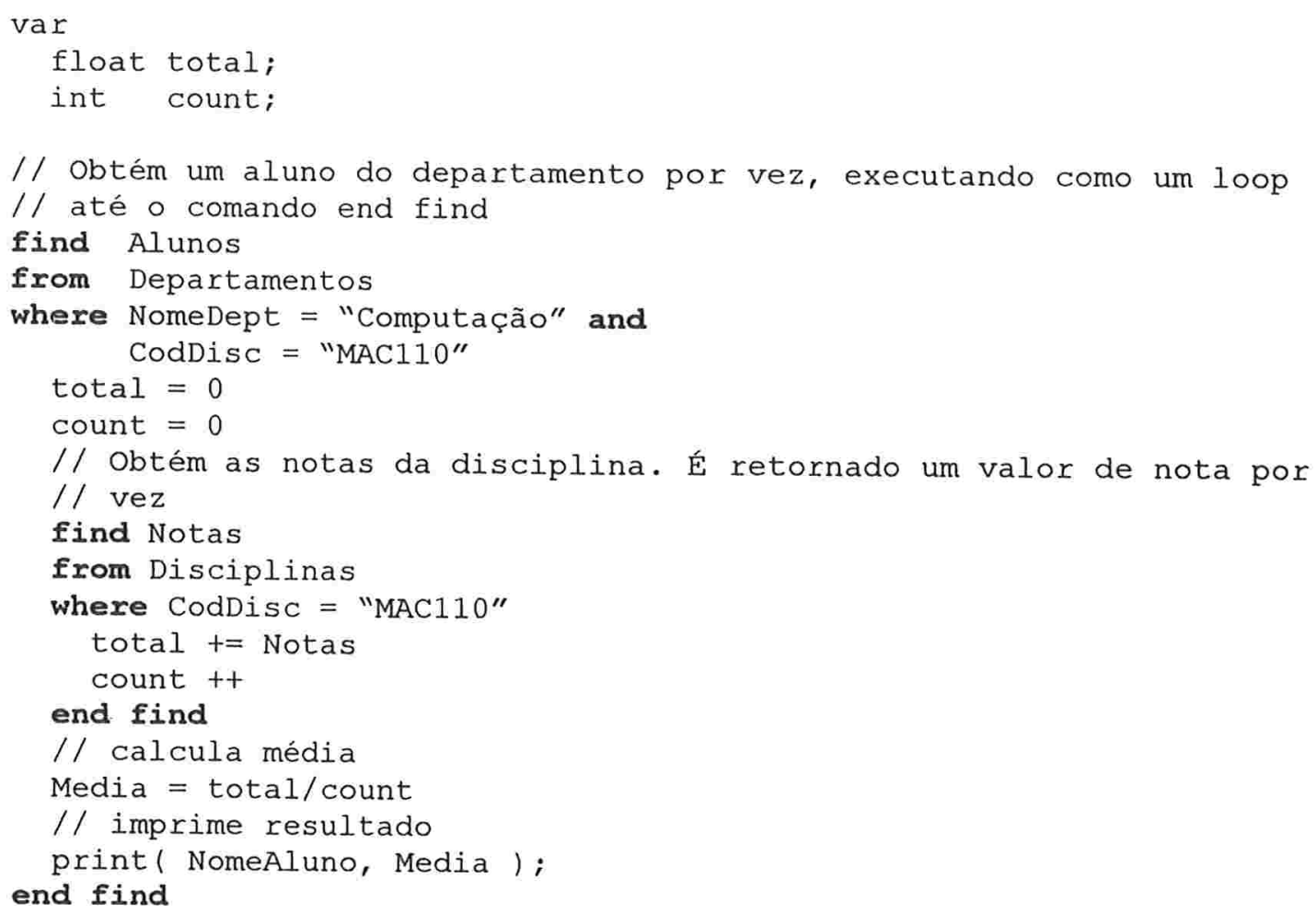

Para poder abandonar a malha de iteração definida por um comando find, antes de esgotar todas as tuplas buscadas por esse comando, propomos o comando exitfind.

Para se fazer alterações nos atributos de um objeto localizado por um find, pode-se simplesmente, dentro de uma malha, atribuir novos valores para os atributos, seguindo-se a execução de um comando update que produz a gravação dos atributos alterados. Já para criar um novo objeto dentro de uma malha de um find, usa-se simplesmente o comando 
insert em lugar do updade. Para excluir o objeto atual, basta executar o comando delete dentro da malha.

Quando a cláusula form do comando find usa relacionamentos, todos os atributos das entidades relacionadas e dos relacionamentos ficam disponíveis dentro da malha.

Vamos definir outros comandos para manipulação dos dados. Para inserir uma nova entidade no banco de dados, usa-se o comando insert.

insert entity Aluno

( Nome="Bill Gates", NumUSP="123456", RG="1123211" )

Esse comando cria um objeto entidade aluno, atribuindo os valores iniciais às variáveis conforme indicado.

Para criar relacionamentos, utiliza-se o comando insert relationship, que é um pouco mais complexo:

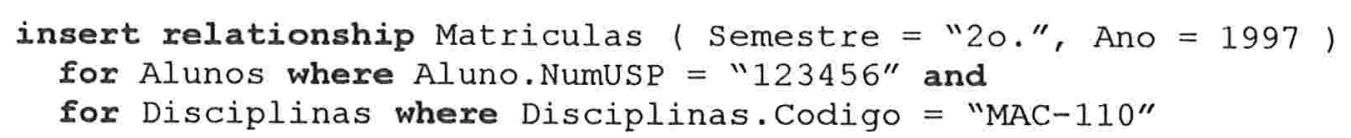

No exemplo, estamos criando um relacionamento entre as entidades selecionadas pelas cláusulas for, além de dar os valores dos atributos do relacionamento.

Para modificar entidades e relacionamentos, utiliza-se o comando update entity e update relationship.

update entity Aluno (Rua = "R São Joao")
where Aluno. Nome = "Roberto Carlos"

Esse comando altera a rua de todos os alunos de nome "Roberto Carlos". Para alterar uma única entidade, seria interessante que a cláusula where incluísse um atributo chave. Uma extensão necessária para atributos multivalorados é a de adição ou exclusão de um valor ou substituição de todos os valores anteriores. No comando a seguir, adicionam-se dois novos números de telefone a uma pessoa com o RG especificado.

update entity Pessoa (Telefone = add ("2223355", "5554467"\})

where Pessoa.RG = "123456"

Para excluir valores do atributo multivalorado, pode-se usar o comando sub

update entity Pessoa (Telefone = sub ("2223355", "5554467"\})

where Pessoa.RG = "123456" 
Nesse caso, os números de telefone na lista são excluídos, se eles pertencerem ao atributo. Para estes comandos, quando o atributo multivalorado é composto, pode ser usado o asterisco $\left(^{*}\right)$ para indicar que o valor desta componente do atributo não tem importância.

Para modificar toda a lista de telefones da pessoa, basta usar uma atribuição normal.

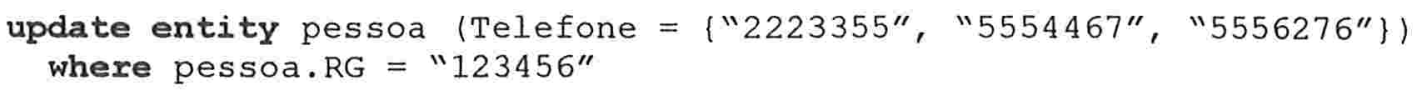

Para modificar os atributos de um relacionamento, a sintaxe será parecida com a inclusão.

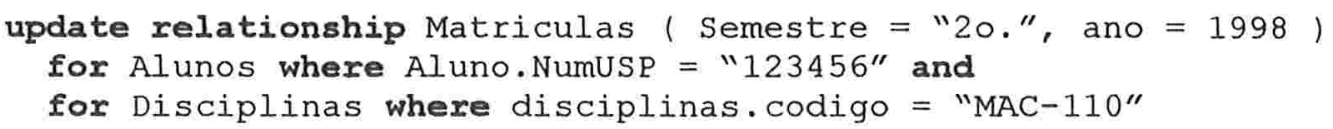

Nesse comando, é modificado o ano de matrícula nos relacionamentos entre as entidades selecionadas. Para modificar atributos multivalorados, podem ser usados os comandos add e sub, analogamente às entidades. Não há modificação das entidades que participam de um relacionamento, uma vez que isso indicaria o fim de um relacionamento entre as entidades, o que pode ser feito com a exclusão e inclusão de um novo relacionamento.

Para excluir elementos do banco de dados, usamos o comando delete de sintaxe semelhante à SQL:

delete entity alunos

where alunos.nome = "João de Nada"

Esse comando exclui todos os alunos com o atributo com o valor especificado pela cláusula where. Da mesma forma que no comando select, pode-se fazer exclusões a partir de relacionamentos do esquema ER, como a seguir:

delete entity alunos matriculados em disciplinas

where disciplinas. codigo = "MAC- $1 \overline{1} 0$ "

Se a entidade em questão for relacionada com outra entidade, o relacionamento automaticamente também é excluído, se isso for permitido pelas restrições de integridade. No exemplo, se o aluno estiver relacionado com alguma disciplina pelo relacionamento Matrículas, o objeto relacionamento correspondente é excluído, a não ser que o número 
mínimo de alunos não seja mantido. Se isso ocorrer, deve ser dada uma mensagem de erro, e opcionalmente pode-se confirmar a exclusão.

Para excluir um relacionamento explicitamente, vamos introduzir o comando delete relationship, de sintaxe semelhante ao insert relationship.

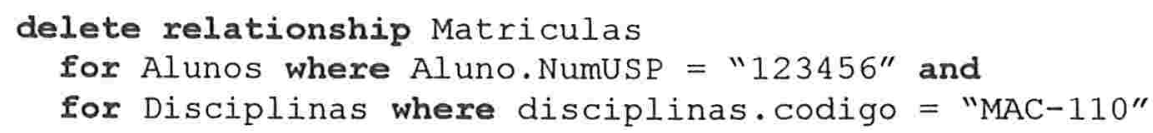

Este comando exclui os relacionamentos criados no comando insert relationship mostrado anteriormente.

Todos os comandos apresentados, além de servirem como linguagem de consulta ad hoc, seriam nativos de uma linguagem de $4^{a}$ geração, para criação de aplicativos utilizando nosso modelo de dados.

\subsection{Exemplos de execução}

A seguir mostramos alguns exemplos de saída de nosso gerador de esquemas. Primeiro vamos mostrar o esquema da faculdade em nosso modelo, e a saída produzida a partir das declarações:

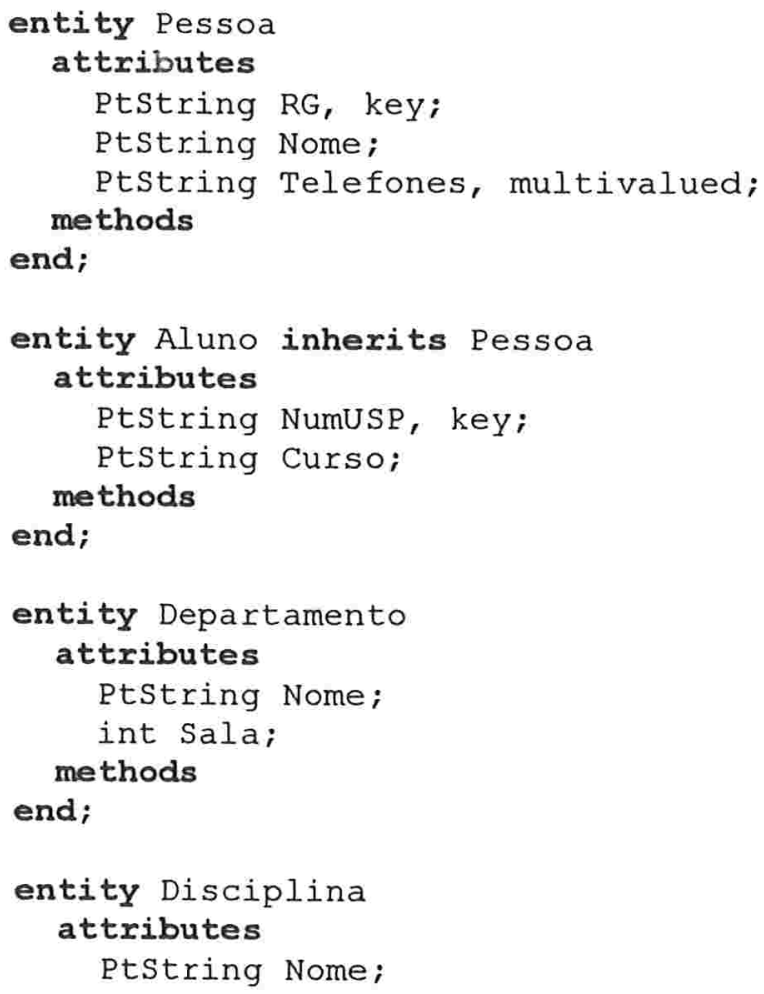




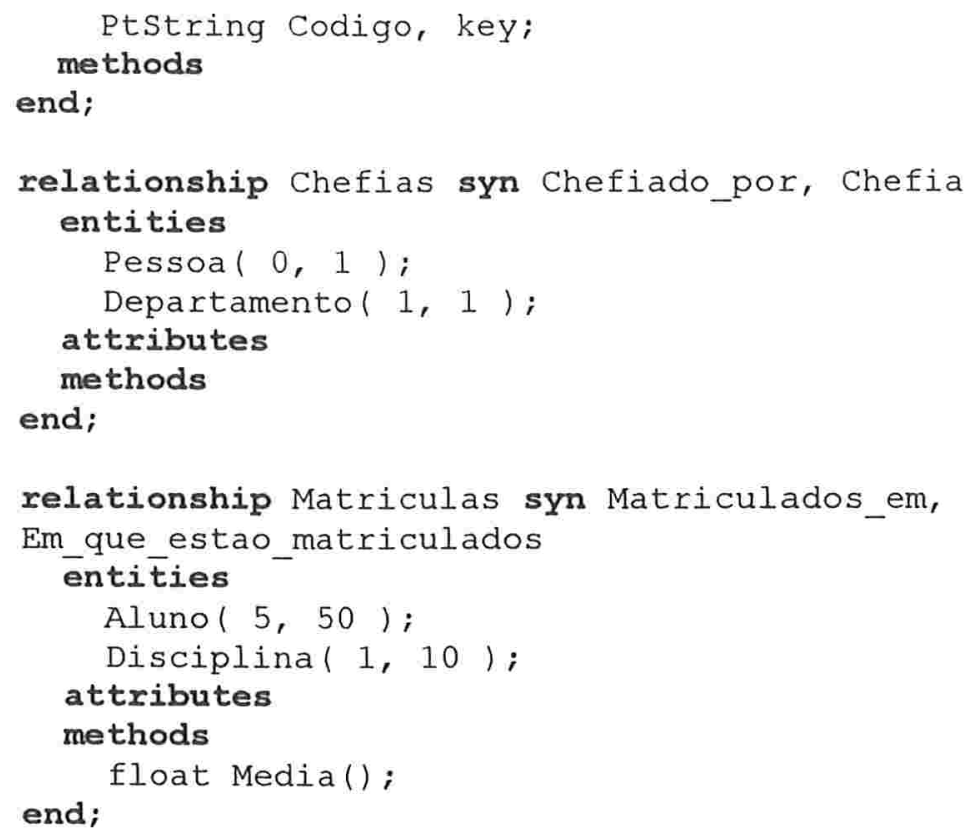

Estas declarações geram a seguinte saída, que é aceita pelo pré-processador PTXX, do Poet (o texto abaixo foi colado a partir do texto produzido pelo próprio gerador):

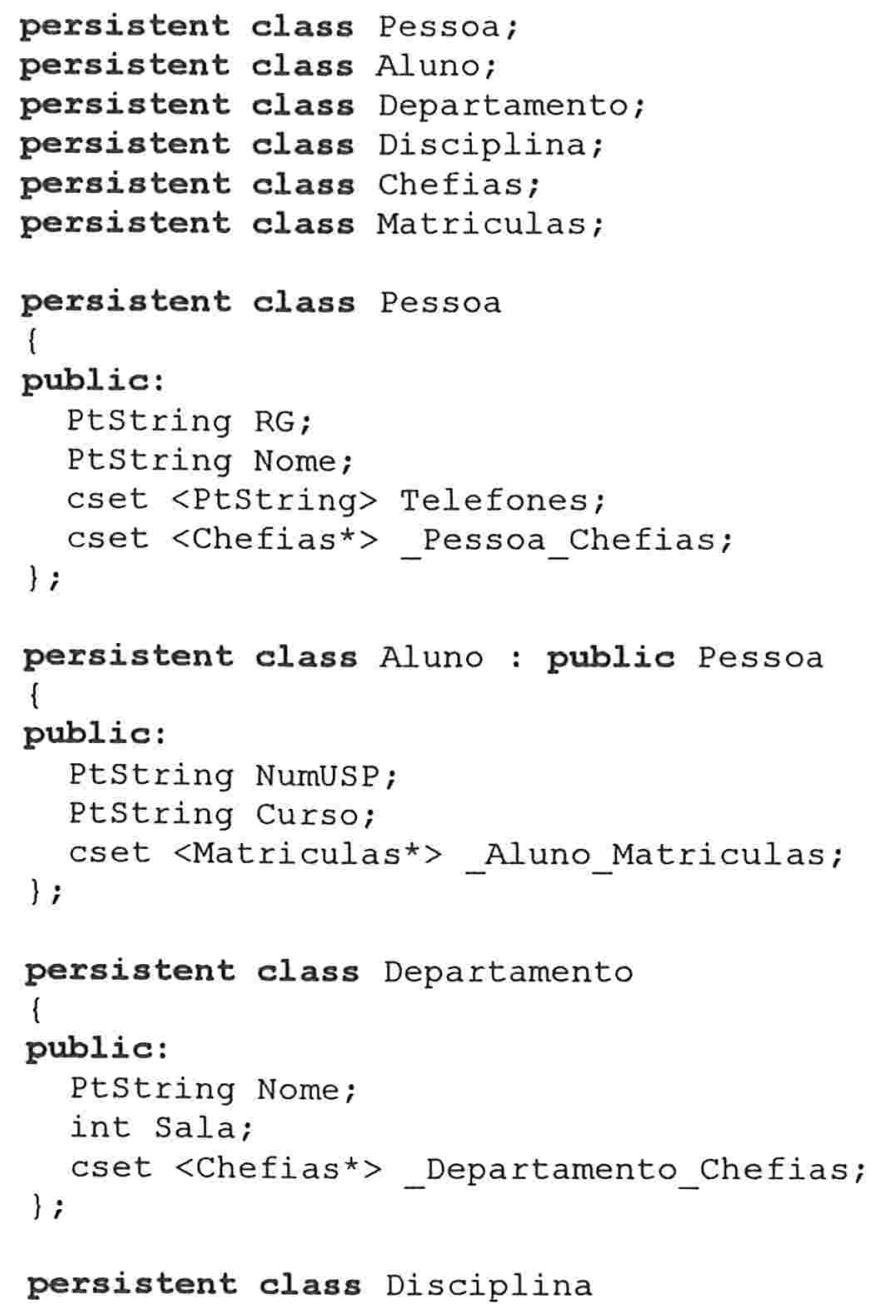




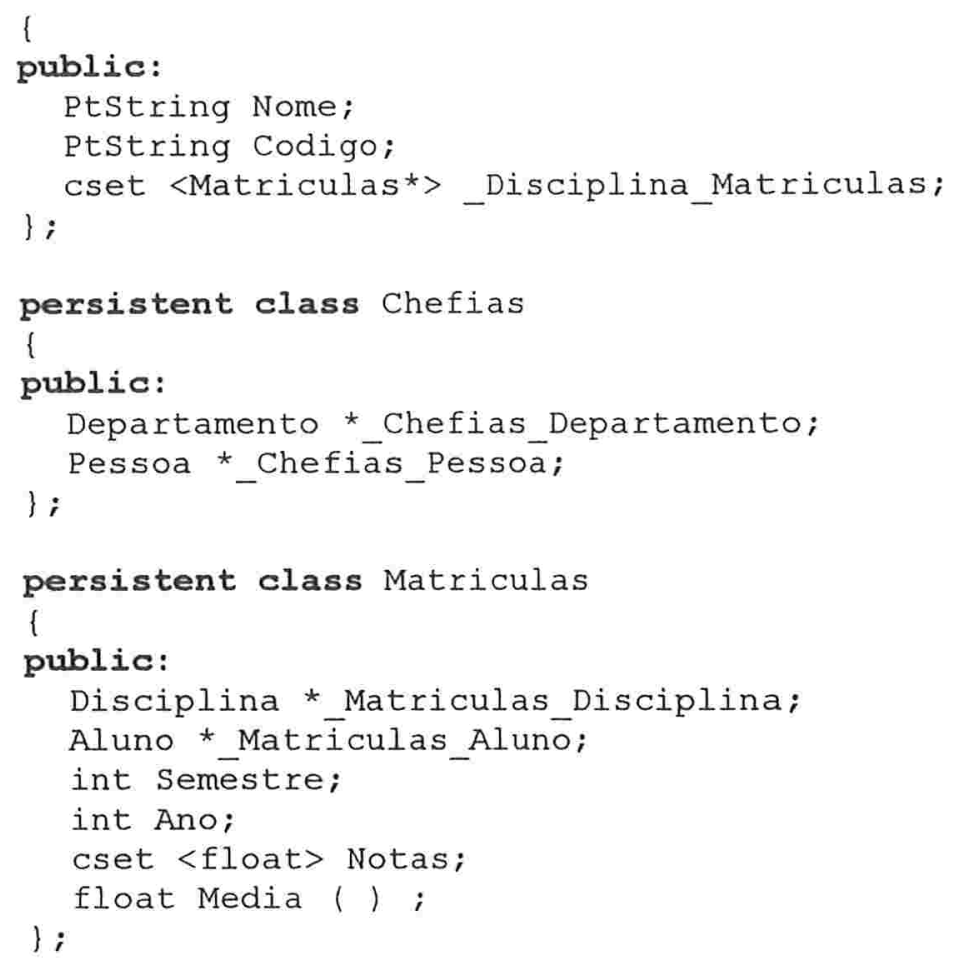

O nome de todas as classes são definidas logo no início, para possibilitar a referência de ponteiros entre as classes. A seguir, um exemplo genérico com uma agregação:

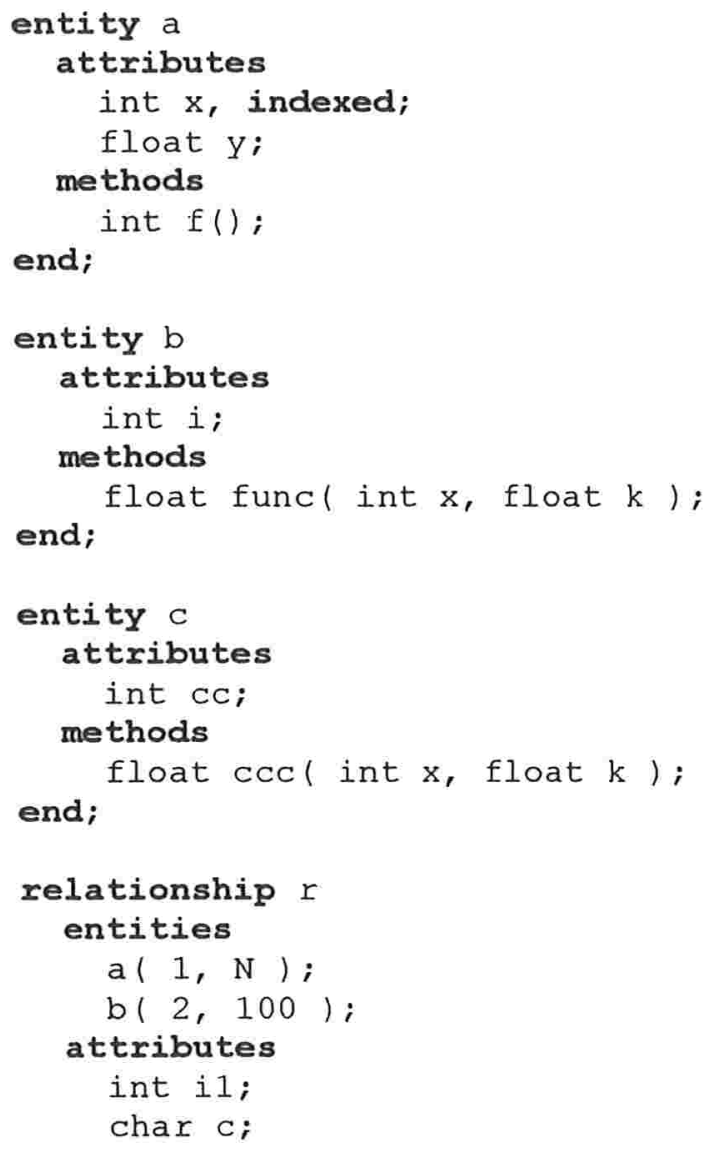




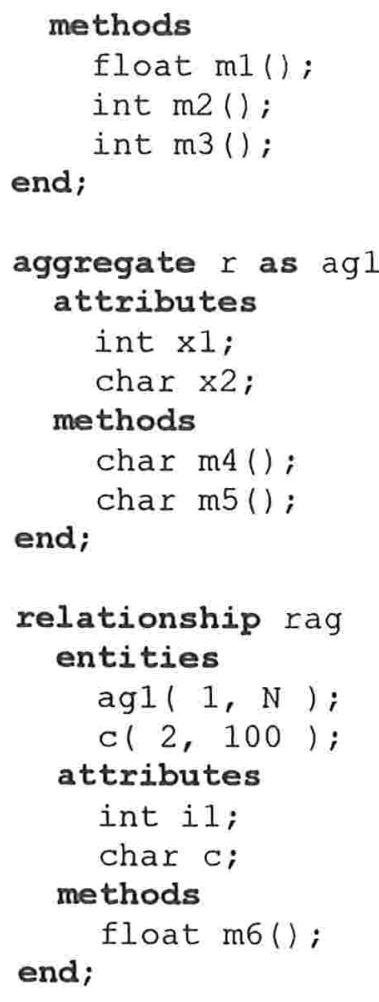

O seguinte esquema é gerado:

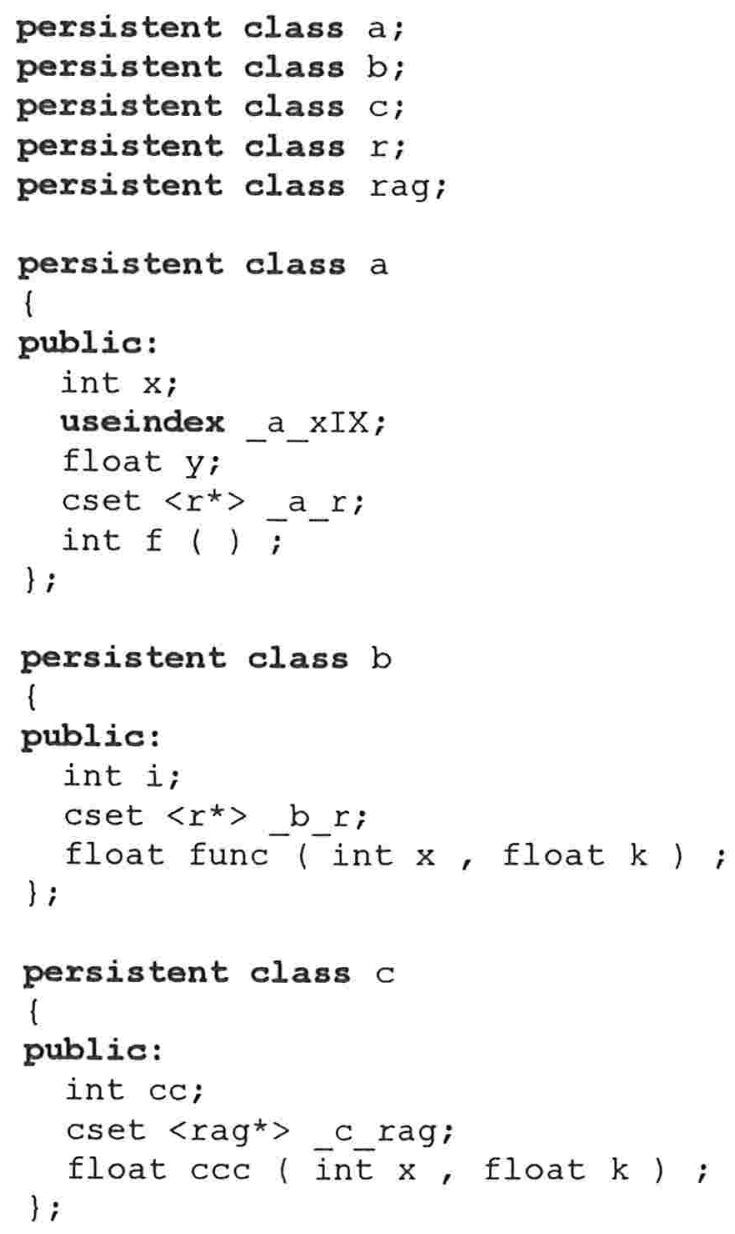




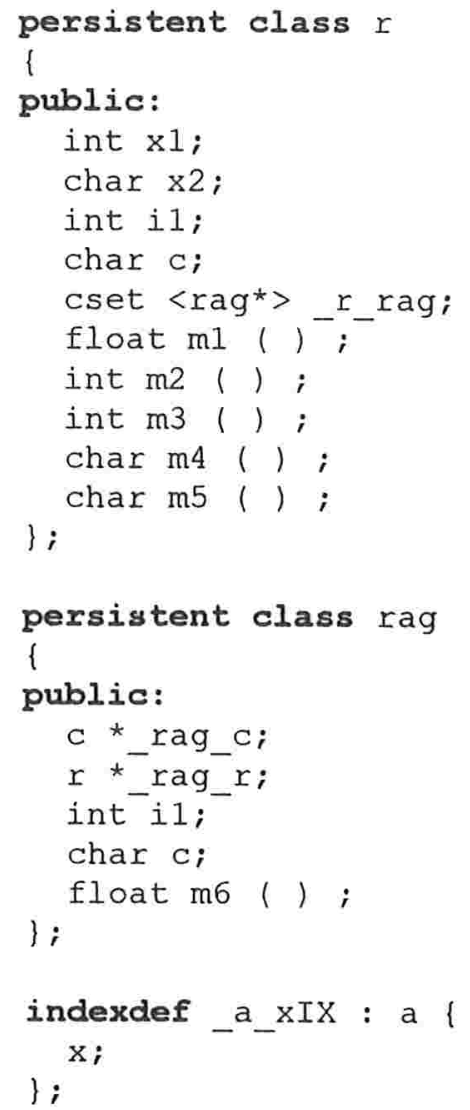

Note a utilização da classe correspondente ao relacionamento como uma entidade, como implementação da agregação. No final, notamos também a definição do índice da classe a.

\subsection{Comparação do OER com sistemas existentes}

A seguir apresentamos um quadro comparativo dos principais sistemas de $\mathrm{BDOO}$ existentes com o OER. 


\begin{tabular}{|c|c|c|c|c|c|c|c|c|c|c|}
\hline & OER & $\mathrm{O}_{2}$ & Poet & Jasmine & ObjectStore & SIM & Cactis & $\begin{array}{l}\text { SQL } \\
\text { Server }\end{array}$ & Postgres & ZIM \\
\hline Tipo & $\begin{array}{l}\text { MER } \\
\text { estendido }\end{array}$ & $\mathrm{OO}$ & $\mathrm{OO}$ & 00 & $\mathrm{OO}$ & 00 & $\begin{array}{l}\text { Baseado } \\
\text { no MER }\end{array}$ & MR & $\begin{array}{l}\text { MR } \\
\text { estend. }\end{array}$ & $\begin{array}{l}\text { Baseado } \\
\text { no MER }\end{array}$ \\
\hline $\begin{array}{l}\text { Declaração de } \\
\text { relacionamentos }\end{array}$ & Sim & Não & Não & Não & Não & Não & Sim & Não & Não & $\operatorname{Sim}$ \\
\hline $\begin{array}{l}\text { Relacionamentos } \mathrm{N} \\
\text { para } \mathrm{N} \text { declarados }\end{array}$ & Sim & Não & Não & Não & Não & Não & Não & Não & Não & $\operatorname{Sim}$ \\
\hline $\begin{array}{l}\text { Uso dos } \\
\text { Relacionamentos nas } \\
\text { consultas }\end{array}$ & Sim & Não & Não & Não & Não & Não & Não & Não & Não & Sim \\
\hline Métodos & Sim & Sim & Sim & Sim & Sim & Sim & Sim & Não & Não & Não \\
\hline $\begin{array}{l}\text { Atributos } \\
\text { muitivalorados }\end{array}$ & Sim & $\operatorname{Sim}(1)$ & $\operatorname{Sim}(1)$ & $\operatorname{Sim}(1)$ & $\operatorname{Sim}(1)$ & Sim & $\operatorname{Sim}(1)$ & Não & Não & Ñão \\
\hline $\begin{array}{l}\text { Tipos complexos de } \\
\text { dados }\end{array}$ & Sim & Sim & Sim & Sim & Sim & Sim & Sim & Não & Sim & Não \\
\hline $\begin{array}{l}\text { Linguagem de } \\
\text { consulta para } \\
\text { atributos } \\
\text { multivalorados }\end{array}$ & Sim & Não & Não & Não & Não & Não & Não & Não & Não & Não \\
\hline $\begin{array}{l}\text { Ortogonalidade da } \\
\text { persistência }\end{array}$ & Sim & Sim & Não & Sim & Sim & Sim & Sim & - & Sim & - \\
\hline Herança múltipla & Sim & $\operatorname{Sim}$ & Não & Sim & Sim & Sim & Sim & Não & Sim & Não \\
\hline $\begin{array}{l}\text { Integrado com } \\
\text { linguagem de } 4^{2} \\
\text { geração }\end{array}$ & Sim & Não & Não & Não & Não & Năo & Não & Não & Não & Sim \\
\hline $\begin{array}{l}\text { Integridade } \\
\text { referencial }\end{array}$ & Sim & Sim & Sim & Sim & Sim & Sim & Sim & $\operatorname{sim}$ & Sim & Não \\
\hline Regras & Não (2) & Não & Não & Não & Não & Não & Não & Sim & Sim & Não \\
\hline
\end{tabular}

(1) Os sistemas em questão possuem conjuntos, vetores e "bags", que podem ser considerados como multivalrodados

(2) Não foi feita a proposta, porém, poderiam ser incluídas no nosso modelo 


\section{Extensões do OER}

Neste trabalho, o sistema implementado não incorpora todos os conceitos e idéias que tivemos. Dos pontos a continuar em nosso trabalho enumeramos os seguintes:

\subsection{Linguagem de consulta e sua implementação.}

Anteriormente descrevemos através de exemplos o que poderia ser a linguagem de consulta de manipulação de dados de um sistema que incorporasse nosso modelo. Um estudo mais profundo na sintaxe dos comandos, para evitar possíveis ambigüidades seria bastante interessante para complementar nosso modelo.

Outro aspecto seria o da implementação da linguagem de consulta apresentada. Alguns dos comandos exemplificados poderiam ser traduzidos em consultas na linguagem OQL, como por exemplo na consulta simples.

select aluno.nome

where aluno. NumUSP $=$ " $1234 "$

Não é necessária nenhuma transformação sintática para traduzir essa consulta. Se a consulta possuir atributos calculados, como média de um atributo multivalorado (no caso de médias das notas), consultas a atributos complexos (atributos compostos multivalorados, por exemplo), chamadas de métodos ou relacionamentos, as consultas podem não ter mais uma tradução tão trivial, podendo ser necessário, em alguns casos, traduzir as consultas para a linguagem $\mathrm{C}$ ou $\mathrm{C}++$.

A definição formal de operadores e da linguagem de consulta para atributos multivalorados com níveis arbitrários de complexidade também representa uma boa área para mais estudos ${ }^{4}$. Em nossa proposta de linguagem de consulta, apresentamos apenas alguns exemplos de consultas a esquemas mais complexos. Também se toma importante a otimização de tais consultas.

\footnotetext{
${ }^{4}$ Em [OZG 87] é apresentada uma extesão da álgebra relacional para atributos multivalorados, porém somente para um nível.
} 


\subsection{Definição e implementação da linguagem de programação}

Como citado em nossa crítica, ao invés de se dar persistência a objetos das linguagens de $3^{\text {a }}$ geração, poder-se-ia estender as linguagens de $4^{\mathrm{a}}$ geração para acomodar alguns conceitos da orientação a objetos.

Em nosso sistema, poderíamos ter uma linguagem desse tipo, com instruções de alto nível para manipulação de telas e formulários, e de processamento registro a registro, além de possuir como tipos de dados nativos nossos elementos do modelo (entidades, atributos), para resolver o problema do não-casamento de impedâncias. Outra característica seria que a linguagem de consulta faria parte dessa linguagem, além de comandos de controle de fluxo tradicionais. Com isso, seria obtida a completude computacional, considerado característica importante para os BDOO.

\subsection{Outras questões da implementação}

Em nosso modelo, não foram tratados os casos de especialização exclusiva e inclusiva. $\mathrm{Na}$ linguagem $\mathrm{C}++$, quando há herança múltipla a classe sempre é subclasse de todas as superclasses. Por isso não se fez a implementação desses casos, uma vez que a herança foi a mesma do modelo do Poet. Talvez com uso de outro BDOO ou com outra modelagem a herança inclusiva e exclusiva possam ser tratados satisfatoriamente.

O Poet possui um bom esquema para o controle de acesso aos dados. Um esquema de segurança semelhante poderia ser adotado no sistema, sendo possível a atribuição de direitos de leitura e escrita para cada atributo de cada entidade, além do direito de se fazer consultas através de relacionamentos.

Outra face seria o de controle transacional, e de controle de concorrência e de distribuição de dados. Esses assuntos, por fugirem do escopo deste trabalho, não foram tratados, porém são de grande importância para a implementação de um SGBD que utilize nosso modelo de dados. 


\section{Conclusão}

Apesar de existirem muitas implementações de BDOO, nenhum sistema é utilizado em grande escala até o momento, pelo menos comercialmente, onde os SGBD baseados no MR normalizado ainda predominam. Cremos que isso se deve principalmente à dificuldade de migração do MR para o modelo de dados Orientados a Objetos, às característica de orientação a dados, sem métodos, do MR, e ao fato dos BDOO não serem adequados para manipular dados normalmente encontrados em aplicações comerciais (grande volume de dados com estrutura relativamente simples). Com a grande popularização da Internet no último ano, os produtores dos sistemas esperam um impulso maior, já que a Internet possui uma grande quantidade de hipertexto e dados multimídia, que poderiam ser armazenados em BDOO.

Em seus artigos, Atkinson [ATK 89], Stonebraker [STO 90a] e Darwen \& Date [DAR 95] e [DAR 95a], procuram um modelo que substitua o MR, porém nenhum modelo ainda se firmou como o sucessor da idéia de Codd. Nosso modelo apresenta várias das idéias propostas em todos esses trabalhos, e cremos ser bem mais aderente ao modelo conceitual de Entidades e Relacionamentos, comurnente usado em Análise de Dados, e esse poderia ser um dos caminhos a serem seguidos para os Bancos de Dados da próxima geração. 


\section{Apêndice 1: sintaxe do modelo OER}

Estamos utilizando a notação para a gramática de acordo com o livro de Setzer \& Melo [SET 83].

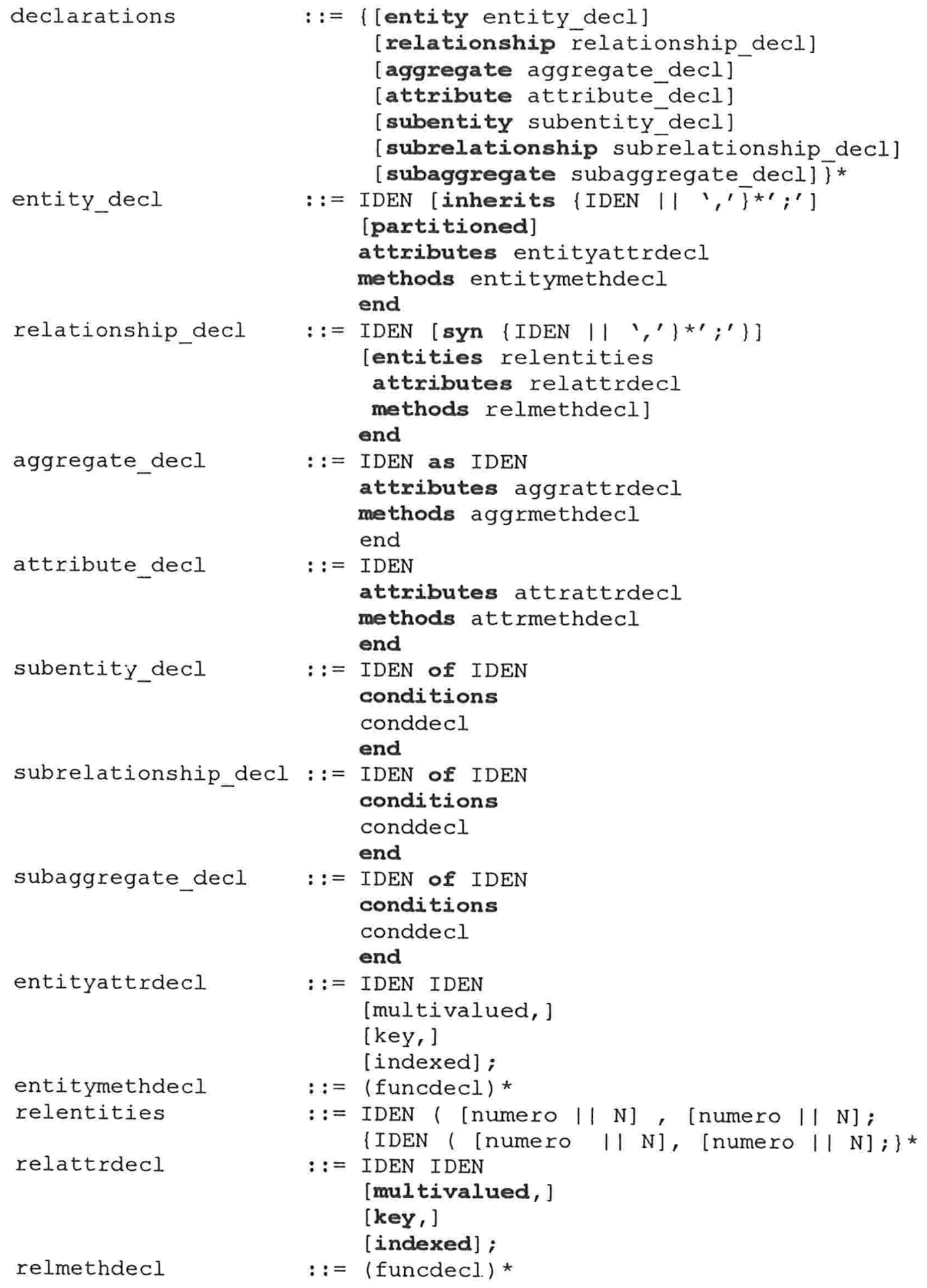




\begin{tabular}{|c|c|c|}
\hline aggrmethdecl & $::=$ & (funcdecl) * \\
\hline attrattrdecl & $::=$ & IDEN IDEN \\
\hline & & $\begin{array}{l}\text { [multivalued, ] } \\
\text { [key, ] } \\
\text { [indexed] }\end{array}$ \\
\hline attrmethdecl & $::=$ & (funcdecl) * \\
\hline
\end{tabular}

As declarações de métodos não são analisadas. As linhas são somente copiadas e inseridas nas declarações das classes. 


\section{Apêndice 2: locais na Internet}

Alguns dos sistemas descritos em nosso trabalho são sistemas comerciais, com pouca literatura a respeito. Porém, hoje a maioria das empresas na área de computação possuem páginas na Internet, onde podem ser obtidas informações a respeito dos produtos. Durante nossa pesquisa, encontramos diversos locais na Internet, que listamos a seguir:

(1) http://www.o2tech.com - Página da $\mathrm{O}_{2}$. Um grande destaque deste local é a utilização do $\mathrm{O}_{2} \mathrm{Web}$, ferramenta de integração dos $\mathrm{BDOO} \mathrm{O}_{2} \mathrm{com}$ a Internet. Estão disponíveis também artigos sobre BDOO.

(2) http://wwww.poet.com/ - Página da Poet Software. Estão disponíveis versões de teste gratuitas, além de atualizações e alguns artigos sobre BDOO.

(3) http://www.objectstore.com/ - Página da ObjectStore. Possui formulário para receber gratuitamente um CD de demonstração do sistema.

(4) http://www.odmg.org/ - Página da ODMG. Possibilita pedido do livro que trata do padrão da ODMG, além de correções e revisões do padrão.

(5) http://www.versant.com/ - Página da Versant.

(6) http://www.cs.berkeley.edu/projects/ - Página do grupo de pesquisas da Universidade de Berkeley. Informações sobre a pesquisa no departamento, além de uma nova versão não comercial do Postgres, o Postgres 95.

(7) http://www.odi.com/ - Object Design Inc.

(8) http://www.objectivity.com/ - Objectivity.

(9) http://www.xcc-ka.de/OBST/OBST.html - Página em que é descrito o BDOO OBS'T+.

(10) http://www.unisql.com/ - Página da UniSQL.

(11) http://este.darmstadt.gmd.de/dimsys/vodak/vodak.html - Página em que é apresentado o VODAK. 
(12) http://w3.iprolink.ch/ibexcom - Página da IBEX, desenvolvedora do ITASCA (antigo ORION).

(13) http://www.sybase.com/ - Página da Sybase, Banco de Dados Relacional.

(14) http://www.oracle.com/ - Página da Oracle, sistema também Relacional.

(15) http://www.cai.com/products/jasmine.htm - Página do Jasmine, comercializado pela Computer Associates. 


\section{Referências Bibliográficas}

As referências que estão marcadas com um asterisco no final $\left({ }^{*}\right)$ foram consultadas e utilizadas. As demais servem apenas para completar a bibliografia.

[AGR 89] Agrawal, R. e Gehani, N., ODE (Object Database and Environment): The Language and the Data Model, SIGMOD'89 Proceedings, pp. 36-45, julho de 1989. $(*)$

[AND 91] Andrews, T., Programming with Vbase, em [GUP 91], 1991

[AND 91a] Andrews, T, et al., ONTOS: A Persistent Database for $\mathrm{C}++$, em [GUP 91], 1991. (*)

[ATK 89] Atkinson, M., et al. The Object-Oriented Database System Manifesto, Proceedings of the First International Conferecnce on Deductive and Object Oriented Databases, Kyoto, Japan. Janeiro de 1989. (*)

[BAN 88] Bancilhon, $\mathrm{F}$, et al, The Design and Implementation of $\mathrm{O}_{2}$, an ObjectOriented Database System, Proceedings of the 2nd International Workshop on $O O D B S$. Lecture Notes in Computer Science vol. 334. Setembro de 1988. (*)

[BAN 89] Bancilhon, F., Delobel, C., A Query Language for the $\mathrm{O}_{2}$ Object-Oriented Database System. $\mathrm{O}_{2}$ Technology Technical Report No 2, 1989. (*)

[BAN 90] Bancilhon, F., Kim, W., Object-Oriented Database Systems: In Transition, SIGMOD Record. 19(4):49-53, dezembro de 1990. (*)

[BAN 92] Bancilhon, F., et al, Building an Object-Oriented Database System: The Story of $\mathrm{O}_{2}$, Morgan Kauffman, 1992. (*)

[BAN 92a] Bancilhon, F. Understanding Object-Oriented Database Systems, $\mathrm{O}_{2}$ Technology Technical Report № 5, 1992.

[BAN 87] Banerjee, J., et al, Data Model Issues for Object-Oriented Applications, ACM Transactions on Office Information Systems, 5(1):3-26, janeiro de 1987(*)

[BAT 86] Batory, D., et al. GENESIS: Na Extensible Database Management System. Em [ZDO 90]. 1986.

[BER 91] Bertino, E., Martino, L., Object-Oriented Database Management Systems: Concepts and Issues, IEEE Computer, pp. 33-47, abril de 1991. (*)

[BJÖ 88] Björnerstedt, A., Britts, S., AVANCE: An Object Management System, OOPSLA ' 88 Proceedings, pp. 206-221, setembro de 1988. (*)

[BRE 89] Bretl, R, et al., The GemStone Data Management System, em [KIM 89], 1989. (*)

[BUT 91] Butterworth, P., et al., The GemStone Object Database Management System, Communications of the ACM, 34(10)64-77, outubro de 1991. (*) 
[CAR 89] Carey, M., et al., Storage Management for Objects in EXODUS, em [KIM 89]. 1989.

[CAT 91] Cattell, R., Object Data Management: Object-Oriented and Extended Relational Database Systems, Addison Wesley, Janeiro de 1991. (*)

[CAT 91a] Cattell, R., Next Generation Database Systems, Communications of the $A C M, 34(10): 31-33$, outubro de 1991. (*)

[CHE 76] Chen, P., The Entity-Relationship Model-Toward a Unified View of Data, ACM Transactions on Database Systems, 1(1):9-36, março de 1976. (*)

[COD 70] Codd, E., A Relational Model of Data for Large Shared Data Banks, Communications of the ACM, 13(6):377-387, junho de 1970. (*)

[COD 79] Codd, E., Extending the Database Relational Model to Capture More Meaning, ACM Transactions on Database Systems, 4(4):397-434, dezembro de 1979. (*)

[DAD 86] Dadam, P., et al., A DBMS Prototype to Support Extended NF ${ }^{2}$ Relations: An Integrated View on Flat Tables an Hierarchies, SIGMOD Record, 1986. (*)

[DAH 66] Dahl, O, Nygaard, K., SIMULA - an ALGOL-Based Simulation Language, Communications of the ACM, 9(9):671-678, setembro de 1966.

[DAM 91] Damon, C., Landis, G., Abstract State and Representation in Vbase, em [GUP 91], 1991.

[DAM 91a] Damon, C., C++ and COP: A Brief Comparison, em [GUP 91], 1991.

[DAR 95] Darwen, H., Date, C., Introducing the Third Manifesto, Database Programming and Design, pp. 25-35, janeiro de 1995. (*)

[DAR 95a] Darwen, H., Date, C., The Third Manifesto, SIGMOD Record, 24(1):3949, março de 1995. (*)

[DAT 90] Date, C., An Introduction to Database Systems, vol 1, 5a. Edição, 1990. (*)

[DEU 90] Deux, O., The Story of $\mathrm{O}_{2}$, IEEE Transactions on Knowledge and Data Engineering, 2(1):91-108, março de 1990. (*)

[DEU 91] Deux, O., et al, The $\mathrm{O}_{2}$ System, Communications of the ACM, 34(10):34-48, outubro de 1991. (*)

[DIE 89] Diederich, J., Milton, J., Objects, Messages, and Rules in Database Design, em [KIM 89], 1989.

[DIT 86] Dittrich, K., et al., DAMOKLES - A Database System for Software Enginnering Environments, Lecture Notes in Computer Science vol. 244, pp. 353371, janeiro de 1986. (*)

[ELM 93] Elmasri, R., et al. Automatic Class and Method Generation for ObjectOriented Databases, Lecture Notes in Computer Science vol. 760, pp. 395-414, dezembro de 1993. (*)

[ELM 94] Elmasri, R., Navathe, S., Fundamentals of Database Systems, 2a ed., Benjamin/Cummings, 1994. (*) 
[EXE 94] Exertier, F., Haj Houssain, S., Issues in Extending a Relational System with Object-Oriented Features, Proceedings of the International Sysposium in ObjectOriented Methodologies and Systems. Lecture Notes in Computer Science vol. 858, pp. 1-19, setembro de 1994. (*)

[FIS 87] Fishman, D., et al., Iris: An Object-Oriented Database Management System, ACM Transactions on Office Information Systems, 5(1):48-69, janeiro de 1987. (*)

[FIS 89] Fishman, D., et al, Overview of the Iris DBMS, em [KIM 89], 1989. (*)

[FON 97] Fong, J., Converting Relational to Object-Oriented Databases, SIGMOD Record, 26(1):53-58. Março de 1997.(*)

[FOR 88] Ford, S., et al., ZEITGEIST: Database Support for Object-Oriented Programming, Advances in Object-Oriented Database Systems. 2nd International Workshop on OODBS. Lecture Notes in Computer Science vol 334, Setembro de 1988. $\left({ }^{*}\right)$

[GOG 93] Gogolla, M., et al., Integrating the ER Approach in an OO Environment, Entity-Relationship Approach - ER'93, 12th International Conference on the E-R Approach, Lecture Notes in Computer Science vol. 823, Arlington, Texas, USA, dezembro de 1993. $\left(^{*}\right)$

[GOG 93a] Gogolla, M., An Extended Entity-Relationship Model-Fundamentals and Pragmatics, Lecture Notes in Computer Science vol. 767, Springer-Verlag, outubro de 1993.

[GOL 83] Goldberg, A., Robson, D., Smalltalk-80: the Language and its Implementation, Addison-Wesley, 1983.

[GUP 91] Gupta, R., Horowitz, E., (ed.) Object-Oriented Databases with Applications to CASE, Networks, and VLSI CAD, Prentice Hall, 1991.

[GUP 91a] Gupta, R., Horowitz, E, A Guide to the OODB Landscape, em [GUP 91], 1991. (*)

[GUP 91b] Gupta, R., A Quickstart Introduction to C++, em [GUP 91], 1991.

[HAA 90] Haas, L., et al., Starbust Mid-Flight: As the Dust Clears, IEEE Transactions on Knowledge and Data Engineering, 2(1):143-159, março de 1990.

[HAR 91] Harris, C., Duhl, J., Object SQL, em [GUP 91], 1991.

[HEU 88] Heuer, A., Foundations of Relational Object Management Systems, Advances in Object-Oriented Database Systems. 2nd International Workshop on OODBS. Lecture Notes in Computer Science vol 334, Setembro de 1988.

[HOH 94] Hohenstein, U., et al., Object-Oriented Database Systems: How Much SQL Do They Understand?, Database and Expert Systems Applications, Lecture Notes in Computer Science vol. 856, janeiro de 1994.

[HOR 91] Horowitz, E., Wan, Q, An Overview of Existing Object-Oriented Database Systems, em [GUP 91], 1991. (*)

[HUD 89] Hudson, S., King, R., Cactis: a Self Adaptive, Concurrent Implementation of an Object-Oriented Database Management System, ACM Transactions on Database Systems, 14(3):291-321, setembro de 1989. (*)

[HUG 91] Hughes, J., Object-Oriented Databases, Prentice Hall, 1991. (*) 
[JAG 89] Jagadish, H. V., Incorporating Hierarchy in a Relational Model of Data, SIGMOD Record, 1989.

[KHO 86] Khoshafian, S., Copeland, G., Object Identity, OOPSLA'86 Proceedings, setembro de 1986. $\left(^{*}\right)$

[KHO 88] Khoshafian, S., Frank, D., Implementation Techiniques for Object Oriented Databases, Advances in Object-Oriented Database Systems. 2nd International Workshop on OODBS. Lecture Notes in Computer Science vol 334, Setembro de 1988.

[KHO 93] Khoshafian, S., Object Oriented Databases, Ed. John Wiley \& Sons, 362 pp. 1993. $(*)$

[KHO 93] Khoshafian, S., Bancos de Dados Orientados a Objeto, Tradução, Ed. John Wiley \& Sons, 1993. (*)

[KIM 88] Kim, W., et al., Integrating an Object-Oriented Programming System with a Database System, OOPSLA '88 Proceedings, pp. 142-152, setembro de 1988.

[KIM 89] Kim, W., Lochovsky, F., (ed.), Object-Oriented Concepts, Databases and Applications, ACM Press, 1990. (*)

[KIM 89a] Kim, W., et al., Features of the ORION Object-Oriented Database System, em [KIM 89], 1989. (*)

[KIM 90] Kim, W., et al., Architeture of the ORION Next-Generation Database System, IEEE Transactions on Knowledge and Data Enginnering, 2(1):109-124, março de 1990. (*)

[KIM 90a] Kim, W., Introduction to Object-Oriented Databases, MIT Press, 1990. (*)

[KIM 91] Kim, W., et al., A Distributed Object-Oriented Database System Supporting Shared and Private Databases, ACM Transactions on Information Systems, 9(1):31-51, janeiro de 1991. (*)

[KON 91] Konstantinov, G., Transition to Object-Oriented Development: Promoting a New Paradigm, em [GUP 91], 1991.

[KOR 86] Korth, H., Silberschatz, A., Database Systems Concepts, $2^{\text {nd }}$ editon, McGraw-Hill, Inc, 1986. (*)

[KOR 86] Korth, H., Silberschatz, A., Sistema de Banco de Dados, tradução, 2 edição revisada, Makkron Books, 1986. (*)

[LAM 91] Lamb, C., et al., The Objectstore Database System, Communications of the $A C M, 34(10): 50-63$, outubro de 1991. (*)

[LOH 91] Lohman, G., et al., Extensions to Starbust: Objects, Types, Functions and Rules, Communications of the ACM, 34(10):94-109, outubro de 1991.

[LOO 93] Loomis, M., et al, The ODMG Object Model, Journal of Object-Oriented Programming, pp. 64-69, junho de 1993. (*)

[LOO 93a] Loomis, M., Object Database Semantics, Journal of Object-Oriented Programming, pp. 26-33, julho de 1993. (*) 
[LOO 93b] Loomis, M., Object Programming and Database Management: Differences in Perspective Between the Two, pp. 31-34, Journal of Object-Oriented Programming, maio de 1993. (*)

[LOO 94] Loomis, M., ODBMS Myths and Realities, Journal of Object-Oriented Programming, pp. 77-80, julho de 1994. (*)

[LOO 94a] Loomis, M., Hitting the Relational Wall, Journal of Object-Oriented Programming, pp. 56-71, janeiro de 1994. (*)

[MAI 86] Maier, D., et al., Development of an Object-Oriented DBMS, OOPSLA'86 Proceedings, pp. 472-481, setembro de 1986. (*)

[MAK 77] Makinouchi, A., A Consideration on Normal Form of Not-Necessarily-Normalized Relations in the Relational Data Model, Proc. 3rd International Conference on Very Large Data Bases, pp. 447-453, 1977.

[NAR 93] Narasimhan, B., et al., On Mapping ER and Relational Models into OO Schemas. Entity-Relationship Approach-ER'93, 12th International Conference on the E-R Approach, Arlington, Texas, Lecture Notes in Computer Science vol. 823, dezembro de 1993. $\left({ }^{*}\right)$

[OZS 87] Özsoyoglu, G., et al., Extending Relational Algebra and Relational Calculus with Set-Valued Attributes and Aggregate Fucntions, ACM Transactions on Database Systems, 12(4):566-592, dezembro de 1987. (*)

[OZS 87a] Ozsoyoglu, Z., Yuan, L., A New Normal Form for Nested Relations, ACM Transactions on Database Systems, 12(1):111-136, março de 1987.

[PAG 95] Page-Jones, Meilir, What Every Programmer Should Know About Object-Oriented Design, Dorset House Publishing, 370 p., 1995. (*)

[POO 87] Pooley, R., An Introduction to Programming in SIMULA, Blackwell Scientific Publications, 1987.

[POS 94] The POSTGRES Group, The POSTGRES User Manual, 1994. ( $\left.{ }^{*}\right)$

[PRI 89] Price, R., Golendziner, L., Bancos de Dados para Aplicações Não Convencionais, IV Escola Brasileira de Informática, janeiro de 1989.

[ROW 87] Rowe, L., Stonebraker, M., The POSTGRES Data Model, Proceedings of the 13th International Conference on Very Large Data Bases, pp. 83-96, setembro de 1987. (*)

[SAN 91] Santos, Paulo, Masiero, Paulo; Um Sistema de Navegação (Browser) para o SGBD DAMOKLES, Anais do 6o. Simpósio Brasileiro de Bancos de Dados, maio de 1991.

[SET 83] Setzer, V, Melo, Inês S. Homem, A Construção de um Compilador, Editora Campus, 1983. (*)

[SET 86] Setzer, V., Bancos de Dados-Conceitos, Modelos, Gerenciadores, Projeto Lógico, Projeto Físico, Editora Edgard Blücher, 3a. edição, 1986. (*)

[SIL 91] Silberschatz, A., et al., Database Systems: Achievements and Opportunities, Communications of the ACM, 34(10):110-120, outubro de 1991.

[SIL 90] Silva, D., Programação por Objetos: Conceitos, Linguagens e uma Experiência, Dissertação de Mestrado, IME-USP, 1990. ( $\left.{ }^{*}\right)$ 
[SKA 90] Skarra, A., Zdonik, S., Concurrency Control and Object-Oriented Databases, em [KIM 89], 1989.

[SMI 77] Smith, J.M. e Smith, D.C.P., Database Abstractions - Aggregations and Generalizations, ACM Transactions on Database Systems, 2:105-133.

[SOL 92] Soloviev, V., An Overview of Three Commercial Object-Oriented Database Management Systems: ONTOS, ObjectStore and $\mathrm{O}_{2}$, SIGMOD Record, 21(1):93104, março de 1992. (

[STO 76] Stonebraker, M., et al. The Design and Implementation of INGRES. ACM Trans. Database Systems. 1(3):189-222. Setembro de 1976.

[STO 90] Stonebraker, M., et al., The Implementation os POSTGRES, IEEE Transactions on Knowledge and Data Enginnering, 2(1):125:142, março de 1990. $(*)$

[STO 90a] Stonebraker M. et al., Third-Generation Database System Manifesto, SIGMOD Record, 19(3):31-44, setembro de 1990. (*)

[STO 91] Stonebraker, M., Kemnitz, G., The Postgres Next Generation Database Management System, Communications of the ACM, 34(10):78-92, outubro de 1991. $(*)$

[STR 86] Stroustrup, B., The C++ Programming Language, Addison-Wesley, 1986.

[RAM 97] Ramanathan, S., Hodges, J. Extraction of Object-Oriented Structures from Existing Relational Databases; SIGMOD Record, 26(1):59-64, março de 1997.

[TAK 90] Takahashi, T., Liesenberg, H., Xavier, D., Programação Orientada a Objetos, VII Escola de Computação, São Paulo, julho de 1990. (*)

[TRA 91] Traina Jr., C., GEO: Um Sistema de Gerenciamento de Bases de Dados Orientados a Objetos: Estado Atual de Desenvolvimento, Anais de 6o. Simpósio Brasileiro de Bancos de Dados, maio de 1991.

[ULL 88] Ullman, J., Principles of Database and Knowledge-Base Systems, vol. 1, Computer Science Press, 1988. (*)

[WAN 89] Wand, Y., A Proposal for a Formal Model of Objects, em [KIM 89], 1989.

[WEI 91] Weinreb, D., Feinberg, N., Gerson, D., Lamb, C., An Object-Oriented Database System to Support an Integrated Programming Environment, em [GUP 91], 1991. (*)

[WEI 90] Weiser, S., Lochovsky, F., OZ+: An Object-Oriented Database System, em [KIM 89], 1989. (*)

[WIL 94] Wilcox, J., Object Databases, Dr. Dobb's Journal, 222:26-34, novembro de 1994.

[ZAN 95] Zand, M., Collins, V., Caviness, D., A Survey of Current Object-Oriented Databases, DATA BASE Advances, 26(1):14-29, fevereiro de 1995. (*)

[ZDO 90] Zdonik, S., Maier, D., (ed.), Readings in Object-Oriented Database Systems, Morgan Kaufmann, 1990. (*)

[ZIM 91] Manual do Usuário do ZIM, tradução. RCM Informática. Sterling Software International, Inc.. Janeiro de 1991. $\left(^{*}\right)$ 


\section{4. Índice Remissivo}

acoplamento tardio, 31

Agregações, 17

Álgebra Relacional, 6

APL, 4

atributos. 12

Auto-relacionamentos, 16

AVANCE, 70

Bancos de Dados Orientados a Objetos definição, 38

BDOO distribuídos, 44

$\mathrm{C}++, 25,29,32,38,41,47,50,52,69,72,74$, $75,77,78,79,81,83,98,99,123,124,125$, 128

CACTIS, 61

CAD/CAM, 2

célula, 5

chave, 5

chave primária, 5

Chen, 1

classe atributo, 83

classe entidade, 84

classes, 27

paramétricas, 35

Classes, 33 genéricas, 34

Codd, 1, 4

coluna, 5

Compartilhamento, 36

Completude computacional, 42

comportamento, 27

Cópia profunda, 36

Cópia rasa, 36

cursores, 43

domínio, 5

encapsulamento, 72

Encapsulamento, 32, 41

Entidades, 12

E-Relação, 7

especialização, 19

esquema, 5

EXODUS, 39

Extensibilidade, 44

flexibilidade, 27

GemStone, 54

Generalidade, 27

generalização exclusiva, 20

inclusiva, 20

total, 20

Generalização, 19

GENESIS, 39

Geradores de Sistemas de Bancos de Dados, 38

Gerenciadores de Objetos, 38

grau de uma relação, 5

herança

múltipla, 28

única, 28

Herança, 28

hierárquico, 1

Identificador de Objeto, 35, 41

IDS, 4

IMS, 4

INGRES, 56

Internet, 121

IRIS, 60

ITASCA, 53

JASMINE, 66

junções, 26

Late Binding, 31

Linguagem de consulta, 100

Linguagem de Consulta, 6

Linguagens de Programação de Bancos de Dados, 38

Mapeamento ER-OO, 81

mensagens, 27

Mensagens, 32

métodos, 27

Modelo de Dados, 1

modelo de entidades e relacionamentos, 1

Modelo de Entidades e Relacionamentos, 11

Modelo de Redes, 4

modelo formal, 73

Modelo Hierárquico, 4

modelo relacional, 1

Modelo Relacional, 4

Modelo Relacional Não-Normalizado, 8

Modularização, 27

não-casamento de impedâncias, 42

$\mathrm{O}_{2}, 46$

OBJECTSTORE, 50

Objetos, 35

comportamento, 35 
estado interno. 35

Persistência. 39

ODMG. 74

OPAL, 54, 55

ORACLE. 43

Orientação a Objetos, 27

ORION, 53

overriding, 30

$\mathrm{OZ}+, 70$

papéis. 16

persistência, 38

Poet, 69, 74

Polimorfismo, 29

Postgres, 56

Primeira Forma Normal, 6

Programação Orientada a Objetos, 2

QBE. 6

QUEL. 6

redes. 1

relação, 5

Relacionamentos, 13, 44, 86, 90

exclusivo, 21

inclusivo, 21

multiplicidade, 14 múltiplos. 16

Relacionamentos múltiplo, 16

Reutilização, 28

$\mathrm{RM} / \mathrm{T}, 1,6$

semântica por identificador, 36

semântica por valor, 36

SIM, 65

SIMULA, 27

sinônimos, 24

Sistemas de Bancos de Dados Estendidos, 38

Smalltalk, 29, 32, 38, 54, 55, 125

sobrecarga, 31

Sobrecarga de operadores, 29

SQL, 6

Subagregações. 98

Subentidades, 97

Subrelacionamentos, 97

surrogate, 7

SYBASE, 43

transações, 43

variáveis de instância, 27

Versões, 43

ZIM, 11, 24 